
THE

CABINET CYCLOP 
LONDON :

Printed by A. Spotriswoode, New_Street_Square. 
THE

\section{CABINET CYCLOPFDIA.}

\section{CONDUCTED BY THE}

REV. DIONYSIUS LARDNER, LL.D. F.R.S. L. \& E. M.R.I.A. F.R.A.S. F.L.S. F.Z.S. Hon. F.C.P.S. \&c. \&c.

$$
\text { ASSISTED BY }
$$

EMINENT LITERARY AND SCIENTIFIC MEN.

\section{海atural 韭igtarp.}

A TREATISE

ON

THE GEOGRAPHY AND CLASSIFICATION of

\section{A NIMALS.}

BY

WILLIAM SWAINSON, ESQ. A.C.G. MONORARY MEMBER OF THE CAMBRIDGE PHILOSOPHICAL SOCIETY, AND OF SEVERAL FOREIGN ACADEMIES.

\section{LONDON :}

PRINTED FOR

IONGMAN, REES, ORME, BROWN, GREEN, \& LONGMAN, PATERNOSTER-ROW ;

AND JOHN TAYLOR, UPPER GOWER STREET. 
4 FOR THE INVISIBLE THINGS OF HIM FROM THE CREATION OF THE WORLD ARE CLEARLY SEEN, BEING UNDERSTOOD BY THE THINGS THAT ARE MADE, EVEN HIS ETERNAL POWER AND GONHEAD."

Romans, I. 20. 


\section{A Treatise \\ ox}

THE GHOTRAPHY ANH (TASSTHICATION

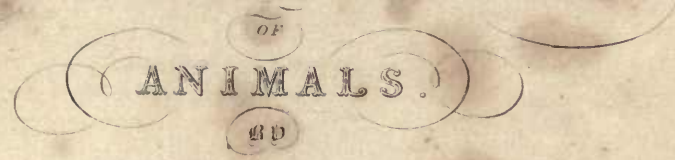

WHLHAM SWAINSON, ESO

HONORARY MEMBF:R OF THE CAMBRIDGE PHILOS OPHICAL SOCIETY, AND OF SEVERAL FOREIGN ACADEMIES.

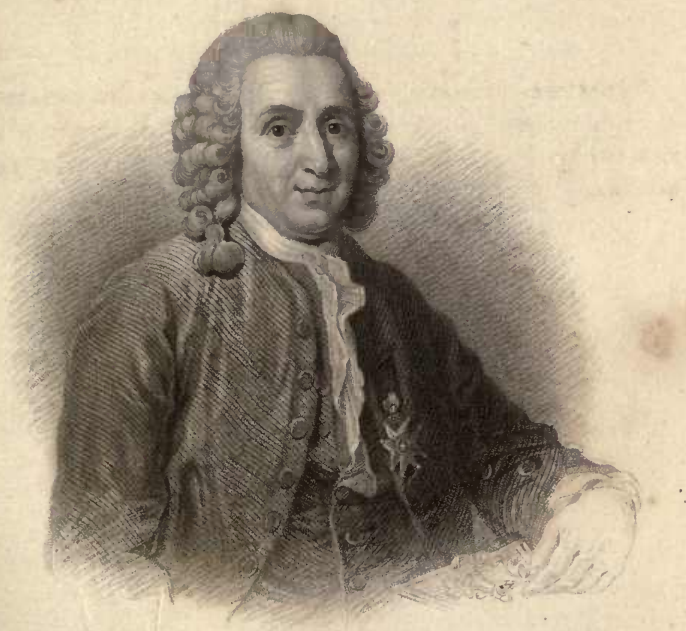

FI Corbould del.

E. Finder. si

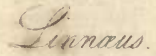

Timuin: 


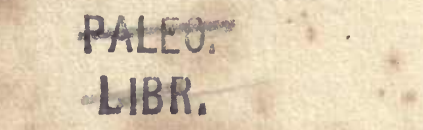

Gift of C. A. Kofoid

\author{
EARTH \\ SOIENCES \\ LIBRARY
}




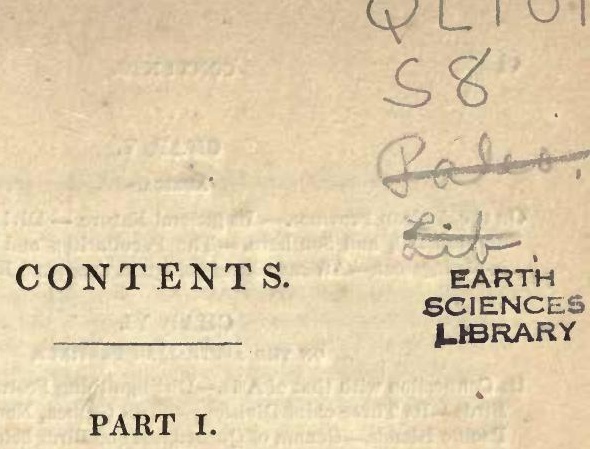

ON THE GEOGRAPHY OF ANIMALS.

\section{CHAP. I.}

Reasons against the Belief that Food, Temperature, and other inferior Agents, are the primary Causes of the Variation of Man. - Limited Range of Animals which yet possess great Locomotive Powers.-Various Opinions on the primary Distribution of Animals. - Linnæus, Prichard, and others. - Theories upon Animal Geography.-Fabricius.-Latreille. -Prichard. - Propositions on this Subject stated. - Geographic Distribution of Man.-Arctic Regions

- $\quad$ Page 1

\section{CHAP. II.}

EUROPE.

Europe considered as a Zoological Province. - This Proposition supported by an analytical Survey of its Ornithology.-Preponderance of its generic Types. - Its Analogy to the Caucasian Type of Man. - Results of the foregoing Analysis. - Its Zoology considered more in detail, under the Three Heads of Arctic, Central, and Southern Europe $\quad$ - $\quad 18$

\section{CHAP. III.}

ASIA.

The Asiatic Province. - Its general Character and Divisions. - Northern, Central, and Southern Asia. - The Peculiarities of each, as shown in their peculiar Animals.- Asiatic Genera of Quadrupeds and Birds - 43

\section{CHAP. IV.}

ON THE AMERICAN PROVINCE.

General Remarks. - Its Zoological Features. - Divided into Arctic, Temperate, and Equinoctial America.-The Peculiarities and Animals of each. - General Remarks upon the Climate añd, Soil of Brazil, with reference to the Distribution of its Animals. - American Genera of Quadrupeds and Birds 


\section{CHAP. V.}

AFRICA.

On the African Province. - Its general Nature. - Divided into Northern, Equinoctial, and Southern. - The Peculiarities and Animals of each. -Madagascar._African Genera of Quadrupeds and Birds - Page 91

CHAP. VI.

ON THE AUSTRALIAN PROVINCE.

Its Connection with that of Asia.-Distinguishing Features._Quadrupeds. Birds.-Its Three chief Divisions - New Guinea, New Holland, and the Pacific Islands._-Genera of Quadrupeds and Birds belonging thereto 114

\section{PART II.}

ON THE RISE AND PROGRESS OF SYSTEMATIC ZOOLOGY.

\section{CHAP. I.}

Preliminary Observations, - Alleged Difference between Systems and Methods. - Objections thereto. - Diversity of Systems. - Natural and Artificial Systems.-Mixed Systems.-Requisites of a natural System 122

\section{CHAP. II.}

Exposition, with critical Remarks, on the principal artificial Systems. Aristotle, Willughby, Linnæus, Cuvier. - Partial Systems. - Illiger, Vieillot, Temminck, in Ornithology. - De Geer, Latreille, Clairville, and Leach, in Entomology. - On Binary, or Dichotomous, Systems 132

\section{CHAP. III.}

On natural Systems.- Preliminary Observations, - Definition of a natural System. - Hermann's. - Observations. - Lamarck's System of the Invertebrated Animals. - System of MacLeay in Entomology. - Fries in Botany. - Alterations in MacLeay's System. - Remarks thereon. - Septenary and other Theories. - General Remarks on numerical Theories, and on the Necessity of proving that Groups are circular - $\quad 196$

\section{PART III.}

ON THE FIRST PRINCIPLES OF NATURAL

\section{CLASSIFICATION.}

\section{- CHAP. I.}

The first Principles of the natural System briefly stated as Five Propositions, the first Three of which are here discussed; viz., the Circularity, the numerical Division, and the Theory of Representation 
CHAP. II.

The Fourth Proposition considered. - The primary Types of Nature

Page 241

CHAP. III.

The Fifth Proposition considered. - On the relative Rank of the different circular Groups in the Animal Kingdom. - On Species and Varieties. On the Means thus offered by the Laws of natural Arrangement, for the Verification of Groups. - Familiar Illustration of the Principles of Classification here developed._Questions on analogical Comparisons 266

\section{PART IV.}

A FAMILIAR EXPLANATION OF THE FIRST PRINCIPLES OF PRACTICAL AND SCIENTIFIC ZOOLOGY, WITH SUGGESTIONS FOR A PLAN OF STUDYING THE DETAIIS OF HACH DEPARTMENT.

\section{CHAP. I.}

Preliminary Remarks.-Distinction between practical and scientific Naturalists. - Qualifications for both - as Accuracy of Observation-Perseverance - Concentration of Study - Memory. - Evils of indiscriminate eollecting. - Plans for collecting recommended

- 300

\section{CHAP. II.}

Importance of acquiring first Principles. - Reasons for supposing a Plan in Creation.- Opinions thereon. - The Circular Theory, and the different Tests which every Circle must undergo, explained and illustrated 317

CHAP. III.

On the Rank and Names of the Natural Divisions, or Groups, in the Animal Kingdom. - Of Species and Varieties

- 341 


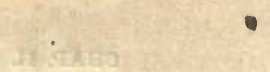

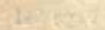

\section{2.}

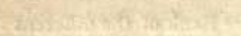

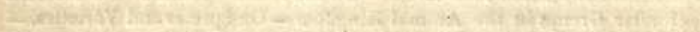

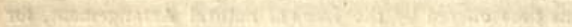

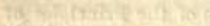

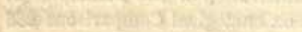

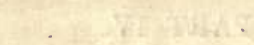

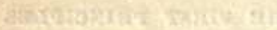

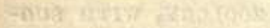

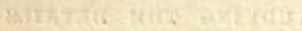

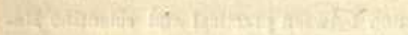

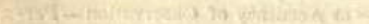

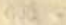

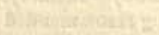

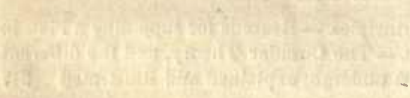

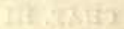

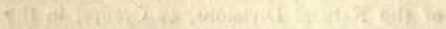

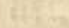


ON THE

\title{
GEOGRAPHY AND CLASSIFICATION
}

\author{
OF \\ A N I M A LS.
}

\section{PART I.}

ON THE GEOGRAPHY OF ANIMALS.

\section{CHAPTER I.}

REASONS AGAINST THE BELIEF THAT FOOD, TEMPERATURE, AND OTHER INFERIOR AGENTS, ARE THE PRIMARY CAUSES OF THE VARIATION OF MAN. - LIMITED RANGE OF ANIMALS WHICH YET POSSESS GREAT LOCOMOTIVE POWERS. - VARIOUS OPINIONS ON THE PRIMARY DISTRIBUTION OF ANIMALS. LINNAUS, PRICHARD, AND OTHERS. - THEORIES UPON ANIMAL GEOGRAPHY. - FABRICIUS. - LATREILLE. - PRICHARD. - PROPOSITIONS ON THIS SUBJECT STATED. - GEOGRAPHIC DISTRIBUTION OF MAN. - ARCTIC REGIONS.

(1.) $\mathrm{O}_{\mathrm{N}}$ looking at a map of the world we inhabit, we find that its surface is divided between land and water, continents and oceans; each, for the most part, thrown together into vast masses, placed under different temperatures, peopled by different races of men, and inhabited by peculiar sorts of animals. "Two questions then occur to the mind. What are the causes that 
have produced this dissimilarity of creatures? and, secondly, is there method in all this amazing diversity? Each of these questions is highly interesting, and demands a separate consideration.

(2.) MAN, although naturally formed to inhabit but one element, is yet enabled, by art, to traverse vast oceans; and, by the peculiarity of his constitution, to live in all climates which produce vegetation. In his natural state, he is among the least qualified of living beings for making rapid transitions from one part of the earth to another, and yet he has peopled its entire surface. A "fair_haired" native of Europe migrates with his family, and settles anong the woolly-haired and swarthy inhabitants of Africa. Do his descendants, in the lapse of a century, born under a scorching sun, begin to assume any of the characteristics of the races that surround them? do their lips gradually become thick, their nose flattened, and their complexion black ? Assuredly not; the supposition is refuted by actual experience to the contrary. Again, does an African diet, or a change of costume, create any change in their form, or their mental perceptions? are their national characteristics, in short, in any degree lost, so long as their race is preserved pure? Let the Spaniards, settled for more than two centuries among the copper-coloured Indians of Mexico and New Spain, - the Dutch boors of Southern Africa, - the descendants of the whites who first settled in the West Indies, - above all, the Jews, now scattered " among every nation under heaven:"-let these, we repeat, tacitly reply to these questions. Such living testimonies, known to all, should at once have dispelled the illusion which many writers, and some of them able ones, have indulged in; that temperature, food, clothing, and other secondary influences, were the chief causes of that extraordinary variation in the aspect of the human species which the different nations of the earth exhibit, and which, so long as each race is preserved pure, is unchanging and unchangeable. Upon such a subject the modest and ingenuous mind may in- 
dulge conjecture; but when we attempt to penetrate the darkness of primitive ages, and pretend to trace the first causes of such things, we wander in regions from which human knowledge is excluded. He alone, that great First Cause, "by whom all things were made that are made," is alone master of this impenetrable secret.

(3.) Let us now look to the animal world. Here we may see thousands of beings, endowed with powers of locomotion which have been utterly denied to man. The swallow, darting. like an arrow through the air at the rate of sixty miles an hour, seems to mock the comparatively snail-like pace of our swiftest vessels; the curlew runs rapidly on the ground, mounts on the breaking surge, or swiftly flies from one continent to another, thus traversing, with perfect ease, three elements, - the earth, the air, and the sea. Thousands, in short, of little tiny birds perform journies, every spring and autumn, any one of which, to us, would be the occupation of a year. Now the theoretical conclusion we should make, on considering these facts, would be, that animals, so peculiarly gifted with the powers of locomotion, would use it to wander in every clime, that they would spread their races in every region of the earth where food could be procured, or where they could enjoy a fit temperature. These deductions, theoretically, cannot be deemed otherwise than just. Yet they are diametrically opposed and contradicted by facts. The swallow of England might reach America or China in as short a space of time as it would travel to Africa, and in either country would find food and warmth congenial to its nature; but it has been appointed to pursue a certain course ; and from that course, whether to the right or to the left, it never deviates. This is only one out of a thousand instances, to prove that the limits of every animal have been fixed by an Almighty fiat - "Hither shalt thou come, but no further." Man may do much with thóse animals which 
have been appointed for domestication; while food and temperature will have their accidental or local effects : but these causes, when viewed in reference to the great harmonies of the animal world, sink into insignificance; and can never, for a moment, be justly made to interpret the causes of animal distribution. Within the limits of the range of every animal there are, like islands in the ocean, spots which are not congenial to its nature; and here the secondary causes, just alluded to, come into play : but we should no more think of making these spots so many characteristics of geographic zoology, than we should say that the sun was not a luminous body, because its entire surface is not equally bright.

(4.) That we may not, however, upon so important a question, appear to undervalue the opinions of those who have already given to the world the results of their investigations, we shall, in the first place, lay before the reader a cendensed statement of what has been published upon the subject, and then notice the different theories that have arisen on animal geography.

(5.) It was the opinion of Linnæus that all races of animals, no less than of plants, originated in one common central spot; from which they were gradually dispersed over those portions of the earth which they now inhabit. This opinion appears to receive full confirmation from the sacred writings; and, in reference to the general interpretation of the deluge, it would appear presumptuous to controvert this belief, were not the inference here deduced from the Mosaic narrative contradicted by innumerable and undeniable facts. If all the tribes of terrestrial animals, now in existence, descended from a stock preserved in the ark, and subsequently liberated, in what way can we account for the remote and partial locations of innumerable families, cut off by deserts and oceans from those regions in which all the events of Scripture history took place? Contradictory, therefore, as these facts, at first sight, may appear to be to the Mosaic account of the deluge, 
the results furnished by zoological science will, nevertheless, on a closer view, rather tend to explain and illustrate the sacred records.

(6.) The hypothesis of Dr. Prichard relative to this important question, and in refutation of the above opinion, is marked by great intelligence. "It seems difficult to maintain, with Linnæus, that all the tribes of land animals now existing descended from a stock that was preserved in Noah's ark, because, in that case, they must all have been congregated in one spot; a supposition which can hardly be reconciled with the results of zoological researches. But, perhaps, there is no necessity of assuming any such position. It is nowhere asserted in the Mosaic history; and who can prove that the various nations of animals which have the centre of their abode, and seem to have had the origin of their existence, in distant regions, as Australia and South America, were not created since the era of that deluge, which the human race, and the species of animals that were their companions, survived? This, indeed, seems to be the conclusion which facts, every day discovered, dispose us more and more to adopt." * "The deluge recorded in Genesis," continues our author, "was, perhaps, not universal, in the strict sense of the word, as it is now understood. The whole earth, the kol aeretz, which is said to have been submerged,

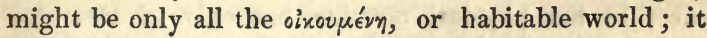
might only extend to the utmost limits of the human race; and other regions, with their peculiar organised creations, might be supposed to have escaped; and this hypothesis might, perhaps, be maintained without doing any violence to the sacred text, of which every expression has received a divine sanction." But this supposition, as our author very candidly admits, " is directly opposed to geological phenomena; which, with a variety of considerations, render it more probable that this deluge was strictly universal. It is incontestable

* Hist. of Mankind, vol. i. p. 81. 
that the fossil remains of animals, every where discoverable, chiefly belong to races different from those which now exist; these were probably exterminated in the great catastrophe. Mankind escaped by the means recorded in the sacred, and in many profane, histories; and with them were saved the stock of animals peculiar to the region in which, before the flood, they had their dwelling, and of which they, and most of the early domesticated animals, are in all probability the native inhabitants. After the deluge, when new regions emerged from the ocean, it is probable they were supplied with organised inhabitants suited to the soil and climate of each district. Among these new races, man, and the tribes which had survived with him, and which were his companions, spread themselves in a later time. The scripture history may thus be reconciled with the facts established by zoological research." Some persons will object to this hypothesis that it assumes positions not laid down in the sacred narrative, such as a partial creation subsequent to the deluge. This must be granted, and the proof of such position must be sought, not in the scriptural history, but in external phenomena. The silence of the Scriptures, in respect to such facts, seems to be of little consequence. It is not to be presumed that these sacred books contain a narrative of all that it has pleased Divine Providence to effect in the physical creation, but only of Hrs dispensations to mankind, and of the facts with which man is concerned: and it was of no importance for man to be informed at what era Australia began to contain kangaroos, or the woods of Paraguay ant-eaters and armadilloes.

(7.) Other writers, by circumscribing their views to the local distribution of a few native animals, have so far lost sight of the original question, as to suppose that " the geographic distribution of each species may be represented by a circle, towards the centre of which existence may be comfortably maintained; but, as we approach the circumference, restraints multiply, and 
life at last becomes impracticable." * It has been further added, that the conditions which regulate the geographic distribution of species appear to be limited to eircumstances connected with temperature, food, situation, and foes.

(8.) This hypothesis pretends not to account for the total difference in the genera and species of animals in two countries, which are yet under the same parallels of latitude, of the same degree of temperature, and fur.nished with the same means of supporting and enjoying life: it leaves this question where it was, and might, therefore, hardly deserve attention in an enquiry directed principally to primary causes. The theory of a circular range being enjoyed by species, may possibly be true in some few instances, although it would be difficult, perhaps, to name them: but, when applied to animals generally, it is not only opposed by facts innumerable, but is destroyed by the very admission that local circumstances exercise a primary influence on the range of animals. The peregrine falcon is found in America, Europe, and Australia, but it is totally unknown throughout the whole continent of Africa, an immense region thus intervening between two of its habitats. The great bustard of Europe is another familiar example: its distribution is latitudinal; it is found in the centre of England, through the heart of Europe, and to the confines of Asia. Now, according to the idea of animals enjoying a circular range, the first of these birds should be found in Africa, and the latter throughout a circle which would then comprise the whole of northern and southern Europe, and Barbary.

(9.) The opinion that those conditions which regulate the geographic distribution of species are limited to circumstances connected with temperature, food, situation, and foes, is totally insufficient to account for the phenomena of animal geography. We know, indeed, that these causes, either singly or collectively, have great

* Phil. of Zool. vol. i. p. 8. 
influence on local distribution, but they have nothing to do with the geographic distribution of animals indigenous to large continents : nor will they even explain the local distribution of some of the commonest birds. It may be said, indeed, that the absence of the nightingale in Northumberland and Scotland is to be attributed to the greater coldness of those parts, compared with the milder air of southern England. But how are we to account for this bird being common in the more northern kingdoms of Sweden and Germany? Climate, in this case, can have no influence; neither can food, since insects and their larvæ, of the same species, are found in all these localities : the thickets of Scotland are as favourable for breeding in as those of Sweden; and in regard to foes, no reason can possibly be devised. In what way, also, can the circular range of the nightingale be made out? Again, we will allow that these causes are sufficient to account for the fire-crested warbler (Sylvia ignicapilla) being found in the Parisian gardens, while it is a stranger to England. The difference of temperature, we will say, is the reason: England is colder than France. But how are we to account for two species of these gold-crested warblers being common in North America, in precisely the same latitudes, yet totally distinct from those of Europe? It is by such questions, of which every class of animals will furnish innumerable examples, that closet theories must be tried : at the same time, they will at once point out the very distinct nature of local dispersion from that of geographic distribution, properly so called.

(10.) Another theory supposes that the same species of animal or plant has been originally placed in many different regions: in other words, to have been at the period of their first existence locally diffused in countries widely distant. Hence it is, that nearly every country in the old world has a particular breed or race of the horse, ox, sheep, and dog; all of which, in common language, are termed the original breed of the particular countries wherein they are found. Little need 
be said to prove the fallacy of this hypothesis ; for although it is utterly impossible to trace the origin of our domestic breeds to one or more original stocks, since even the species cannot now be distinguished from the varieties, still the whole tenor of zoological facts is totally against this belief. The plains of the new world, no less than those of Australia, are as perfectly adapted for the comfortable existence of the horse or the ox, as are the fields and the pastures of Europe, or the grassy deserts of Asia ; yet nature has placed these animals in one hemisphere, and denied them to the other.

(I1.) Some other writers might be mentioned, who, in attempting to explain the causes of animal distribution, have either been but little acquainted with well known zoological facts, or have been led into theories too wild and fanciful to deserve notice. We may, indeed, build a theory upon every thing in nature: but the more we investigate, the stronger will be our conviction in the following deduction:- That the primary causes which have led to different regions of the earth being peopled by different races of animals, and the laws by which their dispersion is regulated, must be for ever hid from human research. This conclusion is strengthened by the inference which will be drawn from the facts we shall subsequently state; an inference so well expressed by a very intelligent writer, that we shall give it nearly in his own words. "It appears that the various tribes of organised beings were originally placed by the Creator in certain regions, for which they are by their nature peculiarly adapted. Each species may have had only one beginning in a single stock ; probably a single pair, as Linnæus supposed, was first called into being, and their progeny left to disperse themselves to as great 2 distance from the original centre of their existence as was compatible with its physical capabilities, and with those unknown laws, by which the Creator has regulated the geographic distribution of his creatures."

(12.) We have now endeavoured to demonstrate the insufficiency of all theories on the causes of animal dis- 
persion, and yet experience teaches us, that certain divisions of the earth are characterised by peculiar animals. We are now to enquire, what are these divisions? how they are to be defined? and what are their peculiarities? We shall, in the first instance, notice the different theories that have been formed upon these points, enquire how far they are in accordance with observed facts, and then explain our own views upon this interesting subject.

(13.) Fabricius appears to have been the first naturalist who ventured on any actual definitions of what he conceived to be natural climates or provinces, and his views are confined alone to the insect world. He considers that there are eight of these divisions, which he has named the Indian, 2. Egyptian, 3. Southern, 4. Mediterranean, 5. Northern, 6. Oriental, 7. Occidental, and 8. Alpine. The first comprehends the tropics of the Old and the New IVorld ; the second, the northern regions immediately adjoining; the third, the southern; the fourth, the countries bordering the Mediterranean, and part of Asia Minor; the fifth, the northern parts of Europe ; the sixth, the coldest regions of northern Asia ; the seventh includes North America, Japan, and China ; and the eighth, all those mountains whose summits are clothed in perpetual snow.

(14.) The objections to this theory, as urged by M. Latreille, are, that the divisions are too vague, and at the same time too arbitrary; and that if heat is to be considered as of such primary importance, it is not sufficiently correct as to temperature. This learned entomologist further observes (what, indeed, must be obvious to every one at all acquainted with the subject), that in places where the temperature is the same, the insects, and, we may add, the animals, in general, are totally different. The fact is, that Fabricius, by not attempting to demonstrate the correctness of any one of his divisions, seems to have subsequently abandoned them altogether, since no one, it may be fairly presumed, 
was more qualified than himself to discover the artificial nature of his theory.

(15.) The views of M. Latreille, in reference to the geography of insects, do not, however, materially differ from those of Fabricius: he divides the globe into climates, which he thinks may be made to agree with our present state of knowledge, and be even applicable to future discoveries. His primary divisions are arctic and antarctic climates, according as they are situated above or below the equinoctial line; and taking twelve degrees of latitude for each climate, he subdivides the whole into twelve climates. Beginning at $84^{\circ} \mathrm{N}$. he has seven arctic ones, which he names polar, sub-polar, superior, intermediate, supra-tropical, tropical, and equatorial ; but his antarctic climates, as no land has been discovered below $60^{\circ}$ south latitude, amount only to five, beginning with the equatorial and ending with the superior. He proposes further to divide his climates into sub-climates, by means of certain meridian lines : separating, thus, the Old World from the New, and subdividing the former into two great portions; an eastern, beginning with India; and a western, terminating with Persia. Finally, he proposes, that each climate should be considered as having $24^{\circ}$ of longitude as well as $12^{\circ}$ of latitude.

(16.) To these views it has already been objected, by a celebrated entomologist, that " any division of the globe into climates, by means of equivalent parallels and meridians, wears the appearance of an artificial and arbitrary system, rather than of one according to nature." * In this opinion we perfectly coincide. The first defect in M. Latreille's theory, which immediately strikes the mind, is its complicated minuteness, by which its author has lost sight of, and frittered away, those grand divisions of animal geography pointed out by nature, and immediately recognised by every naturalist. What entomologist, for example, of ordinary talent, does not, in

- Kirby, Int. to Entom. vol. iv. p. 485. 
eighteen instances out of twenty, instantly recognise the butterflies of Africa from those of America? or what ornithologist would now confound the flycatchers or the warblers of the Old with those of the New World ? These are all indications of those primary and comprehensive divisions, which both Fabricius and Latreille have lost sight of from a wish of attaining precision, and of entering upon details : they have, consequently, produced theories substantially built upon climate and temperature. M. Latreille, indeed, would seem to be fully aware of the slender foundation of all such speculations, since he remarks, with great truth, that as places where the temperature is the same, have different animals, it is impossible, in the actual state of our knowledge, to fix these distinctions of climates upon a solid basis. This opinion, it appears, is entertained both by M. Humboldt and Mr. M'Leay : and Mr. Kirby joins in believing, "that the real insect climates, or those in which certain groups or species appear, may be regarded as fixed by the will of the Creator, rather than as regulated by isothermal lines." * It cannot for a moment be supposed, that the geographic distribution of insects is regulated by other laws than those which affect animals in general ; although each may possess some few peculiarities in their minor details : the above objections, therefore, although more especially urged against the two entomological theories we have here noticed, are no less applicable to all others, intending to trace the phenomena of animal geography to temperature; and to fix their natural provinces or climates by degrees of longitude or latitude.

(17.) There yet remains to be noticed another hypothesis, more recently proposed, not; indeed, by a naturalist, but by one whose physiological researches are of the highest value, and whose opinions, therefore, merit every attention. Dr. Prichard is the first who 
attempted a more natural theory of animal distribution. This intelligent writer has looked more to the configuration of the earth, and to the natural connection or separation of its parts by intervening islands or oceans, than to absolute limits of longitude or latitude. Accordingly, from this very circumstance, his zoological divisions are formed with much greater attention to nature than any of his predecessors. The following are the primary divisions he has proposed:-1. the arctic regions of the New and the Old World ; 2. the temperate; 3. the equatorial or tropical ; 4 . the Indian islands; 5. the islands of New Guinea, New Britain, and New Ireland, and those more remote in the Pacific Ocean; 6. Australia proper; and, lastly, the southern extremities of America and Africa.*

(18.) The objections that may be stated against these divisions chiefly arise from the author not having kept in view the difference between affinity and analogy, as more particularly understood by modern naturalists. $\dagger$ And we may illustrate this position by looking more attentively to the animals of two or three of these provinces. 1. The arctic regions of America, Europe, and Asia, indisputably possess the same genera, and in very many instances the same species; and if it should subsequently appear that these regions are sufficiently important in themselves to constitute a zoological province, then it is a perfectly natural one; for not only are the same groups, but even the same species, in several instances, common to both. But can this be said of the second of these provinces, made to include the temperate regions of three continents? Certainly not. We find, indeed, analogies without end, between their respective groups of animals, but they have each a vast number of peculiar genera; and so few are the species common to all three, that the proportion is not perhaps greater than as 1 to 50 . The genera, with but very few 
exceptions, are peculiar, but are represented by analogous genera ; and each continent is distinctly separated in its animal productions by indications as certain and as indubitable as those which distinguish their respective inhabitants. Can we include temperate America in the same zoological province with the parallel regions of Europe, when there are not three land or rather perching birds common to both ? and when more than two thirds of the genera found in America are totally unknown in Europe or in Asia? Look to the bears of the temperate regions of the three continents : those of America and Europe are similarly constructed, but the species are different; while those, again, of Asia, are formed upon a totally different model. We might fill pages with similar facts; all tending, as we conceive, to exemplify the necessity of preserving these relations as distinct in our views of animal geography, as we are compelled to do in threading the maze of natural arrangement. Dr. Prichard, however, has the great merit of having made the nearest approach to such a theory of animal distribution as is suggested by the natural geography of the earth; nor need we wonder that he has faile in the application, since others, who, from their peculiar studies, might be supposed more competent to the task, have erred from the very foundation.

(19.) Since, then, there is as marked a distinction between the animals of the great continents as there is between the races of mankind by whom they are inhabited, it remains to be considered whether the general distribution of both are not in unison? Whether their Divine Creator has not, by certain laws, incomprehensible to human understanding, regulated the distribution of man and of animals upon the same plan? These questions lead us to the following propositions :-

1. That the countries peopled by the five recorded varieties of the human species, are likewise inhabited by different races of animals, blending into each other at their confines. 
2. That these regions are the true zoological divisions of the earth.

3. That this progression of animal forms is in unison with the first great law of natural arrangement, viz. the gradual amalgamation of the parts, and the circularity of the whole.

(20.) Whether we view the varieties of the human species, with M. Cuvier, as first resolvable into three, of which the Ethiopian is to comprehend the Malay and the American; or whether, following Blumenbach, we consider the number to be five, thus raising the two latter to the rank of primary divisions, is of no consequence to our present enquiry. It is enough that all physiologists agree in these distinctions; and the precise countries inhabited by the typical races of each. 'These territories are not only indicated by the peculiarities of their inhabitants, but are so strongly marked by the hand of nature, in their configuration, that geographers, looking merely to their natural position and boundaries, have long recognised them by well-known names. Assisted, therefore, by these important indications, let us respectively contemplate the animal kingdom as it appears in the following divi.* sions of the earth ; considered, by all physiologists, as the chief seats of the five leading races of mankind. 1. The European or Caucasian; 2. the Asiatic or Mongolian; 3. the American; 4. the Ethiopian or African; and, 5. the Australian or Malay. The precise limits of the five zoological provinces here assumed, will not admit of accurate definition. The first great law of nature is harmonious combination. Whether in the moral or the physical world, the material or the immaterial, all her operations and all her changes are gradually progressive. The past, the present, and the future, are continuous. Changes, between forms and states the most opposite, are effected by transitions so gradual as often to elude definition. No axiom is more important, for the na- 
turalist more especially, to be borne in mind than this. What beings can be more dissimilar than an African negro and a Greek Caucasian? Yet who has ventured to pronounce in what regions the Ethiopian form actually blends into that of the Caucasian? or this, again, into the Mongolian? Such are the difficulties that will for ever baffle all attempts at unexceptionable definition, or every effort to define the precise limits of natural groups or zoological regions. Nature, in fact, seems to abhor those arbitrary rules, with which man has invested her operations; and which, for centuries, have shackled the progress of zoological knowledge.

(21.) In attempting, therefore, to give a more accurate definition to the foregoing divisions, we are compelled to fill up the outline, at the best with diffidence, and, in some cases, by conjecture. The following, however, may be regarded as some approximation to the truth. 1. The European or Caucasian range includes the whole of Europe, properly so called, with part of Asia Minor, and the shores of the Mediterranean: in Northern Africa the zoological peculiarities of this region begin to disappear ; they are lost to the eastward of the Caucasian mountains, and are blended with those of Asia and America to the north. 2. The Asiatic range : comprehending the whole of Asia east of the Ural mountains, a natural and well-defined barrier between the two continents. The chief seat of this zoological region is probably in central Asia; its western confines I' 'nd into the European towards Persia, and disappear on the west of the Caucasian chain; it is united to the African range among the provinces of Asia Minor; and is again connected with Europe, and also with America, by the arctic regions of the three contineuts; finally, its most southern limits are marked by the islands of Java and Sumatra, where the zoological character of the Australian region begins to be apparent. 3. The American range. United to Europe and Asia at its northern limits, this region or province comprehends the whole of the New World; but into which it blends at the other ex- 
tremity is uncertain. 4. The next includes the whole of Africa south of the Great Desert : a part, at least, of the countries bordering on the Mediterranean exhibit a decided affinity to the European range; while the absence of large animals in Madagascar, and the presence of genera peculiar to New Holland and the extreme point of Southern Africa, lead us to the fifth or the Australian range. 5. To this region nature has given peculiar characters, both in regard to its geographic situation and to its animal productions. New Guinea and the neighbouring islands mark its limits in that direction; Australia Proper is its chief seat, and it spreads over the whole of the numerous islands of the Pacific Ocean : whether this province blends with that of America or of Europe, remains for future discovery ; but its connection with Africa and Asia has been already intimated.

(22.) In this distribution, the Arctic regions, it will be perceived, are contemplated as a common bond of union, wherein the three great Faunas of Europe, Asia, and America meet, and are united together. 'They are consequently excluded from the rank of a distinct zoological province, because they do not contain either genera, or but very few species, of animals not found in the temperate latitudes of the other continents. The Polar bear, the Arctic fox, and about a dozen other animals, are surely insufficient to constitute one of the primary zoological divisions of the earth. If we look more particularly to the ornithology of these regions, "we shall be still more inclined to form such a conclusivfn. The number of birds, terrestrial and aquatic, which occur within the Arctic circle, amounts only to twentytwo; most of which, during the greater part of the year, are found in the northern seas of Britain and America, and very many extend their range to the lakes and swamps of Mexico. Can we, therefore, say of the Arctic regions, as of all the preceding provinces, that they are characterised by many exclusive genera, and by numerous forms of species? Certainly not. Not one genus of vertebrated animals is peculiar, unless such may 
be found among the marine tribes; but even these would enjoy a much wider range, had not the persecutior and the increased population driven them, and restricted their limits, to the Arctic solitudes.

\section{CHAP. II.}

EUROPE.

EUROPE CONSIDERED AS A ZOOLOGICAL PROVINCE. - THIS PROPOSITION SUPPORTED BX AN ANALYTICAL SURVEX OF ITS ORNITHOLOGY. - PREPONDERANCE OF ITS GENERIC TYPES. ITS ANALOGY TO THE CAUCASIAN TYPE OF MAN. - RESULTS OF THE FOREGOING ANALYSIS. - ITS ZOOLOGY CONSIDERED MORE IN DETAIL, UNDER THE THREE HEADS OF ARCTIC, CENTRAL, AND SOUTHERN EUROYE.

(23.) The first of the zoological provinces intimated in the last chapter appears, on a cursory view, to be the most objectionable. For not only has it never been viewed in this light, but, from its close connection to that of Asia, it is also peculiarly difficult to characterise. Fully impressed with this difficulty, we considered it essential to the clear elucidation of our present theory, to institute a minute enquiry into those facts upon which alone all such theories can be supported. The quadrupeds of Europe are too few, and their original distribution have been too much altered by the progress of civilisation, to furnish satisfactory results. The insects, on the contrary, are too numerous, and the reptiles too insignificant, for our purpose; while the distribution of the marine animals; peculiarly difficult under the most favourable circumstances, has been hitherto neglected. We have 
consequently selected from the department of ornithology those facts which appeared to authorise us in considering Europe as one of the primary zoological divisions of the earth ; and shall now proceed to lay these facts, and the inferences, before the reader. It has, indeed, been objected to this class of animals, that no very certain results can attend the study of their distribution. Possessing the powers of locomotion in a higher degree than any others, and by their migratory nature perpetually wandering into distant countries, they would seem, of all animals, the most widely dispersed, and consequently the least calculated to assist such an enquiry. How far this may be true, it will be our object to investigate. Certain, however, it is, that if, under such disadvantages, any definite notions on animal distribution can be derived from such volatile beings, the results will go very far to strengthen our views upon two material points : first, that a division of the earth, characterised by strong peculiarities in its ornithology, must be, to a certain extent, a natural division ; and, secondly, that we shall be fully authorised in supposing, by analogy, that the same results would attend an equally close investigation of other animals ; since it cannot for a moment be supposed that man and birds are distributed according to one plan, and all other animals by another.

(24.) Before illustrating the ornithology of Europe, with reference to the geographic range of the genera and species, we must advert to the difficulties by which the enquiry is surrounded. The accounts and relations of travellers, not in themselves naturalists, must, upon this and every other occasion, be received with great caution. Unacquainted with those nice distinctions, on which not only the separation of species, but of genera and families, are now known to depend, these writers perpetually contradict, by a hasty application of wellknown names, some of the most acknowledged truths in animal geography. Nor can the facts collected in the compilations or more scientific writers be always 
depended upon: numerous instances might be mentioned, where not only species, but genera, are said to inhabit countries, where, in fact, they are totally unknown, and to which their geographic range has manifestly been prohibited. It is the misfortune of those who complain of the present refinement in zoological nomenclature, that they debar themselves from a knowledge of these interesting facts ; and, by keeping up old names, contribute, unintentionally, to the continuance of error. It is necessary to state thus much, that the reader who may be disposed to go over the same ground with us, may be warned of the nature of the road he is to travel. He will, however, be materially assisted in his researches by the valuable Manuels of M. Temminck, the American Ornithology of Wilson, the admirable writings of Prince Ch. Bonaparte, and the Northern Zoology of Dr. Richardson. Much, however, of what we are now to state, has resulted from personal knowledge; and this has enabled us to reject, as spurious, many of the localities assigned to species in the general histories of birds.

(25.) Commencing with the Aretic regions, we must again impress on the reader the small number of birds which are natives, during any considerable portion of the year, of the most northern extremities of Furope and its frozen islands. These do not exceed, both in the terrestrial and aquatic orders, the number of twenty-two ; the larger proportion of which are also found, during the greater part of the year, in the northern parts of Britain, America, and probably in Asia : on this latter region, however, we possess but slender information. The foregoing species are chiefly composed of the natatorial or swimming tribes, - of all others, perhaps, the most extensively dispersed: the total number of this order, hitherto discovered on the shores of Europe and Northern Africa, independent of such as are more peculiar to the Arctic circle, is sixty. Of these, two alone have been discovered in the four quarters of the globe; three are common to Europe, Asia, and America; one 
to Europe, Asia, and Southern Africa; and twentyseven to Europe and North America: yet, notwithstanding these deductions, there still remain twentyseven natatorial species (or nearly one half of the total number found in Europe), as peculiar alone to the European range.

(26.) Among the Grallatores, or wading birds, we find some species so widely dispersed, as to make us believe the range of this order is even wider than that of the swimming tribes: and this, generally speaking, may be the fact. Of the sixty-five species described as natives of Europe, thirteen only occur in America, and but two can be denominated Arctic birds, although several others occasionally frequent those regions : of the remainder, four occur in Asia; two in Asia and Africa ; four in Asia and America ; seven in Asia, Africa, and America ; and the whimbrel (Numenius Phoopus) is said to be the same in all the five divisions of the globe. It is, consequently, among the wading birds that we find those whose range is most extensive ; yet, on a general calculation, the number of species peculiar to Europe is considerably greater than those of the Natatores, the former being as one to two, the latter nearly as one to four. This result is highly curious and important, since it at once proves that, even among birds of the most vagrant habits, the ornithology of the European range is characterised by a decided superiority, in the number of its own peculiar species, over those which equally inhabit other countries.

(27.) The rapacious order, next to the aquatic tribes, is, of all others inhabiting the land, the most widely spread. This is particularly the case among the nocturnal \{species. It is remarkable that, of thirteen different owls inhabiting Europe, six only are peculiar, and two of these more particularly inhabit the Arctic regions. Of the rest, four occur in America, two in Southern Africa, and one in both Asia and America. The Falconida, or diurnal birds of prey, in regard to c 3 
their species, have a more restricted distribution than the nocturnal ; yet, of these, the eagles enjoy no inconsiderable range: of four discovered in Europe, one is more properly Arctic, three have been found in several parts of Africa, and one occurs in America, leaving three only to Europe. It is singular that those rapacious birds which, from the peculiar structure of their wings, have been supposed to enjoy the greatest power of flight among their congeners, should nevertheless have a much more limited range. This is proved by the fact, that, of eight genuine falcons inhabiting Europe and Northern Africa, two only have been discovered in America. It has, however, recently been stated, that the peregrine falcon of Australia is absolutely the same as that of Europe. Among the numerous species of falcon in Southern Africa, not one occurs in Europe: the European kestril, long confounded with the montagnard of Le Vaillant, being a decidedly distinct species. Upon the whole, the distribution of the fortyfour European birds of prey appears to be thus regulated : - three are more properly Arctic ; eleven are found also in America, two in Asia and Africa, and one in Asia and America; leaving twenty-seven, or more than one half, as characteristic of European ornithology.

(28.) The gallinaceous genera are few. Their wide dispersion is decidedly against the theory, that all birds, with heavy bodies and short wings, are more limited in their geographic range than other terrestrial tribes. This argument has been ingeniously made use of, to account for the very restricted limits nature has imposed upon the greater number of Indian parrots; many species, as it is stated, being confined to particular islands. We must not, however, expect to find a reason for every thing: in the present instance, the above conclusion is particularly erroneous. Ornithologists, indeed, need not be told, that the wings of nearly the whole of the parrot family are peculiarly alapted for strong and vigorous flight; while those who have contemplated 
these birds in their native regions, cannot fail to have remarked that their flight is particularly rapid : nearly all the genera pass through the air with the celerity of a hawk. The long-winged macaws and parrakeets of the New World are particularly. graceful and powerful on the wing. The wide dispersion of the European gallinaceous birds is very evident. The range of the great bustard (Otis tarda L.) extends from the western extremity of temperate Europe to the confines of Asia ; and the quail, remarkable for its heavy body and short wings, performs long and regular annual migrations, from and to Northern Africa, over the greatest part of Europe and Western Asia. We do not consider any of the European grouse as strictly Arctic; excepting, perhaps, the ptarmigan; the rest appear to occur as plentifully beyond those regions, as within them. Many of the meridional European birds, as the hoopoe, oriole, roller, \&c., might with equal justice be classed as tropical birds, since they are found as often in tropical Africa as on the shores of the Mediterranean. The colder countries, of course, are the more peculiar habitations of the grouse; but even in this family we meet with an insuperable objection against the idea of an Arctic province. If we exclude these birds from the fauna of temperate Europe, do we find the same species in the northern latitudes of America? where, if we admit the existence of an Arctic province, it is natural to suppose they would be also found. Certainly not. The species of the two continents represent each other; but out of thirteen inhabiting America, only two ( $T$. saliciti and Lagopus) have been found in Europe: with these exceptions, they are totally distinct: there is a beautiful analogy, but no similarity. On looking to the whole number of our Gallinacea, we find twenty-seven species, fourteen of which have their metropolis in Europe : the remainder are thus dispersed : - five extend to Western Asia, five to the confines of the great African desert, two are dispersed over Central

$$
\text { c } 4
$$


Asia and Africa; while two only, as before mentioned, occur in North America.

(29.) The swallow-like birds (Fissirostres) are well known by capturing their food on the wing, and by their migratory habits; only one, the common or European kingfisher, being stationary. Hence it is, that most of the European species occur in other regions: the proportion of those which appear confined to Northern Africa is as one to three.

(30.) The finch family, comprising the small seed-eating birds, not only contains numerous species, but these are very abundant in number. We reckon forty-one to be natives of Europe; two of which are common in all the northern latitudes, and, at certain seasons, frequent the polar regions in large flocks: seven also inhabit North America; and three extend their range to Asia and Africa. With these deductions, we find no less than thirty species restricted to the European province.

(31.) The scansorial or climbing birds are few, not amounting to more than fifteen species; yet eight, or one half of this number, are unknown in other countries.

(32.) It is among the insectivorous or soft-billed birds that the principal ornithological features of any extensive region will be traced. The very extensive genus of titmice warblers (Sylvicola Sis.), or the family of humming-birds, would of themselves be sufficient to place America in a distinct province. To what cause it is to be attributed, that birds, by no means defective in the power of flight, should yet be so strictly confined within certain geographic limits, has not been explained. Of eighty-five species belonging to the thrushes, warblers, titmice, and flycatchers, eighty-two have not been discovered beyond the limits assigned to the European range. In this number we, of course, include such as migrate to Northern Africa and Western Asia; these countries being within the province we are now speaking of. Yet, if we deduct those which have actually been detected beyond the shores of the Mediterranean 
and Western Asia, they will amount only to ten ; leaving seventy-two as a marked and very prominent characteristic of European ornithology. In further illustration of the very limited range of these families, it appears that three only, of eighty-five, equally inhabit America; and that even the identity of one of these (Parus atricapillus L.) with a European species (P.palustris L.) is more than questionable.

(33.) The large omnivorous birds of Europe, comprising the crow and starling families (Corvida, Sturnida), appear widely dispersed. Yet, upon the whole, several species, and even peculiar genera, are left to characterise this portion of the world. We may state their number at twenty-one; thirteen of which, or more than one half, habitually reside in Europe; four occur in Northern and Central Africa; one - the beautiful rose-coloured starling (Pastor roseus 'T.) -inhabits likewise the table land of Asia, and the deserts of Africa; while three are found in America.

(34.) These details, of the greatest importance to our present enquiry, yet tedious, perhaps, to the general reader, it becomes necessary to dwell upon, before a competent opinion can be formed on European ornithology. The facts exhibited have never before been stated; and they appear sufficiently strong to justify our looking to Europe as the principal seat of a peculiar geographic division of animals. In this difficult and somewhat laborious investigation, we have been much assisted by the writings of Wilson, Temminck, and Le Vaillant; but more particularly by that liberality which throws the magnificent Museum of the French nation open to the use of all scientific enquirers. Yet, with all these sources of information, and perhaps greater, had such existed, it cannot be supposed that inaccuracies may not occur. Such calculations, in short, from their very nature, cannot be perfect; for they are founded upon a state of knowledge which is ever improving. All we can do, in such cases, is to make as near an approximation to truth as 
circumstances admit; and, having done this, the result may be entitled to proportionate confidence.

(35.) As a general recapitulation of the foregoing details, we may estimate the total number of European species at 388 , excluding a few, which only appear, at remote intervals, as stragglers : of these, thirty-one are more peculiar to the Arctic regions of Europe, America, and probably of Asia; the proportion being as one to thirteen. Such as occur, also, in temperate Asia and America amount to sixty-eight; forty of which are aquatic : nine are dispersed over four divisions of the globe, to none of which can they be particularly appropriated; while one or two extend also to Australia. With all these deductions, the number will be reduced to about 278. If from these we abstract such as have a range beyond the European limits, the number may be further reduced to about 250: so that nearly two thirds of the total number of birds found in Europe, Northern Africa, and Western Asia, are zoologically characterised as peculiar to these countries.

(36.) Another remarkable fact in European ornithology, which deserves attention, is the great number of generic types it contains, when viewed with reference to the number of species. These genera may be calculated at 108, omitting some which have not been generally adopted, and others which may more correctly be termed sections. The proportion which these genera bear to the species (estimated before at 388 ) amounts to more than two to seven; or, in other words, does not give seven birds to two genera. It is further remarkable, that most of these genera are typical of their respective families. True it is, that such genera are usually very widely dispersed; but in no division of the globe do they appear so much concentrated, or so numerous in proportion to the species, as in Europe. This remark not only applies to the typical genera, but is frequently applicable to the number of species they respectively contain. One instance will illustrate our meaning. The noble falcons, or those to which the generic name of 
Falco is now restricted, are the most typical group of their family : of these the kestrel, and five others, have their chief metropolis in the European province. The whole of North America has hitherto produced but four. Le Vaillant enumerates the same number from Southern and Central Africa. Those of Asia Proper are not known; but only two are furnished by the vast regions of Australia. Now, if we merely look to these respective numbers, the difference is sufficiently disproportionate: but when the great inferiority of the European province, to those of America, Africa, and Australia, in point of extent, are taken into the account, the great proportion of these eminently typical species in Europe is particularly striking. The genus Lanius is strictly typical of its own family. In Europe we have certainly five, and probably six, species; while only three inhabit the whole of the New World. In Africa, Le Vaillant discovered five; but two of these, from having their chief metropolis in the heart of Europe, cannot be considered as characteristic of the former continent. The manifest preponderance of genera in the European range is further illustrated by the following fact :- The total number of species among birds, exist.ing in collections, may be safely estimated at 6000 , since it has been asserted that the Museum of Berlin alone contains that number. These have been referred to about 380 genera; but as several of these genera comprise others not yet characterised, we will estimate the number at 400 : this would leave 15 species to each generic group; whlie, if the ornithology of the European range is alone considered, the proportion which the genera bear to the species is no more than as one to three.

(37.) The above facts serve to illustrate a remarkable analogy between the distribution of the feathered tribes, and the various races of mankind inhabiting the European, or rather the Caucasian, province. A modern writer of no mean authority, and to whom the above facts were entirely unknown, when speaking of the 
varieties of mankind, observes, that " the tribes among the Caucasians are more numerous than in any other ;" and, as if impressed with the singularity of the circumstance, he again repeats, "Whether we consider the several nations, or the individuals in each, bodily differences are much more numerous in the highly civilised Caucasian variety, than in either of the other divisions of mankind." " Whether we look to the Caucasian races of man, or the races of birds, these facts are still more curious, since this division is so disproportionately small in comparison to either Asia, Africa, or America.

(38.) That there are instances of typical forms of higher groups than genera, which do not occur within the European province, does not materially diminish the general strength of this analogy. Thus the only bird we possess belonging to the tenuirostral or suctorial tribe, is the European hoopoe (Upupa Epops L.), which is certainly not typical: but this, so far as tribes are concerned, is the only exception that can be named; since, although we have no parrots, we possess many woodpeckers, which are the most typical of all the scansorial birds. It is curious that the above exception should be found in that division alone which comprises the smallest and weakest of birds (Trochilida Sw.). If we descend to the families of the Insessores (the most perfect of the feathered tribe), there is not one, pre-eminently typical, which is not European.

(39.) These results, furnished by facts which are incontestable, are so important to our present enquiry, that we make no apology for having so long dwelt upon them. The ornithology of Europe is better known than that of any other continent, or of any other class of animals distributed in the same regions; it has, consequently, furnished us with facts more unexceptionable and more perfect than could have been drawn from its quadrupeds, fish, or insects. How far this view of European zoology would be strengthened by a similar 
investigation of other classes, it is impossible to judge : for, even did our present very confined limits permit the enquiry, we should have to rely more upon theory than upon facts. Many of the quadrupeds originally dispersed over Europe, have already become extinct as natives, and the races of others are fast disappearing: we know not, in fact, the original and natural dispersion of these animals. Conclusions, drawn from such as are now only known in a fossil state, would be still more vague. Geographic ornithology is nearly exempt from both these objections: since the paucity of fossil remains referred to this class, proclaims how few species must have been extirpated. Birds, more than any other vertebrated animals, seem to have been the least affected by the Deluge, or by other changes calculated to modify their original dispersion. It naturally follows, that, in tracing the distribution of the feathered creation, we have selected that department of nature which has left us unshackled by geological controversy, and that which - from possessing the most authentic materials - is best fitted to illustrate our subject.

(40.) The conclusions which we must arrive at, upon a review of the foregoing statements, are these:- First, that the European province is strikingly characterised by its peculiar animals, and sufficiently so to constitute it one of the primary zoological divisions of the world. Secondly, that it occupies those countries which are the chief seat of the Caucasian race, with which its ornithology presents many singular and undeniable analogies. Thirdly, that these analogies are so remarkable, and so manifest, that we must conclude that the same Alмigh ty Power has distributed both upon one uniform and harmonious plan.

(41.) Having so far pointed out those peculiarities which entitle Europe to be considered one of the chief zoological divisions of the world, we shall now, viewing it in that light, take a rapid survey of its more particular features. Our observations will be arranged under the three divisions it naturally presents; namely, 1 . the 
Arctic ; 2. the Central; and, 3. the Southern. The chief seat, however, of this zoological province is between the 40 th and 50 th degrees of $\mathrm{N}$. latitude.

(42.) Arctic Europe comprehends Greenland, Lapland, the islands of Spitzbergen and Iceland, and a considerable part of Norway, Sweden, and Northern Russia. The intense cold of these regions, being highly unfavourable to animal life, renders the species very few. There must be an exception, however, made in favour of the marine tribes of Mollusca, and of the aquatic birds : vast multitudes of both are regular visitants to these inhospitable shores; the former class supplying food to the latter. Among the quadrupeds, the Arctic foxes, wolves, seals, and Polar bears, are well-known inhabitants. Otho Fabricius mentions thirty-two species of Mammalia as natives of Greenland, nine of which are seals and walruses ; and fifteen belong to the whale class ; thus leaving but eight species of terrestrial quadrupeds. The number of birds, including occasional visiters to Greenland, are fifty-two; among which, seven are rapacious, and only five belong to the warblers and finches; the remainder, with the exception of the ptarmigan (Lagopus mutus), belong to the wading and swimming orders, to whose nourishment and increase the Arctic

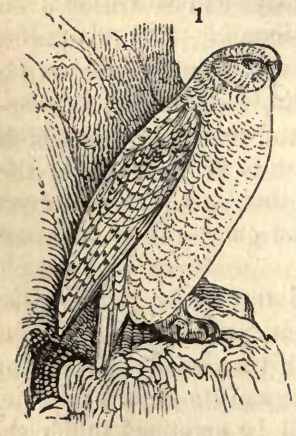
solitudes are highly favourable. Nevertheless, the largest proportion of these birds occur abundantly in southern latitudes; and many extend even to Mexico, Northern Asia, and the shores of the Mediterranean. Those species, in fact, which are confined to the Arctic circle, are remarkably few. The most characteristic bird of Arctic Europe is the great snowy owl (Strix Nyctea L. fig.1.), which extends its range over all the regions bordering upon the north pole. 
(43.) The first indications of the zoology of Central Europe may be said to commence towards the 60th degree of north latitude, where a sensible change in the number and in the species of animals may be perceived. Vegetation supplies food for insects, no less than for birds; while the former become the prey of the latter : thus the supplies" of nature are accurately balanced, with a considerate regard to the wants of all her creatures. This accession of fertility in the vegetable kingdom is accompanied by an accession of animals; the land birds increase, while the aquatic tribes diminish in numbers, although not in species. Most of the Arctic birds, however, occur in the northern parts of Scotland, and in Norway, Sweden, and Denmark. Müller, the celebrated Danish naturalist, enumerates fifty-seven quadrupeds and 131 birds, as natives of his own country: among the former, seventeen only are marine; while the land birds amount to eighty-seven, exclusive of twenty-six eagles, falcons, and owls. On comparing this statement with that already cited of the animals of Greenland, we observe a considerable diminution of the marine Mammalia, and a large addition to the terrestrial birds, this latter fact being accounted for by the circumstances above mentioned. As we approach farther south, this increase becomes more apparent, and can be traced even within the limits of our own islands. Several species of the polar regions, common to the north of Scotland, are unknown in the west of England; which, nevertheless, exhibits a much greater number of others, which that kingdom does not possess; this is particularly the case among the insects of the two countries. Even among the domesticated animals, a greater developement of size is apparent in the horse, the sheep, and the ox of England, than in those of Scotland ; while the peacock, turkey, and Guinea-fowl, so perfectly naturalised in our climate, are reared and preserved with great difficulty towards the north of Scotland.

(44.) It appears, therefore, from the foregoing observations, that the southern part of Central Europe is the re- 
gion best calculated for studying the peculiarities of this zoological province. Confining ourselves to the existing wild quadrupeds, we may remark, that, while two species alone appear to inhabit the cold country of Denmark, there are thirteen described as natives of France and the adjacent kingdoms, seven of which are also found in Britain. The common brown bear takes the place of the Polar species in the central parts of Europe, where, also, the black bear was once common, although now nearly extinct. The wolf and the fox, under different varieties, or perhaps species, are distributed over this region; where also we find the wild cat; and two, if not three, species of lynx. The lesser ferocious quadrupeds are more numerous; for no less than eight species of the weasel family inhabit Europe. Under the head of graminivorous quadrupeds, or such as live more or less upon seeds as well as upon flesh, may be mentioned the hedgehog, squirrel, and seven species of mice. The beaver (fig.2.) is recorded to have inhabited, at one time, the

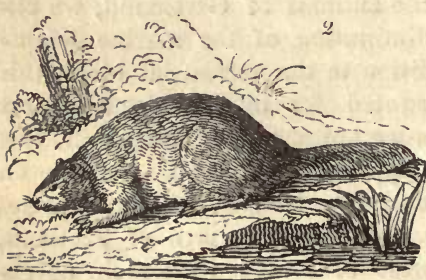

banks of some of the Welsh rivers, but has long been extirpated from these islands, and will, doubtless, in a few years, entirely disappear from Europe. It may be here observed, that the different species of mice, now arranged under several distinct genera, form an important feature in European zoology. The following are their names :-

Arvicola amphibius. Water Rat. Arvicola arvalis. Field Arvicole. Arvicola fulvus. Yellowish Mouse. Arvicola argentoratensis. Strasburg Mouse.

Georychus Norvegicus. The Lemming.

Georychus terrestris. Land Iemming.

Mus sylvaticus. Field Mouse.
Mus campestris. Plain Mouse. Mus musculus. House Mouse. Mus messarius. Harvest Mouse. Mus minutus. Small Mouse. Mus agrarius. Setnic Mouse. Mus soricinus. Shrew-like Mouse. Mus dichrurus. Party-coloured Mouse.

Mus Islandicus. Iceland Mouse. 
(45.) Of the hamsters, remarkable for their cheek pouches, one species is chiefly found in Siberia ; but another (Cricetus vulgaris) is distributed over Central and Northern Europe. Two species of marmots (Arctomys Marmotta and Bobac), and the Spermophilus citillus, or Soulisk of the Germans, occur in this region. Four species of hare and rabbit complete the list of the European Glires.

(46.) On turning to the ruminating order of quadrupeds, we find the elk and the reindeer of the northern latitudes giving place to the fallow deer, the stag, and the roebuck in the central parts of Europe. The lofty and inaccessible precipices of the Alps and Pyrenees still afford shelter to the chamois, the yzard, and the ibex, notwithstanding the daring intrepidity of their hunters. The musmon is another of the wild European animals, possessing much interest, from being the origin of all our domesticated sheep : it is said, although not by any recent authority, still to exist in a state of nature among the high mountains of Corsica and Sardinia ; and although now extirpated from the continent, there is good reason for believing that it formerly existed on the mountains of Spain. In the early ages, wild oxen were common in most parts of temperate Europe ; and they are mentioned, even by our own historians, as infesting the forests which then surrounded London! The white ox, formerly wild in Scotland, is now only known from the breed having been preserved in one or two of the parks of our nobility.

(47.) The ornithology of Central Europe has many peculiarities. On the highest summits of the Alps, and in the large and elevated forests which still remain in Hungary and the Tyrol, are found all the four species of European vultures. Only one of three, the fulvous vulture ( $V$. fulvus L.) appears to enjoy a range further north ; yet all extend their peregrinations as far as Italy, and two are even found on the northermost limits of Africa and Western Asia. The great-eared owl (Strix 
bubo L., fig. 3.) represents, in Central Europe, the snowy species of the Arctic regions. It is common in

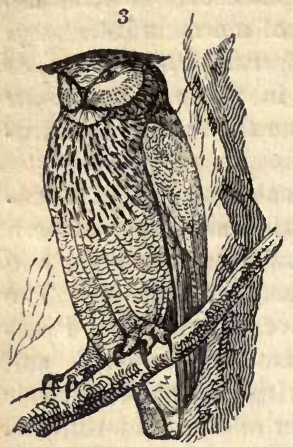
the German and Hungarian forests, although very rare in England. 'The Iceland falcon is not, as it name would imply ${ }_{3}$ confined to that frigid country, but is well known in Germany under the name of the Falco caudicans of authors. The wide geographic range of the class of rapacious birds already noticed (27.), enables us to account for the dispersion of the remaining European falcons over all the temperate and southern parts of this continent, and over the northern regions of Africa, in the greater number of instances. With the exception of the three-toed species, all the other woodpeckers, five in number, are found in the forests and woods of Central Europe.

(48.) To detail the varied distribution of the warblers and the small insectivorous birds would far exceed the limits of this sketch; their northernmost limits, however, do not extend beyond Central Europe; nor are we aware of any one species found in France and Germany, which does not occur in the southern kingdoms. The few gallinaceous birds, with the exception of the grouse, are chiefly found in similar temperatures : they consist of three species of bustards, two of partridges, and one of the quail. The grouse seem to occupy an intermediate station between the centre of Europe and the confines of its polar extremity : the largest is the famous cock of the woods, once an inhabitant of the Scottish forests; which country also produces another species, the red game of the sportsman, which is found in no other part of the world. Four of the most beautiful of European birds, namely, the bee-eater, the roller, the hoopoe, and the golden oriole, in their 
annual migrations from Africa, visit nearly all the central parts of the Continent, and are occasionally carried, by accidental causes, to these islands; but as we advance northward, they are no longer to be met with.

(49.) We now come to the third portion of the European province, comprising the south of France, the whole of Spain; Italy, and Turkey, together with the coasts and islands of the Mediterranean Sea, bordering on Northern Africa and Asia Minor. On the quadrupeds of these countries little can be said, as our materials are but scanty. There is no evidence that the large ruminating animals, such as the elk, reindeer, stag, roebuck, \&c., exist on the shores of the Mediterranean; although a small species, probably the fallow deer, is still to be met with in some of the extensive forests of Calabria, and in the vestiges of those which once spread over the mountains of Sicily. But, on the other hand, there is the porcupine, an undoubted native of Italy, still found wild; and the musmon sheep, already mentioned, truly belongs to this region. The buffalo lives in Greece and Italy, as if in its native country, although now only seen in a domesticated state.

(50.) The ornithology of the Mediterranean shores presents many interesting facts. The vultures, which are seldom found northward of the Alps, occur more frequently as the climate becomes warmer; they appear to follow the course of the Apennines in Italy, and of the higher mountains of Spain and Greece; whence they extend their range on one side to Asia Minor, and on the other to Northern Africa. The imperial eagle (Aquila imperialis Sw.) is chiefly fround in Southern Europe, while the golden eagle is more restricted to the colder latitudes. The gigantic owls of the northern regions are here unknown; but two or three horned species, of diminutive size, follow the migratory flocks of land birds in their annual flights across the Mediterranean from Africa. In the extensive family of warblers (Sylviada Sw.), besides those of Central Europe, 
are several others, altogether peculiar to Italy, Spain, Sicily, and Sardinia. Here, also, the common starling is scarcely known; but its place is filled by another species, the Sturnus unicolor T., hitherto found more particularly in Sardinia. There are two species of bustard (Otis Tetrao and Houbara), which belong more especially to Southern Europe, where the Otis tarda is unknown. The rocky and uncultivated wastes of Spain, Turkey, and Asia Minor, are inhabited by two species of rock grouse (Pterocles), of a genus different from those belonging to northern latitudes. The beautiful wall creeper (Tichodroma phœnicoptera Tem.), with its bright rosy wings, is confined to the southern extremity of the Alps, and the rocks of Spain and Italy; while large flocks of the bee-eater (Merops apiaster L.) skim over the gardens and olive plantations of Southern Italy and Sicily, in every direction, during the spring and autumnal migrations. The golden oriole, the roller, and the hoopoe, at such seasons, are no less common; and we have frequently seen them exposed for sale, with many other birds - rare in Central Europe - in the poulterers' shops of Messina and Palermo. The union of the European, African, and Asiatic ornithology on the shores of the Mediterranean, is further proved by the wading and aquatic tribes. The pelican, the spoonbill, and the flamingo, are still to be met with in these countries, although now less plentiful, from the great attraction which their large size possesses for the sportsman. Our researches in these countries have enabled us to contribute a noble addition to the birds of Europe, in the Ardea pavonia L., or coronated crane, several of which were captured in the small island of Lampidosa in 1812, and brought to Malta alive.

(51.) On the insects and other annulose anima!s, our limits will not permit us to dilate, although, perhaps, these classes supply more interest to the philosophic naturalist than any other. A bare enumeration of the genera alone would almost fill a volume. Suffice it to say, that the entomology of Southern Europe is emi- 
nently distinct from that of the central and northern latitudes. As we approach the provinces of Spain, Southern Italy, and the Peloponnesus, we find many genera which have their chief metropolis in Asia and Northern Africa; 'while the rapacious family of Carabida does not exhibit one fifth of the number of species which inhabit Britain alone. The same may be said of the Staphylinida and the Silphida. On the other hand, all those coleopterous, hymenopterous, and other insects which delight in a sandy soil similar to that of Africa, begin to show themselves; as the genera Scarabaus M'L., Trox, Scarites F., Pimela F., Sphex, Bembex, Anthrax, Osmia, Nomada, Chrysis, \&c. Ants, as in tropical countries, become the universal scavengers, and are of numerous species; while of the Termites, or white ants, hitherto considered as almost restricted to tropical latitudes, one species is found in the south of France, and we have discovered another in Sicily. The Lepidoptera are less peculiar. One half of the British diurnal species are found in Sicily, intermixed with others of Central Europe, and with two or three of those found in Northern Africa. Among these, the most striking and beautiful is the Jasia Europaa Sw., the Papilio Jasius of the old authors. This noble butterfly, however, seems to be rare even in the south of Italy; where, during many years, we captured only two specimens. The Eurymus edusa of Britain is likewise common; as also the Pieris Daplicide, A. Lathonia, and one or two others of our rarest butterflies. The Gonepteryx Cleopa-

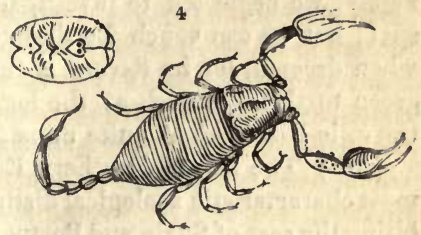
tria takes the place of our G. Rhamni; but all our clear-winged Sesice seem to be almost unknown in Italy. Scorpions, which are happily strangers with us, are frequently met with in the houses of Sicily; and we were

D 3 
once fortunate in discovering one of these disgusting insects crawling under the pillow of the bed: having lost the specimen, we can only give a copy of the original drawing, exhibiting the natural size (fig. 4.). The silkworm of the south of Europe is too well known to require further notice.

(52.) The European reptiles are fortunately few. Lizards, so rarely seen in the temperate latitudes of Europe, abound in the south of Italy, and still more so in Sicily and Malta, where the gecko, or house lizards, are frequently seen, upon a gloomy day, running along the ceiling of old dwelling-rooms. The viper is the only venomous serpent here found, and there are some few others scattered in the different temperate latitudes. The

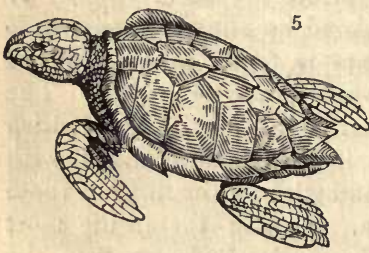
freshwater tortoises, on the other hand, are only to be found in the south of Italy, where they are scarce; and in Greece, where we observed them very common. The species of turtle found in the Mediterranean is that which is usually described by authors as the logger-head of the West Indies ; and, in support of this opinion, they quote the figure given by Gottwold (fig.5.). Unfortunately, we neglected to investigate this question on the spot; but we can vouch for the excellency of this species when dressed, for its flavour is fully equal to that of the green turtle: the flesh of the logger-head, on the contrary, is described as quite unpalatable.

(53.) The fish of Southern Europe form one of its most characteristic zoological distinctions. Of those inhabiting the seas of Spain and Portugal, very little is known; but upon entering the Mediterranean, a large accession of peculiar and very beautiful species appear. The enormous shoals of anchovies (fig.6.), in an economic point of view, are very important - annually employing in their capture and preparation a great number of men. The 
same may be said, but in a less degree, of the tunny 6

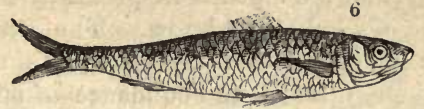

fisheries of Sicily. The herring and the pilchard, on the other hand, are scarcely known. The coast of Nice has been ably investigated, and its productions described by Risso. Of more than 150 species of fish minutely examined by us on the coasts of Sicily, we believe that not more than one third belong also to the ichthyology of Britain and Northern Europe. The only one of these new species we have yet described is the Ammodytes Siculus Sw.*, or Sicilian sandlance ; a local species, but found in such vast shoals, as to supply, at particular seasons, all the inhabitants of Messina with a plentiful meal. This fish is highly prized for its delicious flavour.

(54.) The radiated Mollusca (Radiata) of these coasts are very numerous. The many harbours, caves, and submerged rocks, sheltered from those violent commotions which agitate the Atlantic Ocean, afford them protection, and contribute to their rapid increase. Their investigation, hitherto much neglected, offers a most interesting field for those naturalists who can study them in their native seas. Along the rocky shores of Sicily, but especially those of Malta, many species of sea anemone, and other animal flowers, stud the bottoms of the deep caves ; while the purple Echini . occur in great profusion in similar situations. The stillness and the transparency of the water are such, that all these may be seen with perfect clearness at a depth of eight or ten feet. The tubular and cellular polypes, whose habitations are commonly called corals and corallines, are more abundant in the Bay of Naples ; which, with the coasts of Sicily, has long been celebrated for the abundance of the true red coral.

* Zoological Ill. i. pl. 63.

D 4 
(55.) The testaceous Mollusca, or shellfish, are in. great variety, and are much more prized by the catholics, as an article of food, than by us. The British oyster, muscle, whelk, and cockle are almost unknown; but, in lieu of these, there is an abundance of other species,

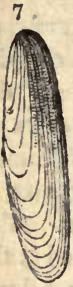
which we do not possess, peculiar to these seas. The Lithodomus dactylus Cuv. (fig. 7.), or date muscle, is found in abundance in the rocks of Malta, which it perforates as smoothly as if the holes were made by an auger. The Pinna nobilis L., or great pinna, grows to the extraordinary length of two feet, and is much sought after by the people of Tarento on account of its byssus, or tuft of silky hairs by which the animal adheres to the rocks : this, after undergoing a prepar-

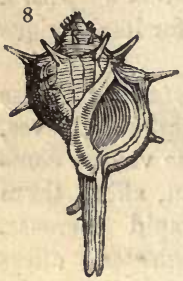
atory process, is made into gloves and stockings; but the manufacture, as may be supposed, is not very extensive. The texture of some of these articles, which we have seen, was beautiful and glossy, and the colour, natural to the substance, is either dark cinnamon, or golden yellow, inclining to brown. C. Ulysses, the only writer, we believe, with the exception of Poli, who has given any connected view of the conchology of the Italian seas, enumerates 180 species, chiefly found in the kingdom of Naples;

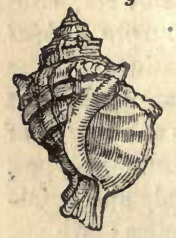
while we could add about thirty or forty more peculiar to Sicily. Ta. rento is so singularly rich in shells, that its fisheries are under the immediate regulations of the governor. If the conchologist who may be in Naples visit the fish-market, he will observe noble specimens of the following large and handsome shells exposed for sale-only to be eaten! Arca pilosa, Cardium spinosum and aculeatum, Solen strigellatus, Pecten maximus, Murex brandanus (fig.8.), 
M. trunculus (fig.9.), Byssoarca Noce Sw., Isocardia Cor; and many other smaller species, which would deserve a place in cabinets. It is also remarkable that, in these seas, the first indications of the conchology of the Asiatic region are found in such shells as Cardium cardissa, Cyprae mus, Chama gryphoides, Oliva (one species), Conus Virgo, C. monachus, and probably several other shells; the above being inserted in the list of Ulysses.*

(56.) The fluviatile shells of Europe are chiefly confined to its central latitudes. Those little sheltered streams, pools, and brooks, which are so abundant in this island, and which appear so congenial to these animals, are very rarely seen in the warm countries of the Mediterranean, where the fervour of a summer sun would soon render them dry. In the deeper rivers however, of France and of Italy, some species of Unio,
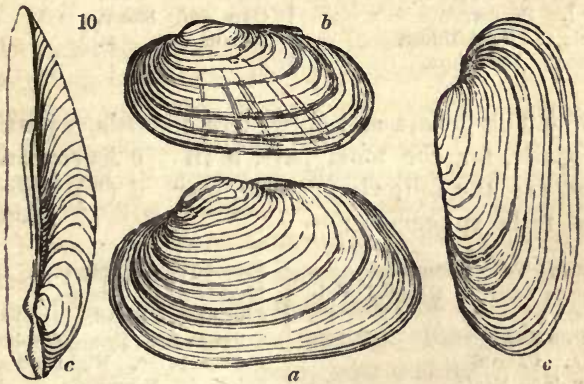

or freshwater muscle, are found, which we do not possess. These are the Unio littoralis ${ }^{\circ}($ fig. 10. a), the $U$. batava $(b)$, and the Unio intermedius $(c, c)$; the latter being a new species sent to us from Gibraltar. The land shells, on the other hand, are more numerous in Italy than in England; and in certain situations, where the surface is rocky, several species are found in the

* Travels in the Kingdom of Naples, 8vo. London, 1795. 
greatest profusion. The cephalopodous Mollusca, or cuttle fish, of the Sepia and Loligo genera, although not of many species, are sometimes found in great numbers, and frequently grow to an enormous size.

(5\%.) The genera and subgenera of the quadrupeds now inhabiting the European range are as follows :-

Rinolphus $C$. Bat.

Plecotus $C$. Bat.

Vespertilio $L$. Bat.

Erinaceus L. Hedgehog.

Sorex L. Shrew.

Mygale $C$. Desman.

Talpa $L$. Mole.

Ursus $L$. Bear.

Meles $\boldsymbol{L}$. Badger.

Martes L. Marten.

Lutra $L$. Otter.

Vulpes I. Fox.

Felis $L$. Cat.

Lynx Ant. Lynx.

Phoca $L$. Seal.

Trichecus $L$. Walrus.

Castor $L$. Beaver.

Arvicola C. Field Mouse.

Myoxus C. Dormouse.
Mus L. Mouse.

Cricetus C. Hamster.

Gerbillus $C$. Terbil.

Arctomys C. Marmot.

Aspalax. Spalax.

Spermophilus. Pouch Marmot.

Sciurus $L$. Squirrel.

Pteromys $C$. Flying Squirrel.

Hystrix $L$. Porcupine.

Lepus $L$. Hare.

Lagomys Geoff. Pika Hare.

Elaphus Ant. Stag.

Capriolus Sm. Roebuck.

Antelope Sm. Antelope.

Rupicapra Sm. Ibex.

Capra Sm. Goat.

Oves Aut. Sheep.

Taurus Aut. $\quad$.

(58.) The genera and subgenera of birds, whose chief metropolis, for the most part, is in e European provinces, are the following: those mar $d(*)$ are ascertained to be subgenera :-

Vultur L. True Vultures.

Grypaetos Storr.. Bearded Vultures.

Neophron Sav.

Falco $L$. Falcon.

Aquila Ant. Eagle.

Accipiter Ray. Hawk.

Buteo Ray. Buzzard.

Milvus Ray. Kite.

Strix $L$. Owl.

* Bubo B. Horned Owl.

Lanius $L$. Shrike.

Corvus L. Crow.

Garrulus Ray. Jay."

* Nucefraga $B$. Nutcracker.

Pyrrocorax $C$. Rock Crow.

Bombycilla B. Chatterer.

Sturnus L. Starling.
Pastor Tem. Sheep.bird.

Merula Ray. Thrush.

Cinclus $L$. Ouzel.

Curruca Sw. Reed Warbler.

Philomela $S w$. Nightingale.

Sylvia $L$. Warbler.

* Erythaica Sw. Robin.

Phænicura Sw. Redstart.

Saxicola $B$. Stonechat.

Motacilla $L$. Wagtail.

*Budytes $B$. Whitetail.

Anthus B. Titlark.

Accentor B. Finch Warbler.

Parus $L$. - Titmouse.

Cuculus L. Cuckoo.

Picus $L$. Woodpecker.

Yunx $L$. Wryneck.

Sitta L. Nuthatch. 1 
Certhia $L$. Creeper.

Troglodytes Cuv. Wren.

* Tichodroma Ill. Wall Creeper.

Upupa $L$. Hoopoe.

Merops $L$. Bee-eater.

Alcedo $L$. Kingfisher.

Hirundo L. Swallow.

Cypselus $L$ Swift.

Caprimulgus $L$. Nightjar.

Alauda $L$. Lark.

Emberyza $L$. Bunting.

Loxia $L$. Crossbill.

Pyrrhula $B$. Bullfinch.

Coccothraustes $B$. Grosbeak.

Fringilla $L$. Fiuch,

Columba. Pigeon.

Phasianus $L$. Pheasant.
Tetrao L. Grouse. *

Perdix $L$. Partridge.

Hemipodius $L$. Turnix.

Glareola $L$. Pratincole.

Otis $L$. Bustard.

Hæmatopus $L$. Oyster-catcher.

Charadrius $L$. Plover. .

Ciconia $L$. Stork.

Ardea $L$. Heron.

Tringa $L$. Sandpiper.

Totanus $L$. Sand-runner.

Limosa $L$. Godwit.

Sturna $L$. Tern.

Larus $L$. Gull.

Anas $L$. Duck.

Alca $L$. Puffin.

\section{CHAP. III.}

ASIA.

TIE ASIATIC PROVINCE. - ITS GENERAL CHARACTER AND DIVISIONS. - NORTHERN, CENTRAL, AND SOUTHERN ASIA. - THE PECULIARITIES OF EACH, AS SHOWN IN THEIR PECULIAR ANIMALS. - ASIATIC GENERA OF QUADRUPEDS AND BIRDS.

(59.) THE second great zoological province of the globe comprehends the entire continent of Asia, and the greater part of its numerous islands. Bounded by the ocean on its northern, eastern, and southern confines, its demarcation to the west is no less natural, being separated from the European range by the lofty chain of the Ural mountains. Assimilating in its productions to those countries upon which it thus borders, this vast zoological region is more particularly blended with those of Europe and Africa ; through the medium of Persia on one side, and of Asia Minor on the other. It unites, likewise, with the American range at its northern extremity, where it also forms a junction with Arctic 
Europe ; while to the south it is connected to the Australian division by the islands of Papua or New Guinea, New Caledonia, and New Ireland.

(60.) A region so vast in extent, and so diversified in its temperature and productions, may naturally be supposed to be extremely difficult to be characterised, as a whole, with precision : nor is this, indeed, necessary to our present purpose. It will be a sufficient sanction to the justness of considering it as a peculiar division of zoological geography, if, upon attentively comparing its animals with those of Europe and Africa, we discover differences so strongly marked as to separate it from both. If, however, any particular feature in Asiatic zoology be selected as peculiarly striking, it would undoubtedly be the number and importance of those domestic animals which it has furnished to the civilised world ; and which are not only useful and necessary to the inhabitants of the older continents, but even more so to those of America and Austra. lia,where there does not appear to have been other species equally destined to supply the wants, or abridge the labours, of civilised man. When it is considered that the horse is generally supposed to have originally been a native of the Tartarian deserts; that the domestication of oxen is conjectured first to have taken place in Western Asia, by the Caucasian nations ; that all the breeds of our domestic fowl have unquestionably sprung from southern Asia, which is likewise the native region of the peacock; we must admit the justness of the above remark.

(61.) The Asiatic range may be divided into three sections, or sub-provinces, indicated both by their geographic peculiarities, and the nature of their respective animals. The first commences from the polar regions, and includes the whole of Asiatic Russia: its natural boundaries to the west are the Ural mountains; and to the south, the lofty Altain chain - the cradle, as it has been termed, of the Mongolian race. The second includes the little known empires of China and Japan, with Thibet, the Tartarian provinces bordering Persia, 
and the eastern shores of the Caspian; while to the south, the stupendous Himalayan mountains seem to form a natural boundary to this intermediate region. The third division comprehends the remaining portion of the continent, together with Java, Sumatra, \&c., and such islands as lie to the westward of New Guinea. We thus exclude the whole of Asia Minor, and the regions immediately around Caucasus, because they exhibit a zoology of no determinate character, further than as they present a union of the European, Asiatic, and African; thus concentrating much of the typical characters of the whole. The same observation, in a more limited sense, may be extended to Persia; but there the African forms almost entirely disappear, and leave only the European and the Asiatic - the latter evidently preponderating.

(62.) The first, or northern Asiatic range, exhibits few peculiarities : the genera of quadrupeds, for the most part, assimilate to those of Europe and the North Pole, but few of the species occur on the western side of the Ural mountains. The sandy and desert steppes of Siberia afford but little nourishment to large animals, but are sufficient to support many of the Glires family: hence the chief quadrupeds enumerated by travellers as natives, are nearly all referred to the field mice ( $A r$ vicola), lemmings (Georynchus), rats (Mus), and hamsters (Cricetus). These generic groups, for the most part, are restricted to the cold or temperate latitudes of Europe, Asia, and America. The field mice (Arvicola) and the true mice (Mus) occur also in Africa. These gnawing animals, however, have a very wide distribution, and have obviously been intended by nature to inhabit climates subject to the severities of winter. The instinct by which they are impelled to hoard up large quantities of provisions against the season of scarcity; the length, intricacy, and warmth of their subterraneous abodes; their food, of dried grass, seeds, or nuts, in winter, and of green or fresh vegetables in summer; are all proofs to this effect. We accordingly 
find these industrious and provident little creatures do not inhabit tropical countries, where all these instincts would be superfluous. The birds, so far as is yet known, appear to be of the same genera as those of Europe; and many species are common to both regions. The beautiful rose-coloured starling

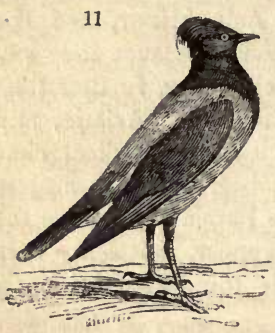

(Pastor roseus Tem.), so rare in Europe (fig. 11.), is one of the most common birds of temperate Asia. Many of the aquatic species are also similar to those of America ; but Pallas enumerates a long list of species unknown to either of these continents. We may suppose, therefore, that the other animals, were they better understood, would agree in these characteristics. The entomology of these northern latitudes is scarcely known.

(63.) The animals of the second Asiatic region are very imperfectly known; it is here, however, that we begin to see those larger and more bulky quadrupeds which are excluded from the frozen regions of Siberia. The famous dzeggtai, or Morgolian horse (Equus Hemionus Pallas), the wild Asiatic sheep (Ovis Ammon.), and probably the Arnee buffalo, may be instanced as characteristic of central Asia. To these we may add the Tartaric or Yak ox (Bos Poëphagus H. Smith), whose southern range extends to the mountains of Bhotan, where alone it has been hitherto seen. If so many quadrupeds, of the first magnitude in their respective families, inhabit these central regions, how many others of a smaller size must still remain unknown to science. The elegant little jumping jerboas (Dipus), also, belong more properly to the central parts of Asia and the warmer latitudes of Siberia: this genus extends to Egypt, but has never been found in the New World, where it is represented only by that of Meriones (IIl.). 
(64.) The birds of Central Asia are still more inperfectly known than the quadrupeds. We are compelled, in fact, to form our judgment of them more from the paintings executed by the Chinese, than from any specimens that have hitherto reached Europe. Many of these native painters, however, are particularly exact in their delineations of the common sorts; and we may, therefore, place a certain degree of confidence in such as have not been actually seen by Europeans. From these drawings it becomes evident that there exists in Central Asia several large and beautiful gallinaceous birds, particularly pheasants, totally distinct from those of Southern Asia. It is here, in short, that we first detect the chief ornithological feature of Asia ; namely, the variety and beauty of its gallinaceous birds. It is probable that the golden (Nycthemerus pictus $\mathrm{Sw}$.) and silver pheasants (Nyc. argentatus Sw.) of our mena-

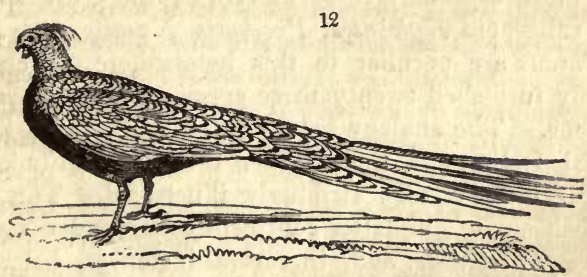

geries, - the latter one of the most chastely elegant birds of Asia (fig.12.), originally came from the interior of China. Many others will doubtless be discovered on the elevated table land of Asia, since even those species more peculiar to India are seldom met with in the maritime or low provinces. The splendid Impeyan pheasant (Lophophorus refulgens T.), and the other species of the same natural group, are stated only to inhabit the hilly and elevated districts of India. Our knowledge of the entomology of this region is chiefly confined to China.

(65.) The third division comprehends Southern Asia, and presents a zoological region of uncommon interest 
and great magnificence. As heat and moisture principally tend to the increase of vegetation, and to its luxurious developement, so is the latter always accompanied by a corresponding exuberance of animal forms : both are in their highest developement in equinoctial latitudes, and both progressively diminish towards the poles. It is, consequently, in the southern provinces of India that all the features of Asiatic zoology are most conspicuous.

(66.) Commencing with the quadrupeds, we find a striking characteristic of this region, in the numerous but disgusting race of apes and baboons ; of whose existence in Europe, even at the most remote period, there is not the slightest record. These satyr-like creatures seem to congregate as we advance to the equinoctial line: the long armed gibbons being principally found

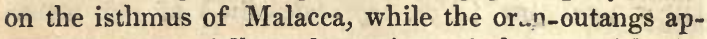
pear more especially to be natives of the great islands. The subgenera Hylobates, Presbytis, Nasalis, and Simnopithecus are peculiar to this hemisphere, which has already furnished twenty-three species of these apes and baboons. The analogy between the animals of Equinoctial India, and those under the same latitudes in Africa, is here very strikingly illustrated. The apes and baboons of the latter continent occur under similar degrees of latitude, and, in several instances, belong to the same genera, but the number is greater. Yet, as a proof how truly distinct are the two zoological provinces, we may remark, as a singular fact, that only one species has yet been discovered as a native inhabitant of both; this is the grey baboon, whose geographic range is also removed from the equator; being found at Moco, the Persian Gulf, and in Arabia ; countries lying on the confines of the two continents. These parallel analogies, or mutual representations, are always highly interesting. Thus we find the Indian oran-outang, typified on the African continent by the Chimpanzee, considered by Linnæus as a wild man, and still affirmed, 
by the negroes of the Gold Coast, to walk erect. The Asiatic elephant is again represented by that of Africa ; so closely, indeed, that it was only of late years ascertained to be quite a different species. These resemblances may be traced in innumerable instances: they are, indeed, so striking, that it is not surprising some authors should have deemed them affinities, from viewing the subject without that extensive reference to the other parts of creation, which is so essential in guiding our judgment in these matters. The zoology of Southern Asia is further distinguished from that of the central regions, by possessing the orangs and apes; while the numerous mouse-like animals, as the marmots, lemmings, \&c., so abundantly spread over Northern Asia, appear to be almost unknown in the southern regions.

(67.) The hears found in other parts of the world, occur only in cold, or at least temperate, climates; but there have recently been discovered, in the interior of India, three distinct and peculiar species, Ursus labiatus, Malayanus, and Thibetanus, all inhabitants of the mountainous districts ; and, therefore, in all probability, belonging more to the fauna of Central than of Southern

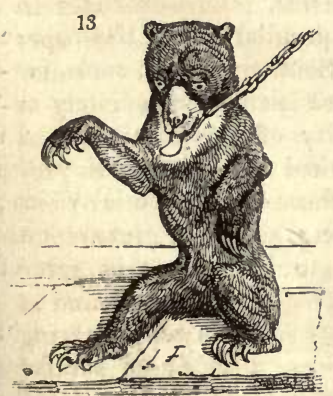
Asia. One of these, the Malay bear (fig. 13.), remarkable for its mildness and docility, has been brought alive to this country. The lion of Asia (Leo Asiaticus Sw.), was thought to be only a variety of that from Northern Africa (Leo Africanus Sw.); but a pair of fine living specimens now in the Surrey Zoological Gardens has enabled us to ascertain that it is a very distinct species from either of those found in Northern or Southern Africa. Another species recently described in the Zool. Trans. is remarkable for the shortness of its mane; a circumstance which might 
have suggested a less barbarous designation than "Felis Leo Goojratensis." The species of Rhinoceras of these continents are known to be distinct; yet the jackal of Sourhern India and of Africa seem to be the same. The more ferocious quadrupeds, generally denominated tigers, are much less abundant on this continent, as regards species, than either in Africa or America. Yet, unfortunately, their numerical amount is unquestionably much greater. The Once (Felis uncia),

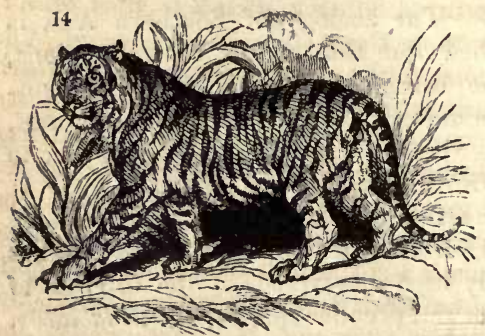
from being found on the high mountains of Persia, is probably more characteristic of Central Asia ; while the true tiger (Felis Tigris, fig. 14.) is most abundant in the low jungles of Hindostan, and the humid forests of Sumatra. The Asiatic tiger-cats appear restricted to the larger islands: none of the species occur in Africa.

(68.) The ornithological peculiarities of the Asiatic range are fully developed in Southern India, more particularly in Malacca, and those islands immediately adjoining the southern extremity of the continent. In some instances, there is a marked similarity between the groups of Tropical Asia and those of Equinoctial Africa; while in others the differences are very great. This comparison will tend much to illustrate this part of our subject.

(69.) Among those families of birds concentrated in Southern Asia, but which appear also, under the form of other species, to be distributed in Africa, are the Drongo shrikes (Edolius Cuv.), the caterpillar-catchers (Ceblepyres Cuv.), the true flycatchers with long tails, typically represented by the paradise flycatcher (Muscicapa paradisea), the beautiful parrot-plumaged barbuts 
(Bucco L.), the singular short.legged thrushes (Brachypus Sw.), the long-legged or aquatic thrushes (Crateropus $\mathrm{Sw}$.), the elegant little finches (Estrelda Sw.), the short-billed weavers, or grosbeaks (Amadina Sw.), the shining black-coloured grakles (Lamprotornis Tem.), and the splendid little sun-birds (Cinnyris Cuv.). All these groups extend to the warm latitudes of Africa, and several are not unknown in the Australian range; yet in Asia they seem confined to the southern region, since no examples have occurred either in Persia or Asia Minor, much less in Siberia or Europe.

(70.) On turning to the ornithological groups which nature has exclusively restricted to Southern Asia, we find this region stamped by very distinct peculiarities. The vivid-coloured ant-thrushes (Pitta), with their representatives the green bulbuls (Chloropsis Jard.), the superb Iöra or black and azure oriole (Iöra Horsf.), the true grakles (Gracula L.) the fork-tailed wagtails (Enicurus Tem.), the bullfinch larks (Mirafra Horsf.), the broad-tailed thrushes (Timalia H.), and lastly, the singular nightfeeders (Nyctiornis $\mathbf{S w}$.), are all promi. nent examples of Indian ornithology, of which no species are to be found in other parts of the world. The rhinoceros hornbill (fig. 15.), one of the largest and scarcest

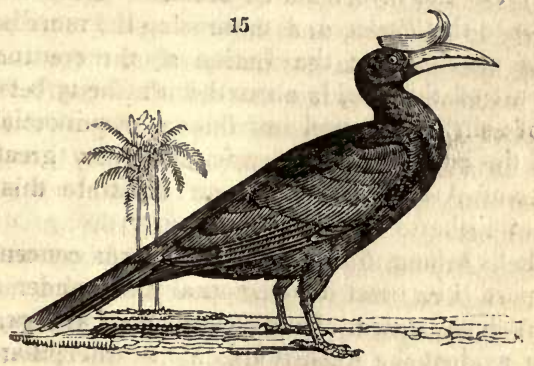

of its family, is among the most remarkable birds of India. But perhaps the most striking birds, to the general observer E 2 
are those belonging to the parrot and gallinaceous tribes. In the former, Equinoctial Africa is very poor; but the same latitudes, in Asia, furnish us with numerous and splendid examples, both of genera and species, altogether peculiar. The suctorial cockatoos (Microglossum Geoff.), the large white cockatoos of Malacca, the elegant ringnecked parrakeets of the continent, and the crimsoncoloured lories of the islands, are appropriated solely. to these regions. Lastly must be enumerated the splendid peacocks of the continent, and the wild cocks of the islands, forming the genera Pavo, Polyplectron, Argus, Lophyrus, Lophophorus, and Gallus, not one of which has yet occurred beyond the limits of the Asiatic range.

(71.) On the remaining vertebrated animals, comprehending the fishes, reptiles, and serpents, peculiar to these regions, little can be said; since their geographic distribution has received little or no attention. The numerous species, however, that have been made known by the researches of Dr. Roxburgh, Dr. Buchanan Hamilton, and General Hardwicke, prove that in these classes nature is equally prolific, and that she has given to India a vast number of genera which do not occur in other countries.

(72.) Of the invertebrated animals we must confine ourselves to the Testacea, as embracing the more popular study of conchology; the Indian seas, more than any other part of the world, abound with the greatest variety of shell-fish, and exhibit a remarkable contrast to the paucity of species found under the parallel latitudes of Africa and America. It is also a singular fact, not hitherto noticed, that nearly three fourths of these shells belong to animals entirely carnivorous; who, to support life, must be perpetually carrying on, like the ferocious tigers of the continent, a destructive warfare against the weaker animals of their own class. The conchologist, who looks beyond the empty shell in his museum, need hardly be reminded that the immense number of species belonging to the genera Conus, Oliva, 
Voluta, Mitra, Cyprcea, Turbinella, Dolium, Cassis, Strombus, and Harpa, are all inhabited by carnivorous Testacea, and that most of these genera have their principal metropolis in the great Indian Ocean. Of the beautiful group of Cones, for instance, nearly 200 species have been named, yet scarcely more than ten are found beyond the Indian Ocean : Lamarck enumerates sixty-two olives, yet five only belong to other seas. The cowries (Cypraa), and the Strombi, or wing-shells, are distributed much in the same proportion. The volutes, however, are nearly divided between Africa, India, and the Australian or Pacific Ocean. The distribution of the Acephala, or bivalve shells, is much less

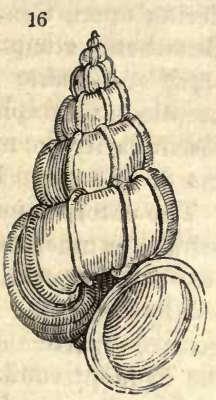
marked; but none that we remember are common both to India and Africa; while the union of Asiatic conchology with that of Australia, as may be expected from the situation of the two countries, takes place towards New Guinea and the adjacent islands. The famous wentletrap (fig. 16.) (Scalaria pretiosa Lam.), the spindle shells (Rostellaria Lam.), the hammer oysters (Malleus Lam.), the Ethiopian and other crowned volutes (Voluta Ethiopica), are good illustrations of Oriental conchology.

(73.) The paucity of fluviatile shells is truly surprising, and constitutes a singular character in the conchology of Asia. The rivers, inferior only to those of the New World, appear almost destitute of shellfish; for they have hitherto not given more than six or seven species to our cabinets, while from North America alone we are acquainted with more than 150 : the genera are mostly the same, but the subgenus Dipsus (Leach) has hitherto only been brought from China. Terrestrial shells appear to be still more rare; but the genus

$$
\text { E } 3
$$


Scarabus of De Montfort is restricted to certain of the Asiatic islands; while among the slugs, or shelless Testacea, the genus Onchidium, as defined by Dr.Buchanan, appears to characterise this part of the world.

(74.) To enumerate the tribes of insects, and of the other annulose animals, is altogether impossible. It will be sufficient to mention, that the entomology of Southern Asia presents us with some few of the most common butterflies dispersed over Europe. The Papilio Podalirius L., Eurymus Edusa Sw., Cynthia Cardui, and Vanessa Atalanta, have been sent from the mountains of Nepal, a region, however,- from the peculiarity of its productions, - which might more properly be considered within the limits of, or at least bordering upon, Central

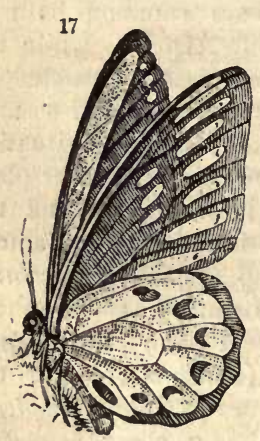
Asia. But these, after all, are but rare and nearly solitary exceptions to the very general dissimilarity between the insects of the two continents. The entomology of Africa assimilates much more closely to that of India; and the latter contains several genera, particularly among the lepidopterous insects, which are precisely the same as those of tropical America. The Indian islands, but more especially Amboyna, appear to be richer in insects, if we may judge from such as have

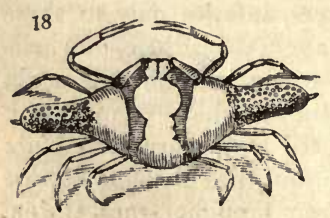
been sent to Europe, than the continent. That rare and lovely butterfly, the Amphrisius Priamus Sw. (fig. 17.), with its velvetlike wings of intense black and rich green, has only

been received from Amboyna.

(75.) Most of the marine Crustacea, or crabs, are 
peculiar to these seas, and many appear under the most grotesque forms: among these, the Ixa canaliculata (fig. 18.) of Dr. Leach* deserves being mentioned. Another species, Ixa inermis, when its limbs are drawn under its shell, might easily be mistaken for a piece of coral. The most valuable pearls in the world are produced from a species of pearl oyster (Margarita Sinensis Leach), which seems confined to the Indian Ocean; those of the American seas being of a totally different species.

(76.) The genera of quadrupeds, and their minor divisions, which more particularly characterise the Asiatic province, are the following: the numbers denote the species already described:-

Simia $L$. Orang Otangs, - - 2
Hylobates $I I$. Gibbons, - 5

Presbytes Es. Tailed Gibbon, - 1

Lasiopyga IIL. Cochin Monkey, 1

Nasalis Geoff: Nose Monkey, - 1

Semnopithecus $\mathrm{Cuv}$, - $-\quad$ - 5

Cercopithecus Ill. Guenon, - 2

Stenops IU. Loris, - - - 1

Nycticebus C. Lemur, - 3

Tarsius Ill. Tarsier, - - 2

Megaderma Geoff: Bats, - 1

Pinclphus Geaff. Bats, _. 8

Nycteris Geoff: Bats, - . 1

Plecotus Geoff: Bats, - - - 1

Vespertilio L. Bats, - . - $\quad$ - 6

Nyctinomus G. Bats, - - 3

Cheiromeles Horsf. Bats, - - 1

Pteropus B. Bats, - - 9

Cephalotes $C$. Bats, - - $\quad 2$

Sorex $L$. Shrew, - - $\quad 1$

Tupaia Buff: Tupay, - - - S

Ursus $L$. Bear, - - - 3

Genetta. Genett, - - - 4

Mangusta C. Ichneumon, - - 3

Paradoxurus C., - - - 3

Prionodon,

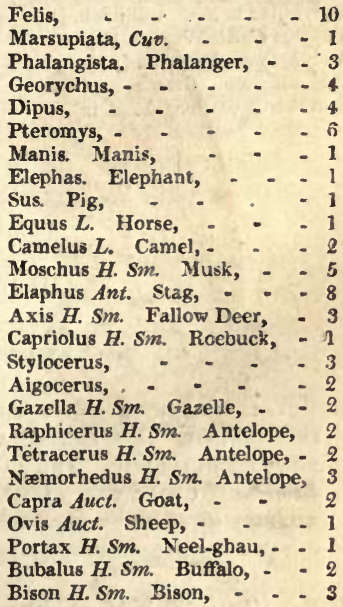

(77.) The birds peculiar to the Asiatic range belong to the following geographic groups, not one of which occurs in Europe, although several of the European forms extend to Asia. The present confusion in ornithological nomenclature renders an estimate of the

- Zool. Misc. iii. pl. 129.

E 4 
species impossible. Some of these genera occur in Africa (A.), and others in New Holland (H.).

Nyctiornis Sw. Night-feeder.

Macropteryx $S w$. Whiskered Swifts.

Eurylaimus Horsf. Broadbill.

Analcipus Sw. Weakfoot.

Ocypterus Cuv. Whitebill, (н.)

Platylophus Sw. Jayshrike.

Irena Horsf. Fairy Bird.

Phoenicornis $S w$. Redbird.

Timalia Horsf. Looseweb.

Iöra Horsf. Puffback.

Brachypterix Horsf. Shortwing.

Prinea Horsf. Wren Warbler. (A.)

Enicurus Horsf. Fork-tail Warbler.

Gryllivora Sw. Locust-eater. (A.)

Calyptomina Raff. Green-crest.

Mirafra Horsf. Lark.

Pyrrhulauda Sw. Bullfinch. (A.)

Pioceus Cuv。 Weaver. (A.)

Vidua Cuv. Widows. (A.)

A madina Sw. Grosbeaks. (A. H.)

Estrelda Sw. Bengals, (А. H.)
Lamprotornis Tem. Grakle. (A.)

Gracula $L$. True Grakle.

Crypserina Vieil. Satin Crow.

Paradisea $\boldsymbol{L}$. Paradise Birds.

Epimachus Cuv. Hoopoe.

Plyctolophus Vieil. Cockatoo. (н.)

Microglossum Geoff. Cockatoo.

Palæornis Vig. Ring Parrakeets.

Lorius Bris. Lories.

Picumnus Tem. Little Barbut. Phœnicophaus Vieil. Redhead.

Cinnyris Cuv. Sun-bird. (A.)

Crateropus Sw. Thickleg. (А. H.)

Pomatorhinus Horsf. Thrush.

Vinago $\boldsymbol{V}$. Green Pigeons. (A.)

Ptilonopus Sw. Green Pigeons. (н.)

Lophyrus $V$. Firecock.

Pavo L. Peacock.

Polyplectron Tem. Argus Pheasant.

Lophophorus Tem. Pheasant.

Argus Tem. Pheasant.

\section{CHAP. IV.}

\section{ON THE AMERICAN PROVINCE.}

GENERAL REMARKS. - ITS ZOOLOGICAL FEATURES - DIVIDED INTO ARCTIC, TEMPERATE, AND EQUINOCTIAL AMERICA. THE PECULIARITIES AND ANIMALS OF EACH. - GENERAL REMARKS UPON THE CLIMATE AND SOIL OF BRAZIL, WITH REFERENCE TO THE DISTRIBUTION OF ITS ANIMALS. -AMERICAN GENERA OF QUADRUPEDS AND RIRDS.

(78.) THE third great zoological province comprehends the whole of the New World. It has been stated in the last chapter, that the animals of Asia insensibly unite with those of Australasia in the islands of the Indian Ocean, which may, in fact, be considered as so many links in the chain of connection. This transition 
is so complete, that it might, perhaps, appear more natural to have followed up the developement of this change by immediately entering upon the zoology of Australasia ; but this transition, striking as it is, is not more conspicuous than that which may be traced from the zoology of Asia to that of America. It must be remembered, also, that each of these zoological provinces are connected with the rest at more than one point. The Asiatic blends into the European, both at its northern and at it western confines; and it is again united to the African range through the medium of Asia Minor and Arabia : nor will it be found less harmonised with the zoology of the New World, when we look to the productions of Kamtschatka, in Arctic Asia, and the opposite shores of California; while the islands of Papua or New Guinea, New Ireland, and New Caledonia, as before remarked, incontestably prove the union of the Asiatic with the Australian range. United, therefore, at so many points, it becomes perfectly immaterial from which we depart, and commence a further investigation, provided we preserve that uniformity of plan so desirable in expositions of this nature.

(79.) The Arctic regions, as we have already urged, can only be considered as equally belonging to the three great zoological provinces of Europe, Asia, and America. Their productions, at these extreme limits, although not, in numerous cases, perfectly similar, belong nevertheless to the same natural groups. Several of the northern quadrupeds of Asia range over the Arctic snows of Europe, and again occur, in similar latitudes, upon the American continent. Many, however, remain within what may be termed their original boundaries. The aquatic birds are more generally dispersed; and there are very few in one continent, that have not been detected in another. In proportion, therefore, as we leave these frozen latitudes, common to animals whose nature fits them for extreme cold, and advance to the more genial latitudes of these continents, shall we discover a corresponding developement of their true zoological features. 
(80.) The zoological productions of the New World, when viewed in their typical examples, are as distinct from those of the Old, as the animals of Australia are from those of Africa or of Asia. There is also a curious analogical resemblance between these two insular continents, deserving notice. The northern latitudes of America present us with European and Asiatic animals; and we can trace in the zoology of Australia, at its northern limits, a manifest approximation to the productions of Southern Africa. But to what zoological province those of America and of Australia are united at their southern extremities, is a question on which we would not even hazard conjectures; since the productions of Western and Southern Australia, of Tierra del Fuego, and of the Pacific Islands, may almost be considered unknown.

(81.) We shall consider the zoology of the New World under three heads, as more calculated to convey distinct ideas of the productions of such an immense and diversified region. The first may be denominated the Arctic or northern ; the second, the temperate or intermediate; and the third, the Southern or tropical: a fourth might be made to embrace the regions towards Cape Horn; but of the productions of these unfrequented parts we are at present almost ignorant.

(82.) The Arctic or northern division includes those icy regions commencing at the shores of the Frozen Ocean, and extending between the 50th and 60th degrees of north latitude. This demarcation, however, is more conjectural than positive, for we are yet without that precise information which will point out the southern limits of the more northern quadrupeds. For it is natural to conclude, that, whatever zoological peculiarities belonged to Arctic America, they would be developed within that range, and beyond the northern countries annually visited by the migratory or summer birds of the United States. Many of these are well known to breed in $\mathrm{Ca}$ nada ; and by the more recent researches of Dr. Richardson, in higher latitudes, we find that several of these land 
birds extend their migrations beyond the 60 th degree of north latitude. It is therefore highly probable, that the zoological peculiarities of Arctic America are confined to much narrower limits than those here specified; and are, probably, concentrated in the direction of the "barren grounds" and the extensive "prairies" of the Arctic navigators. It is, in fact, these grassy plains, which seem to be the chief metropolis of the many peculiar kinds of grouse, and of large quadrupeds which belong to this portion of the New World, mixed, indeed, with some few species equally common to Northern Europe. On the other hand, it may be said, that, as the river St. Lawrence and the vast lakes which it connects, suggest a natural division of Northern America into two portions, so it may be presumed that its zoology might more correctly be treated of in the same way. Our materials, however, for arriving at a correct judgment on these questions, are very defective; and after all, it must be remembered, that where nature has made no absolute line of distinction, it is impossible to be drawn by man.

(83.) The fur-bearing animals, as we might expect in regions of almost perpetual snow, are principally confined to this part of America; and the traffic for their skins is so important to commerce, that mercantile associations have been formed by the Europeans for this express object. The Hudson's Bay Company of England is the best known; and the number of skins they annually import from their different stations, would, to many, appear almost incredible. Among such species as are known to inhabit the same latitudes in Europe and Asia, are the common weasel (Mustela vulgaris), the ermine ( $M$. erminea), the pine marten (Mustela martes), the wolverine (Gulo luscus), and the Arctic fox (Vulpes lagopus); and we may add, the wellknown Polar or white bear, although its fur does not appear much in demand. But the list of truly American species is much more considerable; bearing no pro- 
portion to those which are equally natives of Europe, as will be seen from the following list. Three distinct bears, the black, the barren ground, and the grisly*; the raccoon (Procyon lotor), the American badger (Meles Labradoria), the vison or $\operatorname{minx}$ (Putorius vison), the Pekan (P. Canadensis), the Canada otter (Lutra Canadensis), numerous varieties of species of wolves and foxes, the Americah beaver (Castor Americanus), the musquash (Fiber Zibethicus), with no less than thirty species of lemmings, marmots, and squirrels. The existence of so many quadrupeds, whose geographic limits are confined to the more northern latitudes of the New World, occurring also in that part of the continent where its zoological features are blended with those of Europe, at once forbids us to consider the Arctic regions as constituting, of itself, a zoological province; while it stamps a character on that of America in which no other part of the world participates.

(84.) On turning to the ruminating or herbivorous quadrupeds, we find the facts afforded by their distribution equally tending to the same results. The Polar hare (Lepus glacialis) occurs on both continents; but three others, the American (Lep. Americanus), the prairie (Lep. Virginianus), and the little chief hare (Lagomys princeps Rich.), are exclusive natives of Northern America. The large animals, belonging to the genera Cervus, $\mathrm{An}$ telope, and $B o s$, present us with nearly a dozen similar instances. The elk, called in America the moose (Cervus alces), and the reindeer, here known by the name of caribou (Cervus tarandus), are the only species found in other continents; both, in fact, are Arctic animals ; while the wapiti ( $C$. strongyloceros), two races of the black-tailed deer (C. macrotis R.), the long-tailed deer (C. leucurus), and the prong-horned antelope ( $A$. furcifer), are known only in America. We may include. also, among these northern quadrupeds, the wild goat (Capra-Americana R.), and the sheep (Ovis montana 
R.), of the Rocky Mountains, since their existence in the

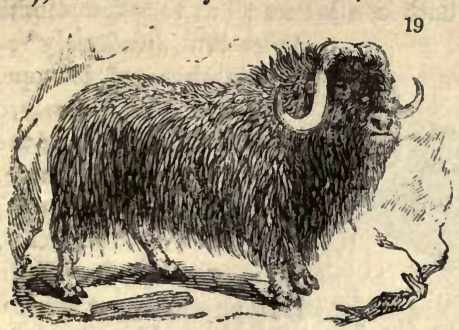
southern part of the chain has not been clearly ascertained. The musk-ox (fig.19.) is truly an Arctic quadruped, yet is unknown both in Asia and Europe ; and the chief

range of the American bison is in latitudes but little more south.

(85.) The geographic distribution of the northern birds is much more general, particularly in reference to the rapacious families, and the wading and swimming orders. Uniting our labours with those of Dr. Richardson, in the ornithological volume of the Northern Zoo$\log y$, we have enumerated the following Euro ean birds of prey, detected by that adventurous traveller in Arctic and British America:-

Aquila chrysaětos? The Golden Eagle.

Aquila leucocephala. White-headed or Sea Eagle.

Aquila Haliæetus. The Osprey.

Falco peregrinus. Peregrine Falcon.

Falco Islandicus. Jer Falcon.

Falco Esalon. The Merlin.

Accipiter palumbarius. The Gosbawk.
Buteo vulgaris. Common Buzzard. Buteo Lagopus. Rough-legged Buzzard.

Buteo cyaneus? Hen Harrier.

Strix Otis. Long-eared Owl.

Strix brachyotos. Short-eared Owl. Strix nyctia. Great snowy Owl.

Strix Tengmalmi. Tengmalm's Owl.

We have thus fourteen species inhabiting the northern regions of the two continents, while the following belong exclusively to America :-

Sarcoramphus Californianus. Californian Vulture.

Cathartes Aura. Turkey Vulture.

Cathartes atratus. Black Vulture.

Falco sparverius. Little rustycrowned Falcon.

Falco columbarius. Pigeon Hawk. Accipiter Pennsylvanicus. Slatecoloured Hawk.
Buteo borealis. Red-tailed Buzzard Strix cinerea. Great cinereous Owl.

Strix arctica. Arctic horned Owl.

Strix Virginiana. American horned Owl.

Strix Acadica Wilson. Little Amcrican Owl.

Strix funerca. Hawk Owl. 
(86.) The ducks, and other swimming families, are nearly the same in both continents; but very few of the

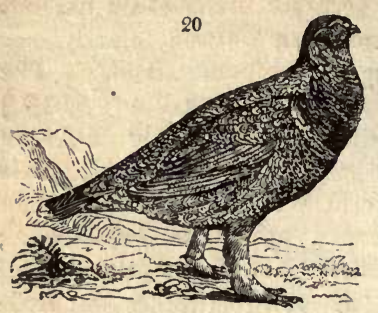
American waders resemble those of Europe. The grouse of the two continents, inhabiting the same parallels of latitude, are still more distinct; only one, or at most two, having been found in Europe and America. The commonest of these is the Tetrao Canadensis L., or Canadian grouse (fig.20.); about the size of the red game, but with the throat and breast glossy black.

(87.) Respecting the other animals of this part of America nothing can yet be stated, since the researches of Dr. Richardson, whose valuable remarks have furnished the materials of the foregoing results, are not yet before the public; and little reliance can be placed on the erroneous compilations and crude theories regarding American zoology, which heretofore have been our only guides. Few naturalists have done as much, and, perhaps, none have done more, towards elucidating the zoological distribution of animals of this country, than the diligent observer above named : his simple and unpretending narrative has cleared from our systems a mass of "learned error" and unintelligible nomenclature, which will sink our former authorities upon Arctic zoology into oblivion. The entomological collections of the northern expeditions, fortunately for science, have been placed by Dr. Richardson in the hands of Mr. Kirby, who has now been engaged some years in preparing this volume for the press

(88.) The second or temperate region of the American province comprehends the whole of the United States, with a considerable portion, probably, of the north-west coast; while its termination (much better understood than its northern limits) is marked by the Gulf of 
Mexico. Our information on the quadrupeds of this range is particularly defective: a circumstance more to be regretted, from the accurate information we have been able to give on the northern animals.

(89.) The ornithology of temperate America possesses many peculiarities. After passing the confines of the more northern regions, we meet with numerous land-birds belonging to species, and even to genera, peculiar to the New World. Our observations upon these tribes will be arranged under the heads of the Rapacious, Perching, Gallinaceous, and Aquatic orders. The Rapacious birds of all countries enjoy the widest range of those inhabiting the land. Hence we find that few species occur in the warmer provinces of America which do not inhabit, either permanently or occasionally, the Arctic latitudes visited by Dr. Richardson. This will be apparent by the following list, selected from the last, which comprises such species of the vulture and falcon family (Vulturida, Falconida) as are spread over the greater part of North America.

$$
\begin{aligned}
& \text { Cathartes Aura. . . Turkey Vulture. } \\
& \text { atratus . . Black Vulture. } \\
& \text { Falco sparverius . . Little Rusty-crowned Falcon. } \\
& \text { columbarius. - Pigeon Hawk. } \\
& \text { Accipiter Pennsylvanicus Slate-coloured Hawk. } \\
& \text { Buteo borealis . . . . Red-tailed Buzzard. } \\
& \text { Strix Virginiana . . American Horned Owl. } \\
& \text { Strix Acadica Wilson . . Little American Owl. }
\end{aligned}
$$

These, with about five additional species of falcons (Falconida), complete the list of North American rapacious birds.

(90.) The distribution of the perchers, as usual, is much more limited. Numerous families of insectivorous birds, unknown in the temperate latitudes of the Old World, or even in the equinoctial regions of the New, spread themselves over the fruitful portions of the Union, either as permanent residents, or as annual migrators from the more genial shores of the Mexican 
Gulf, where the greater number pass the winter. Towards the commencement of May, when the insect world has just assumed life or activity, innumerable flocks of warblers (Sylvicola Sw.), flycatchers (Tyrannula Sw.), woodpeckers (Picus L.), maizebirds (Agelaius V.), thrushes (Merula, Orpheus Sw.), hangnests (Icterus 1).), and other families, make their first appearance in the United States, enlivening the forests by their varied plumage, and delighting man by their melodious song. The arrival of these strangers occasions a prodigious increase in the number of the feathered. inhabitants; yet Providence has ordained that a proportionate supply of food should be provided for all.

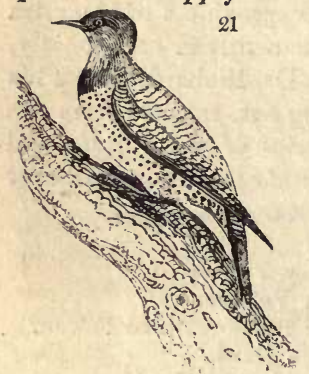

These birds generally feed upon insects: while for the pigeons, blue-birds, the redheaded, Carolina, and goldenshafted woodpeckers (fig. 21.), and such others as partake also of fruits and grain, the seasons, in due course, provide an ample repast of wild berries, the fruits of the orchard, or the corn of the field. When the process of incubation is finished, and the young fully fledged, autumn is at hand; the insect world dies, or retires into concealment; the fruits of the earth fall to decay, or are gathered by the husbandman. Then it is that the parents and their offspring are taught to seek their own food in other climates: they accordingly depart; and, either congregating into flocks or journeying singly, return once more to the genial and ever verdant forests of the Western Indies. Many of these have been traced to the islands, and many to the adjacent coast of Mexico; but scarcely more than two or three species have yet been detected on the terra firma of equinoctial America.

(91.) The gallinaceæ, or birds of game, are remarkably few. Two species of grouse occur on the 
"barren grounds" of Kentucky, and in a few other districts : one of these is the Tetrao umbellus, or ruffled

22

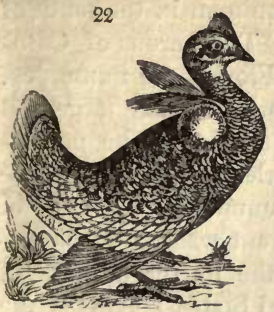
grouse; called, in America, the pheasant. It has an extensive northerly range, and was met with by, Dr. Richardson. The other is the Tetrao Cupido, or pinnated grouse (fig. 22.); so called from two tufts of pointed feathers on the side of the neck, resembling the wings of a little Cupid, and which cover a naked skin, inflated like a ball during the season of courtship. There is a small-sized partridge, called by the natives, with equal impropriety, a quail. To compensate, however, for this deficiency of feathered game, the Americans can boast of the native wild turkey, a bird so truly valuable, that, as Dr. Franklin well observes, it would have been a much fitter emblem of their country than the white-headed eagle; "a lazy, cowardly, tyrannical bird, living on the honest labours of others, and more suited to represent an imperial despotic government than the republic of America." However this may be, the turkey is entitled to the nobility of the farm-yard. Cultivation and population have had their usual effect on large animals, and have driven the wild turkeys from many of their former haunts; yet they are still to be found, in large flocks, in the back settlements of Louisiana, and in a few other states.

(92.) The aquatic orders, among themselves, show a very different disposition. Few of the wading birds resemble those of Europe, and even the snipe and woodcock are distinct from ours. The golden plover is the same; but all the rest, with the curlews, most of the sandpipers, together with the coot and the water-hen, are not only peculiar to America, but very few have been found to the south of the line. The American flamingo (fig.23.), fully as tall as the European, is of a much more beautiful and intense scarlet; while the 


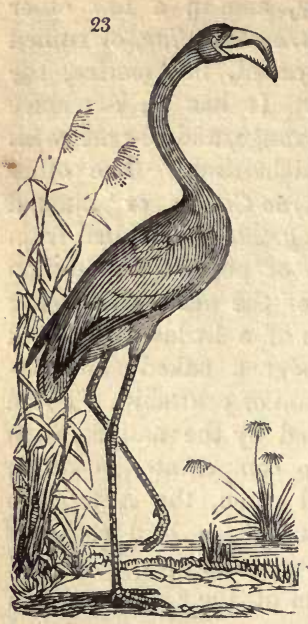

wood ibis, in form at least, seems to represent the glossy ibis, so common in the south of Europe. The herons of Carolina and Florida are numerous, and comprise several large and beautiful species. The magnificent scarlet ibis, also, is there not uncommon : yet few of these elegant wading birds extend to the northern parts of the United States. Among the ducks and other swimming tribes, there is a general similarity in the species to those of Arctic America, two or three only being restricted to the warmer shores of the southern provinces. The chief of these is the splendid Dendronessa sponsa Sw., called there the summer or tree duck of South Carolina. The canvass-backed duck (Fuligula

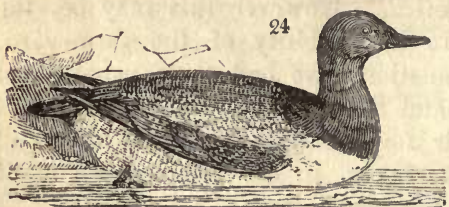

Vallisneria Bon., fig.

24.) is chiefly found in temperate America, and is prized as a delicious food. Nearly all the rest of the duck tribe occur in the northern regions, which they quit for the United States during severe winters, and return to breed in the spring. America, like Europe, thus presents us with a double migration, and both for the same purposes; namely, to avoid cold, to procure sustenance, and to rear their young.

(93.) The fish of the Ohio, and the other great rivers, are stated to be peculiarly abundant, both in number and in species; yet none appear to resemble those of Europe. The famous fishing-banks for cod, on the coast of New- 
foundland, are of vast importance to commerce, and will be noticed elsewhere. The reptiles offer nothing definite in regard to their distribution. The serpents are numerous, and many are believed venomous. The rattlesnakes are peculiar to the New World; but those of North America are of a different species to that found in Brazil. The immense Boa constrictor, and the equally gigantic species with which it has been confounded, are, fortunately, strangers to this region. There are several land tortoises, but, with one exception, they are all of a moderate size. This is a gigantic species, inhabiting the Gallipagos, a cluster of islands which come within the range of latitude assigned to this zoological region. Dr. Harlan, an able and zealous naturalist of America, first made us acquainted with this gigantic creature, named by

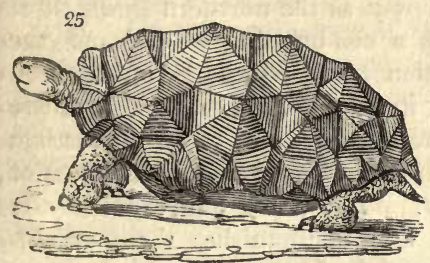

him Testudo elephantopus (fig. 25.), or the elephant tortoise : other writers have more recently considered it a variety of the Indian tortoise ( $T$. Indica), but this appears very questionable. Some curious salamanders have been recently discovered; and the celebrated Siren is an inhabitant of the muddy lakes of Georgia and Carolina: this singular reptile had long perplexed naturalists, some thinking it a tadpole or imperfect frog; it is now, however, fully ascertained to be an adult animal.

(94.) The third great division of American zoology comprises the whole of the southern peninsula, from the Gulf of Mexico to the extremity of Paraguay, beyond which latitude lie regions whose animals are little known. There is, however, no reason to exclude those countries from our survey of this portion of America, although we have nothing to guide our judgment as to the transition which nature may here effect into the Fauna of some other region. 
(95.) The islands dispersed in the great gulf, but more particularly the Isthmus of Mexico, constitute that intermediate region - that "land debateable" in which the Faunas of the two great divisions of America meet, and imperceptibly blend into, each other. Such are the harmonious transitions of nature through all her works; ever varying, her laws are yet the same, in whatever light her operations are studied. To look for absolute divisions were a fruitless and a hopeless task, for they can never be found; and they appear totally repugnant to the laws of creation. It is immaterial, therefore, to our present purpose, at what degree of longitude or of latitude we draw an imaginary line of separation; whether, in short, we consider the table land of Mexico as the southern confines of temperate America, or view it as the northern limits of its tropical portion. As a combination of circumstances has drawn our attention to this hitherto unknown region, a more detailed notice on such of its animal productions as have yet reached us, may prove interesting.

(96.) On the quadrupeds of Mexico, our information, indeed, is but scanty. The short and vague notices given by Hernandez, who distinguishes them only by the unutterable names of the Indians, affords no clue by which we can comprehend their real nature; and, unfortunately for science, the most intelligent and accomplished of our modern travellers in Mexico - one who has supplied us with a fund of most important and sterling information on nearly every other topic - had no knowledge of natural history. Nevertheless, Mr. Ward* occasionally alludes to some of the native quadrupeds. He mentions herds of between fifty and sixty deer, as abounding on the plains of the table-land $\uparrow$ : he alludes to wolves being caught by the lasso; and to a kind of fox or wild dog, which is found in such numbers, that the hunting parties, formed by the peasants, frequently kill great numbers in one season. \$ "The wild animals to be met

* Mexico, by G. H. Ward, Esq. M.P. 2 vols. 8 vo 2 d ed.

† Vol. ii. p. 262.

$\ddagger$ See Ward's Mexico. 
with in the province of Texas, are the buffalo, or bison, known in England as the bonassus, and which enters Texas from the north, in vast herds, during the winter; the panther, leopard, bear, otter, beaver, antelope, deer, racoon, black fox, \&rc. The horses, descended from the Spanish Arabians, have peopled the rich plains of Texas with droves innumerable. These wild horses are often large or heavy, but show blood; and, if caught young, are very docile; although, whenever an opportunity offers, they are apt to rejoin their wild brethren." * It is impossible to ascertain what animals are here called "panthers and leopards," since these names strictly belong to African quadrupeds; nor are we specifically acquainted with any determinate species of antelopes or deer peculiar to Mexico.

(97.) On the ornithology of Mexico, our knowledge, comparatively, is much more advanced. Several collections of birds, formed by our countrymen now resident on the table land, have been transmitted to this country, and forwarded for our examination. The results are highly interesting. Of 114 species $\uparrow$ of land birds whose characters we have thus had the means of ascertaining, sixty-seven, or more than one half, have never been discovered in any other country. Eleven are natives of Mexico and of South America, and thirtysix are found both in Mexico and the United States. It may be urged, that so large a proportion of animals, in one class only, being found on the American isthmus, is surely sufficient to constitute it a distinct zoological province: but it must be remembered, that this peculiarity extends only to species. For it is a singular fact, that not more than one new genus (Ptiliogonys Swains.) is to be found in the entire number of 114 species. This is one of the most interesting genera recently discovered, being that by which nature has connected the family of tyrant shrikes (Tyrannina), with that of the

* Mexico, vol. ii. p. 435.

+ These species are enumerated in Murray's Encyclopædia of Geography, p. 1383 . 
caterpillar_catchers (Ceblepyrina) : two species have been detected, in both of which the males differ materially from the females.* Interesting, therefore, as is the ornithology of Mexico, in demonstrating the transition from the zoological tribes of Northern America to those of the Southern, nature has not, as it were, paused on her route, and given animal forms to this region, which she has withheld from the adjoining. There is no distinction between the geographic groups of Mexico, and those of the countries to which it is united: the genera are common to both; the peculiarity consists in finding these genera intermixed in one and the same spot; and exhibited in the form of species, which appear, for the most part, restricted to the American isthmus. - The following table of the genera of birds hitherto discovered in Mexico, will better illustrate our meaning.

(98.) The genera of birds characteristic of South America, found in Mexico, but either unknown, or only represented by one species (*) in North America, are as follows : -

Prionites Ill. Motmot.

Trogon $L$. Trogon.

Harpya Cuv. Harpy Eagles.

Polyborus Vieil. Carracara Eagles.

Cassicus $D$. Hangnest.

Tanagra Sw. True Tanagers.

Pyranga Vieil. Red Tanagers.

Psittacus $L$. True Parrots.

- Psittacarus Sw. Parrakeets.

(99.) The genera more peculiar to North America, found also in Mexico, but which, with few exceptions (marked *), are unknown in South America, are the following:-

Setophaga $S w$. Fantailed Warblers. Seiurus Sw. Wagtail Warblers.

Sialia Sw. Blue Robins.

Sylvicola $S w$. Titmice Warblers.

Vermivora $S w$. Worm-eating Warblers.

(100.) To state the result in a more popular form, * See Zool. Illus. 2. pl, 62.102.
Macrocercus Vieil. Mackaws.

Xiphorhynchus $S w$. Creepers.

Crotophaga $L$. Ano-bird.

Tiaris $S w$. Crestfinches.

Cynanthus Sw. Fork-tailed Hum. ing-Birds.

Lampornis $S w$. Even-tailed Humming-Birds.
Pipilo Vieil. Groundfinch.

* Ammodramus Sw. Sandfinch.

Sturnella Vieil. Crescent Starling. Colaptes Sw. Ground Woodpecker. 
we may gather from the above facts, that Mexico exhibits nearly as great a variety in her animal productions as she does in her vegetable. Both may be traced to the same cause, - the astonishing variety of climates concentrated in this isthmus; where the traveller can pass, in the space of three days, from the regions of perpetual snow, to the burning sands of Vera Cruz. Between these two extremes of heat and cold are stupendous ridges or platforms, at different elevations, of table lands; as if nature, within a single degree of latitude, intended to represent the climate, the animals, and the vegetables of every region in the New World.

(101.) Aquatic birds are generally more numerous in cold than in warm latitudes; yet Mexico is a remarkable and almost a solitary exception. All travellers agree in stating, that the lakes and marshes on the table land are frequented by innumerable waterfowl; their numbers, in fact, are so immense, that they are killed by batteries placed in a double file, and many hundreds are brought down at a single discharge.* Yet among all those which have been sent to England, we only discovered two new bitterns, the Mexican and the lineated species; the rest were of ducks and waders, well known in the United States, and nearly all inhabiting the Arctic regions. It would thus appear that the freshwater lakes of the isthmus form the southern barrier of all these migratory tribes, no less than of the insectivorous summer visiters of the United States; since we are, at present, unacquainted with a single instance of a natatorial bird of North America having been detected on the Terra Firma. Some few of the small sandpipers may, however, occasionally pass to the south of the equinoctial line.

(102.) The only Mexican reptile deserving particular notice, is the Phyllhydrus pisciformis Br. (the Axolotl of Humboldt), allied to the Siren of Carolina. It seems to abound in the lakes near the city of Mexico, and is much esteemed as an article of food.

* Ward's Mexico. 
(103.) The zoology of Mexico conducts us at once into the third great division of the American province, of whose zoological features we shall now proceed to give a rapid sketch. It must first be premised that the equinoctial provinces, forming the modern republies of Guatemala and Colombia, have never been fully explored by modern naturalists; that, notwithstanding the celebrated Humboldt traversed the whole of Chili and Peru, his other pursuits left him little or no time to collect or to investigate their animal productions; and that many other parts of this vast and fertile continent have hitherto been but superficially examined. Our materials, therefore, must be chiefly drawn from the immense collections that have been made of late years in different parts of Brazil ; from our own personal researches in that vast empire; and from a few other authentic sources. We have before remarked, that both animals and vegetables rapidly increase in number and variety, the nearer we approach the equinoctial line, where the humidity of the atmosphere is more remarkable, to common observers, than any extraordinary degree of heat. That the former is more essential to this fecundity than the latter, is perfectly manifest, upon looking to the deserts of Africa, situated under similar degrees of latitude. But the variety of animals in tropical America is so much greater than in any other part of the world, that we naturally enquire what are the causes generally assigned for this excessive exuberance? This question has been so well replied to by a celebrated traveller, that we shall here insert his observations.

(104.) The causes of the general fertility of America, and more particularly of the southern division, assigned by M. Humboldt, are these : - "The narrowness of this variously indented continent; its great extension towards the icy pole; the wide ocean over which the tropical winds blow; the flatness of the eastern coasts; the currents of cold sea-water which flow northwards from the Terra del Fuego towards 
Peru ; the number of mountains, the sources of countless springs, whose snow-clad summits tower above the clouds; the abundance of large streams, which, after many windings, always seek the remotest coast; deserts without sand, therefore the less heated ; impenetrable forests, which cover the well-watered plains near the equator, and which, in the interior of the country, where the mountains and the water are most remote, exhale immense masses of imbibed or self-producing water. - All these circumstances give to the flat portion of America a climate which, by its moisture and coolness, forms a surprising contrast with that of Africa. To these causes must be ascribed that extraordinary luxuriance of vegetation, that exuberant foliage, which forms the peculiar characteristic of the New Continent."

(105.) In applying these observations to Brazil,an empire, which nearly absorbs one third of the whole continent of South America, - some modifications and particular exceptions must be made; and this we are enabled to do from personal observation. Vegetation, indeed, covers nearly every part of this immense region, but in very different degrees, and with some remarkable peculiarities. A stupendous range of virgin forests may be said to extend from one extremity of the eastern coast to the other; running parallel with the shore, and forming a magnificent belt of verdure between that and the interior: in these parts the soil is amazingly rich, either a black vegetable mould, or a fat red loam. It is in these situations that vegetation attains its highest luxuriance: nearly all the large timber trees are found only in the virgin forests; and the ground, when cleared for cultivation, gives an astonishing produce. But no sooner does the traveller penetrate beyond this natural belt, on his way into the interior, than he meets with a totally different country. The Sertam districts then commence; a name applied generally to all inland parts situated beyond the virgin forests. The Sertam country, however, possesses very 
different features in different localities, and which the Brazilians distinguish by appropriate names. The Campos are vast plains similar to those on the banks of the great Rio St. Francisco, covered with coarse grass, and destitute of trees. They are scorched during summer, and present little other vegetation during the rainy season. The Campos appear, in fact, to be a continuation of the Pampas of Paraguay and the Rio de la Plata, and are analogous to the interior deserts of Africa : water, excepting in the great rivers, is equally scarce ; and in dry seasons, hundreds of cattle perish, and whole villages migrate. These dreary plains are frequently elevated; but in such situations, the coarse and scanty herbage is generally intermixed with stunted trees, growing at short intervals, as in a park: clear of underwood, and open to the route of the traveller in every direction, such tracts are termed Tabularas, or table-lands, since they are almost always raised a few hundred feet above the level of the sea. Lands of this description are frequently broken by narrow valleys, or gentle hollows, wherein the trees become higher, and acquire a more flourishing growth, thus forming woods; yet they are so matted together by a thick underwood of Cacti, Bromelia, and other spinous plants, intermixed with thickets of coarse-leaved flowering shrubs, as to be almost impassable to any but the hunter: these are the Catinga woods of the Brazilians; and it is here that the numerous and splendid family of Epidendrum, and other parasitic plants, few of which are yet known to botanists, root round the bark, or spring from the stems, of the larger trees. The general character of the soil, in all the localities here described, is more or less sandy; and although never destitute of vegetation, the plants have almost always a parched, stunted, and withered appearance, except, as before observed, during the rainy season. These observations, apparently foreign to our present subject, are nevertheless so closely connected with it, that, without them, it would be impossible to 
account for the singular inequality of animal dispersion, which we shall now proceed to notice. We do not, of course, comprehend the mining provinces of Brazil in the above sketch : they are more particularly mountainous ; and must, therefore, be looked upon as an exception to the general features of the whole.

(106.) The dispersion of animals is affected, in a surprising degree, by the above variations in the face of the country. As vegetation is most luxuriant towards the coast, so is the number and variety of animals, on the borders or in the recesses of the virgin forests, much greater than in the interior. It is in these thick and umbrageous retreats that the numerous tribes of monkeys are alone found; for their life is spent, not on the ground, but in wandering through the boughs of interminable forests, leaping from branch to branch, and passing from one lofty tree to another by amazing springs. In conformity with these habits, more especially characteristic of the American monkeys, we find the greater part are furnished with a prehensile tail, of such strength and construction, as to fulfil the office of a fifth hand. No such additional power for climbing has been given to the monkeys of India, much less to those of Africa ; in neither of which is this family so numerous in species or individuals, or so strongly characterised by lofty forests. On turning to the birds, we find the toucans (Ramphastida), manakins (Pipra), jacamars (Galbula), motmots (Prionites), trogons (Trogonida Sw.), tree creepers (Dendrocolaptes, Certhiada), and several other groups, are more particularly inhabitants of the virgin forests ; while the insects, imposing from their size or dazzling from their brilliancy, are found in such incredible numbers, in the more open parts, that the entomologist is frequently unable to capture one half of those that come within his reach, from the time consumed in securing his game.

(107.) On passing from the deep forests, and entering upon the Tabularas, or the more open inland tracts, the naturalist finds himself in a new zoological region 
Few insects appear: and he may frequently ride for hours without meeting with a single lepidopterous insect worth preserving. Vegetation has lost its luxuriance, and with it the power of nourishing those innumerable insects which feed on the tender and juicy leaves of plants flowering in a rich and humid soil. The low trees and scanty thickets produce a variety of small berries, affording nourishment to the hard-billed tanagers and finches, few of which are met with in the forests of the coast. The Sertem, or inland country, particularly the tabulas, are the chosen haunts of nearly all the parrakeets: here they are seen, in flocks innumerable, living upon the berries; while the harder nuts of the different palms so frequently met with in the interior, are the favourite food of the larger parrots and mackaws. The humming-birds, also, are never seen in the recesses of forests ; for, as they principally live on vegetable juices, they naturally frequent the more open tracts and the thickets of the Catinga woods, abounding in small but odoriferous flowers. The Catingas, again, have their peculiar inhabitants. The animals principally found here are the sloths, armadillos, cavies, and squirrels; while a few of the smaller monkeys seem to prefer these lesser woods to the forests. The insects are more numerous than on the Tabularas; but they are small, and only interesting to the na-

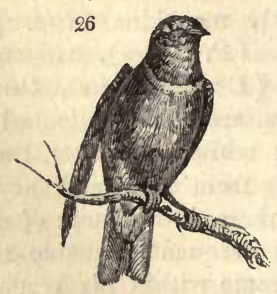
turalist from their locality. The bush-shrikes (Thamnophilus) and the ant-thrushes (Drymophila Sw.) are also nearly peculiar to the Catingas; to which many of the fruiteaters (Ampelida $\mathrm{Sw}$. ) resort, at certain seasons, to devour the berrries. Few of these splendid birds (of which the blue-collared Ampelis Catinga L. (fig. 26.) is, perhaps, the most magnificent) are found near the coast.

(108.) The Campos, or plains, are still more thinly 
inhabited ; but as we avoided these districts, as uninviting to the naturalist, so we cannot detail their peculiarities. The tinnamous (Crypturus Ill.) are the partridges of America, living among high grass, while the rufous baker-birds (Opetiorhynchus Tem.) are principally found in arid plains, always walking or perching upon the ground. - Such appears to be the local distribution of the vast variety of animals belonging to this magnificent portion of the New World. It now only remains for us to take a hasty glance at the general zoology of the whole southern continent.

(109.) Among the quadrupeds, we have already stated that the great variety of monkeys found in tropical America are essentially different from those of Africa and Asia. They are much smaller, more inoffensive, and bear little or no analogy to the satyr-like apes and disgusting baboons of the Old World: they have all tails, generally prehensile; but are without cheek pouches or naked callosities on their hinder parts. The howling monkeys (Mycetes Ill.) live in the deep virgin forests, from which they send forth, morning and evening, such tremendous and frightful howls, as to impress the listener with the apprehension of some gigantic ferocious animal being very near. No less than sixty-five species of this family have been described as natives of South America. The bats are more numerous than in any part of the world: here, again, we see the wise provision of nature in adjusting the balance between the insect world and those animals which draw their support from it. Many, however, live also upon fruit; while others, like the large vampires of the East, enter the cattle sheds, and even the dwellings of man, to suck the blood of both. Horses and mules are constantly attacked in this manner during the night; and although never killed, are generally too weak to be used in work for several days : this we have frequently experienced. Very few of the bats above mentioned occur to the north of the line; and none either in Africa, Asia, or Europe.

(110.) The carnivorous quadrupeds, or beasts of prey, 
with but two exceptions, are of a small size; and although of many species, they appear to be few in numerical amount, and are fearful of man. The largest are the puma and the jaguar; the latter alone being truly formidable, the rest are principally small tiger-cats of several species, beautifully marked and spotted. The lion, tiger, panther, leopard, hyæna, jackal, and the whole list of ferocious quadrupeds so common in the intertropical regions of the Old World, are here utterly unknown. The tapirs, of which two species are known, are the largest quadrupeds yet met with in South America. The sloths, the ant-eaters, and the armadillos are peculiarly Brazilian : the latter are harmless little creatures, very tameable, and are frequently kept as pets in the houses. The scale-covered manis represents this group in Africa. The lama, and the other wool-bearing animals of that description, appear more peculiar to the elevated plains on the Andes of Peru and Chili. Travellers mention small deer, but the species have not yet been well ascertained.

(111.) Brazil is celebrated for its monkeys ; of which large troops are frequently met with in the virgin forests, springing from bough to bough with astonishing celerity: from the quickness of their motions, and the thickness of the foliage, the traveller is only able to catch a partial glimpse of them as they cross his path. Towards evening he is astonished by dreadful howlings, coming from the depths of the forests, and proceeding, as he imagines, from some formidable beasts of prey.

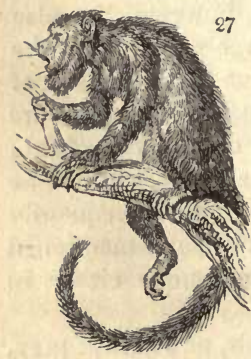
These alarming sounds, however, proceed only from the howling monkeys (Mycetes ursinus, fig. 27.), peculiar to tropical America, possessing neither size nor ferocity to make them really formidable. The compass of their voice is so astonishingly great, that it may be heard for miles. They live only in the most impenetrable recesses; where, perched upon the summit of 
some lofty tree, they make the forests resound with their hideous cries. There is a very beautiful and delicate little species, generally called, in this country, the lion monkey, but which is the silky monkey of Pennant (Midas rosalia). The hair is long, soft, glossy, and of a bright golden or chestnut orange. This elegant little creature is sometimes brought alive to England, but seldom survives during the winter. The real leonine monkey ( $M$. leoninus) is also found in Brazil, but the fur is olive brown, and the face black. The disgusting baboons of Africa, and the large apes of Asia, are entirely excluded from the New World. The true ant-eaters, on the other hand, are found only in tropical America : there are three species, of which the great or maned ant-eater (Myrmecophaga jubata) is the largest. All the species are clothed with thick but cool hair; whereas those of India, forming the genus Manis, are covered with horny scales. The armadillos, again, are only to be found on this continent ; and their vulgar name of hog-in-armour, is characteristic at once of their affinity, and the peculiar defence which nature has given them. The Brazilians are particularly fond of these animals, which they hunt for food; and we can bear testimony to the delicacy of their flesh, which has all the white-

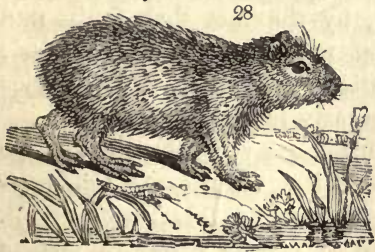
ness and the savour of young pork. On the sides of the rivers are found the capibaras ( $H y$ drocorus Capybara, fig. 28.). This animal, in shape, very much resembles the Guinea-pig, but is greatly superior in size, measuring about three feet in total length : the feet are palmated or webbed, so that it dives or swims with perfect ease; and when. on land it often sits on its hind feet, like the squirrel. It is timorous, and seldom goes abroad during the day; for although it swims well, it runs badly: they are said 
to live in families, and seldom to quit the vicinity of the place where they were born.

(112.) The cavies, or agoutis, as they are sometimes called, are the hares of Brazil (Dasyprocta 1ll.,

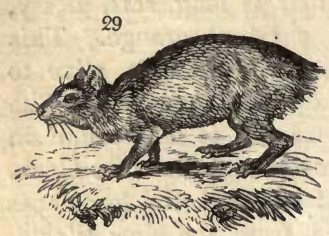
fig. 29.): they have no tails, and feed entirely upon vegetables; shy in manners, and swift of foot, they live only in the forests and Catinga woods. The cattle and horses were first introduced into the New World by the early Spanish invaders, but they have now multiplied into immense herds, and range over the Campos and Pampas of the interior. Sheep are very scarce, and in many provinces almost unknown.

(113.) The general ornithological features of Brazil have already been dwelt upon; while, as regards the number of species, this region may safely be pronounced the richest in the world. Not more than one fifth of the Brazilian empire, for instance, has been explored; yet it has already furnished upwards of 500 different kinds of birds, and new ones are continually sent by travelling collectors to Europe, by which the list is increased. We may, in some measure, account for this abundance, by the fact that fruits and insects constitute the chief nourishment of this class; and that both are peculiarly abundant in countries where vegetation is particularly luxuriant.

(114.) The rapacious birds are very peculiar: large

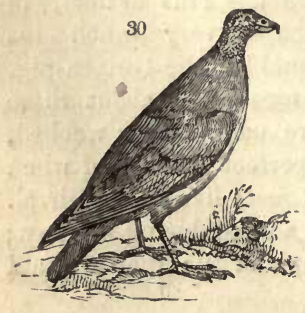
black vultures (Cathartes atratus, fig. 30., Sw. N. Z. ii. p. 6.), fully equal in size to our turkeys, are every where seen, perfectly tame, sitting on trees by the way side, and ready to devour offal, or any animal substance deprived of life. Whether these vultures are of the same species as the 
black and turkey buzzards of North America, is still a matter of doubt. The king vulture $(V \cdot p a p a \mathrm{~L}$. $)$ is also large; and its head and neck, although naked, are beautifully coloured. But the most remarkable bird of this tribe in South America, or in the world, is the

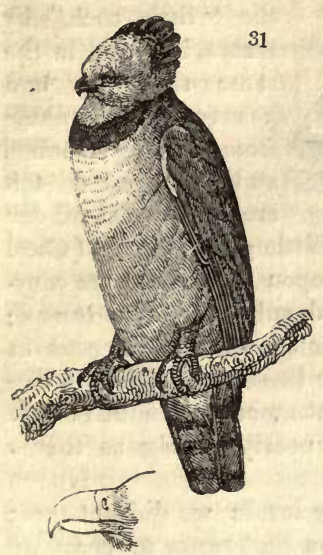
famous condor of the Andes. It appears to extend its range over a long extent of those immense mountains, but has not yet been met with in Brazil, or in the less elevated provinces on the eastern side of the Cordilleras. In these flatter and more wooded districts, the place of the condor is filled by a bird little inferior in size, but much more cruel and destructive in its habits; named, on this account, the destroying eagle (Aquila destructor, fig. 31.). While the condor is restricted to the highest mountains, this formidable bird ranges over the forests of the coast, and particularly those of Demerara, Parà, and Brazil. It flies with majestic rapidity, and preys only upon deer, sloths, monkeys, and the larger quadrupeds; pursuing them with velocity, and tearing them in pieces with its enormous talons. The different Caracaras, more resembling eagles than kites, are also peculiar to this part of the world. The owls, unlike those of the North, are of a small size ; and one species in the gardens of Pernambuco, was, in size, inferior to the thrush.

(115.) The chief families of perching birds we have already enumerated; but many others may be noticed for their beauty or their singularity. The numerous tyrant flycatchers are seen in all the open tracts and gardens, perched on the surrounding branches, and per. petually on the watch for insects. The water-chats 
(Fluvicolina Sw.), analogous to our wagtails, run along the sides of the rivers and lagoons, bent on the same pursuit, and perpetually wagging their tails: the very

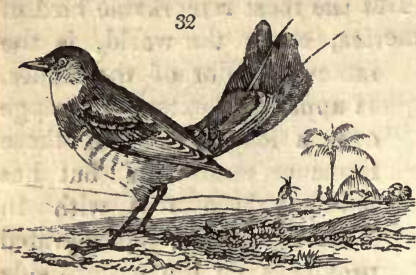
singular genus Alecturus (fig.32.), called the "little cock" by Azara, is found in the same situation, and has received this name from carrying its broad and compressed tail erect, like that of our domestic fowl. The beautiful little ground doves (Che mepelia Sw.), frequent all the open tracts, and are common even in the gardens and suburbs of the towns; while the humming-birds, although more numerous in the interior, are nevertheless to be seen, wherever a tree is in full blossom, darting about among splendid butterflies, and blue-winged bees, nearly as big as themselves.

(116.). Water-birds are very local : we did not meet with them in any abundance, in that range of coast we traversed between lat. $8^{\circ}$ and $23^{\circ} \mathrm{S}$.; but we are informed by Mr. Hesketh, his Majesty's consul-general at the city of Para, directly under the line, that the swamps on the borders of the great river Marañon, extending for hundreds of miles, are filled with innumerable flocks of aquatic and wading birds, sheltered among interminable forests of reeds, as old, probably, as the

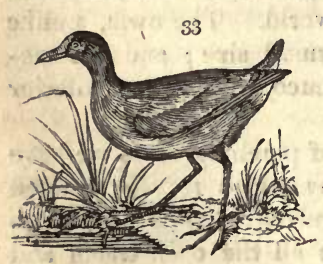
creation. Here the splendid scarlet curlews are found in the greatest abundance; and probably these haunts, impassable to human feet, are frequented by nearly all the aquatic tribes of South America. In nearly all the swamps and savannahs of Brazil is found the Martinico Gallinule (fig. 31.), or water-hen, whose dark purple 
plumage, yellow bill, and crimson frontlet, renders it one of the most elegant of aquatic birds. The spurwinged water-hens (Parra), walking on the broad leaves of aquatic plants, appear as if they trod upon the surface of the water, and relieve the solitude of such dreary tracts.

(117.) Our information on the fish peculiar to these seas is very defective, and not generally interesting. The species materially differ from those of similar latitudes in the Old World; while the beautiful chætodons, which form such a prominent feature in the ichthyolog: of India, are but sparingly distributed in the American seas. The genus Anableps has been named the doubleeyed loach, from what appears to be the real eye being covered with an elevated membrane: it is found in the rivers and fresh waters of Surinam. The Brazilian gar-fish is much smaller than ours, and is distinguished by the excessive length of the lower jaw, and the extreme shortness of the other. The fish generally observed by us in the markets of Pernambuco and Bahia were small; nor did we taste any that could be compared to the cod, turbot, or salmon of our own seas.

(118.) The most extraordinary reptile of South America is the Surinam toad, disgusting and hideous in appearance, but interesting from the manner in which Nature has provided for the safety of its young; the back of the mother being excavated into little hollow cells, within which the young retreat, and are carried about, until able to shift for themselves. The somewhat marvellous adventures of a recent author, among the Cayenne crocodiles of Demerara, are very amusing; but we cannot tell of such " moving accidents :" those we observed in Brazil were small, timid, and more anxious to escape from man than to call forth his prowess. Another reptile, the horned toad (Ceratophrys dorsata Max., fig.34.) is one of the most singular reptiles of Brazil. Its colours are beautiful; the back being bright green, with stripes of deep black, and the sides are variegated with orange: over each eye is a short 


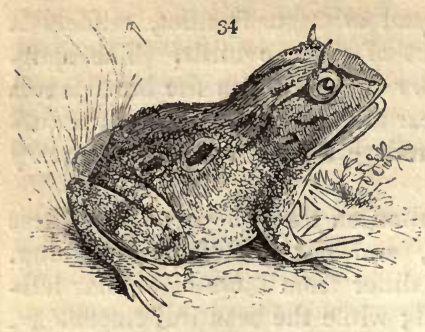

but horn-like protuberance, giving to this really harmless animal a formidable and repulsive appearance.

(119.) Immense serpents, not, indeed, poisonous, but nearly as formidable from their size, are found in the wilds of the interior, principally near the banks of the great rivers. The natives assert that they frequently kill the young oxen, by strangling them in the enormous folds of their body. These monsters are never seen of a large size in cultivated districts; they belong to the genus $B o a$, which here represents that of Python, belonging to the Old World. The species named Boa constrictor has been often described, but probably two or three are still confounded under that name. Frogs of a monstrous size are every where common in the swamps; but musquitoes, their usual attendants, are much less numerous than in the north of Europe. The number of serpents in Brazil appear to us to have been much over-rated: although constantly in situations where they might be supposed, to abound, we met with very few. The rattlesnake of North America is here unknown, but its place is supplied by another species; while the most beautiful are the coral snakes, generally about two feet long, and elegantly banded with black and crimson. The large lizards, called guanas, are common, both on the West India islands and on the continent; and, by the inhabitants generally, are considered very delicious eating, - a fact we can ourselves testify: the flesh,indeed, is firm, white, and very delicate. Turtles are well known as inhabitants of these seas, particularly the green sort, sent to Europe and dressed at our feasts : there is, however, a species in the Mediterranean which appeared to us equally good.

(120.) The wingless insects, as spiders, crabs, \&c. 
may be briefly noticed.-The land crabs are numerous, and very curious; since they live but a part of the year in water, and resort, at other times, to the woods and forests. They seem to abound more particularly in the West India islands ; but whether they are of the same species as those found in Western Africa has not, we believe, been clearly ascertained. Many of the freshwater crawfish are nearly as big as young lobsters. The scorpions are small, and, excepting those of Surinam, not much larger than the species found in the south of Europe. The venomous centipedes of Africa and Asia are strangers to this continent, or, at least, are so rare that we never met with one. The bird-catching spider Mygale avicularia ( $\mathrm{fig} 35$. ), as it is improperly called.

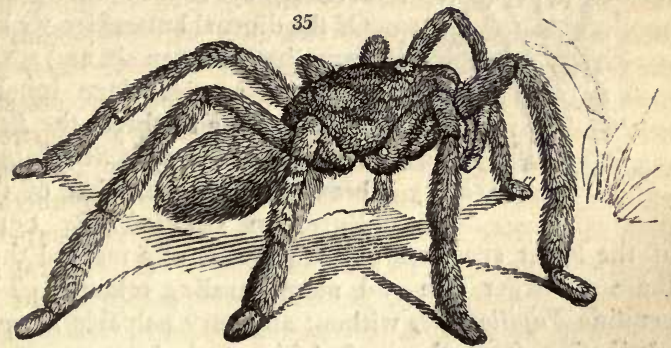

is the largest of this family yet discovered. Madame Merian, in her Surinam plates of insects, represents it as feeding upon the humming-bird; but we never found it on trees, and suspect this habit is entirely contrary to its nature. The silkworm is unknown, either wild or cultivated; but America possesses the cochineal insect, of nearly as much importance to commerce; it has been hitherto confined to the republic of Mexico ; and, besides its use in dyeing, furnishes the rich colour called carmine, the most beautiful of all the pictorial reds.

(121.) To enumerate the tribes of winged insects peculiar, to South America is altogether impossible; yet we cannot pass over this lovely portion of creation 
in silence. As the American continent, more than any other, abounds in forests of timber trees, so do we find that the number of coleopterous insects, which feed, in their larva state, within the substance of wood, are proportionally numerous ; the comparative relations between those of Europe and of Brazil alone being probably as one to nine: while of such Coleoptera as devour decayed animal substances (here removed entirely by ants), the ratio may be inverted. To the abundant supply of soft and nutritious vegetable food, we may, in like manner, attribute the amazing number of lepidop-

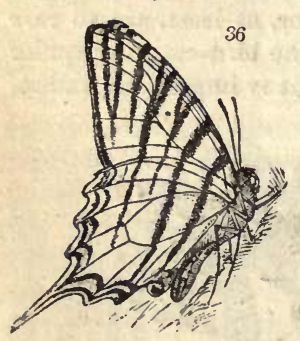
terous insects : in their variety, size, and brilliancy of colouring, they are certainly unrivalled by any in the world. Of the diurnal butterflies, we believe that between six and seven hundred species alone inhabit Brazil. One of these, the Protesilaus Leilus (fig. 36.)* is a beautiful representation of the European swallow-tail. Some of the lesser species are more beautifully marked than those of larger size and more dazzling colours. The genuine Papilionida, without any very palpable generic distinction from those of Africa and Asia, possess a certain aspect, or habit (as it is usually termed), which immediately betrays their country to the eye of the experienced entomologist. The family of Coliada, comprehending those simply coloured, yet beautiful, yellow and orange butterflies, so frequently seen in collections, are particularly numerous both in species and individuals. The hair-streaks (Theclida) is another family so abundant, that we possess near 120 species from Brazil ; but the Hesperida, or skippers, are in still greater profusion, since more than 200 different sorts were captured by us in Brazil, nearly the whole of which are restricted to the 
virgin forests of the coast: very few of the genera comprised in this family are known in other countries.

(122.) Ants are as numerous as inWestern Africa, but they all appear to belong to different species. The red ants of Brazil are so destructive, and at the same time so prolific, that they frequently dispute possession of the ground with the husbandman, defy all his skill to extirpate their colonies, and fairly compel him to leave his fields uncultivated. . The Termites, or white ants, are principally confined to the woods : they are of different species; some building great nests in trees, while others are subterraneous; but there is no evidence to prove them the same as those of Western Africa. Locusts of a beautiful green, with wings resembling the leaves of plants, are not uncommon; but they never become noxious; nor is there, we believe, any instance upon record of their associating in flocks, and devastating the country. They are, in fact, all specifically distinct from those of the Old World. The dipterous insects are remarkably few, - a peculiarity in American entomology, for which we know not how to account: but it is singular, that spiders, which prey more especially upon this order, are still more rare; we never, in fact, met with more than two or three species which spun webs. yet of the little Saltici, or jumping spiders, which wander about in quest of their prey, we described, upon the spot, more than 100 species. Yet, however deficient South America may be in Diptera, there are some belonging to the Aselida, of dimensions far exceeding any in the world. Few persons would believe in the existence of a real fy measuring full two inches long; yet several of these are in our museum.

(123.) The testaceous Mollusca, or shells, are comparatively very few, particularly on the eastern coasts, yet those of Chili and Panama have furnished our cabinets with many beautiful species: from the latter is brought the lovely Murex regius Sw., the Murex radix L., with many others of less note. From Chili and Peru we 


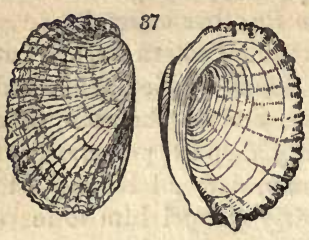

derive the singular Purpura Concholepas Sw. (fig. 37.) which resembles a limpet; and also a considerable number of chitons. The marine shells of Brazil are comparatively few, and offer a singular contrast to the prolific shores of intertropical India, and even to those of Western Africa. The number of fluviatile shells bears no comparison with those of North America ; but whether this is truly the case in nature, or that it results from the rivers of the South not having been sufficiently explored, is still uncertain. The genus Hyria Lam. is as peculiar to these American latitudes, as Iridina appears to be to Africa; while

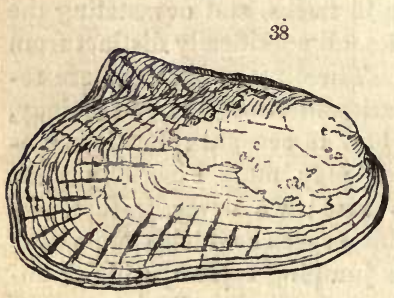
the Lymnadia gigas Sw. (fig. 38.) of the Oronoko is the most gigantic river shell hitherto discovered. The apple-snails (Ampul. laria L.) abound in the swamps and lesser rivers, and exhibit numerous species, none of which appear to have been found north of the line.

(124.) The land shells, although not many, are very curious. The large Bulimus ovatus is common on the continent; while another species (B. hamastomus) appears more frequent in the islands. The Achatina melanastoma Swains. is particularly rare, and none of the species from the continent of tropical America may be termed common. Jamaica, and several of the neighbouring islands, are much richer in these productions.

(125.) The quadrupeds of the American continent chiefly belong to the following genera and sub. genera : - 
Atel is Geaff:

Monkeys.

Lagothrix Humb.

Mycetes Ill.

Cebus Cuv.

Callithrix Ill.

Aotus ILl.

Pithecia IU.

Hapale IUl.

\section{Bats.}

Phyllostoma Cuv.

Vampyrus Spix.

Glossophaga Geoff:

Artibius Leach.

Monophyllus Leach.

Mormoops Leach.

Thyroptera Spix.

Noctilio Geoff:

Proboscidea Spix.

Molossus Geoff.

\section{Ursus $L$.}

Procyon Cuv.

Nasua Desm.

Cercoleptes Desm.

Meles $L$.

Gulo I.

\author{
Didelphus $I_{0}$ \\ Cheironectes Cuv。 \\ Castor $L$. \\ Echymys Cuv. \\ Myopolomus Desm. \\ Arctomys Cuv. \\ Spermophilus $\mathrm{Cuv}$. \\ Pteromys Cuv. \\ Spigurus Cuv. \\ Erethizon Cuv. \\ Hydrochcerus $E x$. \\ Aperea Marcg. \\ Dasyprocta $\mathrm{Ill}$. \\ Cœlogenus Cuv. \\ Bradypus $\boldsymbol{L}$. \\ Dasypus $L$, \\ Myrmecophaga $L$. \\ Dicotyles Cuv. \\ Tapirus $I l l$. \\ Anchenia $I U$.
}

Alce Ham. Smith.

Rangifer Ham. Smith.

Elaphus Ham. Smith.

Mazama Ham. Smith.

Subulo Ham. Smith.

Dicranocerus Ham. Smith.

Aplocerus Ham. Smith.

(126.) The American genera and families of birds are particularly numerous; and in several instances are restricted to the New World. Where, therefore, a family group is strictly and exclusively American, the genera and subgenera it contains will not be enumerated. Those marked (s.) are subgenera.

Rapacious Birds.

Vultur $L$. Vulture. Polyborus Vieil. Caracara. (s.) Harpyia Cuv. Eagle. (s.) Morphnus Cuv. Eagle. (s.) Cymindis Cuv. Kite. (s.) Falco (Harpagus) Vigors. Elanus Sav. Kite. (s.)

\section{Perching Birds. (Fissirostres.)}

Prionites IU. Motmot.

Trogon L. Trogon.

Galbula $L$. Jacamar.

Monassa Vieil. Hermit-bird. (s.)

Tamatia Marcg. Puffbird.

Chætura Stev. Spinetail.

\section{Tenuirostres:}

Trochilidæ Sw. Humming-Birds.

Nectarinea Ill. Flower-sucker.

Climbing Birds. Scansores.',

Dendrocolaptes IIl. Creeper.

Xiphorhynchus Sw. Creeper. (s.),

Dendroplex Sw. Creeper. (s.)

Anabates Tem. Creeper.

Synallaxis Vieil. Thorntail.

Zenops Ill. Turnbill.

Sittasomus $S w$. Creeper. (s.) ,

Lochmias Sw. Creeper. (s.)

Sclerurus Sw. Creeper. (s.)

Troglodytes (Thriothorus Vieil.)

Oxyrhynchus Tem. Sharpbill. 
Colaptes $S_{w}$. Woodpecker.

Malacolophus Sw. Woodpecker.

Asthenurus $S w$. Woodpecker. (s.)

Macrocercus Vieil. Mackaw.

Saurathera Vieil. Rainbird.

Crotophaga $L$. Ani.

Ramphastos $L$. Toucan.

Pteroglossus Ill. Aracari.

Fam. Icterinz Sw. Hangnests.

Sturnella Vieil. Starling. (s.)

Agelaius Vieil. Maizebird.

Fam. Tanagrinæ $S w$. Tanagers.

Guiraca Sw. Finch. (s.)

Tiaris Sw. Redcrest.

Ammodramus Sw. Sandfinch. (s.)

Pipilo Vieil. Groundfinch.

Phytotoma Mol. Plantcutter.

\section{Warblers."}

Culicivora Sw. Gnatsnapper.

Sialia Sw. Bluebird.

Opæeteorhynchus Tem. Bakerbird.

Seĩurus Sw. Watertit. (s.)

Trichas Sw. Yellowthroat.

Setophaga Sw. Mothcatcher.

Sylvicola $S w$. Warbler.

Vermivora $S w$. Wormeater. (s.)

Mniotilta Vieil. Creeper. (s.)

Zosterops Vig. \& Horsf. Whiteeye. (s.)

Parus $L$. Titmouse.

Hylophilus Tem. Titmouse. (s.)

Egithina Vieil. Titmouse. (s.)

\section{- Thrushes."}

Donacobius Sw. Naked-neck. (8.)

Icteria Vieil. Chat-bird.

Orpheus $S w$. Mocking-bird.

Grallaria Vieil. Ant-thrush. (s.)

Myothera Ill. Ant-thrush.

Formicivora $S w$. Ant.wren. (s.)

Drymophila $S w$. Ant-thrush. (s.)

Urotomus $S w$. Ant-thrush. (s.)

Dasicephala Sro. Bristle-head.

\section{Shrikes.}

Thamnophilus Vieil. Bush Shrike. Cyclaris $\mathbf{S} w$. Shrike. (s.)

Sub-fam. Tyranninæ $S w$. Tyrants. Ptiliogonys Sw. Caterpillarcatcher.

Fluvicola Sw. Water-chat.

Nengetus Siv. Water-chat. (s.)

Alecturus Vieil. Cocktail.

Todus L. Tody. (s.)

Platyrhynchus Desm. Tody. (s.)

Psaris Cuv. "Blackhead.

Pachyrhynchus Sw. Thickbill.

Querula Vieil. Fruit-eater.

Chatterers, or Fruil-aters.

Pipra $L$. Manakins.

Ampelis $L$. Chatterers.

Procnias Hoff: Chatterers.

Phibalura Vieil. Chatterers.

Casmorhynchus Tem. Chatterers. Rupicola Vieil. Manakin.

Vireo Vieil. Greenbird.

Gallinaceous Birds.

Meleagris $L$. Turkey.

Odontophagus Vieil.

Ortyx Stev. Tree Quail. (s.)

Crypturus Ill. Tinnamou.

Rhea $B$. American Ostrich.

Ourax Cuv. Orax-bird.

Crax $L$. Curassow.bird.

Penelope Mer. Penelope.

Ortalida Mer.

Phosphia L. Trumpeter."

Opisthocomus Hoff: Serpent_eater. Chæmepelia Sw. Ground Doves.(s.)

Wading Birds.

Aramus Vieil.

Cancroma L. Boatbill.

Mycteria $L$. Jabiru.

Ereunetes $I l l$.

Eurypyga Ill. Snipe.

Palamedia $L$. Screamer.

Many of the foregoing, besides those definitely marked as such, appear to be subgenera, and several may even be of a lower denomination. 


\section{CHAP. V.}

AFRICA.

ON THE AFRICAN PROVINCE. - ITS GENERAL NATURE. - DIVIDED INTO NORTHERN, EQUINOCTIAL, AND SOUTHERN. THE PECULIARITIES AND ANIMALS OF EACH. - MADAGASCAR. - AFRICAN GENERA OF QUADRUPEDS AND BIRDS.

(127.) THE zoology of this vast peninsula assimilates in many respects to that of Western Asia, - a circumstance naturally to be expected from the junction, in this direction, of these two great divisions of the earth; while its northern limits, in like manner, present us with no inconsiderable number of the animals of Europe. As we recede, however, from these points, the peculiarities of the African Fauna become more apparent; and soon convince us of the necessity of considering it as a distinct zoological region. That Nature has been far less lavish, both in the number and variety of her forms, on this continent, than on any other of similar extent, may be readily inferred from its peculiar form. ation. Vast deserts of naked sand, equal in extent to the entire dominions of European sovereigns, are scattered over this continent in various directions, affording neither "green herb or limpid stream," or even the most scanty means for supporting life. These deserts, in fact, are uninhabitable to civilised man, and are only traversed by wandering savages or migratory quadrupeds. The fecundity of animal and of vegetable life is always influenced by the same causes: hence, on the western and southern coasts, where the soil is rich and moist, nature teems with life. Quadrupeds of the largest dimensions are stationary; the forests echo with the notes of birds; and innumerable insects are supported by a luxuriant vegetation. 
(128.) On taking a rapid survey of the productions of Africa, we are naturally led to arrange our observations under three heads. First, as relates to that portion of the continent situated north of the Great Desert, and bounded by the Mediterranean on one hand and the Red Sea on the other. Our second division will comprise Western Africa, and the more equinoctial regions; while the third embraces Southern Africa and the Island of Madagascar.

(129.) The zoology of Northern Africa is no further interesting, than as it presents us with the first indications of a great change in animal distribution. The Mediterranean forms a natural boundary to the northern range of many quadrupeds, unknown to, or long ago extirpated from, the shores of Europe. The lion is occasionally seen, and hyenas are not uncommon; but the jackal, long supposed a universal inhabitant of these countries, is unknown - according to Mr. Ruppel either in Egypt, Nubia, or the adjacent kingdoms. A few species of antelopes range over the arid tracts of Barbary, and are probably peculiar to this side of the Great Desert: with these, also, are intermixed several quadrupeds of Western Asia. The camel is here the chief beast of burthen, and the horses of Arabia are well known. It has been generally asserted, that this noble animal is truly a native of this part of Africa, and that it still exists in its original wild state; but recent travellers contradict this statement, and point to Western Asia and the regions of Caucasus as the original metropolis of the horse. The bats are small, and confined to five species; but in Lower Egypt are found several foxes and wild dogs of peculiar habits. The elegant little gerbells, or jerboas, are chiefly inhabitants of the deserts; while the Felis maniculata of Mr. Ruppel, or the Egyptian wild cat, appears, on the testimony of this traveller, to be the original species from which all our domestic breeds have sprung; the intermediate gradation being marked by the tame cats of the modern Egyptians. 
(130.) The birds of Northern Africa, taken collectively, present but a barren field to the ornithologist : the arid soil and treeless deserts sufficiently account for the paucity of these beings, whose sustenance is drawn from the insect and the vegetable kingdoms. It is generally supposed that the greater part of our summer migratory birds retire to Western Asia and Northern Africa at the approach of winter ; and hence it may be naturally inferred, that no great difference exists between the ornithology of the two shores of the Mediterranean. But as the heat of Africa is so much greater, so do we find an increase in the number of those birds whose province it is to remove putrid matter: hence the number of vultures and of cranes spread over this country, whose services are appreciated and rewarded by the care or

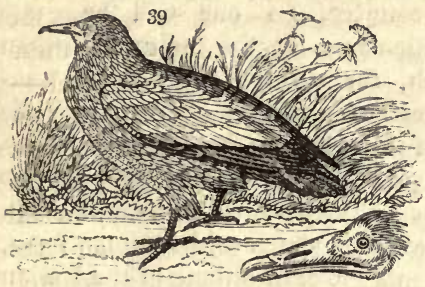
veneration of the inhabitants. Among these, the Neophron percnopterus of Savigny, or Pharaoh's vulture (fig. 39.), is one of the most com. mon. It is rather larger than a crow, with a white plumage and black wings; the bill is remarkably slender. For the rest, the only bird of considerable beauty is the Barbary shrike (Malaconotus barbarus Sw.*); also interesting, as showing us the most northern range of this African genus. The sacred ibis of the ancients, long confounded with some European birds of the same family, is now ascertained to be unknown beyond Egypt. The Arabian bustard differs from that of Europe $(O \cdot \operatorname{tarda} \mathrm{L}$.$) , and$ is of a small size; but the quail is of the same species as that which annually visits the south of Europe in such immense flocks. 
(131.) On approaching the equinoctial regions ef this continent, a material change is seen in the distribution of its animals. The Great Desert seems to form a natural separation between the northern and the tropical Fauna; although we must include in the latter division, Senegal, and the whole range of thickly wooded coasts which begins to appear towards Guinea and Benin. The pestilential nature of the climate, to the European traveller, opposes an insurmountable barrier to the investigation of these countries, rich in every production of nature, but deadly to the constitution of civilised beings. Hence our knowledge is limited to the few gleanings made near Sierra Leone, and to the productions of Senegal. Of all those ardent but illfated travellers who have sunk beneath the poisonous atmosphere of this country, no one will be more deeply regretted, particularly by the naturalist, than the late Mr. Bowdich, for no one was more qualified to reap the harvest of unknown forms which lie hid in the forests of Western Africa. In these impenetrable recesses lives the chimpanzee (Troglodytes niger Geof.), that satyr-like ape, which, of all animals in creation, makes the nearest approach to the human form, and which here represents the oran-outang of the Indian Islands. This, in short, is the region of the African Quadrumana, or four-handed animals. The maned apes, Colobus, and the different baboons and monkeys forming the genera Papio, Cyanocephalus, Cercocebus, \&c., are almost exclusively characteristic of equinoctial Africa, and correspond to other tribes restricted to India and America. In the more inland parts we have the scale-covered manis, representing the armadillo of Brazil: while herds of small antelopes, different from those of Northern Africa, inhabit the more inland open country on the banks of the river Senegal. In general, all animals of rapine have a more extensive geographic range than others: hence we find the lions, the hyænas, and other ferocious genera of this continent, wandering nearly from one extremity to the 
other; a wise dispensation of Providence - since, were they limited to more circumscribed bounds, the animals upon which they feed would soon be exterminated.

(132.) If we are to consider Central Africa as forming part of this division of the continent, - which cannot, in the present state of knowledge, be strictly defined,we may here observe, that in Abyssinia, and those kingdoms which border upon Central and Northern Africa, the elephant and the rhinoceros are not uncommon, while the Camelopardalis antiquorum Sw., or the northern giraffe, has recently been detected by Mr. Ruppel, whose elaborate observations have enabled us to characterise it as a distinct species from the giraffe of Southern Africa (C.australis Sw.). The lion of the ancients (Leo Africanus Sw.), in like manner, is a species peculiar to these regions.

(133.) The quadrupeds of Nubia, from the proximity of that kingdom to the more equinoctial latitudes, may be also comprehended in this division; yet they are more allied to those of Egypt than to the species of Southern Africa. Four sorts of antelopes are enumerated by Mr. Ruppel; who also describes four peculiar kinds of wild dogs, or rather foxes, as natives of the Kordofan deserts. These countries seem not to be inhabited by any of the quadrupeds of the western coast, while as many are common to Egypt and Abyssinia : it appears, on the whole, to belong more correctly to Northern Africa.

(134.) The ornithological peculiarities of tropical Africa are very striking, when compared with those of the northern parts. The birds are not only more numerous, and more beautiful, but exhibit many remarkable and peculiar genera, particularly among the perching tribes. The rapacious birds do not appear so numerous as under the corresponding latitudes of America. Vultures seem to be rare; since, in all probability, the removal of putrid matter is more expeditiously performed by the hyænas. On the coast of Guinea, there is a noble bird, 


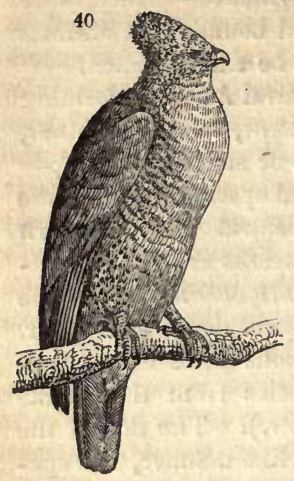

of the falcon race, called the African crowned eagle (Aquila coronatus, fig. 40.), and which would seem to typify the Aquila destructor of tropical America, as the Senegal fishing eagle represents our Osprey. Five other falcons, peculiar to that colony have but recently been described; a proof how little we are acquainted with the ornithology of Western Africa. This region is further characterised as the chief metropolis of the richly coloured bush-shrikes (Malaconotus Sw.); the species called the Barbary, the olive, the black-collared, and several others, being sent from Senegal in considerable numbers; while from the same locality we derive the genus Prionops, or ground-shrike; it is the only example yet discovered of this peculiar form, and it represents the American bristle-heads (Dasycephala Sw.): unlike all other shrikes, it seeks its food upon the ground.

(135.) Among the perching order of birds, there are numerous other intertropical families, or rather genera, entirely unknown in Northern Africa. The Drongo shrikes (Edolius Cuv.) are not uncommon towards Sierra Leone, where also the caterpillar-catchers (Ceblepyris Cuv.), and more particularly the bristlenecked thrushes of the genus Brachypus Sw., have been discovered. We here find the beautiful sun-bird (Cinnuris Cuv.), representing, under the same degrees of 1 se, the humming-birds of America. Three birds 0 . reat beauty - the Senegal, the long-tailed, and the sh ybeate sun-birds - are particularly common; while several others, scarcely inferior in brilliancy of plumage, have been received from the western coast. The richly coloured rollers of these countries have no 
representatives in tropical America; but those with a short bill (Collaris Cuv.) have likewise been found in New Holland. In the elegant family of bee-eaters (Merops), Western Africa is peculiarly rich ; more than two thirds of the species already known having come from thence. But the glory of Western Africa is the magnificent plantain_eater (Musophaga violacea), nearly the size of a crow, with wings of the most lovely crimson, glossed with purple. This rare bird seems only to have been met with in the interior of Guinea. Three or four, others, belonging to the same natural family, are exclusive natives of these regions.

(136.) The gallinaceous order of birds, so numerous towards the equinoctial line in India, and even in America, are found but sparingly on the African continent. The ostrich is well known to be the largest; and probably should be ranked with the giraffe, as more characteristic of Central Africa, as it lives only in the deserts, or on sandy plains. It has not been detected on the western coast, where the largest birds of this order are the Guinea fowls : the most common of these species, long domesticated in Europe, is well known : these birds, in a state of nature, associate in flocks of two or three hundred, and chiefly frequent the marshes and morasses which stretch along the banks of the western rivers. Most of the partridges are small; and many belong more correctly to the genus Pterocles, or the sand-grouse.

(137.) The only birds common to the whole extent of the African continent, and whose migrations are even extended to the middle of Europe, are the European bee-eater, the golden oriole, the common roller, and the European roller. To enumerate the peculiar species, however, which may characterise cyttis? countries, would far exceed our limits. It is su poient that any particular geographic range is found $\left[\omega^{\circ}\right.$, contain peculiar genera or forms of animals, by which it may be recognised, and by which it is stamped with a tangible character. The goatsuckers are well 


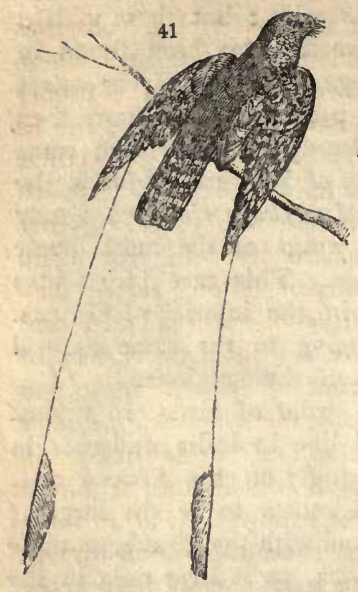

known to be dispersed over nearly every country ; but an extraordinary species, the long_shafted goatsucker (Macrodipteryx Africanus Sw., fig. 41.), may be named as one of the most curious birds of Western Africa : it is not bigger than a thrush; but from each wing projects a feather nearly twenty inches in length, with the shaft naked except at the tip : it has hitherto been found only at Sierra Leone.

(138.) The rivers and coasts abound with fish, beautiful in their colours, and nutritious as food; while the swarms of alligators, and the different snakes and reptiles, need not be dwelt upon. Many of the serpents, however, are not only harmless, but highly beneficial. Mr. Smeathman, who lived many years on these coasts, observes that the snakes get into the thatch of the houses in pursuit of the rats and cockroaches; the former being very harmless, and the two latter particularly destructive. The patient negroes are not without consolation amidst this heterogeneous crowd of inmates. They see the spiders always upon the watch for wasps and cockroaches; the lizards, again, attack the spiders; and these latter not unfrequently fall a prey to the fowls, as the rats do to the snakes.

(139.) On the entomology we may observe, that the notes of Mr. Smeathman convey such a lively picture of African zoology, that we shall repeat it nearly in his own words, particularly as they are contained in the preface to a work*, where they are not likely to be

- Drury's Exotic Insects, 9 vols. sta. 
sought for. "The whole of tropical Africa," observes Mr. Smeathman, " is one immense forest, except where the sandy plains are too unsettled to afford a proper footing for vegetation. Whenever a plantation is to be made, the trees are cut down and burned to fertilise the ground (a practice common throughout South America). The people never sow two years together on the same spot; but suffer the trees to grow again for two or three years by way of fallow, before they get another crop. It is these spots (called recent plantations) which afford such an amazing variety of insects; yet so rapid is vegetation, that in the second and third year these cleared lands become impassable to human feet." There are several edible insects in these countries, which supply a wholesome, if not a delicious, food. The larvæ, or caterpillars, of all those beetles which feed upon decayed wood, Mr. Smeathman affirms to be rich and delicate eating; so that every forest affords the traveller plenty of wholesome nourishment, did he but know where to seek it. Of this kind are the Termites, or white ants; and even the locusts, in general, are not only wholesome, but palatable to many. The native children, at the proper season, are always busily employed in digging out of the ground the females of a particular sort of cricket, which is then full of eggs, and so enclosed in a bag as to resemble part of the roe of a large fish ; these, when roasted, are considered delicate food. The great number of locusts and cicadas is particularly remarkable; but in the sandy plains, thinly covered with grass, they appear altogether innumerable, and their chirping is almost deafening. In such situations they are seen of various kinds, sizes, and colours, skipping or flitting about in all directions, at every step of the traveller.* While upon this subject, we may observe, generally, that those prodigious numbers of locusts mentioned in history, which have astonished and afflicter! mankind at remote intervals, have principally taken flight from this 
continent; where the hot, dry, sandy plains, so congenial to the habits of these insects, occupy such a large portion of the surface. Similar deserts occur in Asia, from whence have issued forth armies of locusts nearly as formidable.

(140.) The myriads of ants, which swarm in Western Africa, no less than in tropical America, can scarcely be conceived by those who have never visited these countries. " "Those of Africa," Mr. Smeathman continues, "are of numerous species, but all seem intent on removing from the face of nature every animal or vegetable substance no longer necessary or useful. Like the destroying angel, they walk steadily forward in the path ordained them, sparing neither magnitude nor beauty, neither the living nor the dead. One species, which seems at times to have no fixed habitation, ranges about in vast armies. By being furnished with very strong jaws, they can attack whatever animal impedes their progress ; and there is no escape but by inmediate flight, or instant retreat to the water." The inhabitants of the negro villages, as Mr. Smeathman assures us he has himself witnessed, are frequently obliged to abandon their dwellings, taking with them their children, \&c., and wait until the auts have passed. Besides these auts, nearly twenty other species are known, of different sizes and colours, each possessing peculiar habits. Some attack the collections of the botanist; and, in spite of weights laid upon his books of dried plants, get in, cut the leaves and flowers to pieces, and carry them away. Others attack all sorts of victuals. Mr. Smeathman has had four large sugar dishes emptied in one night, whenever the least opening has been left or made. Some assail the sideboard, and cover every glass that has had wine or punch left in it. Nay, innumerable multitudes frequently ascend the table, and drown themselves in the very bowls and vessels before you." * To this animated entomological picture we attach the most implicit confidence, inasmuch as, had

- Pref. to Drury's Inseets, vol. iii. 
Mr. Smeathman, in describing the ravages of the ants of Western Africa, written his account for those of tropical America, he could not have more accurately or mure forcibly depicted their habits. This observation, however, cannot apply to the wandering species he first describes, since, although there is one particular ant in Brazil of a gigantic size, its habits are altogether solitary ; at least, we never found it other wise than singly, wandering about sandy plains.

(141.) The nests of the white ants - peculiar, apparently, to Senegal and this part of Africa-form a

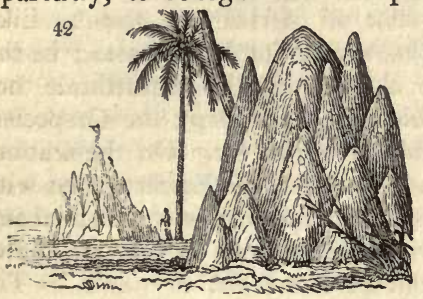
singular feature in its scenery: they rise up from the plains in the shape of sugar-loaves (fig. 42.), but of such a height as to appear like the villages of the natives; and are so firmly constructed, that they bear, with ease, the weight of three or four men. Other races (like some in South America) build their nests on trees, of an oval form; while those of another species ( $T \cdot a r d a$ ) are cylindrical, nearly three feet high, the top terminated by a round vaulted dome, and surrounded by a prominent terrace, - the whole not unlike the shape of a young mushroom.

(142.) Without entering farther into the details of African entomology, it will be sufficient to observe, that nearly all the species, and many of the genera, are totally unknown in such parts of the continent as border upon Asia or the Mediterranean; while not even one may be safely affirmed to inhabit the opposite coast of America. The scorpions and other noxious insects are of a terrific size, and of a most poisonous nature. The natives appear to prize, and even domesticate, the land crabs, which they keep in fenced yards, as we take care of fowls.

(143.) On the Mollusca, or shell-fish, we have been furnished with some valuable information by

A. 3 


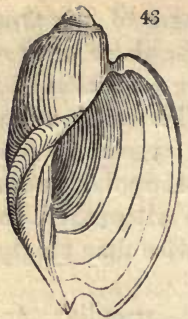

Adanson, who minutely examined and described those of the coast round Senegal. The typical volutes, as Voluta cymbium, proboscidalis, porcina, Olla (fig. 43.), \&c., appear to be particularly plentiful, and lead us to consider equinoctial Africa as the metropolis of this group, as India is of the cowries (Cypraa L.): both these genera, in fact, are closely allied in affinity; and both are predacious, - feeding solely upon other shell-fish. From the western coasts of Africa we also receive many other shells, unknown in the Asiatic seas; such, for instance, as the elegant little Marginellas: the Harpa sanguinea, or blood-spotted harp; the Carduum costatum, or sharp-ribbed cockle, \&c. On the whole, the conchology is richer than that of Eastern America, but cannot be compared with that of Asia; the genera, however, do not materially differ from such as are common to the Red Sea and Persian Gulf.

(144.) The largest land shells hitherto discovered are exclusive natives of these countries, and belong to the genus Achatina. There are several varieties, or rather species, mostly striped with dark brown on a lighter ground, as the Achatina marginata (fig. 44.) *, and ge-

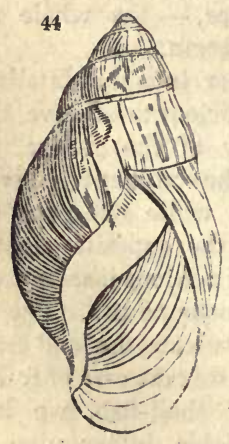
nerally tinged with a beautiful rose colour round their mouth. It is highly probable that the inhabiting animals, like the large slugs of Britain, are carnivorous; and they are themselves eaten by the natives, and considered nutritive and wholesome. Some of these snails are full eight inches long. The fluviatile species appear to be few, but this may originate from their not having been duly sought after. Some very large

* Swainson, Zool. Illust. i. pl. 30. 
tuberculated Melanice occur in the Gambia ; and others, allied to the genus Cerithium, are common in the saltwater marshes towards Sierra Leone; but we have no indication of those numerous fluviatile bivalves, so abundant in the rivers of tropical America.

(145.) The pearl oysters (Margarita Leach) are small, and do not appear worthy of commercial speculation; but the small Cyprcea moneta, or money cowry, is well known as a substitute for coin among the barbaric nations of Western Africa: we know not whether the species is precisely the same as the shell, called by this name, so abundant in the Indian seas.

(146.) Let us now pass to the third great division of African zoology, comprehending the remainder of the continent south of Angola. In no region of the globe does there appear so great a variety of quadrupeds, and of such large dimensions. The limits, however, of this zoological region are altogether obscure. We are still without much information on those animals of Southern Africa, which may inhabit the north-western sides of the Gariep; while the borders of the Great Fish River, forming the boundaries of the Cape Colony, have not yet been explored by the scientific naturalist. The interior deserts, indeed, have been jenetrated, to lat. $26^{\circ} \mathrm{S}$., by that accomplished traveller Burchell; and from him we learn, that the animals he observed in these inland regions do not materially differ from such as frequent the Great Karoos, or those deserts which terminate the northern extent of the colony. The chief seat, therefore, of South African zoology must lie towards that immense line of forests stretching along the coast from Bosjeveld to the banks of the Great Fish River. These forests, in all probability, extend to a vast distance beyond; forming, like those of tropical America, a gigantic belt of verdure between the arid deserts of the interior and the more fertile borders of the coast. We shall now briefly notice the most remarkable of eighty quadrupeds, described by naturalists as inhabiting Southern Africa. 
(147.) Among the ferocious or carnivorous species, the rare black-maned lion (Leo melaceps Sw.) is one of the most remarkable, being quite distinct from the common species, which is frequently met with. The serval (Felis Serva), and two smaller species of tigercats ( $F$. capensis and nigricans), are likewise peculiar: besides these, there are two, if not three, kinds of hyænas, differing from those of Northern Africa; while the hunting hyæna of Burchell (Hyana venatica Burch.) seems to extend its range through the centre of the continent. The polecats, and inferior animals of this tribe, are not numerous: the ratel, the zorilla, and three kinds of ichneumon, are among the best known; not to mention the common jackal ( $C$. aureus), and another (C. mesomalis), peculiar to the Cape. The existence of only two species of apes exemplifies the fact, that we have now nearly passed the limits of the monkey tribe : one of these is the pig-faced baboon (Cyanocephalus porcarius), the other the red-vented monkey (Cercocebus pygerythraus. The hares and other kindred families furnish us with many novelties.

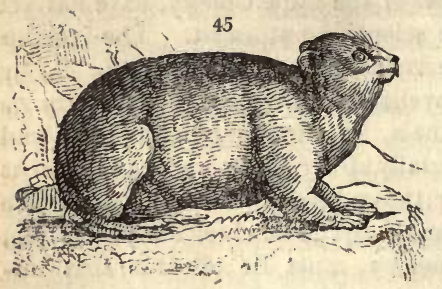

Of the genus Lepus there are three species - the African, the red-naped, and the rock hare; the latter (fig. 45.) living only in the most inacces. sible retreats. The jerboas of Northern and Central Africa give place to three little elegant kinds of dormouse (Myoxis); and the true American ant-eaters appear represented by that called the Cape ant_eater (Orycteropus Capensis). The largest quadrupeds belong, of course, to the herbivorous orders. The two-horned rhinoceros is well known as peculiar to Southern Africa; but it was reserved for Mr. Burchell to discover a second (Rh. sinusus Burch.), equally large, which very properly bears his name in common language. The African elephant is here by no means uncommon, and is imme- 
diately recognised by the superior size of its ears. When to these we add the hippopotamus, we comprehend the largest quadrupeds in the creation.

(148.) But the innumerable herds of antelopes constitute the chief peculiarity in South African zoology, and they appear occasionally in such vast herds that their numbers are almost incredible.

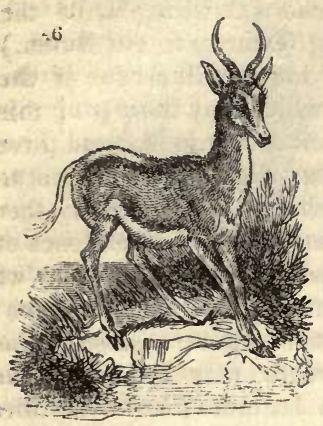
The springbok (Ant. Euchore, Forst., fig. 46.), in particular, often congregates in troops of between 2000 and 3000 ; the name of springing antelope has been given to them, from their habit of springing over bushes and rocks which im. pede their running; and this they often do to the height of four or five feet, clearing at a single bound ten or twelve feet of ground. The variety of species is no less remarkable; and naturalists already enumerate nearly thirty different sorts, from the size of a goat to that of a horse: the gradation, in fact, by which nature passes from the delicate and graceful springer, or blue antelope, to the heavy and unwieldy ox and buffalo, may almost be traced among the animals of Southern Africa alone. 'Several of these, no doubt, range over the uninterrupted line of sandy deserts bordering upon the equator, and, geographicaily, may be viewed as animals equally inhabiting the two more southern districts of African zoology; but by far the largest number have only been detected within, or on the borders of, the Cape Colony, and thus illustrate, in the most forcible manner, the peculiar distribution of animals beloriging to the southern extremity of this continent; while, on comparing these antelopes with the species of Northern Africa, not one has hitherto been found common to both regions.

(149.) The zebras, of which three species are now recognised, belong more to the plains of Southern Africa 
than to the central parts; while the domestic ass, which, in fact, is only an unstriped zebra, if it really exist in a wild state north of the equator, may represent, in those latitudes, its more elegant brethren.

(150.) The ornithology of the more southern latitudes does not exhibit those strong peculiarities which we have seen among the quadrupeds, the greater number of its genera being also found in Western Africa. It, nevertheless, offers some interesting features to our notice; since it is entirely destitute of large gallinaceous birds, excepting, indeed, the ostrich, which may more properly be considered a general inhabitant of interior Africa. The plantain-eaters(Musophaga), the bristle-necked thrushes, (Trichophorus), the ground-shrikes (Prionops), and some few other equinoctial forms, do not extend to the Cape territories; and in all probability, were we better acquainted with the birds of Western Africa, many others would be found restricted to those regions. On the other hand, some few genera may be named as limited to the more southern latitudes; such, for instance, as the Gypogeranus, or serpent-eater, - a bird whose whole conformation and habits are adapted for preying upon the reptiles of the deserts. The longtailed honey-sucker (Melliphaga Cafer Sw.) is confined to the most southern portion of Africa : this bird is the only instance of the genus Melliphaga being found beyond the Australian range; and it is a remarkable fact, that it should occur precisely in that part of Africa which is the nearest to New Holland.

(151.) Vultures and eagles are numerous, as might be expected in a country where quadrupeds, their natural food, are in such abundance. The vultures, however, prey only upon the remnants left by the lions and jackals, or by the native hunters. Several very large species, of both families, are mentioned by Le Vaillant; and nearly all are peculiar to this part of the continent. This is likewise the most southern point reached by the slender-billed vulture (Cathartes percnopterus), whose range extends through the whole continent, and is only terminated to the north by the mountains of Central Europe. 


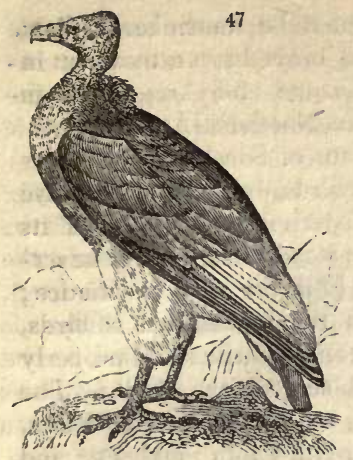

The occipital vulture $(V$. occipitalis Burch., fig. 47.), one of the most imposing species, is very rare, although it has been likewise observed in Nubia by $\mathrm{Mr}$. Ruppel. The Orican is a peculiar vulture, very remarkable from having its ears furnished externally with a pendulous wattle. The basha, or great crested eagle, reminds us of the American Aquila destructor: it is, however, sinaller; and has been likewise named as a native of India. Southern Africa, in short, presents us alone with nearly twice the number of vultures found throughout the whole continents of America or of Asia ; still fewer inhabit Europe; and it is supposed not one occurs in Australia.

(152.) On turning to the smaller rapacious birds, living upon the lesser animals and insects, we trace a singular mixture of local and European ornithology. The common European buzzard is figured by Le Vaillart, who also notices the great horned owl, the long-eared owl, and the scops, cr little owl, as all existing in Southern Africa. The most remarkable species of this part of Africa is the chou-cou of Le Vaillant, the Strix Africana of authors (fig.48.); for it comes nearer in its general form, and long tail, to the falcons, than even the hawk-owl of Hudson's Bay. On the other hand, we have received from the Cape of Good Hope the common barn owl of Europe; brighter, indeed, in its colours, yet, to all appearance, the same 
species as the British. It must be remembered, however, that all these nocturnal birds have a most exten sive range, not only over Europe and Asia, but some have been recently detected in Northern America, while several others are unknown out of South Africa.

(153.) The insectivorous birds, in their genera, differ not from those generally dispersed to the south of the line : one of the shrikes, the wood-chat, is precisely the saine as ours; but another (Lanius equinoctialis Sw.), confounded by authors with the red-backed shrike, is in reality distinct. The Drongo shrikes, called by the , Dutch colonists, from their black colour, Devil_birds, as we have already mentioned, are found also in Western Africa; other species occur in India; and one ( $E d$. australis Sw.) is peculiar to New Holland. The curious birds called caterpillar-catchers (Ceblepyrince Sw.), from their feeding almost entirely on those soft insects, occur very sparingly; since their chief metropolis is the opposite land of Australia : of this genus, no typical examples have yet reached us from Sierra Leone, but the kindred genus Phanicornis* appears to be their representatives towards the equinoctial line. The flycatchers of all these latitudes are not only of the same genera ; but some, as the Paradise, or long-tailed flycatcher, are of precisely the same species as those of India.

(154.) Many of the perching birds are of beautiful plumage and others are no less remarkable for their

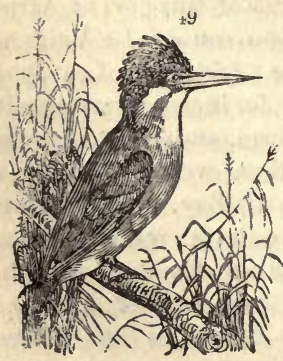
wonderful instinct. The crested kingfisher (Alcedo cristata L.) (fig.49.), is nearly the smallest, and certainly the most elegant, of its congeners. The South African sun-birds (Cinnyris Cuv.) rival those of India and of the Gambia in the brilliancy of their colours, while the more chaste but elegant green and silky plumage of the couracco (Corythaix Illig.) renders these

* Zool. Illustrations, ii. pl. 52. 
lovely birds the glory of African ornithology: nor must the honey-guides (Indicator) be omitted; those extraordinary guides to man in the discovery of the nests of the African bees. The numerous grosbeaks (Amadina Sw.) and weavers (Ploceus Cuv.) form a gay and interesting part of this order; the latter being chiefly found towards the equinoctial line, while the former appear more numerous in the Cape territories: both genera, however, extend to India ; and there is a beautiful species of Amadina in New Holland. The republican grosbeak, famous for its social habits in living and building in large communities, belongs also to this genus. On the water birds our information is very defective; but we do not, at this moment, recollect any genus which exclusively belongs to the southern coast.

(155.) Regarding the ichthyology, the following observation of Mr. Burchell is peculiarly valuable, since it indicates a marked difference in the distribution of certain fresh water species. "Eels," observes this scientific traveller, "are only found in those rivers which lie eastward of the Cape, while the Gariep silurus (S. Gariepinus, fig. 50.) is equally restricted to those on the

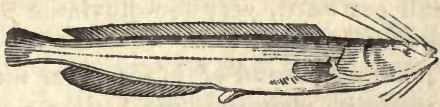

western side." This department of zoology, however, has been so totally neglected, that reither on this or any other occasion can we collect any thing satisfactory on the natural distribution of the groups. The reptiles of Southern.Africa are, if possible, still more imperfectly known than the fish.

(156.) The insects of the virgin forests towards Algoa Bay, and no doubt through the whole extent of that coast, are stated to be in great variety. They yield, however, both in number and beauty, to those of Western Africa; and few species among the Lepidoptera 
are common to both. The more sandy plains of the interior furnish but few butterflies, yet present us with many carnivorous beetles of a large size, particularly the genus Manticora of Oliver. The terrestrial Neuroptera, including the locust tribe, are every where abundant; while the widely spread European Eurymus edusa Sw.

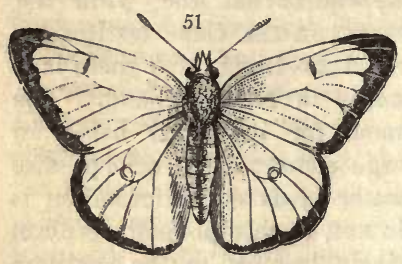

(fig. 51.) is found at the Cape: but, in general, the forms, and a few of the species, coincide more with those of Asia than of Europe or America.

(157.) The testaceous Mollusca, or shells, have no particular interest; the continual agitation of the sea, and the nature of the coast, appearing unfavourable to the propagation, or, at least; to the great increase, of these animals. The wrinkled ear-shell ( $\mathrm{Ha}$ liotis Mida L.), with limpets of a very large size, are common on the rocks of False Bay; while the Cypraa Algoensis Gray is a very local species. The great Achatina Zebra is the largest land shell of this part of Africa: but notwithstanding the numerous rivers to the westward and eastward, very few fluviatile shells have yet been sent to England.

(158.) The great island of Madagascar may here be noticed, as, from its vicinity to the African continent, its productions might be supposed in some degree similar: yet this is not strictly the case. The zoology of this noble island possesses many very peculiar features, and differs more from that of Southern Africa than the latter does from the equinoctial countries. It is difficult to say, in short, under which of the three great zoological provinces in this hemisphere Madagascar should be included; since, although its geographic po. sition places it nearest to Africa, its zoology is much more akin to that of the Asiatic islands, or even to New Holland; at least, such is the inference that may 
be drawn from the very imperfect information we yet possess regarding its productions. It is generally asserted, that not one of the large African quadrupeds, such as the lion, elephant, hyæna, \&c., have been found in Madagascar : and, further, that the country is without apes or monkeys of any sort; these being represented by the family of lemurs, of which no less than seventeen species have already been discovered. These curious monkey-like animals are almost unknown in Africa ; nor have they been discovered in New Holland; yet it is singular that two, if not three, species inhabit Ceylon, and such islands as lie nearest, in that direction, to the northern extremity of Madagasca: The dispersion of the Galago lemurs, however, forming the genus Otolic$n u s$, is divided between this island and Western Africa ; three out of the five being natives of Guinea and Senegal, while two other species are peculiar to Madagascar. Another point of connection with the Indian islands is presented by the genus Tarsius, of which two species inhabit Amboyna and Borneo; the third, together with that singular animal the Aye-aye (Cheiromys Cuv.), being characteristic of this country. It is, nevertheless, highly probable that the zoology of this island assumes, at present, a more peculiarly isolated character than it may really possess. We are, as yet, entirely unacquainted with the animals of that immense line of coast occupying the eastern shores of Africa ; and it is, therefore, quite impossible to say what may be the zoological character or peculiarities of countries so remote from those of the Cape, and still more from the western coast. So far, indeed, as we can at present judge, the chief seat of South African zoology appears to lie at the southern extremity of the continent; but this, after all, is very questionable; since, until we are better informed on the productions of those countries lying nearest to Madagascar, the assumption is altogether gratuitous. It deserves also to be remembered, that we have not found any very striking difference between the ornithology of the Cape terri- 
tories and that of Western Africa; whereas the little we yet know of the birds of Madagascar leads us to suspect, that as great a difference may exist between them and the birds of the Cape, as there is between the quadrupeds of those two countries. To illustrate this idea, we need only turn to the family of shrikes, where we shall find two or three distinct genera (not, indeed, yet characterised as such), which are only known to inhabit Madagascar. Again, we may instance that most extraordinary and extinct bird the Dodo (the rasorial type

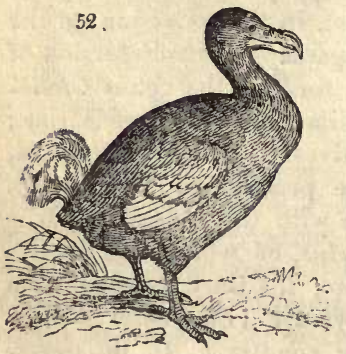
of the vulture family). fig. 52 . as certainly belonging to the zoology of these regions, although it has only been recorded by the early voyagers as a native of the adjacent group of islands. Let the naturalist but glance his eye on the map, and he will then see how incompetent we now are to form any correct ideas on the zoology of these regions, unknown as they are to the geographer, and unexplored, even in the most superficial manner, by the scientific naturalist.

(159.) The Isle of France is as remarkable for its profusion, as the Cape is for its paucity, of shells. The olives, the cowries, and the harps, are larger and more splendid than even those of the Indian seas.

(160.) The African quadrupeds, or those more especially characteristic of this province, have been arranged, by modern systematisis, under the following genera and sub-genera; some groups (I.) exterd to Asiatic India, while others (M.) are confined to Madagascar.

Apes and Monkeys.

Troglodytes Geoff.

Colobus Ill.
Cercolvithecus III.

Circocebus Geoff: (1.)

Cyanocephalus Briss. (i.)

Papio Cun. (1.) 
Lemurs.

Lichanotus IIL. (M.)

Lemur Ill. (M.)

Otolicnus IIl.

\section{Bats.}

Pteropus Briss. (I. M.)

Nycteris Geoff:

Rhinolophus Geoff.

Taphozous Geaff:

Chrysochloris.

Centenes $\mathrm{Il}$. (M.)

Macroscelides $\mathrm{Sm}$.

Ratellus Cuv. (I.)

Mangusta Cuv. (I.)

Ryzæna Itl.

Proteles Is, Geaff.

Hyæna Auct.

Otaria Peron.

Arvicola Auct. (I.)

Myoxus.

Dipus.
Bathyurgus $I l l$.

Pedetes.

Orycteropus.

Manis $L$. (I.)

Phascochærus.

Hyrax.

Cheiromys Cuv. (м.)

\section{Antelopes}

Aigocerus Ham. Smith.

Oryx Ham. Smith.

Gasella Ham. Smith. (I.)

Antelope Ham, Smith. (I.)

Redunca Ham. Smith.

Tragulus Ham. Smith.

Cephalophus Ham. Smith.

Neotragus Ham. Smith.

Tragelaphus Ham. Smith.

Capra Antiq.

Ovis Antiq.

Damalis Ham. Smith.

Catoblepas Ham. Smith.

Bos Antiq.

(161.) The ornithological genera and sub-genera of which Africa appears to be the chief seat, or at least within their geographic range, are as follows. A few of these extend to India (I.), Europe (E.), and Australia (A.).

Halcyon Sw. Crabeater. (I. A.) Muscipeta Cuv. Flycatcher. (I. A.) Edolius Cuv. Drongo. (I. A.) Trichophorus Tem. Hairneck. Malaconotus Sw. Bush Shrike. Prionops Vieil. Ground Shrike. Ceblepyris Cuv. Caterpillar-catcher. (A.)

Drymoica $S v$. Warbler.

Macronyx Sw. Lark.

Certhilauda Sw. Creeper.lark.

Brachonyx Sw. Short-claw.

Ploceus Cuv. Weaver.

Euplectes $S w$. Silk-weaver.

Vidua Cuv. Widow-bird.

Amadina $S w$. Bengaly. (1. A.)

Estrelda Sw. Finch. (I. A.)

Dilophus Vieil. Starling.

Lainprotornis Tem. Grakle. (I.)

Buphaga L. Beefeater.
Colius $L$. Coly.

Pogonias Ill. Toothbill.

Bucco L. Barbut. (I.)

Geocolaptes Burch. Ground Woodpecker.

Leptosomus Vieil.

Indicator Vieil. Honey Guide

Centropus IIl. Lark Cuckoo. (I.)

Corythaix IIl. Touracco.

Musophaga Isa. Plantain-eater.

Buceros L. Hornbill. (I.)

Cinnyris Cuv. Sunbird. (t.)

Promerops Briss. Hoopoe.

Vinago Cuv. Pigeon. (I.)

Numida $L$. Crane.

Ortygis IIL. Quail. (t.)

Struthio $L$. Ostrich.

Anastomus $1 l l$. Openbill. (I.)

Ibis Antiq. Ibis. (I.) 


\section{CHAP. VI.}

\section{ON THE AUSTRALIAN PROVINCE.}

ITS CONNFCTION WITH THAT OF ASIA. - DISTINGUISHING FEATURES. - QUADRUPEDS. - BIRDS. - ITS THREE CHIEF DIVISIONS - NEW GUINEA, NEW HOLLAND, AND THE PACIFIC ISLANDS. - GENERA OF QUADRUPEDS AND BIRDS BELONGING THERETO.

(162.) The extent and limits of the last zoological province have been already intimated. In naming this the Australian, we not only include the vast island of New Holland, and those immediately adjoining, as New Guinea, New Zealand, and Van Diemen's Land, but likewise the whole of the oceanic clusters forming the Polynesian division of some geographers. Our first object will be, to show in what manner this extensive zoological range is connected with others; our next will be, to detail its most striking peculiarities, or those prominent features presented in its animal forms, by which it is manifestly separated from all those we have already illustrated.

(163.) The first indication of Australian zoology appears to take place in some of the Asiatic islands, to the north-west of New Guinea ; for it is there that the Melliphagous family, or honey-sucking birds, appear under the forms of the genera Diceum and Arachnotheres; both of which occur in Java. Unfortunately, we cannot trace the progressive developement of this change, since the animals of Timor and the string of smaller islands intervening between Java and New Guinea have not been sufficiently investigated. It is, however, worthy of remark, that, among the few quadrupeds of Timor discovered by the French voyagers, there is not one of a large size; so that this island may be supposed to lie 
beyond the geographic limits of the monkey tribe. The same paucity of quadrupeds has been remarked in New Guinea ; for although no correct inferences can be drawn from the partial gleanings yet made on the coast, yet, if the interior was inhabited by quadrupeds of any size, it is natural to suppose they would have been mentioned, or alluded to, by the natives, in some way or other : but neither rumour nor tradition assigns any remarkable quadrupeds to New Guinea; while the largest, mentioned in the recent French discoveries, is a peculiar sort of pig. So far, therefore, we observe a strong indication of the chief peculiarity in Australian zoology ; namely, the total absence of large quadrupeds: so that to place New Guinea in the same zoological group with Sumatra and Java, - two islands abounding in apes, elephants, and all the large ferine inhabitants of India, - would be manifestly erroneous. We shall subsequently illustrate this disposition by proofs drawn from the ornithology of these islands.

(164.) That the southern extremity of Africa contains some animals approximating to those of New Holland has been already mentioned; and this approximation is the more remarkable, since the distance between the two nearest points of these continents is very great. In what manner the Australian fauna may disappear through the islands of the Pacific Ocean, we have no present means of judging. Whether, therefore, it unites again with the European, or, what is more probable, with the American range, by means of the small islands approximating to California, are questions for future naturalists to determine.

(165.) The most distinguishing peculiarities of the Australian province are now to be considered. The greatest, undoubtedly, is the total absence of large quadrupeds, and the paucity of the smaller: these latter, also, are so remarkable in their structure, as to appear almost anomalous. Australia has been termed the land of contrarieties: as if nature, in creating the forms intended for this region, had departed altogether from those rules 
to which she had otherwise so universally adhered. That particular form, for instance, which, in other parts of the world, she has given to the smallest race of quadrupeds, - the rats and dormice, - she here bestows upon the kangaroos, the largest animals throughout the whole of Australia! Yet still the analogy, although unquestionable, is apparently reversed, and most artfully disguised ; for these wonderful creatures, instead of fabricating, like their representatives, warm and skilful nests, beneath the earth, for the protection of their young, are provided with a natural nest in the folds of their own skin. The marsupial pouch is expressly adapted to this purpose ; and within this warm maternal nest are the young protected until they can provide for themselves. The great kangaroo (Halmaturus gigan-

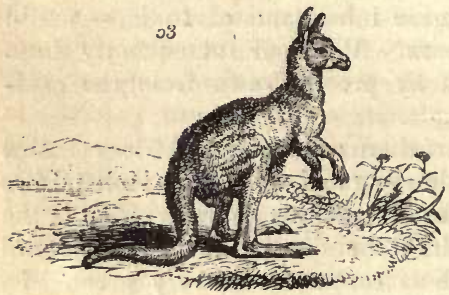
teus Ill., fig. 53.), is the largest quadruped of the Australian range; and although a few other marsupial animals oçcur beyond these limits, nearly all the quadrupeds of Australia belong to this tribe. Whether the kangaroos belong to the Linnæan order of Glires, or to another adjoining group, has not yet, indeed, been satisfactorily determined; but we feel persuaded, from analysis, that the celebrated Ornithorhynchus, peculiar to these regions, is the link of connection between quadrupeds and birds, and that this passage is effected, not by means of the Glires, but by the most aberrant groups of the ungulated quadrupeds. Two thirds of the Australian quadrupeds, in fact, are marsupial, and make their way with more rapidity by springing in the air than by walking. The kangaroos, when using any degree of speed, proceed by prodigious leaps; while the flying phalangers (G. Petaurista), of which six species are described, are even more remarkable for this habit 
than the flying squirrels of North America. We might, indeed, almost be tempted to believe, that if there really exists an animal even more bird-like than the ornithorhynchus, whose structure would indisputably connect the two principal divisions of the vertebrata, quadrupeds and birds, - such an animal might hereafter be discovered in the southern hemisphere.

(166.) The chief distinctions of this region, furnished by its ornithology, is in the vast proportion of its suctorial birds, or of such as derive their principal support from sucking the nectar of flowers. This peculiar organisation, restricted, in Africa, India, and America, to the smallest birds in creation, is here developed very generally, and is given to species fully as large as any of our thrushes. The melliphagous genera may probably be estimated to comprise nearly one fourth of the total number of New Holland perchers ; for not only does this character belong to the honey-suckers, properly so called (Meliphagida Sw.), but it seems to be possessed by a great number of the parrots. The whole of the little green lories (Trichoglossus H. and V.), are said to possess brush-like tongues, and to lick or suck their food, rather than to masticate it by their bills. Independent of these two geographic groups, there is a third, still more celebrated. The whole of the paradise birds (Paradisida Sw.), being natives of New Guinea, belong to this zoological province: these, also, although their economy is not very well known, contain certain species whose tongues have been described as formed upon a similar model. The Australian province being thus characterised, it is only necessary to notice such particular portions as exhibit local peculiarities; hence we may divide the whole region into three subordinate districts. The first may comprehend New Guinea and its adjacent islands ; the second, Australia, properly so called, with Van Diemen's Land, and New Zealand; and the third, the numerous groups of smaller islands clustered in the great Pacific Ocean. (167.) The first division, comprehending New GuiI 3 
nea, New Ireland, New Caledonia, and the little islands surrounding them, constitutes the remote and littleknown region of the paradise birds. None of these magnificent creatures have been actually detected beyond the shores of New Guinea, although it is generally believed that they annually migrate for a few months to the small islands adjoining. Notwithstanding the proximity of the Asiatic islands, they have not as yet furnished any species intimately related to the paradise hirds; yet in the New Holland genus Ptiloris, we have a bird so closely related to this family, that we know not whether, in fact, it does not belong to it. The flying phalangers of Australasia seem to be represented in New Guinea by the genus Cuscus of M. Lesson. The affinity between the zoology of the two countries is established in various ways. The great crab-eaters (Dacelo Leach), the bald-faced honey-suckers (Philedon Cuv.), the helmet-crows (Barrita Cuv.), and the Vanga shrikes (Vanga Tem.), are so many indications of Australian ornithology. The carinated flycatchers (Monarcha $\mathbf{H}$. and V.) again, no less than all the preceding groups, occur both in New Guinea and in New Holland, but are unknown in any other country. The splendid promerops (Epimachus Cuv.), the paradise birds, and the king oriole (Sericulus chrysocephalus Sw.) are peculiar to this first division.

(168.) The great island of New Holland, or rather Australia Proper, may be looked upon as the centre of Australian zoology, since the geographic range of its animals is circumscribed even more strictly than those of New Guinea. The kangaroos and the duckbills (Ornithorhynchus), for instance, are only found here and in Van Diemen's Land: the ground parrakeets (Pezoporus Ill.), the lyre-tail (Menura Sw.), the typical honeysuckers, the flat-tailed lories (Platycercus H. and V.), the superb warblers (Malurus Vieil.), and several others among the perching birds, might be instanced as purely Australian groups. The genus $\mathrm{Pa}$ chycephala Sw., or great-headed chatterers, are entirely 
confined to Australia, and of which the $\boldsymbol{P}$. gutturalis

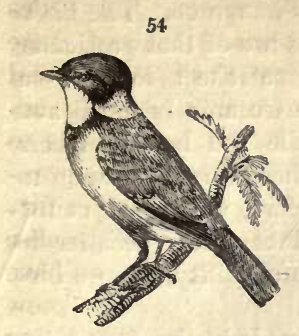

(fig. 54.), or black-crowned species, is the most beautiful: the body is yellow, the throat white, and the breast crossed by a black crescent. Yet, in other groups, we detect the distant ramifications which connect this province both with Africa and with Asia. The short-tailed and the long-tailed finches (Amadina and Estrelda Sw.), the Drongo shrikes (Edolius Cuv.), and the stonechats (Campicola Sw.), are groups belonging likewise to the two adjacent continents; while of the genus comprising the Oriental ant-thrushes (Pitta Tem.), two most lovely species have been found in New Holland: here, also, we find the Indian genus Ocypteryx, or the swallow shrikes, and the cassowary, representing the ostrich of Africa.

(169.) The conchology of New Ireland and New Holland is so similar, that one half of the species found by M. Lesson on the coasts of the former island are no less abundant in New South Wales; while a great proportion of the remainder occur in the Indian Ocean. On the coasts of New Holland are found many of the most

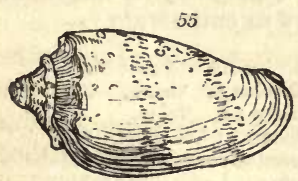
beautiful and rare volute shells known to our cabinets; the snow-spotted volute (Cymbiola nivosa $\mathrm{Sw}.)^{*}$ is one of the rarest $($ fig, 55.): it has two dark bands upon a flesh-coloured ground, and the surface is entirely covered with white dots.

(170.) The nature of the third division is but obscurely known, for the Pacific Islands have never been visited, since the voyages of the celebrated Banks, by scientific naturalists. The quadrupeds are so few that

* Exotic Conchology, plate 5. 
they hardly deserved notice; nor do any of the islands seem to possess a single species of kangaroo. The birds are little better known. The lories are of that particular section named Trichoglossus, or parrakeet lories, - a group 'dispersed over the whole Oceanic Islands, and abundant in New Holland; while the honey-suckers are but slight deviations from those forms common to Australia Proper. As yet, therefore, we cannot name, among the land birds, any distinct genus peculiar to this division; although, in all probability, future discoveries may bring some to light.,

(171.) The paucity of quadrupeds in the Australian region will be further apparent from the following list of the genera and sub-genera, and the number of species described in each : -

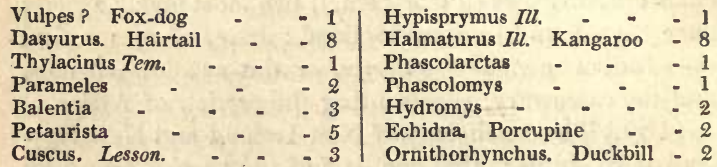

(172.) The greater part of the birds are comprised under the following genera and sub-genera, some of which (*) occur in Africa and ( $t$ ) Asia : there are examples also of other genera, more properly belonging to Europe, which it is not necessary to enumerate :-

Podargus Cuv. Hawk Goatsucker.

* Halcyon Sw. Crab-eater.

Dacelo Leach. Braying Bird.

*+ Merops $L$. Bee-eater.

Falcunculus Vieil. Shrike.

+Ocypterus Cuv. Swallow Shrike.

Vanga $B$. Shrike Crow.

*+Edolius Cuv. Drongo.

* Ceblepyres Cuv. Spinebacks.

* Estrelda $S w$. Grosbeak.

* Amadina Swo. Bengaly.

Malurus Vieil. Soft-tail.

Acanthiza $H$. and $V$. Warbler.

Pardalotus Vieil. Manakin.

Pachycephala Sw. Thickhead.

- Campicola Sw. Stonechat.

Grallina Vieil. Thrush.

+ Pitta Vieil. Short-tailed Thrush.
Sericulus Sw. Regent Bird.

* Oriolus L. Oriole.

Petroica Sw. Robin.

Ptilonorhynchus $K u h l$. Satinbird Glaucopis Forst. Wattle Bird. Scythrops Lath. Channel-bill. Plyctolopha Vieit. Cockatoo.

Calyptorhynchus $H$. and $V$. Cockatoo.

Psittacarus Birss. Parrakeet.

Nanodes $H$. and $V$. Ground Parrakeet.

Pezoporus Ill. Ground Parrakeet. Paleornis $H$. and $\boldsymbol{V}$. Ring Parrakeet.

Lorius Briss. Iory.

Trichoglossus $H$. and $\boldsymbol{\nu}$. Lory Parrakeet. 
Climasteris Tem. Creeper.

Orthonyx Tem. Straight-claw.

Sitella $S w$. Nuthatch.

Dicæum Cun. Honey-eater.

Melliphaga Lewin. Honey-sucker.

Ptiloris Sw. Rifle Bird.

Ptilinopus $S w$. Green Dove.
Dromiceius Vieil.

Menura Shaw. Menura.

Megapodius Tem. Greatfoot.

Chionis Forst. Sheath-bill.

Ceriopsis Lath. Helmet Goose.

Mycteria? Lin. Jabiru.

(173.) In concluding this part of our volume, we consider that the facts now stated are sufficiently strong to establish the propositions with which this investigation was commenced. We have seen, 1 . That animals are distributed upon a plan, sufficiently obvious in its leading outlines, to be comprehended and defined; and, 2. That this plan is found to harmonise, in many remarkable ways, with that circular disposition which is the first law of natural classification. 


\section{PART II.}

ON THE RISE AND PROGRESS OF SYSTEMATIC ZOOLOGY.

\section{CHAPTER I.}

PRELIMINARY OBSERVATIONS. - ALLEged DIfFERENCE BETWEEN SYSTEMS AND METHODS. - OBJECTIONS THERETO. DIVERSITY OF SYSTEMS. - NATURAL AND ARTIFICIAL SYSTEMS. - MIXED SYSTEMS. - REQUISITES OF A NATURAL SYSTEM.

(174.) THE arrangement of objects, according to a scale or table of their supposed relations or qualities, is called a system, a method, or a cLAssification. We shall consider these words as synonymous, and as implying ORDER, without which all knowledge is vague and disjointed. By system, therefore, we are able to gain not only a more ready acquaintance with an individual species, but also general ideas on the larger groups of which it forms but a part. System condenses and facilitates knowledge, and is therefore essential to its ac. quirement. Even if the names of all natural objects were arranged alphabetically, as in a dictionary, there would be system and order in such a plan, for research would be facilitated. Whereas, if all these names were entered indiscriminately, the student would be at a loss at what page to find the particular name for which he was searching.

(175.) Between a system and a method, many writers have drawn a distinction, and have used the two words in totally different senses. Kirby and Spence express themselves on this subject in the following words:- "Thus we hear of a natural method, and a natural system. Linné seems to have regarded the former of these terms as representing the actual disposition of objects in nature, while by system he understands their classification and 
arrangement by naturalists. But, if we consider their real meaning - a method should signify an artificial, and a system a natural arrangement of objects. As many systematists, however, have aimed at giving a natural arrangement, though with various success; and none having a perfect conception of it, it might, perhaps, be as well to call every arrangement whose object is confessedly artificial, a method; and that which aims at the plan of nature, a system." * The objection, however, to this attempt to distinguish systems from methods, is this, that arrangements, confessedly artificial, are sometimes much more natural (that is to say, containing more natural combinations) than those which are here denominated systems, while we are not without instances of others, professing to aim at the plan of nature, or " arranged according to organisation," which are eminently artificial. Such being the case, the dis. tinction here proposed, however excellent in theory, cannot be applied in practice, and we are thus compelled to use the two words as synonymous.

(176.) The diversity of systems, therefore, may be infinite, because there is no end to the different modes by which we may arrange natural objects, from characters or peculiarities belonging to the objects themselves. Some of these systems will exhibit much more harmonious combinations than others. Animals, obviously allied in habits and appearance, will be kept together in one system, while in another they are dissevered, and placed wide apart. Hence has originated the term of natural systems as applied to the former, and artificial systems as given to the latter. Such are the distinctions which most zoologists have made between these two modes of arrangement. Yet a little reflection will convince us that they are equally vague with that just noticed. An artificial system may be based upon erroneous principles, and may present many unnatural assemblages, yet parts thereof may be very natural; on the other hand, a natural system may contain many artificial * Int. to Ent. v. 356 . 
groups (that is to say, groups which the judgment immediately pronounces as not to be those of nature), while, in other respects, it may preserve the natural series. If, therefore, we were to rest content with this difference between a natural and an artificial system, we should have a difference without a distinction; both might be called natural, and both artificial; the difference would only be in degree; and that degree would rest upon individual opinion, becanse, where there are no fixed principles by which the judgment in such matters is to be regulated, there could be no unanimity of opinion. Besides, it would inevitably follow, that our application of these terms to any given system would be subject to change. A system, which we would term natural in one state of the science, would be artificial in another; so soon as it was supplanted by more recent discoveries, and a more harmonious combination of objects. We must search, therefore, for a clearer definition of these two modes of arrangement.

(177.) Much metaphysical discussion has arisen on the difference between natural and artificial systems, which has left the subject pretty nearly in the same undecided state, while some of these discussions have rather increased than dissipated the obscurity in which it has been involved. Some maintain, that, as all systems hitherto promulgated are more or less defective, and have failed to reconcile and explain all the intricacies of the natural series, therefore, they argue, all systems are, and must be, artificial. Mr. MacLeay, in his controversy with Mr. Bicheno * on systems and methods, evidently embraces this view of the subject, and his opinion has been more recently taken up by one of his disciples. He asks : " Pray let me know where I shall find one of these natural systems, and I shall be content." Again: "Naturalists have been looking for one natural system, only one; and, confined as their aim is, they have not as yet been able to attain it?" + What 
are we to understand from this question and remark, but that, in the estimation of our author, his own system, although unquestionably nearest to nature than any other, is, like all others, artificial? According to this view, the natural system can never, by any possibility, be discovered: since, in the most perfect human exposition of the laws of creation, a " remnant of unknown things" will always remain, and the system will thus become artificial. Mr. Bicheno, on the other hand, contends, that " to establish differences is the end of the natural system;" obviously meaning, as it appears to us, that the chief object which the naturalist should keep in view, when prosecuting this search after the natural system, should be to trace and "establish those agreements" which, although unexplained, have, as his opponent truly observes, existed since the creation. The same writer remarks, that " division and separation is the end of the artificial system," or, in other words, is that object which the framer of such a system should keep in view, in order to facilitate the more ready discovery of the species. Now, both these definitions are unquestionably true. For, however objectionable the precise words may be in which they have been expressed, it is clear that our author understood that difference between an artificial and a natural system, which we shall presently investigate. We pass over the confused and unintelligible doctrines of other writers, one of whom maintains, " that in a natural genus, or system, there are artificial combinations ;"* thus denying that there is, in fact, any natural system, and maintaining the ridiculous inconsistency that what is natural may be at the same artificial!

(178.) What, then, is the difference between an artificial and a natural system? The first is, for the ready discrimination of the species; the latter, for the elucidation of those resemblances which such species bear to others, in all their varied and complex relations. The one stops,

* Philosophy of Zoology, vol. ii. p. 141. 
where the other begins. We make use of an artificial system to become.acquainted with the name of a species; and to learn all that has been written upon its peculiar structure. We turn to the natural system, to know the probable station of this species in the scale of being, the affinities it possesses to others, and the analogies by which it is related and represented. Hence the perfection of an artificial system, as we have frequently intimated, consists in the clearness and precision of its subdivisions, and the facilities which it affords to determine the name of the object we are in search of. In this respect, a good artificial system is to be judged by the same rules as those by which we should decide on the merits of a copious index to a voluminous publication, for the purposes of both are the same: both are equally useful, and the merit of both lies in clearly directing the reader to the precise point upon which he desires information. A good artificial system is, therefore, not only a useful, but even, in some respects, a valuable, invention, requiring much more skill than is generally supposed; and it is, perhaps, much more adapted for general use than any other. The most admirable classification of this sort ever invented, is that denominated the Sexual System of Plants, by Linnæus. Many natural assemblages are preserved, without any great violation of the principles on which he set out. This is always a great recommendation to an artificial system, yet it is by no means necessary to its formation. Natural affinities may be overlooked, wherever they interfere with precision of arrangement: the first are secondary, the latter primary. We open an artificial system to come to the knowledge of a matter of fact ; but if we wish to proceed farther, and to know how this fact bears upon other facts, we turn to the natural system. Such are the uses of the two methods of classification upon which we have been speaking, and such the theoretic distinctions by which they are separated. Between them, however, is a third sort of system, which, from combining artificial division with 
some regard to natural affinities, are generally termed Mixed Systems, or Half-artificial methods, while others (and generally among this number are the authors themselves) have pronounced them natural arrangements.

(179.) Of these mixed methods, or half-artificial systems, it has been said, that, "while they are at utter variance with natural affinities, they do not even answer the humble purposes of a catalogue." The severity of this censure has been objected to; but we must still think there is some truth in the remark. These mixed methods are, in fact, called the natural system, by those who have never considered in what the latter truly consișts. The Règne Animal, " distributed according to its organisation," is, perhaps, one of the most striking exemplifications of a semi-natural classification that has ever been published. By assuming that the series there exhibited is natural, it teaches the student to believe that nature, and not the author, places eagles next to whales, and opossums after seals; and this is termed an arrangement of animals "according to their organisation," in other words, according to their natural affinities. Linnæus, on the other hand, in his Systema Naturce, makes no such pretensions; the learned Swede contented himself with framing such an artificial system as would lead to an immediate knowledge of species, and thus to qualify those who came after him to speculate upon Nature's combinations. The consequence is, that his classification, as a whole, is much more comprehensible than that of Cuvier. Let but the genera of the Systema Natura be looked upon as families, and let their contents be arranged under artificial but definite sections, and no one would hesitate to give it the preference, for all practical purposes, over the erudite but cumbrous volumes of the Rène Animal, replete, as the latter unquestionably are, with a mass of new and invaluable materials for the real developement of that with which the learned author was totally unacquainted, - namely, the very first principles of the natural system. We must, therefore, conclude as we 
began, that as these mixed methods of classification do not set out with aiming at that which alone bestows value upon an artificial system, so they do not answer the humble purposes of a catalogue or index; we have, in fact, given an instance, from the most celebrated of their advocates, that they are at "utter variance with natural affinities." Of all systems, they are, consequently, the most objectionable. Having stated the theoretical distinction between an artificial and a natural system, and dwelt more especially on the merits which should be apparent in the former, we shall now proceed to investigate the essential requisites which must belong to the latter.

(180.) It is essential to a natural system that it be based on certain fundamental principles, which, so far as the laws of nature are known, are found to be general throughout all her productions; thus producing that uniformity of plan which every principle of sound reasoning convinces us must belong to the system of the creation. Every one sees that there is a scale in nature: that animals and plants, by the intervention of an infinity of intermediate forms, gradually blend into each other, and are finally so united that we know not where to draw the line of demarcation. This is an acknowledged truth, known for centuries; but whether this series was simple, or whether, in its progress, it branched off into other ramifications, and became complex, were questions which long engaged the attention of philosophers. 'The discoveries, however, of this century have at length set this question also at rest, and decided that the natural series is complex, forming in its progress certain deviations which resemble a series of circles.* It follows, therefore, that no system which represents the natural series as simple, whatever excellencies it may possess in other respects, can be founded on nature, since we now know that such is not the natural series.

(181.) A system can only claim to be natural when

* The circularity of natural groups has been already dwelt upon in our Preliminary Discourse, p. 207. 
it attempts to explain the analogies or resemblances between the individuals or divisions of one circular series, when they are compared with those of another series. It is evident that all natural objects possess two different sorts of relationship: one which is immediate, and another which is remote. The goatsucker and the swallow exemplify the first of these relations. These genera are intimately connected by structure, habits, and economy ; both fly nearly in the same manner, and both live upon insects, captured in the same way: but the goatsucker, besides this relation, has evidently another to the bats, - by flying at the same hour of the day, and by feeding in the same manner. The first relation is intimate - the latter remote. Hence arises the necessity, imposed upon all who wish to develope the natural system, of posséssing clear perceptions of these two sorts of relations; and of becoming well acquainted with the difference between affinity and analogy. ${ }^{*}$ The first is exemplified by the swallow and goatsucker; the latter by the goatsucker and the bat. Now, as these varied relations or resemblances are so universal throughout nature, that they have been perceived since science first dawned upon man, it is obvious that a writer who makes no effort to explain them, or to draw a just distinction between such as are immediate and such as are remote, neglects one of the most striking and wonderful peculiarities of the natural system. Nor is a bare mention of such relations the only notice which is required; for that carries with it no results : the accuracy of his series must depend upon being able to prove that all these resemblances follow each other in a uniform progression : because it has been repeatedly demonstrated that the contents of one circular group represent the contents of another circular group; and this principle of the natural system has been now so much developed, that not a doubt can remain of its prevalence throughout nature. Any system, therefore, which aims at being natural, must

* Preliminary Discourse on Nat. Hist. p. 182. id 
offer an explanation of these resemblances; and if the theory by which this is done can be reduced to one simple and universal law, we may feel assured that law forms part of the system of nature.

(182.) This brings us, thirdly, to the principle of variation, which has long since been pronounced an important characteristic of the natural system. The variety in nature appears infinite. If we only contemplate those beings which have passed under, our own examination, and which everywhere surround us, we cannot fail to be struck with that divine skill which could imagine and produce such an extraordinary diversity of forms under which living beings should exist. It is obvious, therefore, that these, as emanating from a divine Creator, must have been produced upon some one uniform plan. Hence it follows, that no system can be natural which does not aim at the partial developement of this plan, so far, indeed, as its comprehension is permitted to finite beings. The immense difficulties of attaining such an insight have in. duced many of the most profound philosophers to relinquish the search in despair, and have tempted others to pronounce it hopeless : but we are yet to learn the limits which have been assigned to the human understanding in matters of physical research; nor are there valid grounds for supposing that the discovery of those laws which regulate the variation of animals is unattainable, when those which regulate the motion of the heavenly bodies have been detected. It is not enough to tell us in what manner such and such animals vary from each other; for that is to communicate nothing more than a mere matter of fact: the question is, upon what general principle is this variation regulated? Why do we observe, for instance, that one peculiar division of every natural group is aquatic, and another furnished with long tails? * What is the principle, in short, of these variations? and how far is it applicable 
to all known animals? In proportion as we can demonstrate the extent of the theory by which we propose to answer these questions, so do we approach the developement of the natural system, and reduce the elements of science to their most simple definitions. Finally, it results from these considerations that a theory which embraces them all will exhibit a unity of plan which cannot possibly be the result of human ingenuity, and which will, consequently, be the nearest approach to that which must ever distinguish the natural system. Such are the obvious considerations by which we are to be guided in judging the merits of any classification which professes to be according to nature. In describing theoretically what should constitute the developement of the natural system, we have only alluded to those circumstances which have already been partially developed, or which have been admitted as highly probable by others, who have, nevertheless, declared their inability to reconcile them with observed facts.

(183.) Of natural systems, strictly speaking, there cannot, as we have already seen, be more than one; but it is equally clear, that, if we confine this title to that one only which makes the nearest approach to nature, and which gives the fullest explanation of the phenomena she exhibits, we must term all other systems artificial, and thus confound, under one name, two descriptions of arrangements, which are grounded on totally different principles. In order, therefore, to mark their distinction with still greater precision, we shall consider all those systems to be artificial which are not grounded on any universal principles of arrangement; which exhibit the animal series without plan or harmonious connection, - and which disregard analogies and affinities. On the other hand, we shall consider those as natural systems which involve any one or more of these considerations, and which, looking beyond the individual, attempt to ascertain its station in the scale of being, by pointing out the various relations which is respectively holds with other objects. From this view 
of the subject, it results that there are many natural systems, or rather, that there are many attempts to explain those complicated relations which belong to the natural series. We prefer, in this instance, a comprehensive definition to a metaphysical one; because, were we to adopt the latter, we should be compelled to consider the system of Mr. Mac Leay artificial, since many properties of natural groups have been since discovered, and several combinations detected, which were quite unknown when that system was given to the world.

\section{CHAP. II.}

IXPOSITION, WITH REMARKS ON THE PRINCIPAL ARTIFICIAL SYSTEMS. - ARISTOTLE, WILLUGHBY, LINNAUS, CUVIER. I PARTIAL SYSTEMS. - ILLIGER, VIEILLOT, TEMMINCK, IN ORNITHOLOGY. - DE GEER, LATREILLE, CLAIRVILLE, AND LEACH, IN ENTOMOLOGY. - ON BINARY, OR DICHOTOMOUS, SYSTEMS.

(184.) THE advantages and the disadvantages of artificial systems have been already touched upon (178.), and their use explained*; it remains, therefore, to give the reader a general idea of those systems which have been most celebrated, or most extensively adopted. As artificial systems are capable of endless diversity, so it would be impossible to enumerate, within reasonable limits, one half of those which have been already published; setting aside others, which a very slight acquaintance with nature will enable every student to invent. One advantage has certainly attended that deference and respect with which-particularly in this country - the writings of the great Swede have always been treated; for although an implicit deference to the

* Preliminary Discourse, c. iii. p. 188. 
Systema Naturce may have cramped the energies, and stifled the investigations, of those who might otherwise have struck out new paths of enquiry, this deference to Linnæus has prevented our shelves from being burdened, and our attention distracted, by the innumerable artificial systems which have inundated the Continent, and which, it is to be feared, will continue to impede the advance of true science, so long as such inventions are looked upon as authorities, or are quoted as synonymes.

(185.) The history and exposition of zoological systems must not be confounded with the history of the science, the latter exhibiting the progress of discovery, while the former is properly confined to the arrangement of these discoveries. We feel embarrassed, however, at the difficulty of selection: for, independently of those systems which embrace the whole animal kingdom, there are numerous others which relate only to particular classes, each of which (like those which have gone before, and have passed into oblivion) has, at this time, its admirers and its advocates. These also will "have their day," and endure for a season, until the natural classification shall be developed. M. Lesson has been at some pains to perpetuate the memory of no less than fourteen systems of ornithology, nearly all of which have been proposed by eminent naturalists, and he has added the projet of his own, written in 1828, which is, nevertheless, very different from another, which he published two years after. Every year, in short, increases the number of these systems; and in ornithology alone we could almost double the above number. Entomology has been a fruitful mother of systems; although, in conchology, few attempts have been made to set aside the classification of Lamarck. Were we, however, to venture upon a general specification of all these systems, we should weary the reader with interminable columns of names, and occupy space which might be more profitably filled. On the other hand, to omit all details on the systematic views of such men as Aristotle, Linnæus, Cuvier, Illiger, Latreille, and Lamarck, whose 
writings will always possess some authority, and whose opinions, if not followed, should always be consulted, would be an unpardonable omission. Without some acquaintance with the labours of these princes of the zoological world, no one can hope to extend the boundaries of science; nor will their reputation suffer by the occasional fallacy of their opinions ; for that defect, incident to all, is amply compensated by the vast accession of valuable facts which each has contributed to our science. These systems, however, with the exception of that of Lamarck, are artificial, inasmuch as they represent the scale of being as simple, and confound analogy with affinity.

(186.) We commence with the system of Aristotle, the great father of natural history, whose comprehensive views of nature first laid the foundation of all that has been done by his successors. That part of his celebrated work which treats of the vertebrated animals will be best understood by the following table, translated from that given in the Linnæan Transactions (vol. xvi. p. 24.), by one whose labours in the same field renders his name worthy of being associated with that of the renowned philosopher of Stagyra :- 
5. E

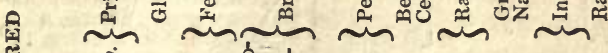

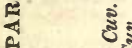<smiles>C1=C[Si][Ge]=C1</smiles>
నุ

仓

2

\%

당

몰

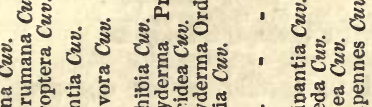
ని .
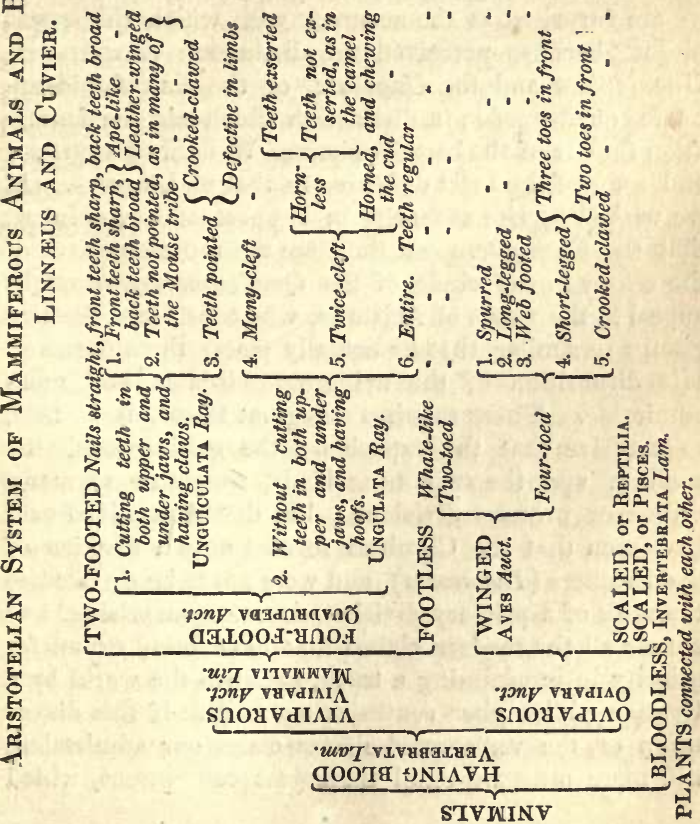
(187.) The system of Aristotle in regard to insects, or annulose animals, has been collected and digested by a commentator eminently qualified for such a task. It is as follows:-

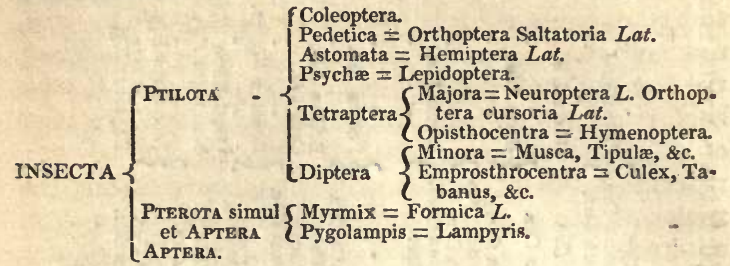

(188.) We shall now offer a few observations on these arrangements of the two most important divisions of the animal kingdom. On looking to the first table, we are surprised at the accuracy with which this great philosopher has perceived the distinction between the Unguiculata and the Ungulata, or the clawed and the hoofed quadrupeds; a distinction which laid the foundation for one of the best divisions of Willughby's system, and some of the most defective in that of Linnæus. If we wished to cite authority in support of our opinion, that the Cheiroptera, or Bats, are the representatives of the Glires in the circle of the Quadrumana, we might appeal to the views of Aristotle, who considered the two groups so similar, that he actually places them together. His disposition of the oviparous birds is still more admirable. There requires no great talent, it is true, to perceive that the rapacious, the gallinaceous, the wading, and the swimming birds, constitute so many orders or primary divisions; but that Aristotle should have seen that the Climbers formed only a division of the Perchers (Insessores), and were not to be elevated to the rank of a primary division, is most surprising, and annuls all the modern claims that have been set up for priority in proclaiming a truth, given to the world by a Grecian philosopher centuries ago. But if this disposition of the vertebrated classes claim our admiration, still more must we extol these just conceptions, which 
may be discerned in the general outlines of his entomological system. Every one of the orders, afterwards more correctly defined by Linnæus, were known to Aristotle, at a time when natural science may be said to have scarcely existed, when collections were perhaps unknown, and when the only materials which furnished the bases of such enlarged conceptions, were in all probability a few Grecian insects, from the scanty gleanings of a small kingdom. Mr. Kirby has not failed to remark, that this wonderful man " had no contemptible notion of the majority of the orders of insects as now admitted. His Coleoptera, Psychce, and Diptera are evidently such. His idea of the Hemiptera seems taken solely from the Cicada or Tetrix; but the manner in which he expresses himself concerning it, as having no mouth, but furnished instead with a linguiform organ, resembling the proboscis of the Diptera, proves that he regarded it as the type of a distinct group. Since he considers the saltatorious orthoptera as forming such a group, it is probable that he included the cursorious ones with the Neuroptera in his Majora section of Tetraptera; and the resemblance of many of the Mantidae to the Neuroptera is so great, that this mistake would not be wonderful." * We question, however; whether these views, entertained by Aristotle, will not eventually be found correct; the " mistakes" lying with those who have followed him. The Cicada, for instance, is one of the most common, and certainly the most noisy insect of Greece: it is not surprising, therefore, that our philosopher should have selected it as a sort of type for his Astomata (or Hemiptera L.), to which order, in our opinion, it truly belongs; the modern Homoptera, in the natural series, being but one of the primary divisions of the Hemiptera, as Linnæus long afterwards perceived. His division $T e-$ traptera is in one respect objectionable, although we are fully persuaded that, in a natural classification, the Neuroptera will be found to blend into the Hymenoptera; while the Orthoptera, considered by the moderns as a dis-

$$
\text { * Int, to Ent. vol, iv. p. 424. }
$$


tinct order, are, unquestionably, a part only of the Neuroptera. This will be apparent to any one who analyses and studies these groups in detail, and with the requisite degree of attention. It is clear, also, from the above table, that Aristotle perceived, theoretically, the two great divisions of Insecta, namely, the Ptilota, or winged group, and the Aptera, or wingless insects. It would, indeed, have been surprising, if, with the few dozen of insects which in all probability formed the scanty materials that guided his judgment, he had not greatly erred in the application of his theory: seeing that in almost every family group there are representations of the apterous classes: but this is a very minor consideration, and detracts nothing from his astonishing talent, in thus anticipating, in part, the discoveries of eighteen centuries. It must ever redound to the fame of Linnæus, that he followed so closely the footsteps of the Grecian sage; for his entomological system, above all others, comes nearest to that of Aristotle, and, in our estimation, nearest to that of Nature. Whether we are right in this opinion, time only will discover.

(189.) The zoological system of Willughby, as given by Ray, cannot be passed over in this place, although we are by no means disposed to unite in the high encomiums which have lately been bestowed upon it. In the classification of the Mammalia we trace nothing of primary importance which had escaped the penetration of Aristotle, unless it be the true character of the Glires, or mouse-like quadrupeds.* The arrangement of the birds, viewed in connection with the injudicious additions of Ray, is any thing but clear, definite, or natural ; while that of insects, as exhibited by Mr. Kirby t, and here presented to the reader, has no very high excellency. Both this and Swammerdam's are founded too exclusively upon metamorphoses; and by this unfortunate bias entomology made a retrograde movement. The primary groups of Aristotle were broken up, and the following artificial arrangement was the result: -

* Linn. Trans. vol, xvi. p. 25. 
SYSTEM OF WILLUGHBY AND RAY.

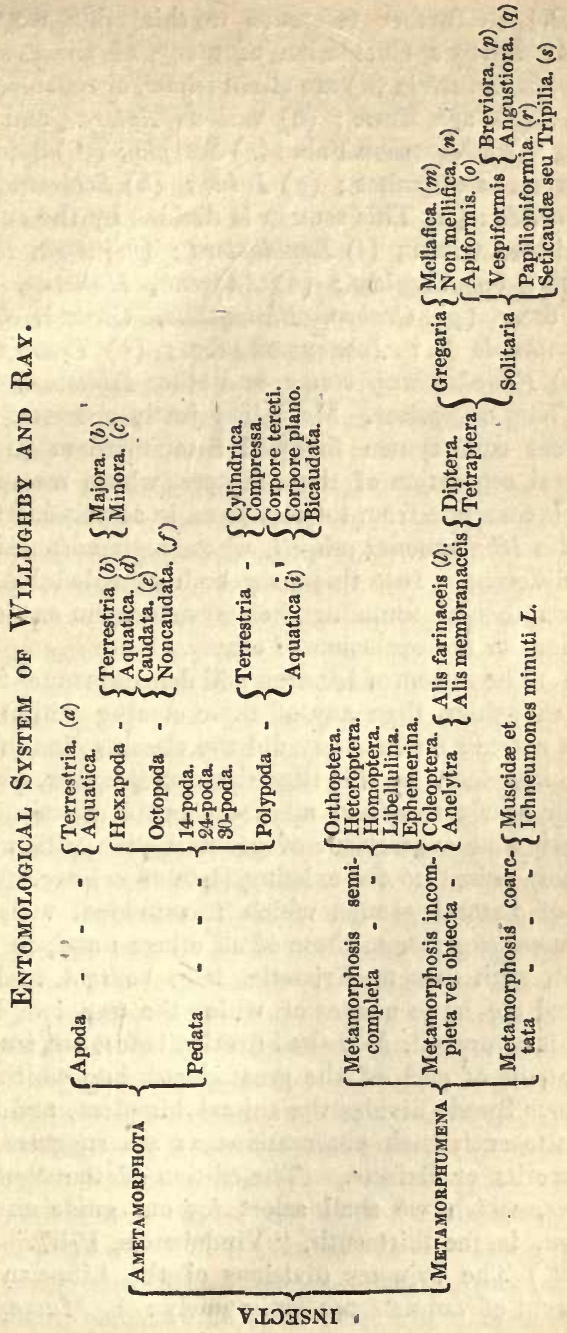


(190.) In further reference to this table, we may give Mr. Kirby's elucidation of many of the groups. The Apoda terrestria $(a)$ are all Annelida, or red-blooded worms; (b) are larvæ; (c) various Aptera, and the bed bug; (d) Nymphon Fab. ; $(e)$ Scorpio ; $(f)$ Spiders, phalangers, and mites ; $(g)$ Iulus; $(h)$ Scolopendra; (i) Annelida: ( $k$ ) This section is divided by the author into thirteen tribes; ( $l$ Lepidoptera; $(m)$ Apis, Bombus, \&c.; (n) Vespida; (o) Andrena, Halictus, Nomada, \&c.; ( $p$ ) Crabro, Philanthus, Cerceris, \&c.; (q) Tenthredo L.? Ichneumon, \&c.; (r) Trichoptera K. ; (s) Pimpla manifestator, and other Ichneumonida, with a long ovipositor. Mr. Kirby justly observes, that our great countrymen followed Swammerdam in the unnatural separation of those diptera whose metamorphosis is coarctate from the rest; and in associating with them the Ichneumones minuti, whose metamorphosis is really different. Into this error both were led by system, or rather by founding their system upon one consideration, to the exclusion of others.

(191.) The system of Linnæus will demand a much more ample exposition than any of those coming within our present notice; for not only did the classification of the animal kingdom, by this illustrious philosopher, supersede for nearly a century all others, but it developed a simplicity and a grandeur of generalisation which was admirably suited to the existing state of science. The views of natural groups which it unfolded, were, in most cases, superior to those of all others; and, in conjunction with that of Aristotle, may be said to have indicated the large masses of which the true temple of nature is composed. We shall first lay before our readers the contents of each of the great classes into which the illustrious Swede divides the animal kingdom, and then subjoin to each such observations as are suggested by their merits or defects. The edition of the Systema Natura, which we shall select for our guide on this occasion, is the thirteenth, "Vindobonae, 1767."

(192.) The primary divisions of the Linnæan arrangement of animals are six, namely: 1. Mammalia, 
or quadrupeds; 2. Aves, or birds; 3. Amphibia, or reptiles ; 4. Pisces, or fish ; 5. Insecta, or insects ; and 6. Vermes, or worms. These he distinguishes in the following manner :-

Cuv. M'Leay.

Heart with two auricles $\{$ Viviparous. Mammalia. Ib. Ib. and two ventricles; blood Oviparous. Iirds. Ib. Ib. warm, red

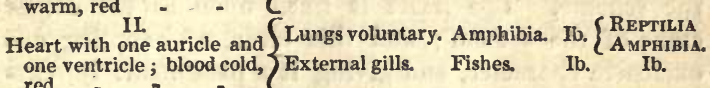

red - - - Furnished with

Heart with one auricle and $\left\{\begin{array}{l}\text { Furnished with } \\ \text { antennæ. } \\ \text { Furnished with }\end{array}\right\}$ Inseets. Ib.

Morlusca.
no ventricle; sanies cold, $\left\{\begin{array}{c}\text { Furnished with } \\ \text { antennæ with }\end{array}\right\}$ Worms.
Acrita.

1. white - $\left\{\begin{array}{l}\text { antennæ with } \\ \text { tentacula. }\end{array}\right\}$ Worms.

Radiata.

(193.) Considering the period when this scheme was drawn up, we must allow it the credit of being much more definite and practically useful than any of those which it supplanted: we allude more especially to the two latter divisions, in reference to the object which our author had in view, namely, the ready determination of the name of a species. The whole is confessedly an artificial system; and the author has obviously made the class Vermes a general receptacle for all those invertebrated animals which could not be classed with any other class. When, therefore, we express surprise that a genius like Linnæus could have brought together animals so totally different in their nervous system, their internal anatomy, and their external organisation, we must re-. member the remoteness of the period at which he wrote, the state of knowledge at the time, and the mistakes, equally glaring, which from the same causes his predecessors, even Aristotle himself, have equally committed. Besides, it must be confessed that the Linnæan Vermes, notwithstanding our increased knowledge of their truenature, have so many external points of general similitude, that we can feel no surprise at the whole being considered as one group: nor is it, in fact, at all improbable that they actually are so. For if, as there is good reason to suppose, reasoning analogically, the modern classes of Acrita, Mollusca, and Radiata form a circle of their own, then 
we shall comprehend, in a single group, nearly the whole of the Linnæan Vermes, the only exceptions being the aberrant or imperfectly organised Insecta; such as the Cirripedes, the intestinal worms, and the Annelides. But let us glance at the principles on which the whole animal kingdom is first divided into three primary groups ; for it is, perhaps, the most defective point in the scheme. The heart is fixed upon as the corner stone of the system; and this error, of adopting one exclusive character, and giving it a paramount importance over all others, contributed perhaps more than any thing else to blind our author, and prevent him from seizing the much more obvious and natural divisions of Vertebrata and Invertebrata as the groundwork of his system. Be this, however, as it may, a natural group will stand any test; and hence we find, that, although the true character of some of these orders were not perceived, they are for the most part truly natural. We shall now proceed to investigate each of these classes in detail.

(194.) The primary divisions and character of Mammalia are as follows :-

I. Primates. Fore teeth cutting, the upper four parallel, except in some species of bats, which have two or three tusks, solitary; that is, one on each side in each jaw; teats two, pectoral; of the feet, two are hands ; nails, usually flattened, oval : feed on fruits, except a few which use animal food.

II. Bruta. Fore teeth wanting; feet with strong hooflike nails; motion slow: mostly feed on masticated vegetables.

III. Feræ. Fore teeth conic, usually six in each jaw ; tusks longer, grinders with conic projections; feet with claws, which are subulate: feed on other animals.

IV. Grines. Two cutting fore teeth in each jaw; tusks none ; feet with claws, formed for running and leaping: feed on bark, vegetables, \&c., which they gnaw. 
V. Pecora. Fore teeth, the upper none, the lower cutting, many; feet hoofed, cloven : feed on herbs, which they pluck, and chew the cud; stomachs four.

VI. BELLULA. Fore teeth, obtuse ; feet, hoofed ; motion, heavy : feed on vegetables, which they pluck like the last.

VII. CETE. Fins instead of feet; tail horizontal, flattened; no claws or hair : feed upon marine animals ; inhabit the ocean.

(195.) The following table will explain how far these divisions correspond with those of M. Cuvier, and the arrangement pursued in this work:-

Linncean orders.

Primates.

Bruta.

Feræ.

Glires.

Pecora.

Bellux.

Cete.
Cuvier.

$\left\{\begin{array}{l}\text { Bimana. } \\ \text { Quadrumana. }\end{array}\right\}$ Pachydermata.

Carnivoræ.

Rodentia.

Ruminantia. Solipeda.

Cetacea.
Cab. Cyclop.

Quadrumana.

Ungulata.

Feræ.

Glires.

Ungulata.

Cetacea.

(196.) It has been well observed, that Linnæus, by some unaccountable oversight, broke up into distinct orders the group kept together by Aristotle, and better defined, perhaps, by Willughby, by the name of Ungulata: he lost sight, in fact, of the whole, in the contemplation of its parts ; for his Bruta, Pecora, and Bellua are only detached portions of the order Ungulata. This is proved, not only from theory, but from minute analysis. With this exception, the remaining orders of the Linnæan arrangement are strictly natural groups, taken with reference to their typical examples. But as the Primates, Ferce, Cete, and Glires had all been indicated by the philosopher of Stagyra, who had, moreover, the merit of preserving the Ungulata entire, a retrograde, rather than an advanced movement, had been made by the learned Swede. M. Cuvier did not fail to perceive this; and, with great propriety, followed Aristotle rather than 
Linnæus, in keeping the ungulated quadrupeds by themselves; though he also has erred in giving to their subdivisions a higher rank than they really possess. The genera characterised by Linnæus under these orders are as follows:-

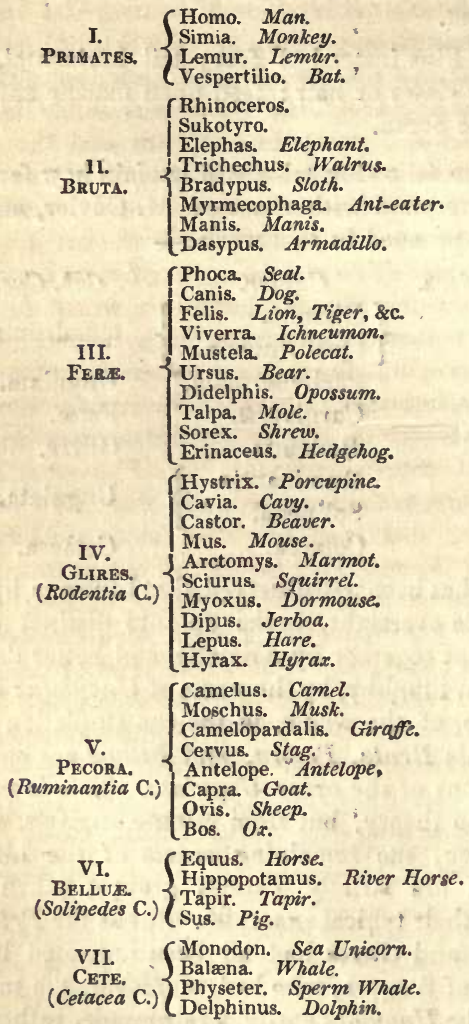

(197.) On glancing over this list, however objectionable are the orders, we perceive that the groups denomi- 
nated by Linnæus genera, are for the most part natural ; for they contain assemblages of animals which, in most cases, have been preserved in more recent systems, although under higher denominations, and split into minor divisions. It is clear, moreover, that this series was never intended to exhibit the progress of nature; but that our author aimed at accomplishing an easy artificial system, suited, in fact, to the then state of science. This is apparent by his placing the rhinoceros after the bat, and the sea-horse between the elephant and the sloth. These monstrous combinations all occur in the order Bruta; which is itself such a strange and inconsistent group, that we must even feel surprise that Linnæus could, for the sake of convenience, sacrifice to his object that keen perception of natural affinities which he most undoubtedly possessed in a very high degree. With this solitary exception, the internal contents of each order are natural assemblages; although the construction and situation of several of the orders themselves are defective, and of course artificial. The Primates, Ferce, Glires, and Cete, are almost precisely what they remain now, excepting that each has been more subdivided; but the Bruta, Pecora, and Belluce, as before intimated, are but parts of one order, the Ungulata, of Ray.

(198.) The ornithological system of Linnæus will now claim our attention. The whole class of birds he divides into six orders, the names of which are as follows. We consider it unnecessary to give the characters in detail, but the modern names are added to each:-

I. Accipitres. Birds of Prey.

1I. PICE.

III. ANSEres. Aquatic, or Swimming.

IV. Gralle. Wading Birds.

V. GALLINE.

VI. Passeres.
Cunier.

\section{Passeres.}

Insessores Vig.

Gallinaceous, or Fowls. GALLINL.

\{ Passeres Tasores $I l l$.

$\left\{\begin{array}{l}\text { Passeres. } \\ \text { Scansores. }\end{array}\right\}$ Insessores.

(199.) The first violation of natural order which the eye seizes upon in this table, is the division of the land or perching birds (Insessores) into two orders, placed 
wide apart, and the introduction of the aquatic orders into the gap: so that our author commenced in this class, as he had already done in the Mammalia, with making a retrograde movement in science, by attempting , to annul the previous arrangements of the great Aristotle. In this respect his system is certainly inferior to that of Willughby, which, however obscure and confused in other respects, preserved a clear distinction between the land and the water birds. Even the most devoted followers of the Systema Naturce - as Pennant, Latham, Shaw,\&c. - pretested against this violation of nature, and rejected it. As to the division of the perching birds into the two orders, of Pica and Passeres, we can only account for it by supposing that Linnæus thought the order itself, although natural, was too large for artificial arrangement : but in that case, one would have thought, he would have done as M. Cuvier afterwards did; that is, keep the perching birds in one order, and place the climbers in another: this would have been more easy of comprehension either in a natural or an artificial system. With the exception, however, of this oversight, the remaining of the Linnæan orders are similar to those long before understood by Aristotle; and, indeed, so obvious to every one, that it would have been surprising had they escaped notice.

(200.) The genera arranged under these orders will now be enumerated. Nothing, perhaps, will show more forcibly the admirable clearness and precision with which this extraordinary man perceived and defined the essential or most striking character of his groups, than the short synopsis by which each of these genera are characterised.

I. Accipitres. Birds of Prey. Upper mandible with an angular projection.

Vultur. Vultur. Bill hooked, naked.

Falco. Hawk. Bill hooked, covered at the base with a cere.

Strix. Owl. Bill hooked, with a frontlet of covered bristles.

Lanius. Shrike. Bill straightish, notched. 


\section{Pic E. Bill compressed, convex.}

A. Feet formed for perching.

Trochilus. Humming Bird. Bill bent down; tongue tubular,

Certhia. Creeper. Bill bent down, sharp pointed.

Upupa. Hoopoe. Bill bent down, somewhat obtuse.

Buphaga. Beef-eater. Bill straight, quadrangular.

Sitta. Nuthatch. Bill straight, wedged at the top.

Oriolus. Oriole. Bill straight, conic, very sharp pointed.

Coracias. Roller. Bill sharp edged, the points bent dowr.

Gracula. Grakle. Bill sharp edged, equal, naked at base.

Corvus. Crow. Bill sharp edged; frontlet reversed.

Paradisea. Paradise Bird. Bill somewhat sharp edged; frontlet velvetty.

B. Feet formed for climbing (Scansores, part)

Ramphastos. Toucan. Bill serrate; tongue feathered.

Trogon. Trogon. Bill serrate, hooked at the point.

Psittacus. Parrot. Bill hooked; tongue fleshy.

Crotophaga. Anoo. Bill wrinkled, angular at the edges.

Galbula. Jacamar. Bill quadrangular, very sharp pointed.

Picus. Woodpecker. Bill angular; tongue worm-shaped.

Yunx. Wryneck. Bill smooth; tongue worm-shaped.

Cuculus. Cuckow. Bill smooth ; nostrils margined.

Bucco. Barbut. Bill smooth, notched, hooked.

C. Feet formed for walking.

Buceros. Hornbill. Bill serrate; front bony.

Alcedo. Kingfisher. Bill straight, triangular.

Merops. Bee-eater. Bill bent down, a little compressed.

Todos. Tody. Bill linear, depressed, straight.

III. Axseres. Swimming Birds. (Natatores Illiger.)

Anas. Duck. Bill toothed, with a nail at the tip; teeth membranaceous.

Mergus. Merganser. Bill with a nail at the tip; teeth subulate.

Phrton. Tropic Bird. Bill sharp edged, compressed, serrate.

Plotus. Diver. Bill toothed, subulate, serrate.

Rhynchops. Skimmer. Bill with the upper mandible shorter. Diomedia. Albatross. Bill with the lower mandible truncate. Alca. Awk. Bill with transverse lateral grooves.

Procellaria. Petril. Nostrils forming a long tube.

Pelicanus. Pelican. Bill girded; face naked; chin pouched.

Larus. Gull. Bill with the lower mandibles gibbous.

Sterna. Tern. Bill subulate, compressed at the point.

Colymbus. Grebe. Bill subulate, the sides a little compressed. 
IV. Grallas. Wading Birds. (Grallatores Illiger.)

Phœnicopterus. Flamingo. Bill toothed, bent as if broken. Platalea. Spoonbill. Bill depressed, widened at the end. Palamedia. Screamer. Bill sharp, hooked at the end. Mycteria. Jabiru. Bill bending upwards. Tantalus. Ibis. Bill bending down; chin with a pouch. Ardea. Heron. Bill straight, sharp, long. Recurvirostra. Avoset. Bill subulate, pointed, turned up. Scolopax. Curlew. Bill straight, round, blunt. Tringa. Sandpiper. Bill blunt; back toe raised. Fulica. Water Hen. Bill at the root and front bare. Parra. Jucana. Bill at the base and front warted. Psophia. Trumpeter. Bill a little arched; nostrils oval. Cancroma. Boat-bill. Bill keeled above; nostrils in a furrow.

Rallus. Rail. Bill somewhat keeled; body compressed.

Hæmatopus. Oyster-catcher. Bill compressed, the tip wedged; feet three-toed.

Charadrius. Plover. Feet three-toed; bill roundish, obtuse.

V. Gallin e. Gallinaceous Birds. (Rassores Illiger.)

Otis. Bustard. Bill convex; tongue notched.

Struthio. Ostrich. Bill conic; wings not formed for flight. Didus. Dodo. Bill straight in middle, and wrinkled; face naked.

Pavo. Peacock. Bill naked; feathers of the crown turned back.

Meleagris. Turkey. Face and neck covered with naked wattles.

Crax. Globe-crest. Bill covered at the base with a cere.

Phasianus. Pheasant. Cheeks naked, smooth.

Numidia. Guinea Hen. Bill with wattles at the base.

Tetrao. Partridge. A naked coloured skin above the eye.

VI. Passeres. Perching Birds. Bill conic, sharp pointed. (Insessores Vig.)

Loxia. Grosbeak. Bill thick, conic, oval.

Fringilla. Finch. Bill thick, conic, sharp pointed.

Emberiza. Bunting. Margins of the bill inflexed; lower mandible thickest.

Caprimulgus. Goatsucker. Bill small, depressed, bristled; nostrils tubular.

Hirundo. Swallow. Bill depressed, bent in on the point. Pipra. Manakin. Bill subulate, tip bent. 
Upper mandible notched at the end. (Dentirostres Sw.)

Turdus. Thrush. Bill subulate, compressed at the base. Ampelis. Chatterer. Bill subulate, depressed at the base. Tanagra. Tanager. Bill subulate, conic at the base. Muscicapa. Flycatcher. Bill subulate, fringed at the base.

** Bill straight, simple, tapering.

Parus. Titmouse. Bill subulate; tongue truncate; front reversed.

Motacilla. Warbler. -Bill subulate; tongue jagged; hind claw moderate.

Alauda. Lark. Bill subulate; tongue cleft ; hind claw long. Sternus. Starling. Bill subulate, depressed at the point.

Columba. Pigeon. Bill subarched; nostrils covered with a tumid membrane.

(201.) Such are the only genera of birds instituted by Linnæus, amounting only to 79. Dr. Latham and a few of his other disciples have the credit of defining the following, which are incorporated in the edition of the Systema Natura edited by Gmelin: some of these we have designated by the more classic names since bestowed upon them:-

Grypogeranus. Secretary.

Glaucopis. Wattle-bird.

Scythrops. Channel-bill. 1

Prionites. Motmot.

Aptenodyta. Penguin.

Cursorius. Courier.

Vaginalis. Sheathbill.
Scopus. Umber.

Glareola. Pratincole.

Cryptura. Tinaumu.

Penelope. Penelope, or Guan.

Colius. Coly.

Phytotoma. Plant-cutter.

(202.) We are to judge of these groups, not as regards their combination into orders (for that, as we have already seen, is in many respects highly objectionable), but as assemblages of species, which our author terms genera. Here, in truth, lies the great and striking merits of the ornithological labours of Linnæus, and where his vast superiority over all who had preceded him is most conspicuous. He placed together a number of objects which, in external structure, or rather in general appearance, possessed such characters in common, as enabled him to give to each a short and clear definition. Having attained this, the artificial object of his system required him to look no further: he was 
not called upon for critical investigation of organs, or nice distinctions of habits or economy; he was addressing himself to those who had merely a bird before them, and who desired to know in what manner its name could be ascertained. He framed his system for the practical, not the philosophic naturalist. The Systema Natura was to be an "Every-day Book," not a sealed volume; and he built the foundation of his system accordingly. It seems, therefore, to us, that the very deficiency which has been so strongly urged against our author, is, in fact, the chief merit for which he should have been extolled. No one knew better that his system was artificial ; for it was, in fact, intended to be so. Had he dwelt upon all those minute circumstances which are now known to determine the natural station of a bird; had he, in a genus which then consisted of five species, but which now comprises thirty-five, minutely described the modifications of their structure, or of their generic peculiarities; his system might certainly have been more philosophical, and possibly more natural, but it would have become perfectly useless to all but a very few deep thinkers. Nor would this have been the only objection: general readers would have turned with disgust from such tedious details; and have justly reproached our author with mystifying information, capable of being conveyed in an intelligible form. The truth is, that those who detract from the merits of the Systema $\mathrm{Na}$ tura forget the object for which it was written, and the state of science when it appeared. Who that compares the Synopsis Methodica Avium with the system of Linnæus, but must be struck with the vast superiority of the latter? Let us not, however, institute invidious comparisons, but rather allow that both these works eminently advanced the progress of science. That the genera of Linnæus, with but few exceptions, are natural assemblages, may be seen by the great number which have been kept entire by the most eminent ornithologists who succeeded him. These groups, indeed, were termed by our author genera,-a term which he applied 
to the lowest assemblages, formed from species. He was obviously ignorant that there were in nature any definite groups. The Linnæan genera, therefore, are found to be, for the most part, families; still they remain groups, many of which, under subordinate divisions, have been preserved entire. And although the orders are objectionable, the series of genera within those orders show that Linnæus consulted natural affinities as much as the artificial plan of his arrangement would possibly allow of. Had his disciples, instead of being indolently content with treading in the footsteps of their master, imitated his example in improving his system, as his materials increased, and as fresh light broke in upon his subject, — had they done this, they would have preserved his name in its original splendour, and their own from oblivion. Notwithstanding this, however, we strongly recommend to every student a careful perusal of the Systema Natura, as essential to an acquaintance with modern and existing arrangements, whether natural or artificial. Of the latter it is unquestionably the best; and by thoroughly understanding its principles, the student will gain a general acquaintance with forms, and a conviction how utterly useless all isolated arrangements now are, when we have to deal with such enormous multitudes of species.

(203.) The reptiles, under the name of Amphibia, were placed by Linnæus after the birds. It does not appear, however, that our author had very definite notions on this class, as will appear from the three subdivisions under which the whole are arranged;-viz. 1. Reptiles, furnished with feet; 2. Serpentes, destitute of feet; and, 3. Nantes, furnished with fins, and breathing by lateral openings. The first and second comprise the modern classes of Reptilia and Amphibia, but the third are true fishes. It is, indeed, surprising that Linnæus should have fallen into this mistake, after Artedi had pointed out the true situation of these animals. The class of reptiles does, indeed, pass into that of fish, by means of the ichthyosaurus, and the sharks ; 
and, possibly, Linnæus, when he placed the cartilaginous fishes among the reptiles, may have had some indistinct perception of their union. It has, however, been remarked, that this arrangemont was made on the supposition of their being furnished both with lungs and gills; an idea which seemed confirmed by the observations of Dr. Garden, of Carolina, who, at the request of Linnæus, examined the organs of the genus Diodon, and found, as he conceived, both external bronchiæ, or gills, and internal lungs. This idea, however, has been shown by later physiologists to have been not strictly correct; the supposed lungs being, in reality, only a peculiar modification of gills.* The genera of the Amphibia are thus characterised : -

\section{Repriles. With feet.}

Testudo. Tortoise. Body four-footed, covered with a shell.

Draco. Dragon. Body four-footed, tailed, and winged.

Lacerta. Lizard. Body generally four-footed, tailed, and naked.

Rana. Frog. Body four-footed, naked, tailless.

Siren. Siren. Body two-footed, tailed, naked.

\section{Serpentes. Feet none.}

Crotalus. Rattlesnake. Plates on the belly and tail; with a rattle.

Boa. Boa. As above; but without a rattle.

Coluber. Viper. Plates on the belly; scales on the tail.

Anguis. Snake. Scales on the belly and tail.

Amphisbæna. Blindworm. Rings on the belly and tail.

Cæcilia. Snake-worm. Body with naked lateral wrinkles.

III. Nantes. Provided with fins instead of feet; breathe by spiracles.

Petromyzon. Lamprey. Spiracles seven, placed on the sides. Raj2. Ray, or Thornback. Spiracles five, placed beneath.

Squalus. Shark. Spiracles many, five on each side.

Chimera. Sea Monster. Spiracle solitary, quadrifid.

Lophius. Fishing Frog. Spiracle solitary; ventral fins two, like feet.

Acipenser. Sturgeon. Spiracle solitary; ventral fins two; mouth without teeth. 
Balistes. File-fish. Spiracle solitary; ventral fins solitary, keel-shaped.

Ostracion. Tortoise-fish. Spiracle solitary; no ventrat fins; body mailed.

Tetraodon. Square-fish. Spiracle solitary; no ventral fins; belly prickly.

Diodon. Porcupine-fish. Spiracle solitary; body covered with spines.

Cyclopterus. Lump-fish. Spiracle solitary; ventral fins united into a funnel.

Centriscus. Snout-fish._Spiracle solitary ; ventral fins united; snout long.

Syngnathus. Pipe-fish. Spiracle solitary; no ventral fins; body crusted, long.

Pegasus. Sea-horse. Spiracle solitary; ventral fins two; snout ciliate-toothed.

(204.) The following genera, belonging to the order Nantes, have been added by the disciples of Linnæus, and incorporated in their editions of his Systema $\mathrm{Na}$ tura: -

Pristis. Saw-fish. Separated from the sharks by Shaw. Gastrobranchus. Hag-fish. The connecting link between

Vertebrata and Annulosa.

Spatularia. Spoon-fish. Allied to the saw-fish.

(205.) The class of fish (Pisces), as may be supposed, was placed by Linnæus immediately after his last order (Nantes) of reptiles. His primary divisions being in number four, characterised as follows :-

I. A podal. Ventral fins none. - II. Jugurar. Ventral fins before the pectoral. - III. Thoracrc. Ventral fins under the pectoral. - IV. Aвpominal. Ventral fins behind the pectoral.

(206.) It is in the arrangement of this class, more than in any other, that we find the strongest proof that Linnæus, so far from wishing the Systema Naturce to be thought the natural system, intended it should be essentially artificial. The two great typical divisions of the class were undoubtedly known to the learned Swede, for he gave them to the world in the admirable volume he edited of the works of Artedi; of whom we shall hereafter speak. In that volume, likewise, we find the Nantes occupying their proper station among the true 
fishes, and forming the orders Branchiosteges and Chondropteriges; but this arrangement, although natural, was too philosophic for general use. Linnæus perceived this; and, therefore, intent upon his primary object of producing a simple and definite artificial arrangement, he had recourse to the position of the ventral fins as the basis of his primary divisions : by attention to which, every one, at the first glance, could determine where he was to search for a particular species.

(207.) The genera composing these orders will now be mentioned : very few of them have yet received English names.

\section{PISCES.}

I. A rodal Frshes. Having no ventral fins.

Muræna. Eel. Aperture of the gills on the side of the thorax. Order A rodes $S w$.

Gymnotus. Naked-back. Dorsal fin none.

Trichiurus. Caudal fin none; body ensiform.

Anarhichas. Wolf-fish. 'Teeth rounded.

Ammodytes. Sand-lance. Head narrower than the body.

Ophidium. Body ensiform.

Xiphias. Sword-fish. Snout ensiform.

Stromateus. Stromat. Body oval, scaly; breast simple.

II. Jugular Fishes. Ventral fins before the pectoral. Callyonimus. Aperture of the gills on the nape.

Uranoscopus. Star-gazer. Head large, rough, depressed. Trachinus. Vent near the breast.

Gadus. Cod. Pectoral fins tapering to a point. Blennius. Blenny. Ventral fins of two united rays.

III. Thoracic Fishes. Ventral fins under the pectoral. Cepola. Ribbon-fish. Body ensiform, naked.

Echineis. Remora, or Pilot. Crown flat, transversely furrowed. Coryphæna. Dolphin. Head sloping suddenly downwards.

Gobius. Goby. Ventral fins united into an oval fin. Cottus. Bull-head. Head broader than the body. Scorpæna.: Scorpion-fish. Head armed with prickles. Zeus. Silver-fish. Upper lip arched by a transverse membrane.

Pleuronectes. Flatfish. Eyes both on one side of the head. Chætodon. Band-fish. Teeth setaceous, flexile, crowded. Sparus. Gilthead. Teeth strong, obtuse; lip double. Labrus. Labbe. Dorsal rays, with a slender skin beyond. 
Sciæna. Sea-perch. Head and gill covers with fixed scales. Perca. Perch. Gill covers three-leaved, the upper serrate. Gasterosteus. Stickleback. Tail carinate at the sides. Scomber. Tunny. Tail carinate at the sides; several spuI |rious fins between the dorsal fin and tail.

Centrogaster. Spine-throat. Tail carinate at the sides; ventral fins connected by a membrane, the first four rays spinous, the other six unarmed.

Mullus. Mullet. Body and gill covers with large lax scales. Trigla. Gurnard. Distinct appendages near the pectoral fins. IV. Aвpominal Fishes. Ventral fins behind the pectoral. Cobites. Loach. Body hardly decreasing towards the tail. . Amia. Head naked, bony, rough.

Silurus. Cat-fish. First ray of the dorsal or pectoral fins tootined.

Teuthis. Head truncate on the fore part.

Loricaria. Body mailed with a bony coat.

Salmo. Salmon. Hindermost dorsal fin fleshy: Fistularia. Snout cylindrical, with a cover at the end.

Esox. Pike. Upper jaw much shorter than the lower. Elops. Branchiostegous. Membrane double, the outer less. Argentina. Argentine. Vent near the tail.

Atherina. Atherine. Body with a lateral silvery stripe. Mugil. Mullet. Lower jaw carinate inwards.

Mormyrus. Teeth notched; scales imbricate.

Exocœtus. Flying-fish. Pectoral fins as long as the body. Polynemus. Distinct appendages near the pectoral fins.

Clupea. Herring. Belly carinate, serrate.

Cyprinus. Carp. Gill membrane three-rayed.

(208.) The additional genera included in the subsequent editions of the Systema Natura are the following: they were chiefly defined by Bloch :-

Gymnothorax. Naked-breast. Ventral and pectoral fins none; body eel-shaped.

Leptocephalus. Morris. Ventral and pectoral fins none; body thin, much compressed.

Sternoptyx. Great-eye. Ventral fins none; body oval, naked; breast folded.

Stylephorus. Long-eye. Ventral fins none; eyes placed on a short peduncle.

Scarus. Scare. Thoracic. Teeth none; jaws crenate at the edges.

Lonchius. Thoracic. Caudal fin lanceolate.

Trachychthys. (Shaw.) Belly armed with large carinate scales. 
These groups, like those of the Linnæan ornithology, are, for the most part, natural : many, to be sure, are families, which of course have now been subdivided to a considerable extent by M. Cuvier and others; but hitherto no effort has been made to determine the truly natural or circular series, even so far as affects the primary groups : we must, therefore, at once proceed to the next class.

(209.) The entomological system of Linnæus, as we have already intimated, forms by far the most valuable part of his zoological labours ; for it not only surpasses in simplicity and perspicuity all that had been done before, but it makes a much nearer approach to the arrangement of nature than any of the modern methods. It must, however, be remembered that the superstructure of this system is built upon the foundation originally laid by the immortal Aristotle. It has been the custom of late years, while the name of its founder is still held in reverence, to reject these views, because they are totally at variance with the notions recently taken up on the same subject. But the cloud which has so long obscured the transcendent merits of these philosophers, in the arrangement of the annulose animals, has already begun to break, and a ray of light has penetrated through the gorgeous drapery which has been spread before our eyes: the time will soon arrive, when we shall wonder at our own credulity in so readily adopting new theories, and rejecting those which are old. Impressed with this conviction, we shall transcribe for the reader the definition of the class Insecta, as given by Linnæus. This definition we wish to perpetuate ; for, although in some respects faulty, it is, upon the whole, in our opinion, infinitely more just and enlarged than any which have since been drawn up.

(210.) INSEcrs, as Linnæus defines them, are small animals, breathing through lateral spiracles, armed on all sides with a bony skin, or covered with hair; furnished with many feet ; and movable antennæ or horns, which project from the head, and are the probable in- 
struments of sensation. They are destitute of external nostrils and ears, though some of them evidently enjoy the senses of hearing and smell. 1. The eyes are usually two, sometimes more, without eyelids, and rarely placed on a movable peduncle. 2. The antennce are two, placed on the head, usually before the eyes : they are composed of an indefinite number of articulations, and convey an unknown sensation, probably that of the touch. 3. The feelers are sensorial, movable, affixed to the mouth, generally four, sometimes two or six ; and consist of two, four, or six joints. 4. The mouth is generally placed beneath the head, sometimes in the breast, and in a few is wanting: the jaws are transverse, and movable laterally. 5. The stemmata are three shining spots placed on the crown. 6. The trunk is placed between the head and abdomen, supported by the feet, with the thorax above; behind which is the scutel, or escutcheon, and the sternum and breast beneath. 7. The abdomen is usually annulate, with five segments; perforated at the sides with five spiracles, or breathing holes, with the back above and the belly beneath ; and is terminated by the tail, which is sometimes armed with a sting. 8. The wings are 0 , or two or four: the upper ones are often crustaceous shells, covering the lower; sometimes semi-crustaceous wingcases, or of a substance between the membranaceous wings and crustaceous shells. 9. The legs consist of three distinct divisions, viz. the thighs, shanks, and tarsi, which are articulated, and terminated by nails : some have a hand, or chelate kind of claw, with a movable thumb. 10. The poisers are composed of a head, affixed to a small pedicle, and placed under the wings of the dipterous order, or such as have but two wings. So far for the parts of insects.

(211.) The changes, or metamorphoses, of what Linnæus considered insects, are thus spoken of :-Most of them undergo a triple metamorphosis or transformation, effected by casting off the different coats or coverings in which the perfect insect is inveloped. The egg 
is first excluded by the female, and contains the insect in its smallest state: from the egg is produced the larva, grub, or caterpillar, of a moist soft substance, without wings, slow in motion ; often with numerous feet, sometimes with none; sterile, and very voracious of its proper food: from this state it passes into that of the pupa, chrysalis, or nymph, which is drier and harder than the last, confined in a narrow compass, naked or enclosed in a web; often without a mouth ; and sometimes with, sometimes without feet: escaping from this last confinement, it becomes the perfect insect, furnished with antennæ. Such is the general definition given by the illustrious Swede of the class Insecta. But we shall gain a better insight into his views by looking to the construction of his primary groups.

(212.) The first divisions of the class are into seven orders, as follows: -

Modern Orders.

1. Coleoptera. $\left\{\begin{array}{c}\text { Wings four ; the upper crustace- } \\ \text { ous, with a straight suture. }\end{array}\right\}$ Coleoptera.

2. Hemiptera. $\left\{\begin{array}{l}\text { Wings four; the upper semi-crus- } \\ \text { taceous and incumbent. }\end{array}\right\} \begin{aligned} & \text { Hemiptera. } \\ & \text { Homoptera. }\end{aligned}$

3. Lepidoptera. $\left\{\begin{array}{l}\text { Wings four; all of them membra- } \\ \text { naceous and imbricate with fine } \\ \text { scales. }\end{array}\right\}$ Lepidoptera.

4. Neuroptera. $\left\{\begin{array}{l}\text { Wings four, all of them membra- } \\ \text { naceous and reticulate; tail un- } \\ \text { armed. }\end{array}\left\{\begin{array}{l}\text { Neuroptera } \\ \text { Orthoptera. } \\ \text { Dermoptera. } \\ \text { Trichoptera. } \\ \text { Strepseptera. }\end{array}\right.\right.$

5. Hymenoptera. $\left\{\begin{array}{c}\text { Wings four, all of them membra- } \\ \text { naceous; tail armed with a sting. }\end{array}\right\}$ Hymenoptera.

6. Diptera. $\left\{\begin{array}{c}\text { Wings two, with a poiser under } \\ \text { each. }\end{array}\right.$ Diptera.

Classes.

Suctoria Lat.

Crustacea Lat.

Aptera Lat.

Myriapoda Leach.

7. Aptera. TVings none in either sex.

$\{$ Thysanura Leach. A metabolia Leach. Arachinoïda Leach. Acari Leach.

\&c. \&c.

(213.) On comparing these primary divisions with those of Aristotle, we observe a marked improvement in two essential points. The first regards the separation of the Hymenoptera from the Neuroptera, both which 
were considered by the Stagyrite as forming parts only of his order Tetraptera. The second is the abolition of the "Pterota simul et Aptera," under which the Grecian philosopher placed the ants and the apterous glowworms. These errors were perceived by Linnæus, and duly rectified. In regard to the Linnæan order Aptera, it would be endless to enumerate the host of objections that have been raised against it by almost every modern entomologist; each having proposed a classification, which has been set asideby the next writer who followed. A wellknown countryman of our own, Dr. Leach, has himself published two or three different theories on the arrangement of the Aptera; and the views of MM. Kirby and Macleay are totally different from these, and from each other. In such a state of things, the reproach - if it be one - that Linnæus failed in his arrangement, is equally applicable to all those who have succeeded him, with ten times the materials and, consequently, the facilities which were possessed by the learned Swede. Every one, in fact, sees and admits that this order required much subdivision; but, unfortunately, no one has been hitherto successful in doing this, upon such natural principles as to satisfy any other entomologist than himself. There is consequently good reason to suppose that, in all these arrangements, some great error has been committed. Nor is it too much to suppose that some important principle of the natural system has never been correctly applied to the determination of the natural groups of the Annulosa. On this subject, however, we feel disposed at present to say but little, further than to intimate, as the result of much investigation, that the greatest part of the Linnæan Aptera form the principal portion of a truly natural group; which, when united to one of his orders (whose affinities to it he himself perceived), will constitute the natural sub-typical class of the annulose circle. But as we wish not that the reader should be in possession of our opinion alone, on a matter of so much importance, let us refer him to what others have expressed on the Linnæan arrangement of insects. 
(214.) MM. Kirby and Spence, speaking of this part of the Linnæan arrangement, observe:- "His system, being founded upon the absence or presence and character of the organs of flight, is in some degree a republication of the Aristotelian. In considering this table of orders, it must strike every one acquainted with the subject, that, although the assumption of a single set of organs, whereon to build a system, can scarcely be expected to lead to one perfectly natural. yet that the majority of groups here given as orders merit that character. The second, indeed, and the last require further subdivision, and concerning the fourth no satisfactory conclusion has yet been drawn. With regard to the series of his orders, it is mostly artificial. Linné has the advantage of all his predecessors in giving clearer definitions to his orders, and in their nomenclature, in which he has followed the path first trodden by Aristotle." *

(215.) The genera of insects, characterised by Linnæus, deserve to be remembered. As the student will find an acquaintance with them of great advantage in the early periods of his study, we shall here enumerate their characters, since by this plan he will be rendered familiar with the types of what are now, for the most part, examples of families or very large divisions.

\section{Coleoptera.}

\section{- Antenna clavate, thickest at the tip.}

Scarabæus. Beetle. Club lamellate, anterior thighs toothed. Lucanus. Stagbeetle. Club compressed, the sides more widely cleft.

Dermestes. Club perfoliate; head inflexed under the thorax. Hister. Club solid; head retractile within the thorax. Byrrhus. Club solid, ovate. Gyrinus. Antennæ rigid; eyes four. Attelabus. Head pedunculated, or attenuated at the base. Curculio. Antennæ placed on a horny rostrum or beak. Silpha. Thorax and elytra marginated.

Coccinella. Club of antennæ obtuse; palpi with a truncated club. 


\section{** Antennce filiform.}

Bruchus. Antennæ filiform, thickened at the end.

Cassida. Body ovate; elytra margined, head covered by a shield.

Ptinus. Thorax receiving the head. Antennæ with the last joint lengthened.

Chrysomela. Body ovate, immarginate.

Hispa. Antennæ porrect, approximate, fuciform.

Meloe. Thorax roundish, head gibbous, inflexed.

Tenebrio. Thorax margined; head exserted; hody oblong.

Lampyris. Elytra flexible. Thorax surrounding and concealing the head.

Mordella. Abdomen with plates at its base; head inflexed.

Staphylinus. Elytra very small, covering the wings; above the tail two exsertile vesicles.

\section{*** Antenna setaceous.}

Cerambyx. Thorax with hard spines on the sides.

Leptura. Elytra with the tips narrowed. Thorax roundish. Cantharis. Elytra flexible; sides of the body plaited and warty.

Elater. A pectoral spine, springing from an abdominal pore. Cicindela. Jaws projecting, toothed. Eyes prominent.

Buprestis. Head partly retracted within the thorax.

Dytiscus. Posterior feet fringed, and formed for swimming.

Carabus. Thorax somewhat heart-shaped; truncated behind.

Necydalis. Elytra shortened; wings naked.

Forficula. Elytra short, wings covered, tail forcipated.

\section{Hemiftera. Elytra semi-crustaceous.}

Blatta. Mouth furnished with jaws, wings coriaceous, flat, legs formed for running.

Mantis. Mouth furnished with jaws. Anterior feet serrated, the claw single.

Gryllus. Mouth furnished with jaws : posterior feet formed for leaping.

Fulgora. Rostrum or snsut inflexed, front projecting, inflated, and capitate.

Cicada. Snout inflexed; hind legs formed for leaping.

Notonecta. Snout inflexed; hind legs fringed, and formed for swimming.

Nepa. Snout inflexed; fore legs cheliform.

Cimex. Snout inflexed; legs formed for running. Antennæe longer than the thorax.

Aphis. Snout inflexed; body terminated by two bristles. 
Chermes. Snout pectoral ; hind legs formed for leaping.

Coccus. Snout pectoral; body, in the males, ending in bristles.

Thrips. Snout obsolete; wings incumbent on the abdomen, which is reflexile.

III. Lepidoptera. Wings imbricate with scales.

Papilio. Antennæ with the tip club-shaped; wings erect when at rest.

Sphinx. Antennæ thickest in the middle.

Phalæna. Antennæ thickest towards the base.

IV. Neuroptera. Wings reticulated. Body without a sting.

Libellula. Tail forcipated; mouth with many jaws; wings expanded.

Ephemera. Tail with two or three bristles; mouth without teeth; wings erect.

Myrmelion. Tail forcipated; mouth two-toothed; wings deflected.

Phryganea. Tail simple; mouth without teeth; wings deflexed.

Panorpa. Tail chelate; mouth with an extended snout; wings incumbent.

Raphidia. Tail ending in a single thread; mouth two-toothed; wings deflexed.

V. Hymenoptera. Body armed with a sting.

Cynips. Sting spiral.

Tenthredo. Sting serrate; two-valved.

Sirex. Sting serrate, projecting from a spine under the abdomen.

Ichneumon. Sting exserted or projecting; triple.

Sphex. Sting pungent; wings smooth; tongue flat, dilated, the tip nearly entire.

Chrysis. Sting pungent; body arched beneath.

Vespa. Sting pungent; superior wings plaited or folded. A pis. Sting pungent; tongue inflexed.

Formica. Sting obsolete. Neuters without wings.

Mutilla. Sting pungent. Neuters without wings.

VI. Diptera. Wings two, with a poiser under each.

* With a proboscis and sucker.

Diopsis. Head iwo-horned; eyes terminal (defined afterwardsj. 
Tipula. Sucker without a sheath; feelers two, projecting, fliform.

Musca. Sucker without a sheath, furnished with bristles.

Tabanus. Sucker with a single-valved sheath, furnished with bristles.

Empis. Proboscis inflexed.

Conops. Proboscis projecting, geniculate.

$$
\text { ** With a sucker, but no proboscis. }
$$

CEstrus. Sucker retracted within the perforated lips.

Asilus. Sucker straight, subulate.

Culex. Sheath exserted, valved, flexile, with five bristles. Stemmata none.

Bombylius. Sucker very long, straight, setaceous, two-valved. Hippobosca. Sucker short, cylindrical, straight, two-valved.

\section{A ptera. No wings.}

* Feet six; head distinct from the thorax.

Lepisma. Tail ending in setaceous bristles.

Podura. Tail forked, inflected, elastic.

Termes. Mouth with two jaws; lip horny, four-cleft.

Pediculus. Mouth armed with an exsertile sting.

Pulex. Snout inflected, armed with a sting; feet formed for leaping.

** Legs from eight to fourteen; head and thorax uniled.

Acarus. Eyes two ; legs eight; feelers compressed. Phalangium. Eyes four; legs eight ; feelers chelate.

Aranea. Eyes eight; legs eight; body with textorial pa. pillæ; feelers clavate.

Scorpio. Eyes eight; legs eight; feelers chelate.

Cancer. Eyes two; legs eight, the first pair chelate.

Monoculus. Eyes two; legs twelve, ten of them chelate.

Oniscus. Eyes two; legs fourteen.

*** Legs numerous; head distinct from the thorax.

Scolopendra. Body linear.

Iulus. Body subcylindrical.

(216.) Such are the only entomological genera founded by Linnæus. In Gmelin's edition of the Systema $\mathrm{Na}$ turce are incorporated all those subsequently defined by Fabricius up to the period of its publication; while the necessity for a much larger number has been so obvious, as new discoveries have been made, that even the dis. 
ciples of the learned Swede have relaxed, in this instance, from their accustomed dread of innovation, by making several genera not to be found in the works of their master.

(217.) Looking to this list, we perceive that the system is not only more natural than any which preceded it, but that nearly all the great families made by more recent entomologists are named and characterised under the denomination of genera. 'The combination of these groups, however, in many instances are obviously intended to be artificial : this is most conspicuous in the order Coleoptera, where our illustrious author truly judged, that as the differences in the antennæ furnished one of the most obvious distinctions among insects, so a classification founded chiefly upon those organs among beetles would offer the greatest facilities to the ready determination of the genera. In judging, therefore, of the entomological system before us, we should bear this in mind, since it cannot for a moment be supposed that such a writer as Linnæus, if he had not this object in view, would have placed Buprestis after Cicindela, or Necydelis after Carabus; still less that he could have fancied any natural affinity between Silpha and Coccinella, or Elater and Cicindela. The Coleoptera, in fact, is nearly the only order where he found it necessary. to group his genera into purely artificial sections, in order that they might more easily be determined. In his other orders these subdivisions were not necessary, and we accordingly find the genera following each other in a much more natural series." On this point Mr. Kirby has justly observed, that, in general, Linnæus had such a tact for discovering natural groups, that in him it seems almost to have been intuitive. $t$

(218.) The Vermes consitute the last class of the Systema Naturce, under which are comprehended all animals whose bodies are not furnished with limbs. As it is curious to perceive how Linnæus contrived to bring

* Except in Hemiptera.

+ Int. to Ent. vol. iv. p. 440. 
into an intelligible shape this immense assemblage of animals, we subjoin the characters he gives to the five principal divisions or orders under which he arranged the whole. However faulty they may now be thought, scientifically, we cannot but admire the ray of genius which he has cast over them.

I. Intestine. Intestinal Worms are of a formation the most simple, and live, some within other animals, some in water, and a few in the earth. The Gordius (hair-worm) perforates clay to give a passage to springs and water; the Lumbricus (or earth-worm) pierces the earth, that it may be exposed to the action of the air and moisture; in like manner the Teredo penetrates wood, and the Pholas and Mytilus rocks, to effect their dissolution.

II. Mollusca. Pulpy Worms. These are naked, furnished with tentacula or arms, for the most part inhabitants of the sea, and by their phosphorous quality illuminate the dark abyss of waters, reflecting their light to the firmament: thus what is beneath the water corresponds with that which is above.

- III. Testacea. Shell-fish. These are Mollusca covered with calcareous habitations or shells, which they carry about with them, themselves producing and often penetrating calcareous bodies: like insects, they are multiplied into a vast number of species and varieties, and both in form and colours exhibit splendid examples of the Almighty Artificer.

IV. Zoophyta (Coralline Worms) are composite animals, holding a medium between animals and vegetables. Most of them take root and grow up into stems, multiplying life in their branches and deciduous buds, and in the transformation of their animated blossoms or polypes which are endowed with spontaneous motion. Plants, therefore, resemble zoophytes, but are destitute of animation and the power of locomotion; and zoo-. phytes are, as it were, plants, but furnished with sensation and the organs of spontaneous motion. Of these some are soft and naked, and are called Zoophytes; 
others are covered with a hard shell, and are denominated Lithophytes.

V. Infusoria (Animalcules). These are extremely minute animals, destitute of tentacula or feelers, and generally not visible to the naked eye: they are mostly found in infusions of various vegetable substances, and, after becoming dry, do not revive upon being replaced in moisture.

(219.) The genera of these orders are thus defined:-

\section{INTESTINAE.}

a. Perforated with a lateral pore.

Lumbricus. Body round, with fleshy wings.

Siphunculus. Body round; head with a narrow cylindrical proboscis.

Fasciolaria. Body depressed; furnished with a ventral pore.

$$
\text { b. }{ }^{8} \text { Destitute of a lateral pore. }
$$

Gordius. Body entirely filiform.

Ascaris. Body round; both extremities attenuated.

Hirudo. Body truncated at each extremity; head and tail dilated when in motion.

Myxine. Body carinated. Mouth furnished with feelers.

\section{Mollusca.}

Actinia. Mouth placed above. Aperture single; capable of dilation.

Ascidia. Mouth above. Aperture double; one terminal, the other beneath.

Limax. Mouth placed before. Body with a lateral perforation. Feelers four.

Vent united with the lateral pore.

Aplysia. Mouth and body as in Limax. Feelers four. Vent dorsal, posterior.

Doris. Mouth and body as in Limax. Feelors two. Vent dorsal, posterior.

Tethys. Mouth and body as in Limax. Body with two small pores on the left side.

Holothuria. Mouth placed before, surrounded with fleshy tentacula, or feelers.

Terebella. Mouth placed before, surrounded with fleshy tentacula or feelers; but the feclers capillary. 
Triton. Mouth before. Body furnished with arms. Arms 12 , divided, some chelate.

Sepia. Mouth and body as in Triton. Arms 8-10, beset with suckers.

Clio. Mouth and body as in Triton. Arms 2; membranaceous, dilated like wings.

Lernæa. Mouth and body as in Triton. Arms 2-3 ; round and slender.

Scyllæa. Mouth and body as in Triton. Arms 6; each pair at a distance.

Aphrodita. Mouth before. Body pedunculated, or with feet, ovate; mouth unarmed.

Nereis. Mouth and body pedunculated, or with feet; elongated; mouth with claws.

Medusa. Mouth inferior, central. Body smooth, gelatinous. Asteria. Mouth inferior, central. Body coriaceous, prickly. Echinus. Mouth inferior, central. Body crustaceous, spined.

\section{Testacea.}

* Multivalve shells, with many valves.

Chiton. Shell composed of several transverse plates, arranged on the back.

Lepas. Valves sessile, of different sizes.

Pholas. Shell bivalve, with accessory pieces at the posterior end.

** Bivalve shells, of two valves only, furnished with teetir.

Mya. Hinge with a broad thick tooth, not entering the opposite valve.

Solen. Shell open at each end; lateral teeth remote from the cardinal teeth.

Tellina. Hinge with the lateral teeth of one valve not let into the other.

Cardium. Hinge with remote, pointed, lateral teeth.

Mactra. Cardinal teeth triangular, complicated; the interstices hollow.

Donax. Hinge with a remote lateral tooth, not let into the other valve.

Venus. Hinge with three approximate, divaricating cardinal teeth.

Spondylus. Cardinal teeth two, separated by a small hollow. Chama. Hinge in one valve, with two oblique, obtuse teeth.

Arca. Hinge with numerous acute teeth.

Ostrea. Hinge without teeth, but with an ovate hollow.

Anomia. Teeth none; the rim with a linear depression; valves unequal. 
Mytilus. Teeth none; linge with a pointed depression. Shell fixed by a byssus.

Piuna. Teeth none; valves united at one end, open at the other.

\section{*** Univalves, spire regular.}

Argonauta. Shell with one cell; spire involute.

Nautilus. Shell with many cells, communicating with each other by a siphon.

Conus. Aperture effuse, longitudinal, without teeth.

Cypræa. Aperture effuse, linear, longitudinal, toothed each side.

Bulla. Aperture a little contracted, and placed obliquely.

Voluta. Aperture effuse; the pillar plaited.

Buccinum. Aperture with a small canal leaning to the right.

Strombus. Aperture with a small canal leaning to the left. Murex. Aperture with a small straight canal.

Trochus. Aperture contracted, and somewhat square.

Turbo. Aperture contracted and orbicular.

Helix. Aperture contracted, lunate on the inner side.

Nerita. Aperture contracted, and semi-orbicular.

Haliotis. Shell with a row of orifices along the surface.

\section{**** Univalve shells, but without a spire.}

Patella. Shell conic, the aperture widening like a bason.

Dentalium. Shell slender, subulate, open at both ends.

Serpula. Shell tubular, mostly serpentine, adhering to other bodies.

Teredo. Shell thin, pierced into wood.

Sabella. Shell composed of agglutinated grains of sand.

\section{ZOOPHYTA.}

* With a hard calcareous stem.

Tubipora. Animal inhabiting a coral, with cylindrical tubes. Madrepora. Animal inhabiting a coral with concave stars. Millepora. Animal inhabiting a coral with subulate pores. Cellipora. Animal inhabiting a coral, with hollow round cells.

\section{** With a softer stem.}

Gorgonia. Fixed. Stem horny. Alcyonium. Fixed. Stem corky. Spongia. Fixed. Stem stringy, flexile, absorbent. Flustra. Fixed. Stem covered with minute cellular pores. Tubularia. Fixed. Stem tubular, filiform. 
Corallina. Fixed. Stem with filiform calcareous joints. Sertularia. Fixed. Stem with filiform fibrous joints. Vorticella. Fixed. Stem with fibrous gelatinous joints. Hydra. Free. Stem medullous, naked. Pennatula. Free. Stem coriaceous, resembling a quill. Tænia. Free. Stem or body moniliform, articulated. Volvex. Free. Body roundish or spherical.

Furia. Free. Body linear, and ciliate on each side with reflected prickles.

Chaos. Free. Body a mere point.

(220.) The most objectionable part of the Linnæan system is unquestionably the arrangement of the soft invertebrated animals, here placed in the class Vermes. But if we bear in mind the state of zoological science when this system was formed, and consider that the labours of this wonderful man were spread over the whole of organised matter, so far from joining in the ill-judged censure that has been cast upon him for neglecting the lower animals, we shall only be astonished that his errors were not greater, or that he was able to contemplate them at all. It is, therefore, no disparagement to Linnæus that the labours of his successors have obliterated this portion of his system from the pages of modern science; yet it must be remembered, that, as the three aberrant divisions of the animal kingdom (Acrita, Radiata, and Mollusca) form a natural group by themselves, this group, with but very few exceptions, will comprise the whole of the Linnæan class of Vermes; so that, even here, in the most objectionable part of our author's system, it seems highly probable that his views, in some respects, are more conformable to nature than many of those which have recently been promulgated. On the whole, therefore, we must express our conviction that the name of Linnæus must ever remain as that of the great father of natural history since the revival of learning; and that the benefits he bestowed upon our favourite science are as multifarious as they are incalculable. By the unrivalled simplicity of his artificial system, and the admirable precision of his nomenclature, he enticed votaries and students to the 
investigation of nature,' who would otherwise have shrunk from those obstacles which he removed.

(221.) The system of Cuvier succeeded that of Linnæus, and equally embraced the whole animal kingdom. The immense increase that had been now made to our knowledge of natural productions called for the institution of new genera and subdivisions, and a general revision of all the groups. Patronised by his govern. ment, and gifted with talents of no common order, this illustrious anatomist conceived the idea of a natural system, founded exclusively upon the organisation of animals. The attempt, however grand, has been eminently unsuccessful. Like all those which have been built on one set of characters, the system of M. Cuvier has eventually become most palpably artificial. But as we shall have frequent occasion to illustrate this opinion, we proceed at once to give a general outline of the great divisions of the animal kingdom as proposed in the Règne Animal.

(222.) In the Cuvierian system all animals are arranged under four principal divisions:- $-\mathrm{I}$. Vertebrated animals (Animalia vertebrata). II. Soft or molluscous animals (Animalia mollusca). III. Articulated animals (Animalia articulata). And, lastly, IV. Radiated animals (Animalia radiata). The principal groups into which each of these classes are next divided will be seen by the following tables.

(223.) I. The Ventebrata, or vertebrated class, are also divided into four groups; namely, 1. Mammalia, or Quadrupeds; 2. Aves, or Birds ; 3. Reptilia, or Reptiles; and, 4.Pisces, or Fishes. These animals in themselves are abundantly different in their external form; but, as our author's system professes to be founded on anatomical structure only, he rejects the more plain and obvious characters, which every one can see, and which had been so happily employed by Linnæus, and makes the differences between these groups to depend upon circumstances which no one but an anatomist can understand. Thus Quadrupeds, or Mammalia, are to be known by 
" their double circulation, and by having the respiratory process simple, that is, performed by the lungs alone. The quantity of their respiration is superior to that of reptiles by reason of the form of their circulating organ, and to that of fishes by the surrounding element which they respire." The primary groups of this anatomical system of Cuvier are, in fact, founded upon motion and respiration, the external forms of the creatures themselves not entering in the least degree into his consideration. This is obvious from the following passage, which appears intended to give the essential distinction of these four primary divisions :"From all this result four different kinds of motion, for which the four classes of vertebrated animals are severally and exclusively designed. I. Quadrupeds, in which the quantity of respiration is moderate, are formed for walking and running, and their predominant characteristic is vigour. II. Birds, whose respiration is greater, possess the lightness and strength of muscles necessary to support them in their airy flight. III. Reptiles, which respire more freely, are doomed to creep upon the earth, and many of them pass more or less of their allotted period in a kind of stupor. Finally, IV. Fishes, which move in a fluid almost as specifically heavy as themselves, are enabled to execute their peculiar motions by an arrangement altogether different from the rest." This extract will sufficiently explain the nature of the principles upon which this system is constructed ; principles, indeed, of the utmost value, when properly used, and combined with other considerations, but eminently calculated - as the event, in the present case, has proved - to substitute complex definitions for others which all the world can see and understand.

(224.) The Mammalia are arranged in orders, the first of which implies that MAN - essentially - is an animal. The following table will show the ranks of the chief groups or families as they are given in the Règne Animal; the sub-genera and smaller divisions being omitted. 
Order I. Bimana. Man.;

Order II. Quadrumana.

Simia. Apes and monkeys.

Simia. Apes and monkeys of the Old World.

Harpales. Apes and monkeys of America.

Lemur. Lemurs.

Order III. Carnivora.

1. Cheiroptera. Flying quadrupeds. Vespertilio. Bats.

Galeopithecus. Flying lemurs.

2. Insectivora. Insect Feeders.

Erinaceus. Hedgehogs.

Sorex. Shrew Mice.

Talpa. Moles.

3. Carnivora.

Ursus. Bears.

Martes. Martens.

Canis. Dogs.

Viverra. Civets.

Felis. Cats.

4. Amphibia.

Phoca. Seals.

Trichechus. Walrus.

\section{Marsupiati.}

Didelphis. Opossums.

Dasvurus. Brushtails.

Phalangista. Phalangers.

Halmaturus. Kangaroos.

Order IV. Rodentia.

Castor. Beavers.

Arvicola. Lemmings.

Echimys. Dormice.

Mus. Mouse.

Dipus. Jerboa.

Arctomys. Marmots.
Spermophilus. American marmots.

Sciurus. Squirrels.

Pteromys. Flying Squirrels.

Hystrix. Porcupines.

Lepus. Hares.

Order V. Eidentata.

Bradypus. Sloths.

Dasypus. Armadillo.

Myrmecophaga. Anteater.

Manis. Manis.

Monotrema.

Echidna. Echidna.

Ornithorhynchus.

Order Vi. Ungulata.

1. Pachydermata.

Elephas. Elephant.

Hippopotamus. River-horse.

Sus. Sow.

Dicotyles. Pecary.

Rhinoceros. Rhinoceros.

Hyrax. Rock rabbit.

Tapirus. Tapir.

2. Solipedes.

Equus. Horse.

3. Ruminantia.

Camelus. Camels.

Anchenia. Lamas.

Cervus. Stags.

Camelopardalis. Giraffes.

Antilope. Antelopes.

Capra. Goats.

Ovis. Sheep.

Bos. Oxen.

Order Vil. Cetacea.

Lamantins.

Dolphins.

Whales.

(225.) The above sketch will give the reader a general idea of the method employed by our author in the arrangement of the Mammalia. We observe a vast addition to the materials possessed by Linnæus, and a corresponding increase in the number of divisions and subdivisions ; all of which, as tending to point out dif- 
ferences, are highly valuable. But, in arranging these into a comprehensive form, our author falls far short of his illustrious predecessor. He has rested his distinctions, as we have already seen, upon characters which, however good, are not always comprehensible, except to the anatomist. The utility of his system, for general use, is consequently much diminished, and it gives the student an impression (certainly an erroneous one) that the internal, and not the external, structure of an animal alone decides its place in nature. These difficulties are further increased by the want of those synoptical tables, so admirably constructed by Linnæus, where the essential characters of each group are clearly and luminously stated, and where the eye, at a single glance, can embrace them all. On the other hand, we cannot but admire the precision with which the anatomical distinctions of many of the minor groups are made out, and the vast additions which this celebrated writer has made to the other details of zoology. His work, with all its imperfections of arrangement, has been justly designated a " mine of wealth, as rich as it is inexhaustible."

(226.) The class of birds is arranged in the following method; the whole being divided into six great orders, five of which are natural, namely, the Raptores, the Insessores, the Rasores, the Grallatores, and the Natatores of this work; the sixth being composed of the climbing birds (Scansores), which Linnæus, more correctly, arranged with the Passeres or, Perchers.

Orner I. Accipitres $L$.

\section{Vulture Family.}

Vultur.

Cathartes.

Percnopterus.

Gypaetos.

\section{Falcon Family.}

Falco $L$.

Hierofalco $\mathrm{Cuv}$.

Aquila Auct.

Haliæetus Sav.

Pandion Sav.

Circætus Vieil.
Harpyia Cuv.

Morphnus Cuv.

Cymindis Cuv.

Astur Cuv.

Milvus Bech.

Buteo Bech.

Circus Bech.

Gypogeranus nliger

Owl Family.

Otas (Asio Antiq..)

Ulula Cuv.

Strix Sav.

Syrnium Sav. 
- Bubo Cuv.

Noctua Sav.

Scops Sav.

Order II. Passeres $L$.

1. Dentirostres.

Shrike Family.

Lanius $L$.

Vanga Buff:

Ocypterus Cuv.

Barita Cuv.

Chalybæus $\mathrm{Cuv}$.

Psaris Cuv.

Graculus $\mathrm{Cuv}$.

Bethylus Cuv.

Falcunculus Vieit.

ज1 Pardalotus Vieil. :

Flycatcher Family.

Tyrannus Briss.

Muscipeta $\mathrm{Cuv}$.

Muscicapa $L$.

- Gymnocephalus Geaff.

Cephalopterus Geoff:

\section{Chatterer Family.}

Ampelis $L$. :

Tersina Vieil.

Ceblepyris $\mathrm{Cuv}$.

Bombycilla Briss.

Procnias Haff.

Gymnoderus Geoff:

Edolius Cuv.

Phibalura Vieit.

Tanager Family.

Tanager $L$.

Euphonia Vieil. ']

Thrush Family.

Turdus $L$.

Myothera $\mathrm{Ill}$.

Cinclus.

Orthonyx.

Philedon Cuv.

Eulabes $\mathrm{Cuv}$.

Gracula $\boldsymbol{L}$.

Manorhina.

Pyrrhocorax.

Oriolus.

Gymnops. :

Menura.

Warbler Family.

Motacilla $L$.
Saxicola $B$.

Sylvia Auct.

Curruca Bech.

Regulus Ray.

Troglodytes Ray.

Motacilla $\boldsymbol{L}$.

Budytes Cuv.

Anthus Bech.

Manakin Family.

Rupicola Briss.

Calyptomina Raffles.

Pipra $L$.

Eurylaimus Horsf.

2. Fissirostres.

Swallow Family.

Hirundo $L$.

Cypselus $I l l$.

Caprimulgus.

Podargus Cuv.

3. Conirostres.

Lark Family.

Alauda.

Conic-billed Groups.

Parus $L$.

Emberiza $L$.

Fringilla $\boldsymbol{L}$.

Ploceus Cuv.

Pyrgita Antiq.

Carduelis Briss.

Vidua Cuv.

Coccothraustes Briss.?

Pitylus Cuv.

Pyrrhula Cuv.

Loxia, Briss.

Corythus.

Colius.

Buphaga Briss.

Cassicus Cuv.

Icterus Dand.

Xanthornus.

Oxyrhynchus $S w$.

Dacnis Cuv.

Starling Family.

Sturnus.

Crow Family.

Corvus $L$.

Pica Briss. 1

Garrulus Briss. 


\section{Caryocatactes Cuv. \\ Crypsirina Vieil. \\ Glaucopis Forst.}

\section{Roller Family.}

\section{Coracias $L$.}

Colaris Cuv.

Paradisea $L$.

\section{Tenuirostres. \\ Sitta $L$. \\ Xenops $I l l$. \\ Anabates Tem. \\ Synallaxis Vieil. \\ Certhia $L$. \\ Dendrocolaptes Herm. \\ Tichodroma IIl. \\ Nectarinia $I I I$. \\ Dicæum Cuv. \\ Melithreptes Vieil. \\ Cinnyris Cuv. \\ Arachnothera $\mathrm{Tem}$.}

Humming-Bird Family.

Trochilus $L$.

Orthorhynchus Lacep.

Hoopoe Family.

Upupa $I$.

Fregilus $\mathrm{Cic}$.

Promerops Briss.

Epimachus Cuv.

Syndactyle Family.

Merops $L$.

Prionites III.

Alcedo $L$.

Ceyx Lacep.

Todus $L$.

Buceros $L$. :

Order III. Scansores.

Galbula $L$.

Picus $L$.

Yunx $L$.

Cuckow Family.

Cuculus $\boldsymbol{L}$.

Saurothera Vieil.

Centropus IIl.

Leptosomus Vieil.

Indicator Le Vail.

Monassa Vieil.

Phænicophaus Vieil.
Scythrops Lath.

Bucco $L$.

Pogonias IIl.

Tamatia Marc.

Trogon $\boldsymbol{L}$.

Crotophaga $L$.

Ramphastos $I$.

Pteroglossus Ill.

Parrot Family.

Psittacus $L$.

Ara $K u h l$.

Conurus $K u h l$.

Pezoporus IIl.

Turacco Family.

Corythaix IIl.

Musophaga Isert.

Order IV. Gallina $L^{\prime}$

Curassow Family.

Alector Merrem.

Crax $L$.

Ourax Cuv.

Penelope Merr.

Ortalida Merr.

Opisthocomus Hoff.

Peacock Family.

Pavo $L$.

Lophophorus Tem.

Meleagris $L$.

Numida $L$.

Pheasant Family.

Phasianus $L$.

Gallus $L$.

Tragopan Cuv.

Cryptonyx.

Partridge Family.

Tetrao $\boldsymbol{L}$.

Lagopus Ray.

Pterocles Tem.

Perdix Bris.

Coturnix Auct.

Hemipodius Tem.

Ortygis IIl.

Syrrhaptes $I I l$.

Crypturus $I I l$.

Pigeon Family.

Columba $L$. 
Lophyrus Vieil. Vinago Cuv.

\section{- Order V. Gralla $L$.}

Ostrich Family.

Struthio $L$.

Casuarius Briss.

Plover Family.

Otis $L$.

Charadrius $L$.

CEdicnemus Tem.

Squatarola $C$.

Vanellus Bech.

Hæmátopus $L$.

Tach ydromus $\mathrm{Ill}$.

Dicholophus $\mathrm{Ill}$.

\section{Heron Family.}

Grus Antiq.

Psophia $L$.

Eurypyga $\mathrm{Ill}$.

Cancroma $L$.

Ardea $L$.

Ciconia Briss.

Mycteria $L$.

Scopus $L$.

Anastomus $I l l$.

Dromas Pay.

Tantalus $L$.

Platalea $L$.

Snipe Family.

Scolopax $L$.

Ibis Antiq.

Numenius Cuv.

Scolopax $L$.

Rhynchæa Cuv.

Limosa Bech.

Tringa $L$.

Arenaria Bech.

Pelidna Cuv.

Falcinella Cuv.

Machetes Cuv.

- Eurinorhynchus Wilson.

Phalaropus Briss.

Strepsilas Ill.

Totanus Cuv.

Lobipes $\mathrm{Cuv}$.

Hemantopus Briss.

Recurvirostra $L$.

Rail Family.

Parra $L$.

Palamedia $L$.
Megapodius Dup.

Rallus $L$.

Fulica $L$.

Gallinula Briss.

Porphyrio Briss.

Chionis Forster.

Glareola $\mathrm{Gm}$.

Phoenicopterus $\mathcal{L}$.

Order Vi. Palmipedes.

Grebe Family.

Colymbus $L$.

Podiceps Lath.

Podoa Ill.

Eudytes Ill.

Uria Briss.

Alca $L$.

Phaleris Tem.

Aptenodytes Forster.

Catarrhactes Briss.

Spheniscus Briss.

Puffin Family.

Procellaria $L$.

Puffinus Ray.

Halodroma Ill.

Pachyptila $1 l l$.

+1 Diomedia $L$.

Gull Family.

Larus $L$.

Lestris Tem.

Sterna $L$.

Rhynchops $L$.

Pelican or Web-footed Family.

Pelecanus $L$.

Carbo Meyer.

Tachypetes Vieit.

Dysporus Ill.

Plotus $L$.

Phæton $L$.

Duck Family.

Anas $L$.

Cygnus Ant.

Anser Ant.

Cereopsis Lath.

Fuligula Ray.

Clangula Leach.

Somateria Leach.

Rhynchaspis Leach.

Tadorna Leach.

Mergus $L$. 
(227.) On comparing this ornithological system with that of Linnæus, there are several features which require separate consideration. First, as to the grand divisions of the class; the unaccountable error of Linnæus, in separating the aquatic orders by the intervention of the land birds, is avoided, and the five leading groups, recognised in the natural system, are preserved. Unfortunately, however, the climbing families have been detached from the Insessores, and elevated to a rank they do not, in reality, hold. This departure, however, from the views of Linnæus, is a matter of no moment in an artificial system, but rather an advantage; since it tends to bring this remarkable group more immediately under the eye of the general reader. Another great advantage apparent in this system, is the formation of families, or groups intermediate in rank between orders and genera. In the days of Linnæus, the birds then known were so few that these intervening divisions were not necessary, and they were consequently omitted. Here, however, the merits of the system before is terminates. For although the whole is interspersed with original and valuable anatomical remarks, and additions to correct nomenclature, the fitting in of the genera (if we may be allowed the expression) is not only unnatural," and consequently erroneous, but at variance with the plan of the work; namely, that of an arrangement founded upon natural organisation. The whole is like a building, of which most of the materials, in themselves, are good; but which, by some unaccountable mistake of the architect, are combined in such a way as to produce any thing but that beauty and order which might have been expected. The ornithological labours of M. Cuvier, in short, do not appear to us to have effected either the establishment of an artificial system, or the advancement of the natural system. This truth has been so often repeated, even by those who have done ample justice to his high and distinguished merits as a comparative anatomist, 
that we deem it unnecessary to cite particular instances. The best, indeed, which the experienced ornithologist can possibly have, is the preceding table of the series of genera, containing a full exposition of the ornithological system of the Règne Animal, which, except in the primary divisions, and with reference to the materials possessed by each, is inferior to that of Linnæus.

(228.) The Cuvierian arrangement of the Reptiles and Fishes need not be here enlarged upon; for, inde. pendent of the space which the details of these divisions would occupy, our own arrangement of these classes will be nearly the same as that of the Rènne Animal. With the class of insects M. Cuvier had no acquaintance, that having been entirely written by the celebrated Latreille, of whose system we shall subsequently speak. M. Cuvier's great merit lies in the anatomical investigation of those soft animals, placed by Linnæus in the class of Vermes. Here his discoveries and observations are so original and valuable, that we feel assured the student will be desirous of seeing them noticed somewhat more in detail.

(229.) II. The Mollusca, with M. Cuvier, form the second of his great divisions of the animal kingdom; and he divides them into the six following classes:1. Cephalopoda, or cuttle-fish ; 2. Pteropoda, or wingfooted Mollusca; 3. Gasteropoda, or univalve shellfish ; 4. Acephala, or bivalve shell-fish ; 5. Brachiopoda, or parasitic shell-fish; and, lastly, 6. the Cirripeda, or barnacle shell_fish. The following table, which enumerates most of the family groups, will give a good idea of the system pursued : -

Orner I. Cephalopoda. Cuttlefish.

Sepia $L$.

Loligo Lam.

Nautilus Lam.

Belemnites.
Ammonites.

Nummulites.

Ozder II. Iteropoda.

Clio.

Cymabulia. 
Cleodora.

Pneumodermon.

Order III. Gasteropoda.

Pulmobranchia.

Limax.

Helix.

Onchidium.

Limnea.

Nudibranchia.

Doris.

Polycera.

Tritonia.

Tethys.

Scyllæa.

Glaucus.

Inferobranchia.

Phyllidia.

Diphyllidia.

Tectibranchia.

Pleurobranchus.

Aplisia.

Dolabella.

Notarchus.

Akera.

Bulla.

Heteropoda Lam.

Pterotrachia.

Carinaria.

Firola Peron.

Pectinibranchia.

Trochoides.

Buccinoïdes.

Tubulibranchia.

Vermetus.

Magiles.

Siliquaria.

Scutibranchia.

Haliotis.

Fissurella.

Emarginula.

Parmophorus.

Cyclobranchia.

Patella.

Chiton.
Order IV. Acephala. Bivalve Shells.

Acephala testacea.

Ostraceæ.

Radiolites.

Spherulites.

Ostrea.

Pecten $L$.

Lima Brug.

Spondylus $L$.

Perna $L$. .

Arca.

Mytilus.

Unio.

Chama.

Cardium.

Venus.

Mactra.

Mya.

Solen.

Pholas.

Teredo.

Clavigella.

Acephala nuda.

Salpa.

Ascidia.

Botryllus.

Pyrosoma.

Polyclinum.

Order V. Branchiopoda.

Lingula.

Terebratula.

Spirifer.

Thecidea.

Orbicula.

Crania.

Order VI. Cirripeda. Bam nacles.

Anatifera.

Pollicipes.

Cineras.

Otion.

Tetralasmis.

Balanus.

Diadema. 
(230.) III. The third great division of M. Cuvier is composed of the articulated animals, of which INSECTs present the typical perfection. The whole group is divided into four great sections: - 1. The Annelides, or red-blooded worms; 2. The Crustacea, or crabs; 3. The Arachnides, or spiders; and, 4. The Insecta, or insects. It is in this part of his laborious work that our author has found it necessary to call in the assistance of M. Latreille, from whose pen the whole of the third and fourth volume has proceeded. We advert to this fact, as the circumstance has been overlooked by some modern writers, who have attributed to one what belongs to the other.

(231.) IV. The fourth and last division of our author comprises what he terms the radiated animals, or Zoophytes (Animalia radiata); although the term belongs but to a small part of those he has placed under this denomination. The group, in fact, comprises two classes of animals, so totally different, that we cannot but feel surprise they should have been associated together. One of these groups constitute the Acrita, or polypes; the other the true Radiata of this work. In other respects the arrangement before us is highly valuable, and evinces that intimate acquaintance with the details of these animals which laid the foundation for the brilliant career of this incomparable anatomist. Under these circumstances we feel compelled to be more particular on this class than the last.

(232.) The class of Zoophytes is divided by $\mathbf{M}$. Cuvier into five large groups, viz.:-1. The Echinoderma, or the star-fish and sea eggs, forming the genera Asterias and Echinus of Linnæus. 2. The Intestina, intestinal worms. 3. The Acalepha, or medusas. 4. The Polypi, or polypes. And, 5. The Infusoria, or animalcules. Each of these, again, are divided in the following manner :- 
Order I. Echinoderma.

Asterias. Star-fish.

Asterias $L$.

Alecto Leach.

Encrinus $M$.

Echinus $\boldsymbol{L}$.

Cidaris $K l$.

Spatangus Lesk.

Conulus $\mathrm{Kl}$.

Cassidulus Lam.

Echinanthus $K l$.

Echinocyamus Lesk.

Holothuria $L$.

Molpadia Cuv.

Minyas Cuv.

Priapulus Lam.

Lithoderma Cuv

Siponculus $\mathrm{Gm}$.

Bonellia Bol.

Thalassema Cuv.

Echiurus Cuv.

Sternaspis Otto.

Order II. Intestina.

1. Entozoa Nematoïdea Rudolphi."

\section{Filaria $L$.}

Trichocephalus Rud.

Capillaria $R u d$.

Oxyuris Rud.

Cucullanus.

Ophiostoma.

Ascaris $L$.

Strongylus Müll.

Spiroptera Rud.

Physaloptera Rud.

Leorhynchus Rud.

- Pertastoma Rud.

Prionoderma Rud.

Lernæa $\boldsymbol{L}$.

Pinnella $O k$.

Clavella Ok. \&c.

Chondracanthus.

Nemeries Cuv.

\section{Les Parenchymateux.}

Echinorhynchus.

Hæruca $\mathbf{G m}$.

Fasciola $L$.

Tænia $L$.

Scolex Miill.

Ligula Bloch.
Order III. Acalephas Cuv.

Medusa $\mathrm{L}$.

Medusa $L$.

Beroe Mïll.

Porpita Lam.

Veletta Lam.

Physalia Lam.

Physsophora $F$.

Hippopus.

Diplyyes.

Order IV. Potypt.

1. Polypes charnus.

Actinea $L$.

Lucernaria Miull.

2. Polypes Gélatineux.

Hydra $L$.

Cristatella $C$.

Vorticella.

Pedicellaria Miull.

3. Polypes d polypiers.

Tubipora $L$.

Tubularia $L$.

Sertularia $L$.

Cellularia $L$.

Flustra $\boldsymbol{L}$.

Corallina $L$,

Antipathes $L$.

Gorgonia $L$.

Isis $L$.

Madrepora $L$.

y Millepora $L$.

Pennatula $L$.

Alcyonium $L$

Spongia $L$ :

Order V. Infusorta. Animalcules.

1. Rotiferce.

Rotifera.

Vaginicola.

Tubicolaria.

Brachionus.

2. Infusoria homogenea.

Urceolaria.

Trichoda.

Cercaria.

Vibrio.

Proteus.

- Monas.

Volvox. 
(233.) Notwithstanding the length of the above table, we have found it impracticable to insert the whole of the divisions and sub-genera which crowd the pages of the Règne Animal. Many of these are designated only by their French names; a practice highly detrimental to that clearness and perspicuity of nomenclature which should be preserved in works of science : and this, added to the want of synoptical tables throughout the work, materially diminishes its utility for facile reference. We have, however, enumerated the leading groups ; and these will sufficiently explain to the student the nature of the whole, and guide him in his search after the lesser divisions.

(234.) We have now given an exposition of the two most celebrated systems of modern times; namely, those of Linnæus and of Cuvier. They are the only two which have embraced the whole of the animal kingdom, from the higher groups down to the lowest. Several others, indeed, have been given to the world; but they are rather compiled than original schemes; and, from not carrying with them internal evidence of adequate knowledge, have received neither support from the scientific, nor popularity from the public. These may, therefore, be passed over in silence. But there are others, relating only to particular classes of animals, which are not only highly important as emanating from men justly celebrated in the ranks of science, but equally so as having furnished materials of such value, that without them even the Systema Natura, or the Rène Animal could never have been given to the world. Like those celebrated works, the classifications we are now to notice come also under the head of artificial systems, because they merely tend to illustrate the peculiarities of the individual when viewed by itself, without any reference to its analogies or representations in the general scheme of nature. The partial system of Illiger is confined to quadrupeds and birds ; while those of Vieillot and Temminck are restricted to the latter only. Those most celebrated in entomology have emanated from De Geer, Fabricius, Latreille, Leach, 
and Clairville. Following the order of these names, we proceed to give a slight sketch of each.

(235.) Illiger published his classification of quadrupeds and birds in 1811. The former he divides into fourteen orders, from characters taken from the feet. These orders he arranges under two great or primary divisions : the first containing the true quadrupeds; the second the aquatic or cetaceous Mammalia, and the seals : thus making, at the outset, a retrograde movement from natural arrangement. - These orders, again, are divided into families, under which are arranged the genera. As the groundwork of this system is eminently artificial, and as the genera (excellent in themselves) have been all incorporated in the Rène Animal, there is no occasion to enter upon further particulars. In arranging the class of birds, our author has been somewhat more successful in his higher combinations, although here, likewise, he is inferior to Aristotle. He makes seven orders of the whole; considering the Scansores, or climbers, as distinct from the perching birds (Insessores), which he terms Ambulatores; while he separates, in like manner, the Cursores, or ostrich family, from the Rasores, to which they truly belong: for the rest, the genera are all good, although the series in which they are placed evinces that the author had no idea of the difference between analogy and affinity. These genera are all incorporated in the present work, under the classical and appropriate names bestowed upon them in the Prodromus Systematis Mammalium et Avium of this accomplished zoologist.

(236.) The ornithological system of M. Vieillot is chiefly remarkable for the incorporation of the scansorial birds with the perchers, both forming a part of our author's second order, Sylvicola. He likewise rectified the error of Illiger, in regard to the ostrich family, which he makes the first group among the waders. This arrangement is not far from natural; so that we find, for the first time in modern systems, the natural series of the five orders of birds. M. Vieillot's system 
is further remarkable for the number of new types or sub-genera it contains; nearly all of which, however ill-defined, are natural, and combined together with an evident perception, in many instances, of natural affinities. Our author, it is true, has availed himself largely of the valuable labours of Illiger, and has been justly censured for doing this without any acknowledgment of the aid he thus received; but, in the formation of his groups, and the separation of his genera, he has evidently not been influenced by the example of his more learned predecessor. It will, nevertheless, be unnecessary to give further details of this system; for the genera are so loosely defined that they can be only understood by a reference to the type (generally a wellknown bird) which the author quotes. The priority of the nomenclature, also, is not to be relied upon; since, in many cases, new names have been given to groups previously defined and named by Illiger, Cuvier, and others, all of which are made to appear as emanating from the author himself. M. Temminck has publicly protested against these plagiarisms, and others have spoken of them in terms of severe censure.

(237.) The system of M. Temminck deserves much more attention. Of all those which have been framed without a reference to the general laws of the natural system, it is decidedly the best. This may appear unmerited praise, when we perceive that the very foundation, or, in other words, the primary divisions, are forced and unnatural. M. Temminck loses sight of the groups of Aristotle, and subdivides the leading orders of the class into no less than sixteen divisions. These, however, when viewed in reference to artificial arrangeinent, - and the author is evidently unacquainted with any other,-are very clear, and, consequently, excellent. The genera, it is true, are few, but they are defined with great care, and evince an acquaintance with this class of zoology far superior to that possessed by any of the moderns. Our author's forte, indeed, like that of Illiger, is detail ; but he seems, unfortunately for his 
own fame, to have imbibed the ancient notion that no genus is to be retained, if the links by which it is connected to another are discovered. Hence he adopts very few of the genera intimated by $M$. Vieillot, and even omits some of those defined by M. Cuvier. His merits, however, in the arrangement of his generic groups, and the high finish he has bestowed upon them, have given to his system a prevalence and popularity above all others which have appeared since the days of Linnæus ; next to whom, as an ornithologist, he assuredly ranks. The experienced ornithologist will perceive the artificial nature of the following orders, but the natural connection of a number of the genera they contain :-

Order I. Raptores.

Vultur Illig.

Cathartes Illig.

Gyphætus Storr.

Gypogeranus Illig.

Falco $L$.

Strix $L$.

Order II. Omnivora.

Opisthocomus Illig.

Buceros $L$.

Prionites Illig.

Corvus $I$.

Nucifraga Briss.

Pyrrhocorax Cuv.

Barita Cuv.

Glaucopis Forster.

Gracula $L$.

Buphaga $L$.

Bombycilla Briss.

Ptilonorhynchus $K u h l$.

Coracias $L$.

Colaris Cuv.

Oriolus $L$.

Icterus Dandin.

Sternus $L$.

Pastor Tem.

Paradisea $L$.

Lamprotornis Tem.

Order III. Insectivora.

Turdus $L$.

Cinclus Bech.
Menura Shaw.

Pitta Vieil.

Myothora Illig.

Thamnophilus Vieil.

Vanga Vieil.

Lanius $\boldsymbol{L}$.

Psaris Cuv.

Sparactes Illig.

Ocypterus Cuv.

Fdolius Cuv.

Ceblepyris Cuv.

Coracina Vieil.

Ampelis $L$.

Casmarhynchus Tem.

Procnias Hoff.

Rupicola Cuv.

Phibalura Vieil.

Pipra $L$.

Pardalotis Vieil.

Todus $L$.

Platyrhynchus Des.

Muscicapa $\boldsymbol{L}$.

Malurus Vieil.

Sylvia Lath.

Saxicola Bech.

Accentor Bech.

Motacilla $L$.

Anthus Bech.

Order IV. Granivora.

Alauda $\boldsymbol{L}$.

Parus $L$.

Emberiza $L$. 
Tanagra $L$.

Ploceus Cuv.

Loxia Briss.

Psittirostra Tem.

Pyrrhula Cuv.

Fringilla $L$.

Phytotoma Moll.

Colius Lath.

Order V. ZYgodactyli.

Musophaga Isert.

Indicator Le Vail.

Cuculus $L$.

Coccyzus Vieil.

Centropus Illig.

Phœnicophaus Vieil.

Leptosomus Vieil.

Sythrops Latham.

Pteroglossus Illig.

Ramphastos $L$.

Crotophaga $L$.

Trogon $L$.

Capito Vieil. (Tamatia Cuv.)

Bucco $L$.

Pogonias Illig.

Psittacus $L$.

Picus $L$.

Galbula $L$.

Yunx $L$.

\section{Order VI. Anisodactixl.}

Oxyruncus Tem.

Orthonyx Tem.

Dendrocolaptes Herman. .

Xenops Illig.

Anabates Tem.

Opetiorhynchus Tem.

Certhia $L$.

Cæreba Briss.

Trochilus $L$.

Nectarinia Illig.

Climacteris Tem.

Tichodroma Illig.

Upupa $L$.

Epimachus Cuv.

Drepanis Tem.

Meliphaga Lewin.

; Order VIl. Alcyoni.

Merops $\boldsymbol{L}$.

Alcedo $L$.

Dacelo Leach.
Order VIII. Chruidoni.

Hirundo $L$.

Cypselus Illig.

Order IX. Columbe.

Columba $L$.

Order X. Gillinfi.

Pavo $L$.

Gallus $L$.

Phasianus $L$.

Lophophorus Tem.

Polyplectron Tem.

Meleagris $L$.

Argus Tem.

Numida $L$.

Pauxi Tem. (Ourax Cuv.)

Crax $L$.

Penelope Merr.

Tetrao $L$.

Pterocles Tem.

Syrrhaptes Illig.

Perdix Lath.

Cryptonyx Tem.

Tinamus Lath.

Hemipodius Tem.

Order XI. Alectorides.

Psophia $L$.

Dicholophus Illig.

Glareola $L$.

Chauna Illig.

Order XII. Cursores.

Struthio $L$.

Rhea Briss.

Casuarius Briss.

Otis $L$.

Cursorius Lath.

Order Xill. Grallatores.

Edicnemus Tem.

Calidris Illig.

Falcinellus Cuv.

Hemantopus Briss.

Hæmatopus $L$.

Charadrius $L$.

Vanellus Briss.

Strepsilus Illig.

Grus Pallas.

Aramus Vieil.

Ardea $L$.

Ciconia Briss. 
Anastomus Illig.

Scopus Briss.

Phœnicopterus $L$.

Recurvirostra $L$.

Cancroma $L$.

Platalea $\boldsymbol{L}$.

- Tantalus $L$.

Ibis Antiq.

Numenius Briss.

Tringa $L$.

Totanus Bech.

Limosa Briss.

Scolopax $L$.

Rynchæa Cuv.

Eurypyga Illig.

Rallus $L$.

Gallinula Briss.

Parra $L$.

Porphyrio Briss.

Order XIV. Pinnatipedes.

Fulica $L$.

Podoa Illig.

Phalaropus Briss.

Podiceps Lath.

Order XV. Palmipedes.

Cereopsis Lath.
Chionis Forst.

Rhynchops $L$.

Sterna $L$.

Larus $L$.

Lestris Illig.

Procellaria $L$.

Pachyptila Illig.

Halodroma Illig.

Diomedia $L$.

Anas $L$.

Mergus $L$.

Pelecanus $L$.

Carbo Meyer.

Tach ypetes $V i e i l$.

Sula Briss.

Plotus $L$.

Phæton $L$.

Uria Briss.

Phalaris Tem.

Mormon Illig.

Alca $L$.

Spheniscus Briss.

Aptenodytes Forst.

Order XVI. Inertes.

Apteryx Shaw.

Didus $L$.

(238.) We must here close our enumeration of ornithological systems : very many others are enumerated by M. Lesson, who is himself the author of two. The prince of Musignano has more recently given the outlines of another, and we know not how many have been lately drawn up by the writers of Germany.

(239.) Of partial systems, restricted to entomology, that of the celebrated baron De Geer must be first mentioned; not only because of its priority, but because it approaches most nearly to that of Aristotle and Linnæus of any in modern times. The following exposition of the orders will show how nearly the views of this great man coincided with those of his two illustrious predecessors. De Geer at once perceived the typical peculiarity of the class Insecta to consist in their being winged; and he, accordingly, sets out with dividing the whole into two primary groups : but let us look to the annexed table for the details :- 
'Div. I. Alata. (Ptilota Aristotle.)

I.

GYMNOPTERA. Four wings, without wingcases.

1. LEpidoptera. Wings covered with scales, tongue spiral.

2. Elinguia. (Neuroptera $L_{\text {.) }}$ Wings four, tongue and teeth none. (Trichoptera K.)

3. Neuroptera. Wings membranaceous, equal reticu. lated; mouth furnished with teeth.

4. HYMENOPTERA. Wings membranaceous, unequal; nervures mostly longitudinal; mouth with teeth. Fe. male with a sting.

5. Siphonata. (Hemiptera L.) Wings membranaceous ; tongue bent under the breast. (Homopetra Leach.)

6. Derma ptera. (Hemiptera L.) Elytra half memII. branaceous, half coriaceous, crossed. A pair of membranous wings, tongue bent under the breast.

VAGINATA. Two wings, covered by two wingcases.

7. HEMIPTERA. Elytra coriaceous, or semi-crustaceous, aliform; a pair of membranous wings; mouth with teeth. (Orthoptera Lat.)

8. Coleoptera. Wings hard and crustaceous, with a pair of membranous wings beneath; mouth furnished with teeth.

III 9. Halterata. (Diptera $L_{\text {.) }}$ Wings two, membrana.

Diptera.

Two wings

uncovered.

ceous; poisers two; mouth with a tongue, but without teeth.

10. Рroboscidea. (Hemiptera L.) Wings two, membranaceous. Male without either poisers, tongue, or teeth. Female apterous, with a tongue in the breast.

Div. II. Aptera. (Aptera L.) $\left.\begin{array}{l}\text { IV. } \\ \text { SAltatoris. } \\ \begin{array}{l}\text { Undergoing } \\ \text { a metamor- } \\ \text { phosis. }\end{array}\end{array}\right\} \begin{gathered}\text { 11. Suctoria. Wings none; feet six; mouth with a } \\ \left.\text { proboscis. (Pulex } \mathrm{L}_{\text {. }}\right)\end{gathered}$

V.

Gressoria. Undergoing no metamorphosis.

12. Aucenata. Wings none; feet six; head and thorax distinct. (Hexapod Aptera, Termes, Psocus.)

13. Atrachelia. Wings none; feet six or more; head united with the trunk. (Octopod Aptera, Arachnida, Crustacea.)

14. Crustacea. Wings none; feet fourteen or: more; head separated from the thorax. !(Polypod Aptera, Crustacea.)

(240.) It has been well observed on this system, that this great naturalist, - whose merits repose on a much more permanent basis than mere classification, - by following too strictly the number and substance of the organs of flight, has been led to place in different classes insects which ought not to have' been so separated.* He appears, nevertheless, to have been convinced of the propriety of Aristotle's primary divisions of winged and 
wingless insects ; but, like him, he had a most imperfect conception of the latter group. His departure from the orders established by Linnæus will, by many, be extolled as the commencement of all the good that has been since matured; while, by others, it will be designated as the first commencement of those erroneous theories which, in modern times, have led us astray from nature.

(241.) Fabricius was the great systematist of his day; but his classification, once so prevalent, has long been abandoned. He published two systems; one in 1775 , and the other in 1798 . The primary groups of the latter, as drawn up by Messrs. Kirby and Spence, are here subjoined; chiefly for the purpose of showing the passion for new names, which now began to arise among the continental naturalists, and to illustrate the different conceptions of entomological groups entertained by our author from those of Aristotle, Linnæus, and De Geer: -

1. Eleutherata. (Coleoptera L.) Maxilla naked, free, palpigerous.

2. Ulonata. (Orthopterous Neuroptera L.) Maxilla covered by an obtuse lobe.

3. Syristata. (Neuroptera L.) Maxilla geniculated at the base, and connate with the labrum.

4. Piezata." (Hymenoptera L.) Maxilla corneous, compressed, often elongate.

5. Odonata. (Neuroptera L.) Maxilla corneous, toothed, palpi two.

6. Murosata. (Myriapoda Leach.) Maxilla corneous, vaulted, palpi none.

7. Unogata. (Pulmonary Arachnida Lat.) Maxilla corneous, armed with a claw.

\section{***}

8. Polygonata. (Isopod and Branchiopod Crustacea Lat.) Palpi mostly six, maxillæ many, placed within the labium.

9. Kleistognatha. (Brachiurus, Decapod Crustacea of Lat.) Many maxillæ without the labium, closing the mouth.

10. Exochnata. (Macrourus, Decapod Crustacea Lat.) Maxillæ many, without the labium covered by palpi. 
****

11. Grossata. (Lepidoptera L.) Mouth with a spiral tongue between reflected palpi.

12. Ryngata. (Hemiptera L.) Mouth with a rostrum having a jointed sheath.

13. Antriata. (Diptera L. Anoplura, Leach. Trachean Arachnida, \&.c.) Mouth with an haustellum without joints.

(242.) "In estimating the value of the above system, we must bear in mind," observe Kirby and Spence, " that, according to the statement of its author, it was intended to be partly artificial and partly natural ; that is, artificial as to its classes and orders, but natural as to its genera, species, and varieties."* Whatever were the intentions of the author, his system, founded in all its parts upon the minute organs of the mouth, is, of all others, the most artificial, the most difficult, and the most discouraging and repulsive to the student. So that whatever merits belong to Fabricius in other respects, there is great truth in the opinion generally entertained of his system; namely, that it retarded, instead of advanced, the progress of entomological science.

(243.) The system of the celebrated Latreille, whose recent loss we so much deplore, soon superseded that of Fabricius. It possesses the advantage of being founded on a consideration of the entire structure of these animals; and hence gives us the first example, in theory, of the natural principle of classification. To show in what manner this principle is applied, we shall copy his distribution of insects, given in his last work. $\downarrow$ The first divisions of the whole class are three; viz. Crustacea, Arachnida, and Insecta; each of which is again subdivided as follows : -

\section{Crustacea.}

1. Malacostraca.

a. Decapoda. Brachyura. Macraura.
b. Stomapoda.
Unipeltata.
Bipeltata.
c. Amphipoda.
d. Læmodipoda. 
e. Isopoda.

2. Entomostraca.

f. Branchiopoda.

g. Pœcilopoda.

Xyphosura.

Siphonostoma.

$h$. Trilobites.

\section{Arachnidzs.}

Pulmonariæ.

Araneides.

Pedipalpi.

Tracheariæ.

Pseudo-Scorpiones.

Pyenogonides.

Holetra.

Phalangium.

Acarides.
III. INSECTA.

Myriapoda.

Chilognatha.

Iulus.

Chilopoda.

Scolopendra.

Thysanura.

Lepismidæ.

Poduræ.

Parasita (Anoplura Leach).

Pediculus.

Siphonaptera.

Pulex.

Coleoptera.

Orthoptera.

Hemiptera.

Neuroptera

Hymenoptera.

Lepidoptera.

Rhipiptera.

Diptera.

(244.) It must be remembered that, although this system is by Latreille, it forms part of the Rène Animal, and apparently stands under the name of Cuvier: the latter, as we have already seen, places the Annelides, or red-blooded worms, in the same class as insects, thus making the primary divisions four. We regret our space will not permit a fuller elucidation of this system, which, however defective in its primary groups, is the most elaborate and the most perfect in its details that has yet been given to the world.

(245.) Thê system of Clairville is chiefly remarkable for having given rise to the theory of dividing perfect insects into the two great typical groups, as they are thought to be, of Haustellata and Mandibulata. The following table explains his primary divisions :-

\begin{tabular}{|c|c|c|c|}
\hline $\begin{array}{c}1 . \\
\text { Pterophora. } \\
\text { Winged. }\end{array}$ & $\left\{\begin{array}{l}\text { Mandibulata. } \\
\text { Haustellata. }\end{array}\right.$ & $\begin{array}{l}\text { Clairville. } \\
\left\{\begin{array}{l}\text { 1. } \text { Elytroptera. } \\
\text { 2. Deratoptera. } \\
\text { 3. Dictyoptera. } \\
\text { 4. Phleboptera. }\end{array}\right. \\
\left\{\begin{array}{l}\text { 5. Halteriptera. } \\
\text { 6. } \text { Lepidoptera. } \\
\text { 7. } \text { Hemimeroptera }\end{array}\right.\end{array}$ & $\begin{array}{l}\text { Linnaus. } \\
\text { Coleoptera. } \\
\text { Orthoptera. } \\
\text { Neuroptera. } \\
\text { Hymenoptera. } \\
\text { Diptera. } \\
\text { Lepidoptera. } \\
\text { Hemiptera. }\end{array}$ \\
\hline
\end{tabular}

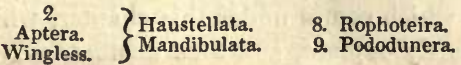


(246.) It has been said " that the principal merit of this system is the division of insects, tacitly pointed out by Fabricius, into two groups or sub-classes, from the mode in which they take their food." If by this it is meant that these two sub-classes are natural, then they will form two circular groups exclusive of the Aptera, which they do not, even according to the circular theory which has been founded upon them.

(247.) Dr. Leach, whose labours are so well known to entomologists, appears, according to Samouelle, to arrange the annulose types under five leading classes; thus:-

1. Gills for respiration. Legs 16. Antennæ 2 or 4. 1. Crustacea.

2. Sac for respiration. Legs 12. Antennæ none. 3 ARAchNoIdea.

3. Trachea for $\{$ No antennæ.

respiration. $\{$ Two antennæ.

Six thoracic legs. 2. MYriapoda.

4. ACA RI.

$\left\{\begin{array}{c}\text { Six thoracic legs, } \\ \text { but no abdominal. }\end{array}\right\}$. Insecta.

(248.) His divisions of the last class, or that of Insecta, have been thus registered in the third volume of his "Zoological Miscellany :" -

I. Sub-class.

A meta Bolia.

No metamorphosis.

Body ending in bristles.

1. Thysanura.

2. Anoplura.

3. Coleoptera.

4. Dermaptera.

5. Orthoptera.

6. Dictuoptera. Blatta L.

7. Hemiptera.

II. Sub-class. Metabulia.

8. Homoptera. Metamorphosis

9. Aptera.

ro. Lepidoptera. triple.

11. Trichoptera.

12. Neuroptera.

13. Hymenoptera.

14. Rhipiptera.

15. Diptera.

16. Omaloptera.

(24.9.) We may now be allowed to close this enumeration of artificial systems, which serve to mark the rise and progress of systematic arrangement, but which exercise very little influence on the present state of the science, pursued, as it now is, upon principles of inductive philosophy. There is, however, another mode of arrangement, which comes under this chapter, which we shall now shortly explain, and then dismiss. 
(250.) Binary or dichotomous systems, although regulated by a principle, are among the most artificial arrangements that have been ever invented. This great principle upon which the advocates of such tables insist, simply consists in arranging animals according to their positive and negative characters; as, for instance, birds with perfect wings, and, secondly, birds with imperfect wings ; and so on. Now this mode of arrangement is, perhaps, the most simple, and the most easy of comprehension, of any that has been devised; and was, therefore, the earliest in use. It likewise seems to offer a ready clue to the discovery of any particular species or genus, because the student has no occasion to look beyond the table before him: he need not trouble himself about affinities or analogies, for he has merely to see what particular character his specimen has, and what it has not. When, therefore, his object is either to ascertain the recorded name of a species, or whether it be described or undescribed, he will often find this sort of catalogue useful. But the misfortune of the binary methods of arrangement is this, that they may be multiplied ad libitum. As their advocates profess not to pursue any one principle in the selection of their characters, it follows that we may have a hundred different binary systems, each good in its way, but each different from the other. One entomologist may choose to divide all insects into such as have wings, and, secondly, such as have none. Another, looking to the manner of feeding, may make his two groups depend upon one having jaws, the other none. A third, considering metamorphosis as the corner-stone of his system, may divide all insects into such as undergo this transformation, and such as do not. Hence, it follows, that every one may form a binary system of his own, provided he closely attends to, and "possesses distinct conceptions on, positive and negative characters ;" the only requisite, as its advocates affirm, for this mode of arrangement. As for preserving the natural affinities of groups, it is by no means necessary to the systems in question that any regard should 
be paid to such matters; their advocates, very judiciously, do not insist on such considerations, nor do they attempt to point out in what way nature gradually passes from one group to another. That the reader, however, may be better able to judge for himself on the merits of a binary or dichotomous arrangement, we here present him with a table of the class of birds, as given by one who is, we believe, the only advocate of dichotomy*:

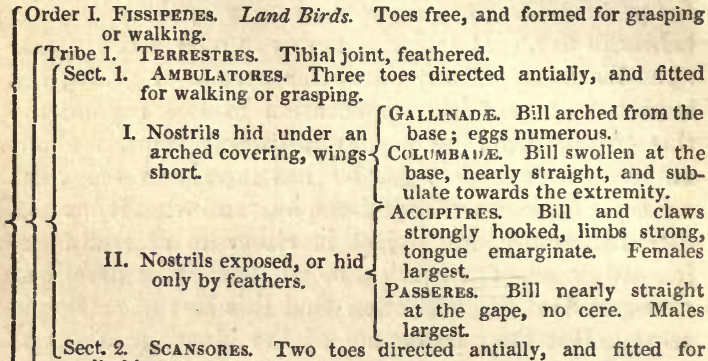
climbing trees.

LTribe 2. GRALle. Waders, lower end of the tibial joint and tarsus naked.

Lorder II. Palmipedes. Water Birds. Toes webbed to their extremity, and formed for swimming.

(251.) The value of a theory can only be determined when we bring it into practice, and when, by following it down to its lowest details, we can judge how far it is agreeable with our ordinary conceptions of nature, and how far it answers the purposes of arrangemient. With this view let us examine the foregoing table, which we must presume has been drawn up by one having " distinct conceptions on positive and negative characters ;" and let us do this, both with reference to its natural order, and to the help it gives for the determination of a species. We need not be long detained on the first, for it is difficult to name any two families of birds more unlike each other than the pigeons ( $\mathrm{Co}$ lumbada) and the eagles (Accipitres), which are here brought together. A greater violation of nature was

* Dr. Fleming's Philosophy of Zoology and British Animals. 
never, perhaps, ventured upon in any system; and this alone is sufficient to take from the whole scheme any pretensions to the claim of a natural series. But the merit of Dichotomy, it may be urged, lies in the strength of its absolute characters, by which a student can at once determine the division to which a genus or a species belongs. We will, therefore, test it by this principle. Every ornithologist is aware that the feet of the kingfishers (Halcyonida), bee-eaters (Meropida), and the puff-birds (Tamatina), have two toes before and two behind, but that these families, so far from climbing, like the Scansores, are only able to sit still upon a branch, and watch for their prey, which they take upon the wing after the manner of swallows. Here, then, is an entire natural division, containing nearly 100 species, recognised by all modern writers out which, in this dichotomous system, has no place whatever assigned to it. Again, the family of tree creepers (Certhida), well exemplified both by our common creeper and nuthatch, are eminently scansorial, and live, as it were, on the upright trunks of trees; but the student, knowing this, and wishing to find their station among the "Scansores," may search in vain either for one genus or the other. To multiply further instances will be needless. It appears, therefore, that a dichotomous or binary system will not even answer the purpose of an index to the genera or species, while it makes pretension to placing those groups together which every one sees that nature has united. The Linnæan arrangement of birds, with all its defects, is more natural, and more easy of comprehension.

(252.) It is quite unnecessary to particularise the different binary systems which have been published by various hands ; since we, no less than our readers, might draw up fifty others, each different from the other, and each as worthless for use. 


\section{CHAP. III.}

ON NATURAT SYSTEMS. - PRELIMINARY OBSERVATYONS. - DEFINITION OF A NATURAL SYSTEM. - HRRMANN'S. - OBSERVATIONS. - LAMARCK'S SYSTEM OF THE INVERTEBRATED ANIMALS. - SYSTEM OF MACLEAY IN ENTOMOLOGY. FRIES'S IN BOTANY. - ALTERATIONS IN MACLEAY'S SYSTEM. - REMARKS THEREON. - SEPTENARY AND OTHER THEORIES. - GeNERAL REMARKS ON NUMERICAL THEORIES, AND ON THE NECESSITY OF PROVING THAT GROUPS ARE CIRCULAR.

(253.) WE have already touched upon the essential distinctions between an artificial and a natural system; but the latter will now claim more of our attention. As every principle of analogical reasoning, and every result of minute investigation, leads to the conclusion that there is a unity of plan throughout that part of creation which embraces the animal world, so it follows that there cannot, strictly speaking, be more than one natural system. It may, therefore, be objected to us, as it has already been to others, that, by speaking of natural systems, we imply that there may be several. Let us, therefore, at the commencement, be clearly understood upon this point. If, by the natural system, we are to understand a complete developement of all the properties and relations of animated beings; the functions they are intended to perform; the principles upon which their forms have been regulated ; their indisputable affinities among themselves, and their innumerable analogies to all others, then the natural system is a pinnacle of knowledge to which finitebeings can obviously never reach. But this, though a just definition, is too theoretical for practical use; seeing that human knowledge must be for ever imperfect, while the faculties of the 
mind are limited. In adapting our terms, therefore, to the actual state of things, we shall consider that to be a natural system which endeavours to explain the multifarious relations which one object bears to another, not simply in their direct affinity, by which they follow each other like the links of a vast chain, but in their more remote relations; whereby they typify or represent other objects, totally distinct in structure and organisation from themselves, by certain general laws. Hence it follows, that there may be many natural systems, or, rather, attempts at the partial discovery of that one which Armighty Wisdom pursued in the creation of irrational beings. This, therefore, is the true object of a natural classification; and none which professes not to set out with this aim, and does not keep it in view as the goal to be arrived at, can claim the title of a natural system. Our first attempts at such a mode of studying nature are comparatively easy : we begin from a given point, and the regular gradation which we are able to trace from one form to another, leads us to believe that the natural series is much more simple and easy of detection than we at first imagined; but, as we advance, we find the relations of our animals multiply: they seem, indeed, to preserve their line of affinity, but to branch off in various directions to the right hand and to the left, until they blend into other races, far removed from that with which we first commenced our enquiries. Here, then, our difficulties begin; and it is here that the study of the natural system commences. It may well be supposed that, on a subject so intricate, great diversity of opinions may arise, and that, while all such naturalists are striving at the discovery of one system, " the only one of nature," that they may, in reality, produce several - all, indeed, professing to expound the same thing, but all doing so on a different theory, and with more or less success. How, then, it may be asked, are we to decide on their respective merits, and to which are we to give the preference? Our answer will 
be this:- The merits of a natural system are in proportion to the number and universality of the facts which it can explain by certain general laws. The system, therefore, which developes principles of the widest application, and brings the elements, if we may so term them, of natural classification into the narrowest compass, is that which obviously makes the nearest approach to nature, and, therefore, deserves to be distinguished, par excellence, as the natural system.

(254.) From this definition of a natural system, as opposed to one that is artificial, it becomes extremely difficult to name that naturalist who deserves to be placed first on our present list. Many of the groups of Aristotle are, undoubtedly, natural, and will stand as such, in opposition to the neglect they received from subsequent zoologists; yet others, in the same system, are in the highest degree artificial. The same may be said both in regard to the systems of Willughby and of Linnæus; yet both these are more properly artificial systems, for they merely attempt to combine the groups in detached portions of a simple series, without any reference to their remote relations. Now, as this latter train of enquiry is that more especially in which the essence of the natural system consists, we may probably regard Hermann as the first who, in regard to animals, entered into any details on this interesting subject. His work, entitled Tabula Affinitatum Animalium, printed in 1783, contains numerous comparisons, and many valuable observations, on the resemblances which different animals bear to each other. But the materials he has thus brought together do not appear to have been applied to any definite or general result ; and it has been justly observed*, that Hermann seemed to have no clear perception of the difference between analogy and affinity, although, like most others who had gone before him, he did not confound them when treating of very remote

- Linn. Trans, vol, xvi, p. 15, \&c. 
resemblances. His work, unfortunately, is so rare in this country, that, having in vain endeavoured to procure a copy, we can only form our opinion of it from $\mathrm{Mr}$. MacLeay's paper in the Linn. Trans. From these notices, it certainly appears that our author laid the first foundation of a natural system - rude, indeed, as may be expected, but replete with comparisons hitherto scarcely noticed. Hermann's system may, therefore, be said to have been long superseded; "for his table, as given at the end of his work, is any thing but a diagram: it is more confused than the Mappa Geographica of Linnæus, both of which have expressed analogies as if they had been affinities." *

(255.) The system of Lamarck, in regard to the soft or invertebrated animals, deserves particular attention, since he was unquestionably the first who, by his unrivalled perception of natural affinities, "obtained an indistinct view of that circular arrangement," which was more clearly and fully developed by his successors in this intricate field of enquiry. This has been most fully and most honourably admitted by Mr. MacLeay in the following passage:- "In the first volume of his (Lamarck's) celebrated work, he acknowledges that the idea of a simple series constituting the whole of the animal kingdom does not agree with the evident order of nature, because, to use his own words, this order is far from simple: it is branched, and is at the same time composed of several distinct series. He then presumes, that animals offer two separate subramose series, one commencing with the Infiusoria, and leading by means of the mollusca to the cuttlefish (Cephalopoda), and the other commencing with the intestinal worms, and leading to insects. Now, this notion could only have gained a place in the mind of Lamarck from a conviction by experience of its being an incontrovertible truth." After enumerating the series thus indicated by Lamarck $t$, our author adds, "Now,

* Linn. Trans, vol. xvi. p.11. note.

† Nat. Hist. des Anim. sans Vert. vol, i. p. 456.

o 4 
this table of affinities, however confused it may appear, or subramose, as it is termed, coincides with the tabular view which I have laid before the public.* We have only to join the Radiata to the Cirripeda, and the Annalides to fishes, and Lamarck's table of affinities, with scarcely any alteration, becomes precisely the same as mine." It is therefore clear, that the first perception of that circular series of affinity which pervades the animal kingdom was gained by Lamarck in the year 1815. But this was done without the least suspicion arising, on his part, that the circularity of natural groups was the first principle of natural arrangement. His studies, in fact, did not extend to vertebrated animals; but he had an intuitive perception of natural affinities; and by following these he traced the natural series, without, however, perceiving that it assumed the disposition of a circle, which the vertebrated animals would render complete. That this fact may be more apparent to our readers, and that we may justify our opinion that the system of this able but fanciful zoologist was eminently natural, we here subjoin the table in question:-

Series of Inarticulated Animals.

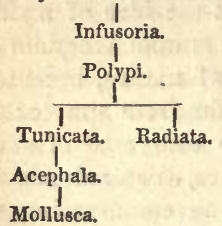

Series of Articulated Animals.

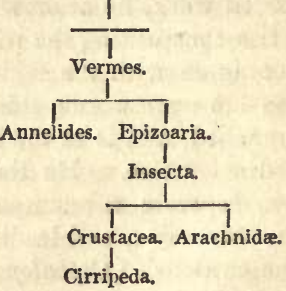

Pisces.

Reptilia.

A ves.

Mammalia.

(256.) Lamarck is chiefly known in this country by his admirable arrangement of the testaceous mollusca or shells, a department in which he created so great a reformation 
that he has left comparatively little to be done, as regards the definition of natural genera, by those who come after him. All must admire the acumen, judgment, and extensive knowledge which this celebrated man possessed, and which shines forth in the admirable manner in which he grouped those objects which were his peculiar study. Yet, while we do justice to his memory in this respect, we must reprobate those atheistical theories, no less impious than absurd, which he has introduced in his writings, - theories which are inconsistent with his own words, and which are too ridiculous even to be repeated.

(257.) The circular system of MacLeay, as following in the order of succession, is now to be noticed. We have seen that Lamarck, so far back as 1815 , had not only positively declared his conviction that the natural series was neither simple nor linear, but that he had given a table indicating a union of all the large divisions of the animal world; but this, after all, was but the first glimpse of these important discoveries regarding the fundamental principles of the natural system which were first made known by the Hora Entomologica. Lamarck, likewise, although he partially traced the animal circle, had no true perceptions of the course it was taking. His table, in fact, was not unlike an architectural drawing, where the great rules of perspective had been pretty well adhered to, but which rules could not be explained by the artist upon their true principle, having been drawn merely by the help of a remarkably accurate eye. Here, then, is one of the chief merits of the system of Lamarck, a system which must certainly be considered as the first promulgation of any universal law in natural classification.

(255.) The Hore Entomologica, unluckily for students, can only be thoroughly understood by the adept, since the results and observations are explained in different parts, the style is somewhat desultory, and the groups, for the most part, are rather indicated than defined. The whole, in short, is what it professes to be, more a 
rough sketch of the leading peculiarities of the great divisions of animals, and the manner in which they are probably connected, than an accurate determination of the groups themselves, or a demonstration of their real affinities. More than this, perhaps, could not have been expected, considering the then state of science, and the herculean difficulties which the author had to surmount. The work in question has now become exceedingly scarce, and this will be an additional reason with us for communicating occasional extracts from it to the reader. Mr. MacLeay's theory will be best understood by consulting his diagrams ; for he has not, as we have already remarked, defined any of the vertebrated groups. Condensing, however, the result of his remarks, we shall state them as resolvable into the following propositions: - 1 . That the series of natural animals is continuous, forming, as it were, a circle ; so that, upon commencing at any one given point, and thence tracing all the modifications of structure, we shall be imperceptibly led, after passing through numerous forms, again to the point from which we started. 2. That no groups are natural which do not exhibit, or show an evident tendency to exhibit, such a circular series. 3. That the primary divisions of every large group are ten, five of which are composed of comparatively large circles, and five of smaller: these latter being termed osculant, and being intermediate between the former which they serve to connect. 4. That there is a tendency in such groups as are placed at the opposite points of a circle of affinity " to meet each other." * 5. That one of the five larger groups into which every natural circle is divided, "6 bears a resemblance to all the rest, or, more strictly speaking, consists of types which represent those of each of the four other groups, together with a type peculiar to itself." + These are the chief and leading principles which Mr. MacLeay considers 
as belonging to the natural system. We shall now copy his diagram, or table of the animal kingdom, and then endeavour, with this help, to explain the system more in detail.

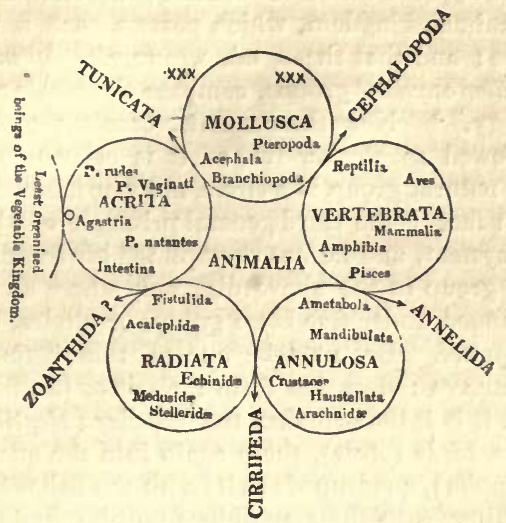

(259.) We must, in the first instance, look to the above tabular disposition of all animals, as forming themselves collectively into one great circle, which circle touches or blends into another, composed of plants, by means of the "least organised beings of the vegetable kingdom." Next we are to look to the larger component parts of this great circular assemblage. We find it, in accordance with the third proposition, to exhibit five great circles, composed of the MouLusca, or shell-fish; Acrita, or polypes; Radiata, or star-fish; Annulosa, or insects ; and Vertebrata, or vertebrated animals ; each passing or blending into each other, by means of five other groups of animals, much smaller, indeed, in their extent, but forming so many connecting or osculant circles. The number, therefore, as many erroneously suppose, is not five, but ten. This is quite obvious; 
and our opinion on this point is confirmed by the author himself, in the following passage, when alluding to his remarks upon the whole:- "The foregoing observations, I am well aware, are far from accurate, but they are sufficient to prove that there are five great circular groups in the animal kingdom, which possess each a peculiar structure: and that these, when connected by means of. five smaller osculant groups, compose the whole province of zoology." * Now these smaller osculant groups are to be viewed as circles, for, as it is elsewhere stated, "every natural group is a circle, more or less complete." This, in fact, is the third general principle of Mr. MacLeay's system, and he has exemplified his meaning of a natural group in the above diagram, where all animals are arranged under five large groups or circles, and five smaller ones. Let us take one of these groups, the Vertebrata : does that form a circle of itself? Yes; because it is intimated that the reptiles (Reptilia) pass into the birds (Aves), these again into the quadrupeds (Mammalia), quadrupeds unite with the fishes (Pisces), these latter with the amphibious reptiles, and the frogs bring us back again to the reptiles, the point from whence we started. Thus the series of the vertebrated group is marked out and shown to be circular; therefore it is a natural group. This is an instance where the circular series can be traced. We now turn to one where the series is imperfect, but where there is a decided tendency to a circle: this is the Moluusca. Upon this group our author says, "I have by no means determined the circular disposition to hold good among the MotLuscA; still, as it is equally certain that this group of animals is as yet the least known, it may be improper, at present, to conclude that it forms any exception to the rule: it would even seem unquestionable that the Gasteropoda of 'Cuvier return into themselves, so as to form a circular group; but whether the Acephala form 
one or two such, is by no means accurately ascertained, though enough is known of the Mounusca to incline us to suspect that they are no less subjected, in general, to a circular disposition than the four other great groups." * This, therefore, our author considers as one of those groups which, without actually forming a circle, yet evinces a disposition to do so ; and it is therefore presumed to be a natural group. But, to illustrate this principle farther, let us return to the circle of VerteBRATA. This, as we see by the diagram, contains five minor groups, or circles, each of which is again resolvable into five others, regulated precisely in the same way. The class Aves, for example, is first divided into rapacious birds (Raptores), perching birds (Insessores), gallinaceous birds (Rasores), wading birds (Grallatores), and swimming birds (Natatores); and the proof of this class being a natural group is, in all these divisions blending into each other at their confines, and forming a circle. $t$ In this manner we proceed, beginning with the higher groups, and descending to the lower, until at length we descend to genera, properly so called, and reach, at last, the species; every group, whether large or small, forming a circle of its own. Thus there are circles within circles, "wheels within wheels" - an infinite number of complicated relations; but all regulated by one simple and uniform principle, - that is, the circularity of every group.

(260.) We must return, however, to the number of divisions of which our author considers every natural group is composed ; because on this point he appears not strictly consistent with himself. We have seen, in the foregoing diagram, that the first division of the animal kingdom are resolved into ten circles or groups, five large and five small. In the following passage, however, when speaking of this diagram, Mr. MacLeay seems to lose sight of these lesser circles, and reckons the larger

* Hor. Ent. p. 322.

+ First pointed out by Mr. Vigors, Linn. Trans. 
only, which are but five:- "Indeed, when it is considered that there were so many affinities to be reconciled with this constant use of the number five, it is clearly absurd to imagine that I would have hampered myself needlessly with such a rule. My sole object has been to demonstrate natural affinities; and in doing this I have fallen on a distribution into five groups, so uniformly, that where there seems to be an exception to the rule, it appears to be as much the consequence of our little acquaintance with the manifold productions of nature, as of any other cause whatsoever. No person, however, can be more reluctant than I am to make any conclusion on this subject precipitately ; and, therefore, in saying that there is a general tendency, in every natural group of animals, to be subdivided into five others, I would only have this opinion accounted an hypothesis, which is rot entirely destitute of arguments wherewith we may support its truth. Yet I must acknowledge that it appears to me, even by what we have already seen, to be so far established, that, in future, where great chasms occur in smaller groups, I shall consider myself entitled to suppose that these proceed from our ignorance of the productions of nature."* Upon the whole, therefore, we are justified in concluding that our author believes some groups to be composed of ten circles, and others of five, or, what is the same thing, that sometimes there are five large groups and five smaller ones, and sometimes five only.

(261.) We now come to the fourth principle of natural arrangement, pointed out by our author, viz., that here is a tendency in such groups as are placed at the opposite points of a natural circle to unite. But on this intricate subject we will take his own words, and his own illustrations of their meaning. For this purpose let the reader refer to the diagram of the animal kingdom, as to a map, while he peruses attentively the following passage:- "On the examination of this 
sketch," observes our author, "we are at first struck with the analogy which opposite points of the same circle bear to one another, - an analogy sometimes so strong that it has been mistaken for a relation of affinity; and, indeed, I am still unable to state whether this be not the fact, and that the opposite points of the curve, if I may so express myself, do not meet each other. Thus the resemblance which the intestinal Acrita (Intestina) or Monogena of Latreille bear to the Nematoidea of Rudolphi, and the Annelides, need not be descanted on, nor the affinity which the Cirripeda, according to some naturalists, appear to have with the branchiopod Mollusca. It will be sufficient to state, that as this peculiarity of natural distribution was detected by analysis in the former part of this work, and the use to be made of it was visible among the Petalocera, so the discovery of it served to prevent my falling into several mistakes, which I could not otherwise have avoided, in deciding between relations of analogy and affinity, as they exist in the more general groups. The quadruped reptiles may, in this way, be separated from the Mammalia by the intervention of birds on one hand, and of fishes on the other; and yet Dumeril may, possibly, not be far wrong in urging that the paradoxical ornithorhynchus bears a nearer relation to reptiles than to birds. But my province more particularly is entomology ; and this property of a distribution, which, for convenience only, we have considered as circular, will serve to make the hexapod Acarida approach to the Anoplura of Leach, as appears to be the case in nature."* That the meaning of this passage may be rendered more clear to the student, we must beg his attention to the following diagram, - which, in its outlines, is precisely the same as the former, but those groups, not now alluded to, are omitted, while those which are supposed to " meet each other," that is, to unite, are indicated by dotted lines. 


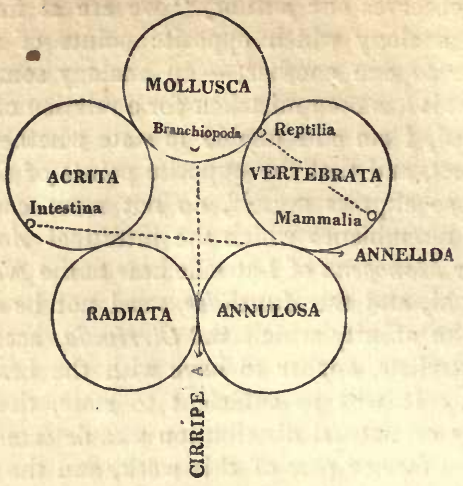

(262.) This diagram fully explains our author's meaning in the foregoing passage, when he supposes that "opposite points of a circle may possibly meet each other," and consequently unite. Now, if this, in the sense here taken, and in the instances here stated, were true, the inevitable consequence would be, that the Acrita, the Mollusca, and the Vertebrata, would form one great circle of their own, by the union of the intestinal Acrita with the Annelida, while the circle of Vertebrata would be divisible in the first instance into two, by Ornithorhynchus uniting the reptiles with the quadrupeds (Mammalia). It is somewhat surprising, therefore, that our acute author did not perceive the inevitable consequences which would result to his own theory, by admitting the possibility of such a principle of affinity: for either it would, if correct, entirely overturn his own theory on the animal kingdom being first resolvable into five large and five smaller circles; or it would show that circles of affinity could be expressed in more ways than one, - in other words, that there was more than one natural system. The truth, however, appears to be, that some of the foregoing resemblances are relations of affinity, while others are 
of strong analogy. The groups in question have so long engaged our attention, that we shall venture now to express our opinions upon them. The intestinal worms (Intestina) do not appear to enter into the circle of the Acrita, but rather represent that class among the $A n$ nulosa, where they follow, in close affinity, the Annelida or red-blooded worms. The Cirripeda, which enter also among the Annulosa, may possibly represent the 'Branchiopod Mollusca; but we think this very doubtful: while the analogy between the reptiles and Ornithorhynchus is neither direct nor natural, seeing that it is by this latter form that the Mammalia are connected in the most satisfactory manner to birds. If any naturalist should be inclined to doubt this latter theory, he will be fully convinced of its accuracy by analysing the class of Mammalia to which it belongs. If, however, Mr. MacLeay had merely said that the opposite points of a circle always evince a strong analogy to each other, he wquld only have illustrated one of his own propositions; for this resemblance follows, as a matter of course, if the contents of one circle show parallel relations of analogy to the contents of another circle.

(263.) The fifth proposition of our author, and which he considers as one of the characteristics of natural groups, is this, - that one of the five larger groups in every circle contains representations of all the others. An instance of this will best explain to the reader his full meaning. Mr. MacLeay considers that the polypes (Acrita) form one of the five great classes or groups of the animal circle; and he proceeds to explain how this group contains types of all the others, together with one peculiar to itself. "At first sight," he observes, " there appears to be a want of that symmetry in this circle (the Acrita), so observable in the others which compose the great divisions of the animal kingdom; for the $R a$ diata (or star-fish) have all a classical type to which their several structures may be referred, as also have the Annulosa, Vertebrata, and Mollusca; whereas here we see nature choosing every possible type of form, and 
sporting, as it were, with every thing like regularity. But this, I apprehend, is the consequence of a too rapid glance; since nature, so far from forgetting order, has, at the commencement of her work, in these imperfect animals, given us a sketch of the five different forms which she intended afterwards to adopt for the whole animal kingdom. In the soft, mucous, sluggish Intestina, she has given the outline of the Mollusca. In the fleshy living mass which surrounds the bony and hollow axis of the Polypi natantes, she has sketched a vertebrated animal. In the crustaceous covering of the living mass, and the structure, more or less articulated, of the Polypi vaginati, we trace the form of the Annulosa; while the radiated forms of the Rotifera, and the simple structure of the Polypi rudes, may, in general, remind us of the Radiata." * Assuming, therefore, that the Acrita, as here defined, is really a natural group, and allowing the analogies for the sake of explaining the principle, we see a complete exemplification of our author's meaning in one of the primary groups of the animal kingdom. We shall now cite another instance given by him in one of the smallest groups, namely, the typical group of the genus Scarabaus (Gymnopleurus, Ill.). In speaking of this, our author thus expresses himself :- " I have thus attempted to find characters for the natural groups which appear on disposing the Gymnopleuri according to their affinities ; but the proper method of considering them all is, as referable to one or other of forms which may be expressed by the five following species:-1. Azureus; 2. Flagellatus; 3. Carulescens; 4. Konigii; 5. Miliaris. In almost every group which has been set before the reader, he must have perceived that one of the five minor groups, into which it is resolvable, bears a resemblance to all the rest; or, more strictly speaking, consists of types which represent those of each of the four other groups, together with a type peculiar to itself. This is visible in the composition of the Acrita among the divisions of the 
animal kingdom; in that of the Ametabola among the classes of Annulosa, and of the Coleoptera among the orders of Mandibulata. It is a disposition, also, which can scarcely have escaped our notice on examining the genus Phanaus, the fifth type of which contains insects resembling all the other types, together with $P$. carnifex, which has a form peculiar to this fifth type. What this fifth type is to Phanceus, Gymnopleurus is to the genus Scarabceus; that is, while it has a form peculiar to itself in G. fagellatus, it contains insects varying in the structure of those parts which remain constant in the other sub-genera."*

(264.) In the foregoing extracts, we trace the first perception of that system of representation which we have elsewhere enlarged upon $t$, and which there is every presumptive evidence to believe exists throughout nature. Not only does one of the five groups contain types of all the rest, together with a form peculiar to itself; but this principle pervades every natural group, whether large or small. The principle is, undoubtedly, the discovery of Mr. MacLeay ; and had he prosecuted his researches, and followed the clue thus afforded him, very little, on this subject, would have been left us to elucidate. This representation, which he supposed to be partial - that is, confined to one only out of the five groups - we have found to be universal, and belonging equally to the other four.

(265.) We have been induced to devote more space to the developement of the leading principles of this system, than we should otherwise have done, on many important accounts. First, because it is unquestionably the first which clearly defined any one philosophic principle of classification ; so that, strictly speaking, we must date the first partial developement of natural arrangement, from the publication of the Horce Entomologica. Lamarck, it is true, traced the outlines of the circle, without knowing that he had done so: while Mr. MacLeay,

* Hor. Ent. 518. + Northern Zoology 
by a totally different process of investigation, arrived at the same general result ; but with this difference,- that he discovered properties, which belonged to this series, of universal prevalence in natural groups, and he determined several of those laws which regulated the variation of animals; a process of induction which heretofore had never been dreamed of. These discoveries let in a flood of light on the study of nature, and converted that which hitherto had been a science of observation into one of the deepest philosophy. In such a new and untrodden field, it would have been strange indeed, if subsequent researches had not detected errors. Our surprise, therefore, is, not that this theory should be partially defective, but that it should develope so much that is to endure so long as science is cultivated. The system of Mr. MacLeay is eminently natural ; although, as he himself repeatedly declares, it does not claim to be the natural system; meaning thereby, we may presume, that many principles of that system, and many properties of natural groups, were unknown to him. This admission, on the part of the master, should be borne in mind, when reading the commentaries of his disciples; for it has unfortunately happened in this, as in other instances, that the reputation of this eminent naturalist has suffered much more from the zeal of his admirers than from the hostility of his adversaries. On a careful consideration, therefore, of the principles of natural arrangement developed by our author, they may be all comprised under one or other of the following:1. The demonstration of the circular nature of affinities in natural groups; 2. The component parts of every group being regulated, in their variation, by some definite number; and, 3. The system of representation, by which the contents of one natural group are represented analogically by the contents of other groups. This last law, indeed, was not suspected to be universal; but merely confined to one in every fifth group. The theory of analogy and affinity comes also under this latter head ; being, in fact, one of the tests or proofs to 
be applied. Such are the fundamental principles of classification contained in the Hora Entomologica; the modifications which they subsequently received from its author, will be presently stated.

(266.) The system of M. Fries is the next in order of succession; for, although it was applied by this distinguished botanist only to a natural group in the vegetable kingdom, its principles are too important not to be equally deserving the attention of the zoologist. It is very remarkable, that this consummate botanist, totally ignorant of the previous publication of the Horce Entomologica, should have detected the same principles of circular affinities therein developed, and should have illustrated them, by analyses, much more fully. Yet, although these naturalists agree in considering the circularity of groups to be the first principle of the natural system, they differ in the determinate number of their groups ; those of Mr. MacLeay being, in fact, ten (or, according to his subsequent belief, five); and those of M. Fries four. It seems, however, that the centrum, or typical group of the German botanist, is always divisible into two series (sed centrum abit semper in duas series); and that each of his series or groups is a circle, appears evident from the following words:-Omnis sectio naturalis circulum per se clausum exhibet, that is, every section, series, or group, forms, of itself, a circle. Hence it follows, that, as one of M. Fries's groups, according to his own account, is always divisible into two, thus their total number is not four, but five. The difference, therefore, between this theory and the last is rather nominal than real: for as M. Fries at the same time detected the theory of representation, by which the contents of one circle typified the contents of a neighbouring circle, this, of course, led him clearly to understand and to define the difference between analogy and affinity. It is plain, therefore, that the three great principles of natural arrangement given to the public in the first instance by Mr. MacLeay, were also discovered by M. Fries; we say discovered, in contradistinction P 3 
to adopted; because it is not to be doubted, that our author was totally ignorant of the previous publication of a theory perfectly resembling that worked out by himself, unaided and unassisted, and solely resulting from the profound study he had devoted to the plants whose natural arrangement he wished to understand. We cannot trace, however, either from the valuable paper on this subject by Mr. MacLeay*, or from the work of M. Fries itself, that any new principle or property was made known by the Systema Mycologicum. Those, indeed, which had been previously made known, were much more fully illustrated than in the Hore Entomologica, where two genera only are thoroughly analysed; whereas M. Fries applied his theory to the full investigation of the whole class of Fungi, through all its minor groups or subdivisions.

(267.) We must now advert to Mr. MacLeay's second or quinary theory, which differs from the first in several important particulars made known in the writings of its author, soon after the publication of M. Fries's work. It is much to be regretted, that these deviations from the principles advocated in the Horce Entomologica were not more clearly stated; since this circumstance has produced much misapprehension on the part of his disciples, and has obscured rather than illustrated the theory which was to be demonstrated. It is, therefore, with the object of placing the whole in an intelligible light before the student, that we venture to follow up this task. We have seen that, according to our author's first theory, every great circle was connected to that of the same rank which followed it by a smaller circle, so that the animal kingdom was represented by five large and five smaller circles; the same principle was also stated in regard to the Mandibulata, where the groups are not five, but ten. $\uparrow$ These five small or osculant groups are, consequently, essential to the tirst theory of Mr. MacLeay. But, in his subsequent paper + ,

- Linn. Trans. vol. xiv. p. 46.

‡ See Hor. Ent. p. 438 . 
written for the purpose of showing the identity of his theory with that of M. Fries, we do not discover any allusion to these osculant groups. Whether this omission originated in a desire to show that, in the main, his views were essentially the same as those of M. Fries, or whether he had already discovered that these small circles were, in fact, but part and parcel of the larger ones, does not sufficiently appear : certain it is, however, that this part of his former theory is passed over, both in the paper here alluded to, and in the Annulosa Javanica. Five is now declared to be the definite number; and nothing is said, so far as we can trace, of the five small osculent groups. This alteration, the naturalist will immediately perceive, not only affects the details of the whole theory on the animal circle already exhibited (p. 203.), but likewise alters every diagram of the annulose groups given in the Horce Entomologica : for if the principles laid down in this latter work are adhered to, then our author's views, in regard to the number of types in every natural group, most materially differ from that of M. Fries; while, if we are to exclude osculant groups, as in the subsequent table given by Mr. MacLeay of the Ptilota*, or winged insects, then the whole of the diagrams given in the Hora Entomologica require re-modelling. This is so obvious, that we very much regret no explanation, upon so important a change, has been given. There is another distinction introduced by $\mathbf{M r}$. MacLeay in his more recent essays on the quinarian theory, which also merits attention; not so much as to the effect it has upon the groups themselves, but as having given rise to erroneous impressions on their primary divisions, and apparently contradicting the former definitions. Our author has very clearly shown the impropriety of M. Fries considering his centrum, or typical group, to be but one; because, according to $\mathbf{M}$. Fries's own definition, this group is composed of two. "Centrum abit semper in duas series;" yet, per 
ceiving this error of the German cryptogamist, and joining him in maintaining that no group is natural which does not form a circle, Mr. MacLeay subsequently adopts the plan of M. Fries, by first dividing his group into two divisions, one of which he terms normal, and the other aberrant. Now, this normal group corresponds to the centrum of M. Fries ; that is, it contains two series, and not one. We may here repeat our author's words, in speaking of the central group of M. Fries, as perfectly applicable to his own binary division of a typical or normal group. " $\quad$ In the first place, M. Fries lays it down as a rule that he admits no groups whatever to be natural, unless they form circles more or less complete. Let us, then, apply this rule to what he terms his central group, and which he makes always to consist of two. Does this form a circle? If not, the group cannot be natural, according to his own definition." We may, in like manner, enquire, Does our author's admission that every group is a circle, apply to that which he calls his normal group? If not, this group, any more than the centrum of M. Fries, cannot be natural. Of this, indeed, Mr. MacLeay is perfectly aware ; for he obviously merely uses this term to assimilate his normal group with the centrum of Fries, which, as we have already seen, contains the two most typical groups of every circle. The disadvantages of this mode of division are several : first, it has conveyed the impression to others, that Mr. MacLeay's system is, in the first place, binary, and, in the second, quinary. A countenance has been thus given to the binary method, which superficial writers have adroitly used, by appealing to this constant and primary use of the number two, while others insist that there must be always " a great typical group resolvable into two." It likewise gives to the term group two distinct meanings : one as used to denote an artificial division (every natural group being a circle); and another as denoting a natural, and therefore a circular, division. It is to be hoped this elucidation of Mr. MacLeay's theory, prolix and perhaps tedious as it necessarily has been, will not 
be uninteresting to science. To the student we feel assured it will be acceptable; since no one has yet attempted to place the subject in a clear light; and the Horce Entomologica is now so scarce, that few can hope to consult its philosophic pages. We have also felt desirous to place the value of Mr. MacLeay's discoveries in their true light, and clearly to explain those fundamental principles of the natural system which he has the high and undoubted honour of having discovered. How far he may have been successful in the application of these principles, belongs not to our present enquiry, which regards the principles of natural classification, not the results of their application.

(268.) In connection with the denomination or rank assigned by Mr. MacLeay to some of his groups, a few remarks are necessary, as they are not considered by him in the same uniform light. In some of the diagrams he has given to explain the affinities of the annulose animals, the very same group which is called typical in one, is made aberrant in another. Thus, on turning to the diagram of the Annulosa*, we find that the Chilopoda and Thysanura are typical groups: but in the diagram of the Mandibulata, the denomination and situation of the Thysanuriform type are changed ; it is no longer typical, but aberrant; while the Chilognathiform, placed at p. 390. as aberrant, is now made typical: this, of course, brings with it a complete change, not only in the smaller circle which contains these types, but in the situation of every other in these two diagrams. As nothing, so far as we can discover, is stated in explanation of these contradictory denominations of the same groups, we can only account for it, either by supposing Mr. MacLeay not to have then discovered that the same group which was external or typical in one circle, was also external in another,- or that, in the eager and natural desire to make good his circle of the Annulosa, he overlooked this transportation of his groups. Certain, however, it is, that this oversight has not only

* Hor. Ent. p. 390. 
thrown great uncertainty on his circles of Ametabola and Crustacea, but alters the position of every group in the diagram. If, on the other hand, we are to believe that the positions of these groups in the annulose diagram is correct, then that of the Mandibulata* must be reconstructed; for the Thysanuriform type cannot be at once both typical and aberrant; nor can the Chilognathiform Ametabola be aberrant, and the Chilognathiform Coleoptera typical. We are convinced, therefore, that this talented author had not ascertained the fact, that the denomination of a group is always definite; that is to say, it is either always typical or always aberrant: he justly supposes that the contents of one natural group represent the contents of another natural group; but he did not perceive that one of the consequences of this fact was, that the divisions which were typical in one would be typical in another; for if otherwise, the parallel between the two would fail. This oversight, in fact, has not only proved the artificial nature of the ametabolous circle, but has been no small source of embarrassment to the attempt of arranging the order Lepidoptera in conformity therewith. Every entomologist must perceive that the two typical (or external) divisions of the diurnal butterflies, as Shrank and the authors of the Vienna Catalogue long ago intimated, are represented by the genera Nymphales and Papilio; the first being the Chilopodiform stirps of Dr. Horsfield, and the latter the Chilognathiform: but if the series of the Ametabola is to be adhered to, as given in Hor. Ent. p. 390., then this theory must be altogether abandoned; the genus Morpho, as corresponding to the Thysanura, must be a typical group ; that of Nymphales, the other; while that of Papilio becomes aberrant, leading directly out of the circle! It is clear, therefore, that if, as many passages in his work indicate, our learned author entertained a suspicion that the rank of his groups was definite, he did not believe that this property was univer- 
sal, or he would not have abandoned this principle of the natural system in the two most important diagrams of his essay ; being those, in fact, by which he intended to show the natural distribution of the Annulosa, and the sum and substance of his entire theory on this class of animals.

(269.) A few other systems, claiming to be natural, may be briefly glanced at, as having been intimated or projected by subsequent writers, without, however, exhibiting any attempt at demonstration, much less of establishing any new principle of natural arrangement. The laborious author of the " Systematic Catalogue of British Insects," - adopting a favourite notion of an eminent entomologist whose writings we have frequently quoted, - thinks that seven is the definite number employed by nature in the construction of her groups, and therefore divides all insects into seven orders; professing at the same time to be "c convinced that natural objects cannot be arranged agreeably to their affinities, otherwise than by a series of circles, returning, as $\mathrm{Mr}$. MacLeay expresses it, into themselves." Admitting this as an undoubted truth, our author, nevertheless, continues "sceptical as to the quinary arrangement being universal throughout nature." In pursuance of his belief in the circular system, he has given a table of the supposed affinities of the order Coleoptera, and three others of different groups of the Lepidoptera. As no details, however, are entered into, the reader is left to make out these affinities as he best can, and the tables themselves (possibly by the mode in which they are printed) appear to us not well calculated to elucidate the notions of the author. A much more able attempt to revive this system has been recently made by the ingenious author of Sphinx Vespiformis, wherein he advocates the circular theory of Mr. MacLeay, but maintains that the number of divisions throughout nature are seven. These divisions he arranges, so that one, the assumed pre-eminent type, occupies the centre of a diagram; the other six being 
disposed around it. No attempt, however, is made to show that there are seven primary divisions in the animal kingdom, or in the division of Annulosa; but the order of Lepidoptera is selected as more especially containing seven groups; and to the same number, of course, our author restricts the class of Insecta. The chief object which Mr. Newman seems to have in view, is that of connecting the six minor divisions with the seventh or typical one, which he places in the centre. A glance at his table of the classes of Insecta will enable the experienced entomologist to decide at once how far he has been successful in this effort. The Neuroptera is his central circle, round which he places the following genera:-1. Mantispa; 2. Psocus; 3. Psyche; 4. Cloëon ; 5. Termes; and the 6 . he states as unknown. These, then, are neuropterous genera: let us now see how they are supposed to be connected with the other orders; or, as they are termed, the classes of insects.

1. Mantispa passes into the Orthoptera by Mantis.

2. Psocus Hemiptera Aphis.

3. Psyche Lepidoptera Tirea.

4. Cloëon

5. Termes

Diptera

6.

Hymenoptera Formica.

Coleoptera unknown.

(270.) The Neuroptera are defined in these words:"Class 7. Central, partaking of the characters of all the others." (p. 27.) In what manner these insects form a circle of their own, so that Mantispa is connected to Psocus - Psocus to Psyche - Psyche to Cloëon Cloëon to Termes - and by what link of affinity we are again to reach Mantispa, after leaving Termes, is not mentioned. The mode in which the external orders or classes are connected, the author has not explained; how, for instance, we can pass from the Lepidoptera to the Diptera, and so on? The diagram of the subclasses of Lepidoptera is a little more filled up. Here we find Papilio p assing on one side into Geometra by means of Leilus, Sw. (Urania, Fab.) and Ouropterys, Leach. The union of Papilio with the Bombyces is 
thought to be effected by Barbicornes (an Erycinian butterfly) and Lasiocampa.

(271.) Without entering more into the details of the various hypotheses last mentioned, it appears expedient, in this place, to recall the mind of the naturalist to the essence of those remarks which have been given more fully in another place*, and which are applicable alike to all theories which set out with the admission of the first law of natural classification - the circularity of groups. It is evidently easy, for it requires no great ingenuity, to divide a group into three, four, five, seven, or any other given number; but before such a division can be called " natural," there are certain peremptory conditions, which, in the present state of science, must be complied with. The first of these is a demonstration of the theoretic principle upon which the author builds his system. He is not merely to assert, but he is to prove, that his " natural" orders, - or whatever other denomination he affixes to his groups, - are each of them circles of affinity. To profess a belief in the circular system, and yet set at nought its practical exemplification, is childish; and, but for its inconstancy, would injure science, by despising inductive reasoning. An author who fixes upon any definite number, for the division of an entomological group, should first prove that the same number also exists in the ornithological and all other zoological circlest, otherwise he tacitly admits the monstrous and exploded supposition that there is no uniformity of plan in the creation beyond circles. If, therefore, the annulose kingdom, in its primary divisions, is resolvable into seven circles, so also must be the vertebrated kingdom: otherwise we exhibit insects as created upon one plan, birds upon a second, and quadrupeds (probably) upon a third. It is really most disheartening to find naturalists (especially

* Preliminary Discourse on Nat. Hist. p. 225.

+ The ingenious author of Sphinx Vespiformis, however, promises to do this in a separate essay, already (1832) in a state of forwardness. We hope this will soon appear. If he is successful in establishing a more har. monious theory than that which is already known, we shall be the first to proclaim the fact. 
entomologists) so confident in their conviction of the truth of circular affinities, and yet so unconsciously regardless of those principles which must establish this theory in the minds of acute reasoners. The pronf of a circle of affinity, as laid down by its discoverer, rests, in the first instance, upon its complete analysis; and, secondly, in its contents intimately and regularly corresponding in analogy with the contents of a neighbouring circle. There may be seven, ten, twenty, or fifty natural orders, for what we know, and they may possibly be circular, and therefore natural; but with the above conditions of a circle before us, we must ever withhold our belief in such divisions, until they rest upon a more solid foundation than arbitrary opinion. Although somewhat backward in viewing zoology as but a branch of physical science, we are happily so far advanced in its philosophy, as to consider facts more weighty than assertions, and cautious induction more valuable than hypothesis. If, then, the number seven is to be substituted for that of five, let it be made out analytically and analogically in any two groups out of the many which have been assumed as "s natural," and we will venture to predict that the learned author of the Hora Entomologica would be one of the first who would proclaim the truth of the demonstration. We offer these observations generally, and as equally applicable to any determinate number which may be thought the true one of nature.

(272.) It has been said, in reference to the quinary theory, that in most cases the number of divisions in a natural group is five, but that in many instances there appear to be as many as seven. Now, this may be very true in one sense, and very erroneous in another. 1. If a circular group is to be divided merely according to the fancy of the divider, or according to those marks or characters which he thinks most important, without reference to any other considerations, it is obvious that scarcely two persons will agree in the number they eventually fix upon: one may make three, another five, and another seven. But then comes the first test of accu- 
racy. The question is not, how many apparent divisions can be made? but does each division, by itself, form a circular group? If not, they cannot be natural. If such writers would only recollect the admission which they set out with, that every natural group is a circle, " they would not so often flounder about in all the difficulties which necessarily attend the supposition of two determinate numbers." *

(273.) Mr. MacLeay makes the following sound observations regarding septenary theories; and they are equally applicable to any determinate number which speculative ideas may give rise to. "The number seven might also, perhaps, for obvious reasons, occur to the mind, were it allowable in natural history to ground any reasoning except upon facts of organisation. The idea of this number is, however, immediately laid aside, on endeavouring to discover seven primary divisions of equal degree in the animal kingdom. It is easy, indeed, to imagine the prevalence of a number; the difficulty is to prove it. The naturalist, therefore, requires something more than the statement of a number, before he allows either a preconceived opinion, or any analogy not founded on organic structure, to have an influence on his favourite science. He requires its application to nature, and its illustration by facts." $\dagger$

i- $\quad$ * MacLeay's Letter to Dr. Fleming, p. 33.

+ Linn. Trans. vol, xiv. p. 57. note. 


\section{PART III. \\ ON THE FIRST PRINCIPLES OF NATURAL \\ CLASSIFICATION.}

\section{CHAPTER I.}

THE FIRST PRINCIPLES OF THE NATURAL SYSTEM BRIEFLY STATED IN FIVE PROPOSITIONS, THE FIRST THREE OF WHICH ARE HERE DISCUSSED; VIZ., THE CIRCULARITY, THE NUMERICAL DIVISION, AND THE THEORY OF REPRESENTATION.

274.) IN submitting to the zoological world - for he first time in a connected form - the result of our researches on the first principles of the NATURAL SYSTEM, it seems the most simple and preferable method to state them, as heretofore *, in the form of distinct propositions, which we shall endeavour to substantiate by sub. sequent details.

I. That every natural series of beings, in its progress from a given point, either actually returns, or evinces a tendency to return, again to that point, thereby forming a circle.

II. The primary circular divisions of every group are three actually, or five apparently.

III. The contents of such a circular group are symbolically (or analogically) represented by the contents of all other circles in the animal kingdom.

IV. That these primary divisions of every group are characterised by definite peculiarities of form, structure, and economy, which, under diversified modifications, are uniform throughout the animal kingdom,

- See Fauna Boreali-Americana (Northern Zoology), vol. ii. pref. p. 48. 
and are therefore to be regarded as the PRIMARY TYPES OF NATURE.

V. That the different ranks or degrees of circular groups exhibited in the animal kingdom are NINE in number, each being involved within the other.

(275.) We shall now proceed, without further comment, to adduce, in detail, the reasons upon which these opinions are grounded, and state these reasons as simply and as concisely as their nature will admit of.

(276.) I. In regard to the first proposition on the circularity of natural groups, it seems needless to repeat what has already been said both in this and in a preceding volume.* For the sake, however, of exhibiting collectively the first truths of the natural system in a connected series, a popular explanation may not be misplaced. The progression of affinity in any assemblage of animals is known to be natural, if it is circular. This is shown when, by beginning at some one point of the series, and following closely the line of affinity, we are imperceptibly conducted to that point again. The two extremities of the series will thus obviously be united; and this union, of course, gives us the figure of a circle. Between the two points, thus blending into each other, a greater or lesser number of modifications of form, in the intervening animals, will occur, depending entirely on the greater or lesser extent of the circle we are tracing. These deviations, however (as will be hereafter shown), are all upon a uniform plan; and, besides, in all cases, are secondary, or inferior, to the leading characters of the whole assemblage, which - in one way or other - they all retain. Such a circle is called a natural group: the word group being employed, on this occasion, to designate, 'indiscriminately, every series or assemblage of beings, whose affinities have been so made out. When such a series is so gradually developed that no link in the chain of continuity appears wanting, it is then termed a perfect group.

* Preliminary Discourse on Nat. Hist. 
But when a part of the series is perfect, and the other part presents the idea of a chain where several of the links are wanting, then the group is called imperfect. Now this imperfection arises from two causes: either these absent links have not yet been discovered, or they have been destroyed in the revolutions which have agitated our globe. This is the first great law of the natural system; it is that upon which all others repose, and which has been already demonstrated in almost every department of zoology, but more especially in ornithology. If the reader wishes to see this theory made good in the animal world, we must refer him to the Horce Entomologica and to the Northern Zoology. We may refer him, in the last-mentioned work, to the genus Picus, and to the sub-family Piciance, as examples of perfect groups; and to the family Picida (of the same volume) for one that is imperfect. 'The circle of the animal kingdom (p.203.) is also a familiar illustration upon a large scale. Commencing with the Polypes, we pass on to the Mollusca; from these we are led to vertebrated animals; thence to insects and radiated animals; and, finally, arrive once more among the polypes. Our course has thus been circular; the two ends of the series meet; and we have, theoretically, a natural group.

(277.) II. We now pass to our second proposition ; viz. The primary circular divisions of every such group are three cctually, and five apparently.

(278.) As it is manifest that every group, according to its magnitude, will exhibit more or less variety in its contents, the first question which suggests itself is, Are these variations regulated by any definite number? And is that number so constant, in all such groups as have been properly investigated, as to sanction the belief that it is universal ? The answer is in the affirmative. Every group, whatever may be its rank or value, (that is, its size or its denomination,) contains, according to our theory, three other primary groups, whose affinities are also circular. One of these is called the typical, the other the sub-typical, and the third the aberrant group. This 
latter is so much more diversified in its contents (for reasons hereafter to be stated) than the other two, that many naturalists reckon five groups in all; the number five being made out by dividing the aberrant group into three, instead of considering it as only one. We have seen, however, that the first test of a natural group is its circular chain of affinities. If, therefore, the three divisions of Mr. MacLeay's aberrant group can be shown to form a circle of their own, independent of the other two, then we must reckon them as one only, thus making the primary divisions of every circle three.

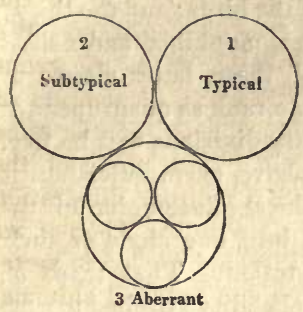

We, consequently, have, in every natural group, three primary circles, one of which (the aberrant) is divided into three secondary circles. A good idea of this disposition may be gained by the annexed diagram. If, on the other hand, we adopt Mr. MacLeay's theory, that every group is first divided into five circles (the three aberrant not being united into one), then we may express them in this manner:-

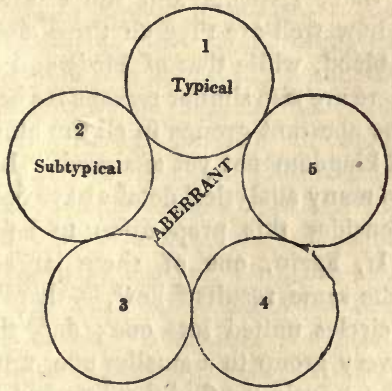

(279.) Let us illustrate this first division of a natural group by an instance drawn from the animal kingdow. 
Every one knows that vertebrated animals, above all others, are the most distinctly marked by possessing an internal skeleton. They have been, moreover, demonstrated to be a circular group. What, then, are the divisions? These are no less obvious. Quadrupeds, birds, reptiles, amphibia, and fishes, are acknowledged to be so many types of the vertebrated circle. There is, however, good reason to believe that the last three of these types form a circle of their own; in which case, we should have, in fact, three primary circles of vertebrated animals: the first, or typical, comprising the quadrupeds; the second, or sub-typical, consisting of the birds; and the third, or aberrant, including the reptiles, amphibia, and fishes. On the other hand, if each of these latter classes of animals is found to be of the same rank as quadrupeds or birds, then the number of primary divisions will be five. In reference, however, to the above exemplification, it should here be observed, that the absolute union of the reptiles, amphibia, and fishes, into one circle of their own, has not yet been demonstrated. That there is, nevertheless, a high degree of probability attached to such a supposition, will be apparent, when we consider how much nearer they are allied to each other, in comparison to their affinity with birds and quadrupeds. How closely the water serpents and the eels approach each other, and how well are they all three characterised by their cold blood, while that of birds and quadrupeds is warm. There are also similar reasons for believing in this union of the aberrant groups in all the other divisions of the animal kingdom not yet analysed. In ormithology, however, so many analytical details have been gone into*, that we consider this proposition to be fully demonstrated. If, again, one of these larger divisions is analysed, the same results follow, - there will be three secondary circles united into one; and thus we go on, reducing every group to a smaller one, until we come to a genus, where again we find three groups of sub-genera, 
the aberrant one always being so much diversified, that it wears the appearance of being three, making the number five. Thus, for instance, the class of birds contains three primary groups; but the aberrant one is so large and varied, that we are accustomed, for the sake of perspicuity, to divide it into three; nainely, the Rasores, the Grallatores, and the Natatores.

(280.) The difference of considering a natural group as divisible into threc, instead of five, does not, in the least, affect the natural series by which they are united. The discovery of the union of Mr. MacLeay's three aberrant groups into a circle of their own, is the addition only of a property superadded to that which they were known to possess ; this property consisting of uniting into a circle among themselves, as well as passing into the typical and the sub-typical groups. It is, however, a distinction to be kept in mind, since without it we should be unable to substantiate that uniformity of plan which embraces every natural group, and renders them but types of higher assemblages. The first divisions of matter, or natural bodies, are obviously three, - animals, vegetables, and minerals; and this number coincides with that found in the primary divisions of animals, and in all their inferior groups. This, of itself, is strong presumptive and analogical evidence. If, on the other hand, every natural group was first resolvable into five, then, to support the theory of perfect uniformity in creation, we must show that there are five primary divisions of natural bodies; a division which no one has ventured to point out. The plan of nature implies perfect harmony and uniformity, not only in generals but particulars. All that is yet known by analysis confirms this theoretical conclusion; and this, independent of any other consideration, is conclusive against the idea that there should be only three primary circles in some groups, and five or seven in others.

(281.) It has been observed, however, that, in groups termed imperfect, some of the links of connection are Q 3 
wanting. The question then arises, upon what grounds do we contend that such are natural groups, seeing that their circularity cannot be traced? This leads us to consider the different relations which belong to every organised being, and to the developement of another law of nature, - both of which are now to be explained.

(282.) We are thus conducted to our third proposition. The contents of every circular group are symbolically or analogically represented by the contents of every other circle in the animal kingdom. There are, in nature, two sorts of resemblances, which are termed analogy and affinity. We have so fully explained these relations in our preliminary volume *, that it is only in consequence of our wish to exhibit in a connected series all the laws of natural arrangement yet discovered, that we now repeat, in some measure, the substance of what has already been stated.

(283.) The most ordinary observer perceives, that every created being has different degrees of relationship or of resemblance to others. Where this is immediate, it is termed an affinity; where, on the other hand, it is remote, it is a relation of analogy. $\uparrow$

(284.) The theoretic distinction between affinity and analogy, in a more scientific point of view, has been thus stated by the naturalist who first gave a definite meaning to the terms:- "Suppose the existence of two parallel series of animals, the corresponding points of which agree in some one or two remarkable particulars of structure. Suppose, also, that the general conformation of the animals in each series passes so gradually from one species to the other, as to render any interruption of their transition almost imperceptible. We shall thus have two very different relations, which must

* Preliminary Discourse on Nat. Hist.

+ There cannot be a better proof of the low ebb to which the higher departments of zoology have sunk, and the ignorance of those persons who are engaged to write reviews of scientific works for the daily press, than the fact of one of those critics, who undertook to censure our former volume, being totally unacquainted with the difference between analogy and qfinity! To him, it seems, they are only synonymous with "resemblances," and such "resemblances," forsooth, are to be ridiculed! 
have required an almost infinite degree of design before they could have been made exactly to harmonise with each other. When, therefore, two such parallel series can be shown, in nature, to have each their general change of form gradual, or, in other words, their relations of affinity uninterrupted by any thing known when, moreover, the corresponding points in these two series agree in some one or two remarkable circum. stances, there is every probability of our arrangement being correct. It is quite inconceivable that the utmost human ingenuity could make these two kinds of relation tally with each other, had they not been so designed in the creation. Relations of analogy consist in a correspondence between certain insulated parts, or properties, of the organisation of two animals which differ in their general structure. These relations, however, seem to have been confounded, by Lamarck, and, indeed, all zoologists, with those upon which orders, sections, families, and other subdivisions, immediately depend.*

(285.) To illustrate by an example the above definition, we will take two groups of birds, whose relations are unquestionable. The first shall be the primary orders of the class; the second, the primary tribes of the perching order. By placing these in " parallel series," it will be found that the corresponding points of each agree in some one or two remarkable peculiarities of structure or of habits.

Orders of Birds. Tribes of Perchers.

1. Typrcal Group. Insessores. . Conirostres.

2. Sub-typical Group. Raptores. . Dentirostres.

3. Aberrant Group. $\left\{\begin{array}{l}\text { Natatores: }: \text { Fissirostres. } \\ \text { Grallatores : } \\ \text { Rasores }: \text { Tenuirostres. }\end{array}\right.$

Here we have two series of natural groups arranged parallel to each other, but of different ranks. The first 
exhibits the orders or first divisions of birds; the second, the tribes of one of these orders, namely, the Insessores, or perching birds. Each of these is a circular group: for in one column we find the Rasores pass into the Insessores on one side, and into the Grallatores on the other; while in the other column the Scansores, in like manner, blend into the Conirostres, although connected also with the Tenuirostres. We shall now show in what way each of these parallel series analogically agree in the details of their corresponding points, in some one or more remarkable peculiarities of structure. The Insessores and the $\mathrm{Co}$ nirostres, besides being the most perfectly organised in their respective groups, are remarkable for the comparative smallness of the notch or tooth of their bill: here, then, is their analogy. In the Raptores and the Dentirostres, the notch is so large as to assume the shape of a tooth, a peculiarity which belongs to these alone. The Natatores and Fissirostres again preserve the same chain of analogy by the smallness and slight developement of their feet, and by possessing the greatest powers of flight. The Grallatores resemble the Tenuirostres in having very small mouths, and long soft bills. Finally, the Scansores and the Rasores are the most intelligent and docile of all birds, and have a short thick bill, generally entire at the tip. Now as these resemblances of analogy are totally independent of the affinity between the groups in each of these two columns, and as they follow each other precisely in the same order, there is, so far, analogical demonstration that this arrangement is natural. Here, then, the difference between affinity and analogy is exemplified. Analogies will be more or less apparent, according as the groups compared are of equal value, and approximate to each other in the general system. On the other hand, they will be more or less faint, and difficult to be traced, as the groups differ in value, and are remote. In speaking generally of affinity and analogy, we must always take into consideration the nature of the groups compared. 
Thus, if we spoke of the relation which the bat has to a bird, we should term it an analogy; because between the two there is a vast number of intervening groups, but, if we compare the Ornithorhynchus with a bird, the resemblance is an affinity, inasmuch as no quadruped yet discovered shows such a decided tendency to connect these two classes of animals. The foregoing observations may be considered as a recapitulation only of what has already been stated of these relations generally. We must now proceed to a more detailed explanation of the relations of affinity than has hitherto been given.

(286.) Every object in nature has three distinct relations of affinity: one, by which it is connected with that object which precedes it in the scale of being; another, by which it is united to that which follows it; and a third, which connects it to some other object placed out of its own proper circle. That these may be expressed with precision, we term the first two simple or internal affinities, and the latter external.

(287.) Simple or internal affinities must exist under any system which notices the progression of nature, whether the series be represented as simply linear, or circular : they are not, therefore, peculiar to the latter theory. The dog, for instance, is intermediate between the fox and the wolf; it has, consequently, two direct affinities.

(288.) External affinities are not always so obvious as the former, except in those aberrant groups which connect two different circles; for it is manifest that if this third sort of affinity did not exist, the two circles would not blend into each other, as we see they do in nature. But in groups which are unusually abundant in species and in slight modifications of form, there is reason to believe that these external affinities will be found both in typical and aberrant circles. To give an instance of this. The annexed diagram explains the connection of two families, the shrikes (Laniada), and the thrushes (Merulada). Each of these is a circular group, their subdivisions perfectly representing each 


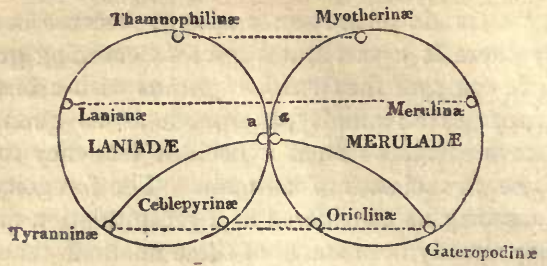

other in many points of strong analogy.* It will be seen that these two circles touch, or blend into each other $(a$ a), by means of the Edolina $(a)$ in one circle, and the Brachypodina (a) in the other. This is the usual and most obvious point where circular groups respectively meet : but the sort of affinity of which we are now speaking also regards the union of the typical groups in two distinct circles. In the present instance these are the Laniance and Thamnophilince in one, and the Merulada and Myotherince in another. The internal affinities of the Thamnophilina are two; one to the Laniance, the other to the Edoliance; all three groups being parts of the same circle; but then there exists, at the same time, such an intimate resemblance also between the Thamnophilina and the Myotherince, that we believe the relation is one of affinity; and this affinity, being out of the circle, we term external. In ordinary cases, where groups so situated are not very rich in species, the resemblance between them is not so strong, and is then termed an analogy ; but sometimes, as in the present instance, we believe that analogies blend into affinities, and that the two circles are actually united at more points than one. The subject, however, of the external affinities of typical groups demands much abstruse investigation, before the theory can be placed beyond doubt; and the student will do well to pass it over, until he is fully master of such principles

* See the demonstration of this group, and of all its divisions, in North. Zool. vol. ii. p. 164, \&c. 
of the natural system as have been extensively demonstrated.

(289.) The nature of external affinities was first intimated in the following passage :- "I must now advert to another, and, in my estimation, an unquestionable principle of natural arrangement: this is, the direct union of typical groups, without the intervention of those which are aberrant. A vague suspicion of something like this first occurred to me when studying the affinities of the Laniada, in the year 1824.* This property, however, belongs to very few groups, since it has only been detected in such as are pre-eminently abundant in species, and are not of a higher rank than families. Beyond such groups, the higher we ascend the more dissimilar are the typical groups in approximating circles, until, in looking to a diagram of the vertebrated animals, not only does all appearance of affinity between the external or typical divisions vanish, but it becomes even difficult, in some instances, to trace their analogy. The theory of external affinities, however, belongs to a question so abstruse, and requires such nicety of investigation, that, for the present, I should rather, perhaps, put it as a query, than consider it as a demonstrated fact. At the same time, I must confess my utter inability to reconcile, by any other theory, the evident and universally acknowledged affinity between the Thamnophilina and the Myotherina; between the Meruline and the Philomelina, and more especially between the typical Setophaga and the typical Sylvicola. Unless these affinities, which I have fully detailed, can be disproved or explained by some other mode of reasoning, it seems to be impossible to arrive at any other conclusion." $\phi$

(290.) From the above theory on external affinities would result another principle of natural arrangement, superadded to those we have already explained as belonging to natural groups. On this principle we shall not,

- See Zool. Journ. vol. i. p. 502.

+ Swainson, in North. Zool. vol. ii. pref, li. 
however, at present dilate, but merely call the attention of the philosophic enquirer to what we have already stated elsewhere. "Recent investigations in another department of zoology, more abundant in forms and species than that of the class Aves, leads me strongly to suspect the existence of another property in natural groups, which, at present, I shall merely state as an hypothesis. It is the union of the most aberrant group in one circle with the most aberrant in the next ; so that, in a diagram of the order Insessores, formed either on Mr. MacLeay's plan of five circles, or of mine upon three, one circle would unite all the Tenuirostral types, another the fissirostral and scansorial, and a third the typical and sub-typical. The whole would thus be represented by three great circles, one within the other, and this without the least derangement of the series here exhibited. It must, however, be premised that this principle cannot be clearly traced in ornithology, because the Tenuirostral or grallatorial groups are remarkably deficient in their numerical contents. In entomology the very reverse of this appears to be the case ; and it is there, if my suspicions are well founded, that this abstruse property of the natural system may hereafter be more especially detected."*

(291.) Having now sufficiently explained the various relations of affinity which animals bear to each other, the reader will be better prepared to understand the principle of the proposition more immediately before him; namely, the analogical or symbolical representation of the contents of one circle with those of the contents of all circles in the animal kingdom. This may be distinguished as the law of representation. This property of natural groups was first intimated in the Hora Entomologica; but it was only partially employed as a verification of the groups therein mentioned, nor was it at all suspected to hold good throughout nature. It was perceived in theory; but, the laws by which it was regulated not being then 
discovered, it was often most erroneously applied. The result of our researches in following up this law will now be given.

(292.) No law of the natural system is more calculated to keep in check the ardour of imagination than this. So numerous are the resemblances between objects, that, without a better guide than the return of a series into itself, we may form circles ad infinitum under the idea that they are natural, when, in truth, they are artificial. We could even cite many instances where, by the help of much ingenuity, parallel relations of analogy between artificial groups have been made out, and where, in truth, the whole theory has been misapplied. But when, superadded to these, we apply the theory of representation in all its bearings, as a third test to the accuracy of our groups, it is next to impossible that we should err or violate the series of nature. It is, in fact, as we have elsewhere demonstrated*, " the only certain test of a natural group." This will be evident when we exemplify the theory by a reference to acknowledged facts.

(293.) The class of Birds, as being that which of all others in the animal kingdom has been most analysed, is, in consequence, best calculated for our present purpose. Every natural group, as we have seen (285.), contains representations of the divisions composing a neighbouring group. Thus the tribes of the order Rasores t represent, by analogy, the tribes of the order Insessores; and these tribes, in a similar way, represent the primary orders of birds. Now this principle pervades every natural group, whatever may be its value, or size, or denomination. It extends not only to orders, tribes, and families, but even to genera and sub-genera. So that, if a sub-genus is sufficiently numerous in species, it will contain types of representation of the remaining sub-genera composing the entire genus, and, consequently, of every natural division in the whole class of 
Birds. But the operation of the law does not stop here: every thing yet known conspires to prove that, in the animal creation at least, it is universal. The classes of Birds and of Quadrupeds are each circular groups : their minor divisions are, consequently, analogical; hence it follows, that if the types of a genus of birds represent the primary divisions of the feathered creation, so also must they represent the primary groups in the circle of quadrupeds. The principle which regulates one extends to all, or there would be no uniformity of plan or harmony of parts. This result, theoretically, or arguing upon abstract reasoning, we should expect; and, accordingly, the more we study nature, the more is this theory confirmed by analysis, and facts are explained which by no other theory can be explained. Nor is this principle of the natural system circumscribed to the animal world; although so little attention has been bestowed on the natural groups of plants, that, as yet, the primary groups only of the vegetable kingdom have been recently pointed out. We have elsewhere* illustrated this theory in so many groups, of different denominations, in the class of Birds, and have shown its prevalence in others, that to go into further details, in this place, would be superfluous.

(294.) One of the most important results of the law of representation is the clue that it affords to the location of types, and to the determination of such chasms as occur in imperfect groups. If the divisions of one circle represent those of all others, it follows that each of these divisions must have certain definite peculiarities, either of structure or of economy, by which they can be distinguished, and which belong only to them, and the groups by which they are represented. If, therefore, a perfect group is compared with one that is imperfect, - that is, with one whose affinities appear broken and interrupted, - we are materially assisted in determining the nature of the missing types, and know, with almost mathematical certainty, the true station

* North. Zool, vol, ii. The Birds 
which they would occupy in our imperfect group. Let us illustrate this by an example. The perching, or insessorial, order of birds, collectively, is a perfect group, because its primary divisions are all known; but the rapacious order is imperfect, because one of its primary divisions is extinct, or, at least, undiscovered. We say one, and not two, as is generally thought, because the Dodo was, in our opinion, the rasorial type of the raptorial order. By comparing these two series, we shall at once see which is the missing type in that of the Raptores.

\begin{tabular}{|c|c|c|}
\hline $\begin{array}{c}\text { Imperfect circle. } \\
\text { RAPTORES. }\end{array}$ & $\begin{array}{l}\text { Analogical } \\
\text { characters. }\end{array}$ & $\begin{array}{l}\text { Perfect circle. } \\
\text { INSESSORES. }\end{array}$ \\
\hline Vulturidæ. & $\begin{array}{l}\text { Notch of the } \\
\text { bill obsolete. }\end{array}$ & Conirostres. \\
\hline Falconidæ. & $\begin{array}{l}\text { Notch very } \\
\text { conspicuous. }\end{array}$ & Dentirostres. \\
\hline Strigidæ? & $\begin{array}{c}\text { Head very large, } \\
\text { flight rapid. }\end{array}$ & Fissirostres. \\
\hline Didiadæ. & $\begin{array}{l}\text { Bill long, soft. } \\
\text { Wings very short. }\end{array}$ & $\begin{array}{l}\text { Tenuirostres. } \\
\text { Rasores. }\end{array}$ \\
\hline
\end{tabular}

(295.) The structure of the Dodo is essentially that of a large vulture; but, as it should represent the gallinaceous birds in some one respect, we consequently find it possessed of very short wings. This is one of the peculiarities of all rasorial types, and is never found in those of the tenuirostral structure: hence we are led, by analogy of reasoning, to conclude that the imperfection of the raptorial circle consists in the tenuirostral type being unknown. The Raptores, in fact, when we consider its rank, is the most imperfect, as a group, in the whole class of birds. It is, therefore, one of the best which could be cited, on the present occasion, to illustrate an imperfect circle.

(296.) The theory of symbolical types involves, in its application, another principle, from inattention to, or ignorance of, which great mistakes have arisen*, and are still likely to arise. In tracing the analogy between two

*. As in Linn. Trans, vol. xvi. p. 46 
series of animals, we can never compare a typical group in one circle with an aberrant group in another; for these groups, being of different denominations, would destroy at the very outset the harmony of the comparison: it would render the law in question indeterminate, and, therefore, no law. Every perfect group has its own typical and aberrant forms; and these are represented by the typical and aberrant forms in another perfect group. When, therefore, the toucans (Ramphastida), as a whole, are made to represent the entire group of Conirostres, the analogy or representation is false; because the Ramphastida are admitted by all to be an aberrant family in the scansorial circle; and the Conirostres are likewise admitted to be the typical group of another circle. But when, on the other hand, the Conirostres are stated to represent the Insessores, then the analogy is true, because both of these groups are pre-eminently typical in their respective circles: although unequal in their rank or extent, they are equal in their denomination. This rule, however, by no means affects the comparison of the contents of a typical with those of an aberrant group; for as each have types of perfection, so these types should justly represent each other. To vary our examples, we shall take an instance from two familiar animals in the class of quadrupeds. The Fere and the Ungulata are two natural orders; but one is typical, and the other aberrant: yet as each of these are circular, so their respective typical and aberrant groups may justly be compared as representing each other; and this they accordingly do. The tiger is one of the typical forms of Ferce, and we see how beautifully it corresponds to the zebra, which is a typical form in the Ungulata. This analogical resemblance does not consist merely in the remarkable similarity of stripes on the two animals, but actually extends to their moral character: both are vicious, wild, and untameable, and both are inferior to that form which is pre-eminent in each genus; namely, the lion in one, and the horse in the 
other. This instance of analogy, which must come home to the comprehension of the most unpractised naturalist, may be cited as one of the innumerable proofs of the universality of symbolical representation; a principle which extends from the very highest groups of ponderable matter, down to the series in which individual species follow one another. We know not, in fact, which to admire most, - the vast and unlimited extension of the principal itself, or the simplicity of those laws by which it is regulated.

\section{CHAP. II.}

THE FOURTH PROPOSITION CONSIDERED, - THE PRIMARY TYPES OF NATURE.

(297.) In the last chapter we endeavoured to elucidate the truth of the three first laws, upon which the System of Nature, or, in other words, natural classification, is framed. We now come to our fourth proposition, which maintains that the primary divisions of every circular group are characterised by definite peculiarities of form, structure, and economy; which, under diversified modifications, can be traced throughout the animal kingdom; and are, therefore, to be regarded as the PRIMARY TYPES OF NATURE. Upon this generalisation we have not been enabled to receive any assistance from the labours of our predecessors, since we are not aware of its having hitherto been hinted at.

(298.) It would seem to follow, as the next stage of induction, after gaining the law of representation, that this representation necessarily involves the prevalence of certain definite forms, following each other in a uniform series, and, therefore, capable, from these circumstances, of a general definition. But, unfortunately, the few eminent naturalists who have prosecuted these higher objects of the science have limited their studies, for the 
most part, to one department of zoology; and have, therefore, been unprepared to state in what manner the forms therein contained re-appear, as it were, under an almost infinite variety of modifications, in other divisions of the animal kingdom, totally different from that which has been the object of their peculiar study.

(299.) Before proceeding, however, to the main object before us, a few observations become necessary on the characteristic properties of the different denominations of groups. In using the term denomination, we apply it not to the rank or station of a group among its congeners, but solely in reference to its typical or aberrant nature; in other words, whether it exhibits the greatest perfection of any particular structure, or whether this perfection is deteriorated, so to speak, by the admixture of other characters belonging to a neighbouring group.

(300.) As every natural group is first divided into three circles, so it follows that there are three primary denominations of groups ; and these, as we have already explained, are called the typical, the sub-typical, and the aberrant: by these names we express their denomination, and we shall now treat of each in detail.

(301.) I. The first distinction of TYPICAL groups is implied by the name they bear. The animals they contain are the most perfectly organised: that is to say, are endowed with the greatest number of perfections, and capable of performing, to the greatest extent, the functions which peculiarly characterise their respective circles. This is universal in all typical 'groups; but there is a marked difference between the types of a typical circle, and the types of an aberrant one. In the first we find a combination of properties concentrated, as it were, in certain individuals, without any one of these preponderating, in a remarkable degree, over the others; whereas in the second it is quite the reverse : in these last, one faculty is developed in the highest degree, as if to compensate for the total absence, or very slight developement, of others.

(302.) Let us exemplify this proposition by fami- 
liar instances. The crow has been most truly considered the pre-eminent type of all birds*, it is also the type of a typical circle. It consequently unites, in itself, a greater number of properties than are to be found, individually, in any other genus of birds ; as if, in fact, it had taken from all the other orders a portion of their peculiar qualities, for the purpose of exhibiting in what manner they could be combined. From the rapacious birds this " type of types," as the crow has been justly called, takes the power of soaring in the air, and of seizing upon living birds like the hawks, while its habit of devouring putrid substances, and picking out the eyes of young animals, is borrowed from the vultures. From the scansorial or climbing order it takes the faculty of pecking the ground, and discovering its food when hidden from the eye, while the parrot family gives it the taste for vegetable food, and furnishes it with great cunning, sagacity, and powers of imitation, even to counterfeiting the human voice. Next come the order of waders, who impart their quota to the perfection of the crow, by giving to it great powers of flight, and perfect facility in walking, such being among the chief attributes of the grallatorial order. Lastly, the aquatic birds contribute their portion, by giving this terrestrial bird the power of feeding not only upon fish, which are their peculiar food, but actually of occasionally catching it. $\dagger$ In this wonderful manner do we find the crow partially invested with the united properties of all other birds, while in its own order - that of the Insessores, or perchers - it stands the pre-eminent type. Here, then, is an example of the characteristic properties of the type of a typical circle.

(303.) Let us now look to the type of an aberrant circle. The woodpecker is of this description, for it is the preeminent type of the climbing birds (Scansores), which is an aberrant tribe. Here, instead of finding a combination of diversified characters, similar to those be-

- Linn. Trans. vol. xiv. p. 445.

† Wilson's American Ornithology, article, Fishing Crow. I 2 
longing to the crow, the whole structure becomes adapted for one particular purpose - that of climbing trees, and extracting from them the allotted food. The energies of nature are concentrated, as it were, to the production of that form most adapted for one especial purpose. Fvery part of the structure of a woodpecker, not immediately essential to its peculiar habits, is found to be in a subordinate state of developement,-for the best of reasons, because their greater developement is unnecessary. Its flight is comparatively feeble, for it merely journeys from tree to tree even in its migrations: the feet almost incapacitate the bird from moving upon the ground, for there its food does not exist: the position of its legs, placed very far back, gives it an awkward appearance on an even surface; but what is this to a bird which usually sits in a perpendicular position? Its food is almost entirely restricted to particular insects; and to procure these it is gifted with powers which are withheld from all other birds. It is the type of the climbing race; and, consequently, exhibits the scansorial structure, and no other, in the highest degree of perfection. Great muscular strength, for striking blows which may be heard half a mile; a bill as hard as ivory, formed on the model of a perfect wedge ; a strong rigid tail, acting as a buttress to the body when the bird is at labour; short robust feet, armed with strong claws for grasping the bark, and a long spear-shaped tongue for inserting within its clefts, - these are the typical distinctions of the family before us, which, however inferior to the crow in the number of its perfections, far exceeds it in one, that one being the characteristic of its whole tribe. The union of many properties is, therefore, the usual character of types of typical groups; while the highest developement of some one property is the distinguishing mark of types belonging to aberrant groups. In the former, this perfection of structure is seen in the mammalia among vertebrated animals; in the winged insects, or the Ptilota of Aristotle, in the sab-kingdom Annulosa; in the testaceous shell-fish 
among the Mollusca, and in the Medusa in the circle of radiated animals. In short, there is no end to the proofs which illustrate both these principles.

(304.) Perfection in the number of species or of forms is also a remarkable and very general character of preeminently typical groups. This is not, indeed, apparent in the mammalia which stands at the head of the vertebrated circle, and the reasons are obvious; but in the order Quadrumana, which is the pre-eminent type of quadrupeds, and in the Insessores, which is the same in birds, we have the largest groups in their respective circles. Among the Annulosa, also, the Ptilota, or winged insects, are probably ten times more numerous than all other annulose groups put together. In tracing this peculiarity in the lower divisions we see it very prevalent; and in looking to natural genera we find that the genus Picus, Sylvicola, Sylvia, and several others among birds, and that of the restricted sub-genus Scarabaus (MacLeay) among insects, are all remarkably abundant in individuals, when compared with the remaining contents of their respective circles. This numerical preponderancy is not, however, by any means universal, because in very many instances nature seems to make up by number what she withholds in size. The infusorial animalcula are, therefore, the most numerous of all organised beings.

(305.) II. Sub-ty PICAL groups, as the name implies, are a degree lower in organisation than those last described; and thus exhibit an intermediate character between typical and aberrant divisions. They do not comprise the largest individuals in bulk, but always those which are the most powerfully armed, either for inflicting injury on their own class, for exciting terror, producing injury, or creating annoyance to man. Their dispositions are often sanguinary; since the forms most conspicuous among them live by rapine, and subsist on the blood of other animals. They are, in short, symbolically the types of evil; and in such an extraordinary way is this principle modified in the smaller groups,

n 3 
that even among insects, where no other power is possessed but that of causing annoyance or temporary pain, we find, in the sub-typical order of the Annulosa (Aptera Lin.), the different race of scorpions, Acari, spiders, and all those repulsive insects, whose very aspect is forbidding, and whose bite or sting is often capable of inflicting serious bodily injury. If, again, we look to the sub-typical groups of quadrupeds and of birds, this principle of evil is developed in the highest degree; both are armed with powerful talons, both live on slaughtered victims, and both are gloomy, unsocial, and untameable. The formidable toothed bill, which so strikingly distinguishes rapacious birds, will be found in every group which represents them in the entire order of perchers, and these groups amount to more than one hundred. Even in the genus Sylvicola, among the warblers, the bill of the sub-typical group represents in miniature that of the rapacious order, the peculiar character of which consists in a conspicuous tooth or notch, placed more remote from the end of the upper mandible than it is in all other types. Even in the smaller sub-typical groups of larger circles, which are themselves typical, this extraordinary characteristic is manifested, although in a much slighter degree. Take, for instance, the American group of monkeys (Cebida. Sw.) which belong to the typical order of Quadrumanes; of that circle it is the sub-typical group, and we accordingly find, that while the family of true apes (Simiada) live in a state of nature upon vegetable diet alone, the $\mathrm{Ce}$ bidae are partially carnivorous, and that many prowl about to destroy life by feeding upon insects, and even small birds.

(306.) The above are sufficient demonstrations of this law in larger groups; but as the best test of a theory is to follow it down into the lowest form of analysis, we will now see in what manner it is exemplified in species of the same genus. Let us first look to that of Bos, where we have the ox and the bison actually following each other in close affinity, and yet no two 
animals, in their moral character, can be more opposite : the one is the most useful, docile, and tameable of the brute creation ; the other wild, revengeful, and showing an innate detestation of man. The ox is the typical example of the genus; the bison is the sub-typical. In the genus Equus, as already intimated (p.240.), the same beautiful and wonderful prevalence of this universal law of nature is manifested; the horse being the typical, while the zebra is the sub-typical form of the genus.

(307.) In regard to the numerical contents of these groups, they are almost universally less than those which are typical, and the reason is manifest: were it otherwise, we should have the carnivorous tribes extirpating those which had not their ferocious dispositions : the wild beasts of the forests, were they equal in number to the peaceful inhabitants of the plains, would in process of time effect their entire destruction; while the same result would be accomplished by the rapacious birds upon the rest of the feathered creation: nor would the insect world preserve its nicely adjusted balance : the carnivorous spiders and scorpions, were they as numerous as the flies, and others upon which they feed, would soon destroy all the tribes of herbivorous insects. It is therefore wisely ordained, that the animals belonging to sub-typical groups (especially such as are pre-eminently so) should be comparatively few, and that their increase should be slow. Eagles and hawks rarely lay more than two eggs, and fecundity is well known to be much greater among the smaller quadrupeds than with the Ferc. The singular threatening aspect which the caterpillars of the sphinx moths assume, on being disturbed, is a remarkable modification of the terrific or evil nature which is impressed, under one form or other, - palpable or remote, - upon all sub-typical groups; for this division of the Lepidopterous order is precisely of this denomination. How then, it may be asked, is this repulsive property shown among the true butterflies (Papilionides Sw.), which are the pre-eminent types of the order? The Papilionides are a circular group; consequently they 
have, like all other circles, a sub-typical division of their own. These are distinguished by their caterpillars being armed with formidable spines or prickles, which in general are possessed of some highly acrimonious or poisonous quality capable of injuring those who touch them. In short, the infinite variety of ways by which this peculiarity is modified is so wonderful, as, but for unquestionable facts, would appear incredible. The suspension of the chrysalis is another intimation of the same symbolical character. That of the butterfly, the pre-eminent type of annulose animals, is fixed with its head upwards, as if it looked to the pure regions of heaven for the enjoyment it is to receive in its last and final state of perfection; but the chrysalis of the brushfooted butterflies (Nymphalides Sw.), whose caterpillars are. stinging, is suspended with the head downwards to the earth, thus pointing to the world as the only habitation where its innumerable types of evil are permitted to reside : or to that dark and bottomless region, where punishment awaits the wicked at their last great change. It is only when extensive researches bring to light a uniformity of results, that we can venture to believe they are so universal as to deserve being ranked as primary laws. Thus, when a celebrated entomologist denounced as "impure" the black and lurid beetles forming the Saprophagous Petalocera of Mr. MacLeay, a tribe living only upon putrid vegetable matter, and hiding themselves in their disgusting food, or in the dark hollows of the earth, neither of these celebrated men suspected the absolute fact, elicited from our analysis of this group, that this very tribe constituted the sub-typical group of one of the primary divisions of coleopterous insects : nor had they any suspicion that by the filthy habits, and repulsive forms of these beetles, nature had intended that they should be types or emblems of hundreds of other groups, distinguished by peculiarities equally indicative of evil. On the other hand, the Thalerophagous Petalocera, forming the typical group of the same division, present us with all the perfections 
and habits belonging to their kind. These families of beetles live only on fresh vegetables: they are diurnal, and sport in the glare of day, "pure" in their food, elegant in their shapes, and beautiful in their colours.

(308.) III. The characters belonging to ABERRANT groups, when viewed as a whole, for reasons already given, are too varied to admit of general application, further than that they depart much more from those which belong to pre-eminent types than these latter do from the subtypical. It will, therefore, be necessary to consider aberrant groups as naturally divided into three distinct types. We shall, for the present, distinguish these by the names which we have assigned to them in ornithology, - the only division of zoology wherein they have been accurately traced. It may be objected to this plan, that to designate a type of quadrupeds or of insects by the same term as that which is appropriated to birds will lead to a confusion of ideas. But, on the other hand, as these types, throughout the animal kingdom, are found to present certain characters in common, the advantages of designating them by common names are abundantly obvious. Hereafter, when the subject has undergone deeper investigation, we shall suggest more comprehensive and appropriate names. For the present, therefore, we shall term them the Aquatic, the Suctorial, and the Rasorial: these, collectively, form the aberrant circle of every group in the animal kingdom.

(309.) The NATA TORIAL or AQUATIC types, represented by the natatorial order of birds, as the name implies, are more especially inhabitants of the waters. They possess many and striking peculiarities, modified, indeed, in the most astonishing manner, but more conspicuous, perhaps, throughout all natural groups than any of those belonging to other types. We shall consider these characters under the heads of structure and economy, and exemplify our remarks by some familiar instances. I. As to structure,-aquatic types are chiefly remarkable for their enormous bulk, the disproportionate size of their head, and the absence or very slight developement 
of the feet. If we look to the primary divisions of the vertebrated animals, we see one of these peculiarities very strongly marked in the fishes, the only class wherein the feet, in all the individuals, are entirely wanting, while every one is aware that no fish can exist unless in its own element. On taking a wider survey of the animal world, we find that the radiated mollusca (Radiata) are pre-eminently aquatic, destitute of any organs analogous to feet, but often swimming with their arms, in the manner of the cuttlefish (Cephalopoda), which are, in fact, the aquatic types of the testaceous Mollusca. These latter are the largest of all invertebrated animals, and thus unite three of the great characteristics of the aquatic natatorial type; namely, an aquatic nature, enormous size, and a large disproportionate head. It may be urged, indeed, that the absence of feet cannot be looked upon as a peculiar mark of the natatorial structure, seeing that these organs are wanting, not merely in one but in three of the chief divisions of the animal world; but it must be remembered, that a natural group rests not upon any one single and exclusive character, but upon a combination of several. Thus, although fishes and medusæ are aquatic, and move without feet, they are not the largest animals, either among the vertebrated or invertebrated, and, therefore, do not possess all the characters of the natatorial type ; but those which they do possess are more developed in them than in any other of the chief divisions of animals, or of the classes of the vertebrata: hence, although they do not possess all, they exhibit some, of the characters of their type, which characters are not found in any other of those which we term primary types. As we approach the more perfect animals, we begin to see the developement of another singular feature ; namely, a very large, thick, and obtuse head, furnished with jaws capable of great expansion, and terminated by a blunt or truncated muzzle or snout. This structure implies the peculiar power of seizing their food by the mouth alone, without the assistance of feet or claws; and as this power would only be necessary 
to such animals as lived upon others, we accordingly find that nearly all natatorial types are carnivorous : the medusa, the cuttlefish, the whales, and innumerable . other groups demonstrate this, but none more perfectly than the order Natatores among birds, the owls among the Raptores, and the Fissirostres in the circle of the perchers (Insessores). Sub-typical forms, as we have already seen, are pre-eminently carnivorous, but they differ from the natatorial (which always follow them) in this, that the food is captured by the aid of the claws, whereas in the types we are now speaking of the mouth alone is the instrument of capture.

(310.) We are thus led to the feet of this type, the absence or slight developement of which, in natatorial forms, is almost universal. As Fishes constitute the pre-eminent natatorial type of vertebrated animals, so we find that those groups which represent them in other of the vertebrated circles have the feet transformed, as it were, into fins. How beautifully is this exemplified in the whales and porpoises (forming the natatorial order of quadrupeds), the swimming order of birds, and the Elaniosauri, or fin-footed reptiles! Analogies, if they are true, are universal; and thus we find the same general structure, under different modifications, both in the Mollusca and in the Annulosa. The Pteropoda, the Cephalopoda, and the Crustacea, or crabs, employ the same organs for swimming: these animals, above all others in their respective circles, are the most expert swimmers, and the most adapted for inhabiting a watery element. Even when we descend to more minute groups, the same general structure, under new and surprising modifications, can be distinctly traced. The apodal larvæ, for instance, of all the Ptilota or winged insects, are natatorial types ; while the order Neuroptera, in the circle of Ptilota, is precisely of the same description, being analogous to the Crustacea, or crabs.

(311.) II. As to the economy of the aquatic types, we have already premised that they are almost entirely carnivorous, - a habit which is naturally to be expected 
in any group which joined, and immediately blended into, the sub-typical (304.). We have seen that the feet are slightly, and often not at all, developed: an incapacity for quick motion is the natural result of such an organisation; and hence it might theoretically be concluded that the feet are never used in the pursuit or capture of their prey. Now this is truly the case in numerous instances : natatorial types seize their food by the mouth alone; and all such as do not swim, or pursue their prey by their wings, dart upon it from a fixed station, as if incapacitated to rove about in its search, like other animals, by the imperfection of their feet: the kingfishers, the herons, flycatchers, and innumerable other groups, are all well known instances of this habit, not to mention the whole tribe of Fissirostres among perching birds. The Cirripedes, or barnacles (the natatorial type of the Annulosa), and all others whose body is fixed, show us the same principle developed under a different aspect ; for here the habits of the animal at all times are so sedentary, that they seem absolutely incapable of moving from the spot where they complete their last or final change of form. The Hesperian butterflies (Hesperida) are the most sedentary, in their larva state, of all true insects, for they fabricate and live in a little cell, formed by a leaf rolled into a cylinder. Every natural group, in short, contains some one representation of this type: we have not yet determined, however, whether all internal feeders are of the natatorial (or apod) type.

(312.) Let us now look for verifications of the foregoing theory among some of the best known animals; all of which, in their own respective circles, belong to this type of form. First we have the whales, the leviathans of creation; before whose stupendous size even the elephant shrinks into moderate dimensions: the head is nearly as large as the whole body, the mouth is of vast size, and although a quadruped, it is apodal, or without feet. It lives in the waters, and the snout is so obtuse and blunt, that the extremity appears as if cut off. Next to these gigantic animals the hippo- 
potamus, or river horse, but for the extreme shortness of its legs, would vie in bulk with the elephant: 'this also is a natatorial type, and we find it possessed of all the leading characters, under new modifications : a large head, thick and blunt snout, short and imperfect feet, and aquatic habits, leave the analogy indisputable. The ostrich is the largest bird in existence: it is not natatorial, because it belongs to a different order; but nature has contrived that all the other indications of its type should be preserved: the bill (corresponding to the snout of quadrupeds) is broad, depressed, and obtuse, and the wings (the chief organs of motion among birds, as feet are among quadrupeds,) are so short as to be almost useless. Crabs, among annulose animals, are the largest and the most aquatic of all wingless insects (Aptera L.), for in that division were they placed by Linnæus, and to that they truly belong: the head is enormous, and in many is so confounded with the thorax that the two parts appear but one. If we pursue the analogy to the winged orders (Ptilota), we find the gigantic Neuroptera, at the head of which stand the dragon-flies, living the greater part of their lives in water, and the genus Mantis far surpassing all other insects in bulk. We shall hereafter endeavour to point out the probable station of those stupendous fossil reptiles, the ichthyosaurus; plesiosaurus, \&c., and which we consider as constituting the natatorial type of the Reptilia; preserving, even in their fossil remains, all the properties of such types. Now, to prove that these examples are not taken at random, but are actually supported by analysis, we shall place before the reader a table of the aberrant types of some of the groups we have here intimated : -

Aberrant Group of the

\begin{tabular}{|c|c|c|c|}
\hline $\begin{array}{l}\text { Series of } \\
\text { Quadrupeds. }\end{array}$ & $\begin{array}{l}\text { Series of Verte- } \\
\text { brata. }\end{array}$ & $\begin{array}{l}\text { Series of the } \\
\text { Pachydermata. }\end{array}$ & $\begin{array}{c}\text { Series of the } \begin{array}{c}\text { Series of } \\
\text { Rasores. }\end{array} \text { the Ptilota. }\end{array}$ \\
\hline $\begin{array}{l}\text { Ungulata. } \\
\text { Glires. } \\
\text { Cetacea. }\end{array}$ & $\begin{array}{l}\text { Reptiles. } \\
\text { Amphibia. } \\
\text { Fishes. }\end{array}$ & $\begin{array}{l}\text { Megatherium. } \\
\text { Hyrax. } \\
\text { Hippopotamus. }\end{array}$ & $\begin{array}{l}\text { Guan. Hymenoptera. } \\
\text { Pigeon. Coleoptera. } \\
\text { S. Ostrich. Neuroptera. }\end{array}$ \\
\hline
\end{tabular}


(313.) Let us for the present suppose, theoretically, that each of these columns is a circular group. One of the tests, therefore, of such a group is, that it finds its contents represented in all others; hence, the results in the present instance completely confirm what has just been advanced: we find the cetacea, or whales, representing the fishes, the hippopotamus, the ostrich, and the Neuropterous dragon-flies. By this series we know, therefore, to demonstration, that the analogies are correct, because they are the result, not of a studied adaptation, but arise, as it were incidentally, from following closely the line of affinity in each column; the affinities being expressed perpendicularly, and the analogies horizontally.

(314.) We are now to consider the suctorial type of form: this corresponds with the tenuirostral type among perching birds, the grallatorial in the orders of that class, the gliriform among quadrupeds, and the onisciform and vermiform in the class of insects. We shall, however, designate all these under the common name of suctorial, because it is more generally applicable to the habits of the animals here alluded to than to any other. One of the chief peculiarities of this type is, that the food is imbibed by suction; a mode of nourishment which is, of course, accompanied by many remarkable deviations from the structure of all other types. These are always the smallest in point of size, the most feeble and defenceless in structure, and the most defective in the organs of mastication. In all these characters, the suctorial stands in direct opposition to the natatorial type. In such as belong to the vertebrated circle, the feet are always fully developed; for these animals are peculiarly active, and enjoy, in a remarkable degree, the power of running and of leaping. The suctorial form is also widely different from the natatorial in other respects; there is a great length or attenuation of the body, the head is always very small, generally prolonged into a pointed snout, and the mouth, as adapted for sucking, is uncommonly small : in some few in- 
stances it is not, in fact, apparent. All animals belonging to this type are shy, and evince little or no propensity to become domesticated. They are without offensive protection; but nature, as if to screen them from their enemies, has endowed them with great caution, uncommon vitality, and in many cases has protected them either with a hard skin or a coating of bony armour, which entirely envelopes their body, and repels all injury. When compared to the pre-eminent examples of their respective circles, the suctorial type may be viewed as the most imperfect ; that is, the most simple in its organisation, and the most dissimilar from all others.

(315.) Let us now see in what manner this type is developed in the more comprehensive divisions of the animal world. The polypes and the animalcula (Acrita) are the smallest of all living beings. Thousands are invisible to the naked eye; and these, even when viewed under the microscope, appear but as grains of sand, mere particles of matter, so simple in their structure as often to be without limbs, and only recognised as animals from being endowed with voluntary motion. In what manner they are nourished, - whether by absorbing the fluid in which they live, or by sucking the juices of other beings still more imperceptible than themselves, -is immaterial to our present purpose, as both are obvious modifications of the suctorial process. In the vertebrated circle, comprehending the most perfect of all animals, this type of imperfection is confined to a very small number. Of these the siren of Linnæus is probably the type: it is, perhaps, the most defenceless of animals ; living, like the worms, in the muddy bottoms of ponds, destitute almost of eyes, without teeth, and whose feet are so inefficient as to appear like unserviceable appendages. In the great division of annulose animals we have all these types represented by the intestinal worms; whose structure, indeed, is so imperfectly jointed, that in some of the modern systems we find them referred to the Acrita or polypes: they are nevertheless truly annulose, and give us the most perfect 
idea of the suctorial structure. That well-known animal, the common medicinal leech, represents the suctorial Vermes in the circle of the Annelides, or red-blooded worms, and brings before us some of the most striking properties of this type. As we proceed to trace these characters in the groups of more perfectly constructed animals, we find in the tortoises the faintest developement of the vertebrated structure; while the singular defence with which nature has provided them, is again produced in the more immediate groups of Dasypus and Manis (the armadillo and scaly ant-eaters) among quadrupeds, in the remoter instances of the Coleoptera among the Ptilota, and the larva of the Ericinida among the Lepidoptera. The singular resemblance which the chelonian fishes, forming the order Branchiosteges, bear to the tortoises and turtles, must strike every one; and it is worthy of notice, that throughout these groups the mouth is particularly small, and in very many instances entirely destitute of teeth. The suctorial types among the quadrupeds contain all those which have the jaws or muzzle produced to an extraordinary length; witness the moles, the ant-eaters, the armadillos, the pigs, and the whole family of mice. Now, this is precisely the structure of all the types of the suctorial birds : for the Grallntores, or waders, have the longest bills and the smallest mouths of any in the whole class; while the humming-birds (by which the waders are represented in the great order of Insessores) live entirely by suction, and are remarkable both for the great length and slenderness of their bill, and the extreme narrowness of their gape.

(316.) In regard to the motion of suctorial types, we have said that they exhibit amazing powers of leaping; but this does not appear to be a character of such universality as many of those we have noticed. The flea is, nevertheless, a well known and familiar example among insects, as the jerboa and the kangaroo in the circle of quadrupeds; while the wading birds, although not saltatorial, are the swiftest runners of the feathered 
creation. In no one instance do we find that suctorial types, like the natatorial, are fixed, as are the Polypes and the barnacles, to one particular spot: free powers of locomotion, and these generally accompanied with great agility, are, consequently, among its chief characters. Nearly all the animals which, from imbibing their nourishment by sucking the juices of others, and whose structure at the same time is very simple, are of this type: it might, from this fact, be termed parasitic, for it comprises almost every animal which usually bears that name. The intestinal worms, the common Cimex, Pediculus, and Pulex, the gold wasps (Chrysis), the Acari, or harvest bugs, and the Cocci, or cochineal insects, are a few out of the multitude of examples which can be proved, by analysis, to be modifications of this primary type. Among quadrupeds, this latter character is not strongly developed; but every one knows the parasitic nature of the cuckow, and the cow-pen bunting of America (Molothrus pecoris Sw.); while the Gastrobranchus, among fishes, illustrates this peculiarity in the most striking manner.

(317.) The rasorial type, so termed in ornithology, is the third and last which enters into the aberrant circle - which circle is always closed by the union of this type with the NATATORIAL; hence it follows, that both approximate in their general characters. First, as to the form and structure of rasorial types. They are, in general, remarkable for their size; being inferior only to the natatorial. From these they are further to be distinguished by the strength and perfection of their feet; the toes of which, in vertebrated animals, are never united so as to be used for swimming. This perfection, however, is of a very peculiar kind; since it is confined to the powers of walking on dry land, or of climbing among trees. These scansorial powers, in fact, although occasionally found in other types, are so very frequent and remarkable in this, that it may be considered one of the peculiarities of the rasorial structure. This is the type so remarkable for the greatest developement of tail ; and of those appendages, for ornament or defence, 
which decorate the head. If we went through the whole class of birds, and selected those, beginning with the peacock, wherein the tail was most conspicuous, either for its size, its singularity, or for the beauty of its colours, we should, unknowingly, fix upon those birds which analysis has already demonstrated to be rasorial types. The same result would attend a similar selection of quadrupeds, and of winged insects. All these, collectively, would furnish many hundred proofs by which the uniformity of this type is preserved. Appendages to the head, whether in the shape of horns, crests, or fleshy protuberances, are no less a prevalent character of the type now before us. Among birds, indeed, we scarcely know of more than two or three groups furnished with crests, which do not appear to be rasorial types; and this very circumstance is sufficient to raise a doubt on their real denomination. But it seldom happens that both these peculiarities are united in the same group. Nature will sometimes indicate her types by two only of its leading characters, while she withholds a third, in order to bestow it, in its full developement, upon another group modified upon the same general principles. Thus we see that the horse, one of the types of the rasorial order of ungulated quadrupeds (Ungulata), is superior to all the Mammalia in the beauty and elegance of its tail: but then this noble animal is destitute of another indication of its type; for the head is without either horns or protuberances: these, however, are bestowed upon the ruminants, belonging to the same circle, who, on the other hand, are destitute of the flowing tail of the Solipedes. We thus see how two of the typical characters of the rasorial structure is distributed between two groups*, which, nevertheless, collectively belong to the same order. This, in fact, seems to be one of the principles by which Creative Wisdom has produced such infinite variety in His works; for if, in reference to the horse and

* This is still more strongly exemplified in the two primary groups of the Scansores - the Psittacida and the Picida. 
ox, the former were to have horns, and the latter a flowing tail, how closely would they resemble each other! On such principles, that beautiful and astonishing variety, which constitutes one of the most remarkable features in the creation, would be destroyed; and if each type were to exhibit all the properties or peculiarities theoretically belonging to it, we should have but five unvaried forms of living beings. This is the rock upon which many naturalists, who have not sufficiently reflected on the subject, are continually splitting. They argue after this fashion:- How can you maintain that a bat represents a mouse or a wading bird, when the first has wings, the second none, and the third has but two long legs? or, how can you draw up a set of characters purporting to belong to the rasorial type, when many of the animals you bring forward in support of your theory are actually without some of these characters? Such reasoners appear to forget, that if a mouse had wings, it would be no longer a mouse - it would be a bat; while the analogy of these quadrupeds to a wading bird, from being very remote, must not be made an immediate object of comparison, but must be traced through a number of intermediate analogical forms.

(318.) The economy and instinctive dispositions of the rasorial type are stamped with many remarkable circumstances, deserving our deepest attention. So little, however, is known of such invertebrated animals as come under this denomination, that we must, in the following observations, be understood to speak more particularly of the rasorial types of quadrupeds and of birds ; thus selecting our illustrations from the most perfectly organised, and the best known, of vertebrated animals. The economy of this type is in direct opposition to that of the natatorial; for it is strictly terrestrial: we know not, in fact, a single instance where the individuals belonging to it frequent water or its vicinity. This propensity to live removed from that element does not, however, confine these animals to the bare ground; for they either walk upon the surface with 
ease, or climb trees with singular facility. These faculties, nevertheless, are never found in the same individuals; but are distributed on the same principle as that illustrated by the instance of the horse and the ox. This is manifestly the case in the rasorial order of birds, and the Scansores, or rasorial tribe of the perchers. The first never climb, but seem to delight in dry soils; they never perch upon trees but to roost: whilst the Scansores, comprehending the parrots and woodpeckers, reverse the picture, and show us the climbing property of the type in its greatest perfection. The same disposition is observed among the rasorial groups of quadrupeds. The habits of the ruminants are those of the gallinaceous order of birds, while those of the sloths are precisely similar to the climbing habits of the woodpeckers. The food, in conformity to their dispositions, is almost always vegetable. The peaceful order of ungulated quadrupeds seek their food from the vegetable world, and the parrots live entirely upon fruits. This is, again, one of the strong points of opposition between this and the last type ; for natatorial groups are almost always purely carnivorous; and it is only among such forms as serve to connect the two, that we find species that live both upon animals and vegetables : the trogons (Trogonide) and the toucans (Ramphastida) are striking examples of this union of different foods.

(319.) But what more especially distinguishes the type we are now describing, is the superior degree of intelligence and docility that runs through all the groups of vertebrated animals belonging to it. It seems to have been ordained, by Ammighty Wispom, that there should be onc type, above all others, whose powers were to be more especially devoted to MAN, and which should evince an aptitude and a disposition to submit to his dominion, far above all other created things. This is the grand characteristic of all rasorial types among the more perfectly formed vertebrated animals, whose size or structure are in any way adapted to answer the end proposed. This principle of nature was partially per- 
ceived by Linnæus, when he compared the ruminating quadrupeds to the gallinaceous birds; an analogy, indeed, so apparent to the commonest observer, that we can only feel surprise at its ever having been questioned by any one, much more by those who are naturalists. Nature seems to have intended that a few of her analogies should be stamped by such striking and indisputable resemblances, that the most ordinary capacities should acknowledge them; and by giving us, as it were, these landmarks, or stations, to depart from, she seems to have invited and encouraged our further research into the more complicated parts of her system. Any theory, therefore, which sets out with denying what the rest of mankind have long perceived, requires more than ordinary proofs of demonstration; and, at best, is calculated to excite onr caution in its adoption, if not our suspicion of its correctness. There is no one truth in natural arrangement capable of such varied and overwhelming demonstration as that upon which reposes the analogy of the ungulated quadrupeds ( $\mathrm{Un}$ gulata) to the rasorial order of birds ; both of which show the highest intelligence, the greatest docility, and the most cheerful contentment under the domestication of man. We are surrounded with proofs of this, which meet us in every direction. All our quadrupeds of burthen or of food are taken from the Ungulata. The horse, the ox, the sheep, and the goat are in our meadows and pastures; while the dog is a rasorial type of the Ferce.

(320.) Let us now look to the feathered creation. The varied contents of our farmyards belong solely and exclusively to the rasorial type ; for even the common duck, although a natatorial bird, is yet the rasorial type of its own family: this we have elsewhere proved by strict analysis*; and on the same conclusive evidence can be established the accuracy of the original opinion entertained by Linnæus regarding the Ruminantia and the Rasores. But this is not all. It has been our especial

* Journal of the Royal Institution, new series, No. iv. p. 11. 
object, in another work*, to demonstrate the particular fact of which we have just spoken, by tracing the rasorial type through the vast order of perching or land birds; and had our limits there permitted, we should have continued the demonstration, by giving the result of a similar analysis of all the orders in the feathered class. But it is not among birds only that the sociality and docility of the rasorial type is manifest: the same is apparent through all the chief groups of quadrupeds; while it can be traced, with equal clearness, in many' of those belonging to the Annulosa. The hymenopterous order of the Ptilota, or winged insects, is, in its own circle, a rasorial type; and we thus find that the ants and the bees - the most useful insects to man, and the most intelligent and social of annulose animals - are actual representatives of the ruminating quadrupeds and the gallinaceous birds. In proportion as we recede from those animals whose size, intelligence, and structure renders them fit companions or assistants to man, and advance towards the invertebrated groups, this analogy, of course, becomes fainter and fainter. Thus, on looking to the testaceous Mollusca, as the rasorial division of the animal kingdom, their services are simply confined to the power of supplying us with a wholesome and nutritious food: for it is remarkable, that nearly the whole of these animals are edible; while, in the natatorial division of the Radiata, where we have the Medusa, the star-fish, and the Echini, scarcely one species is used as food by the most uncivilised people. This property; however universal, is nevertheless modified in an infinity of ways. It is seen in its greatest developement in the ox, the elephant, and the horse ; for these quadrupeds actually labour in our service. In the dog it is manifested by affectionate attachment; in the domestic fowls, by perfect contentment in a state of partial confinement. The Robin shows his attachment to man by living near his dwelling; the honey-guide (Indicatar), by assisting him to discover what, in Africa, is an im-

* Northern Zoology, vol, ii. The Birds. 
portant article of food; while the bird called by Le Vaillant the Importan, accompanies him in his woodland rambles. ${ }^{*}$ All these instincts are evident modifications of one and the same principle; and this is so strong, that. it is sometimes extended to the indirect representations of rasorial types in other groups : hence we find that the swallows, although a natatorial type, always build, by preference, in the vicinity of human habitations; there being a parallel analogy between this family and the rasorial parrots (Psittacida). Yet not one of the natatorial types can be domesticated.

(321.) That the characters of the rasorial type may be rendered more apparent, we shall now bring before the reader a more condensed enumeration of the chief types in which they are conspicuous; leaving him to investigate, through the natural history of the animals themselves, the degree of analogy they respectively possess. These rasorial types are arranged in columns, indicating the developement of each of those rasorial characters which have already been explained. To those who, in a good or in a captious spirit, have objected, that we are perpetually talking of demonstration, when not one demonstration in these volumes has yet been given, we shall here, once for all, address a few words. Wherever in this, or in the Preliminary Discourse, such an appeal has been made, we have referred to the previous and well-known labours of Mr. MacLeay and of others; or to our own in the work so often quoted. $\dagger$ No demonstration is, or was intended to be, given in that volume; nor is there one in this, because such proof depends upon analysis, and not one group of animals has yet been analysed in these volumes. Results of previous analysis, indeed, have been often quoted, as at p. 234. When, therefore, the supposed errors of the

* Oiseaux d'Afrique, vol, iii. p. 41. Andropadus viridis Sw., N. Zool, 485. $+\mathrm{Had}$ one of our reviewers known any thing of the Fauna BorealiAmericana, beyond the title-page, he would not have asked why constant reference was made to that,volume rather than to Wilson's American Orni.. thology : the first containing all those demonstrations of the ornithological. groups to which we have appealed; while the latter, as every one knnws, is a mere history of species. 


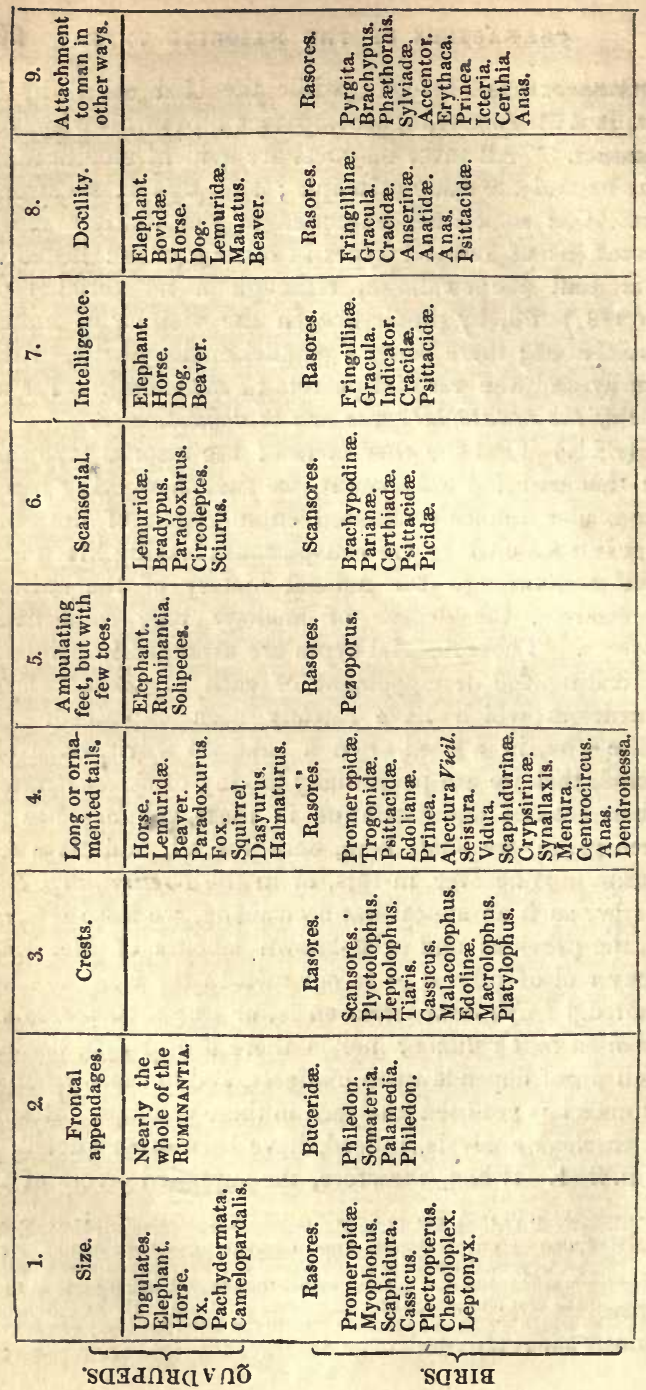


facts upon which these results are founded, be pointed out, it will then be time enough to talk of " want of demonstration." We would even wish, that every thing that has been hitherto said upon the natural system were considered as an hypothesis, which remained to be proved in those volumes where the details of each class of animals are to be entered upon.

(322.) There is one question which the reader may possibly wish answered, arising out of the assertion just made, that the dog is a rasorial type ; and it would be this:- The dog belongs to the carnivorous order of Ferce; how, then, can it be of a different type? does not this imply a contradiction? By no means. The Ferce, as a whole, is a sub-typical group (305.); but as it is a natural group, it contains, within itself, a rasorial division. Hence, although this animal belongs to the Ferce, it is one of the rasorial examples of that order; and, accordingly, we find it the most intelligent and docile of all its congeners. If the order Ferce had no rasorial types, then it would be an imperfect group; and so, from not being circular, there might be reason to suspect it was not a natural one. But, as all its divisions assimilate to the other types here defined, it is, therefore, presumed to be both natural and perfect. So in like manner, among birds, Melanerpes Sw. is the aquatic (or fissirostral) type of the sub-family of woodpeckers (Piciance Sw.); although this group, of which it forms a part, is, as a whole, a scansorial type.

(323.) In substantiating the proposition with which we commenced this chapter, we have endeavoured to consult, in our definitions and examples, brevity and perspicuity. It is obvious, that where the modifications of a particular form pervade the whole animal creation, the difficulty of definition becomes vastly increased. We have, therefore, drawn our explanations and illustrations chiefly from the best known vertebrated groups, and from such only as have been submitted to analysis. A far greater number might have been adduced from the annulose kingdom, reposing on the same grounds; but 
their introduction in this place would have extended our remarks to a volume, and have so embarrassed our definitions, that, although the adept could have understood them, the student would have been perplexed. When each class of animals, in the succeeding volumes of this series, comes to be treated of separately, we shall then, and then only, enter upon demonstration.

\section{CHAP. III.}

THE FIFTH PROPOSITION CONSIDERED. - ON THE RELATIVE RANK OF THE DIFFERENT CIRCULAR GROUPS IN THE ANIMAL KINGDOM. - ON SPECIES AND VARIETIF.S. - ON THE MEANS THUS OFFERED BY THE LAWS OF NATURAL ARRANGEMENT, FOR THE VERIFICATION OF GROUPS. - FAMILIAR ILLUSTRATION OF THE PRINCIPLES OF CLASSIFICATION HERE DEVELOPED. - QUESTIONS ON ANALOGICAL COMPARISONS.

(324.) The fifth and last proposition with which we commenced this part of our volume, is as follows :That the different ranks or degrees of circular groups in the animal kingdom are nine, each being involved within the other. The full demonstration of this law would obviously require an analytical exposition of the whole number of circles here mentioned; which, to do tho roughly, would in itself require a volume. We can, therefore, only offer presumptive evidence on its apparent accuracy, drawn from facts, observations, and inferences already before the public, and which have remained unquestioned. Species and varieties will next claim our attention: and, finally, we shall conclude this division of our volume with a brief enumeration and a familiar application of those laws by which natural groups are to be verified.

(325.) We have seen that the whole animal kingdom is composed of an infinite number of circles, touching 
and blending into each other at different points of contact; and representing each other by innumerable analogies. If we begin with species, we find they form a little circle of themselves : several of these little circles congregate, as it were, and unite into a larger one ; this circle in its turn unites to others, and is again involved in a larger one ; " another and another yet succeed." And thus does nature proceed; every combination being greater than the last: small circles are absorbed in larger; until she finally combines them all into one, composed of the whole animal kingdom. It follows, therefore, that although all natural groups are circles; yet are these circles of different sizes, ranks, and value. It consequently becomes necessary to designate these different groups by particular names, that their com-. parative value may be understood, and that they may become efficient instruments for reasoning.

(326.) It was long a favourite and an unqualified assertion among naturalists, even of late years, that the only absolute divisions in nature were species; an assertion which must now, however, be relinquished. Species are as much connected among themselves, as are genera ; the progression of affinity, in most cases, being as gradual in one as in the other. Every natural group, when perfect, is definite; because it not only shows a circular series of affinities, but also a series of types or representations. Thus, in many cases, we can demonstrate the precise station of an animal ; at least, so far as to form a pretty accurate opinion whether it stands within the range of one circle, or enters the confines of another immediately contiguous. The intervals between one species and another is not wider, or more decidedly marked, than that between two kindred genera : for it frequently happens that varieties, as they are called, occur between two supposed species, which leaves us in doubt what to term them; whereas we seldom find that one genus blends into another so completely as to render it impossible to say to which of them a particular species belongs. Nature's groups are, therefore, 
more definite than her species; and it must consequently follow, that, as they are of different ranks, there must be some prevalent number of these ranks.

(327.) Upon this abstruse question little has been said or written, although all naturalists have long been accustomed to use different names to denote the relative value of their divisions. Mr. MacLeay, looking to annulose animals alone, in speaking of the rank of the genus Scarabceus, seems to think that there are eight different descriptions of circular groups; but this opinion is the result, as he himself premises, more of conjecture than of analysis. It is, nevertheless, much nearer the truth than could have been supposed; for if he had been aware that sub-genera are likewise circular, the number would have been nine. Now, this is precisely the very highest number of circular groups, differing in value each from the other, that can be traced in ornithology; and in the typical divisions of the order Lepidoptera among insects. This fact, in both instances, rests not upon theoretical supposition, but upon demonstrative analysis. We mean not to assert that there can be no divisions of sub-genera, which may not, in themselves, be circular; because it seems to be a law of nature to carry this principle into her lowest assemblages; but hitherto we have not clearly detected any sub-genus of this description. Should the divisions of sub-genera, in such cases, really be, in themselves, distinct circles, they may be detected, probably, in the family of Carabida Sw., composed of the Carabida and Harpalidae of authors.

(328.) The animal kingdom, then, may be presumed to contain nine different ranks or gradations of circular groups, commencing with the highest, and terminating with the lowest assemblages. These groups have received the following names, which at once indicate their relative value: -1 . Kingdom; 2. Subkingdom; 3. Class; 4. Order; 5. Tribe; 6. Family; 7. Sub-family; 8. Genus ; 9. Sub-genus. This latter is the lowest description of circular group hitherto de- 
tected in nature : for although, when a sub-genus is very perfect, it sometimes contains the five types of form common to all circular groups; yet, as we have just observed, no instance has yet been pointed out, wherein each of these types is also circular.

(329.) It is clearly impossible to define any of these groups by characters which are applicable to all such as hold the same rank; nor can their value be known by any other rules than those resulting from analysis and comparison. The characters which belong to a family in one tribe, are totally different from those which characterise a family in the next; while such as are exhibited in a third, will be very different from either. Nor can we tell, at first sight, the difference between a tribe and a family; or whether any particular form is the representation of a genus or a sub-genus. The true rank of a natural group, in short, can only be detected by analysis and analogy ; and the more extensively these enquiries are carried into the neighbouring groups, the more likely are we to understand its true rank. But as this mode of investigation is not only laborious, but too difficult to be extensively prosecuted, it is the custom with most writers to throw several genera into a group, and call that group a family, or a sub-family. This is all very well, and really useful, if it be considered, as it truly is, but a temporary expedient, - a mode of abridging labour, by assuming what has not been proved, and pointing out to the reader the most probable station of the group or species under his consideration. But no faith can be placed in such tables or scales of gradation*, until their circular arrangements and analogies have been made out by analysis. We shall now proceed to make some general remarks upon these groups.

(330.) The common consent of mankind has sanctioned the belief in the three kingdoms of nature,- the

* Such, for instance, as that in the Introduction to Entomology, vol. iv. p. 393. 
animal, the vegetable, and the mineral. These divisions are palpable; and our belief in them is not to be disturbed by the subtleties of philosophy or the arguments of metaphysicians. From this point, therefore, if we wish to pursue the synthetic mode of investigation, we may start, as from an incontrovertible truth. The animal kingdom is admitted to be a circular group: its first divisions are, therefore, into sub-kingdoms. Vertebrated animals form one of these sub-kingdoms; and annulose animals, or insects, generally speaking, another. These are next divided naturally into classes, of which description are quadrupeds, birds, fishes, reptiles, and Amphibia in one ; and winged insects, apterous insects, barnacles (Cirripeda), \&c. in the other. So far we can have no doubt as to the kingdom, subkingdom, or class to which an animal, whose rank we wish to ascertain, belongs; and we will suppose this to be the common-bearded titmouse (Parus biarmicus). Every one sees that this is a bird not formed either for swimming, wading, or running upon the ground: we consequently conclude that it perches, and refer it at once to the division of birds named, from this circumstance, Insessores; and by this means arrive at its order. Its perfect and well-proportioned feet guide us to the particular tribe of Insessores which is distinguished by these characters; and we then proceed, by still further examining its structure, to refer it to the family of warblers, and to the sub-family of titmice (Pariana).* The sharp conic bill, and other minute peculiarities of structure, show that it belongs to the genus of Parus; and to that little group, or sub-genus, which contains the most typical examples, or Pari proper. But even a sub-genus, as we have already seen, contains in its own little circle, when perfect, a representation of all the types of nature; and thus the bird before us, as representing the natatorial or aquatic type, inhabits the marshy borders of lakes and rivers, 
and lives only in such situations. Now, if this aquatic division of the sub-genus Parus, instead of merely containing this one bird, comprised twenty or thirty species, we have every reason to conclude, judging from analogy, that it would of itself form a little circle; and would, consequently, contain a new set of representations of the usual types. But this, as we have already remarked, does not occur in the class of birds; although it may possibly be found among insects. We therefore terminate our series of circles with the subgenus Parus proper; and thus get the following scale of rank in the groups we have progressively passed through. As the same results would attend our search after the station of the common swallow-tailed butterfly (Podalirius Machaon Sw.), we shall give the results of both enquiries together - the number being three times three.

Parus biarmicus.

Podalirius Machaon.

1. Kingdom. Animalia. 1. Kingdom. Animalia.

2. Sub-kingdom. Vertebrata. 2. Sub-kingdom. Annulosa.

$\begin{array}{ll}\text { 3. Class. Aves. } & \text { 3. Class. Ptilota. }\end{array}$

4. Order. Insessores. 4. Order. Lepidoptera.

5. Tribe. Dentirostres. 5. Tribe. Diurnes.

6. Family. Sylviadæ.

7. Sub-family. Parianæ.

8. Genus. Parus.
9. Sub-genus. Parus proper.
9. Sub-genus. Podalirius.

6. Family. Papilionidæ.

7. Sub-family. Papilionæ

(331.) There are several deductions of the highest importance to be made from this table, but at present we must view it only with reference to the value of the groups in the first columns. That these, and these only, so far as the bird in question is concerned, are natural, is, to be inferred from the fact that they are each circular groups, already demonstrated as such by rigorous analysis.* Each circle, according to its superior rank, embraces all those that are beneath it; the test or proofs of the accuracy of each reposing on precisely the same principles. We traverse, in fact, eight circles, one within the other, before we arrive at that which brings us directly to the bird before us. It would, no

* Northern Zoology, vol, ii. p. 200, \&c. 
doubt, be easy to divide the family of warblers in twenty different ways, if mere division were the object; and thus to increase or diminish the number of the groups: but to do this in more ways than one, so that each division shall be a circular group, is utterly impossible; and it therefore follows, that these groups, and their relative value, exist as truly and as absolutely in nature, and are as capable of being defined, as quadrupeds are from birds, or fishes from insects. It will be our object, at a more convenient season, to exhibit an analysis of the second column. This analysis, in short, has been made : and as the results have been procured by the same means, we could not withhold from our readers so interesting a coincidence of the definite number and rank of natural groups, taken from two different classes; although the truth of one must at present be assumed.

1. " (332.) Although we have not yet been able to detect any circular groups below the rank of sub-genera, the species composing these little assemblages, when they. are numerous, always present us with representations of those primary types of form already defined, and to which nature so tenaciously adheres. We see an example of this in the bearded titmouse, which is the natatorial or aquatic type of a sub-genus; while Podalirius. Machaon, in like manner, is an aquatic or fissirostral type. The student must not, however, look to these two series with any expectation of tracing transverse analogies: for although the two orders of Insessores and Lepidoptera really happen to represent each other, and are typical orders, the other groups are of different denominations; and therefore cannot, as we have already explained, be analogous.

(333.) In further proof of the universality of these groups, both as regards their number and their rank, we shall now produce two other series: one of which is selected from the class of Mollusca, for the purpose of ascertaining the rank of that lovely shell, the Harpula Vexillum Swains. ; and the other from the sub-kingdom 
of insects (Annulosa), pointing out the probable station of the Scarabaus Sacer of Mac Leay.

Harpula Vexillum, Zool. Ill.2. pl.77. Scarabeus Sacer MagL. i"

1. Kingdom. Animalia. 1. Kingdom. Animalia.

2. Sub-kingdom. Mollusca $L$. 2. Sub-kingdom. Annulosa.

(Mollusca, Radiata, Acrita,

MacL.)

3. Class. Testacea. (Mollusca MacL.)

4. Order. Gasteropoda Cuv.

5. Tribe. Zoophaga.

6. Family. Volutidæ.

7. Sub-family. Volutinæ.

8. Genus. Harpula Sw.

9. Sub-genus. Harpula proper.

3. Class. Ptilota Arist.

4. Onder. Coleoptera Lin.

5. Tribe. Chilognathiform

(MacL.)

6. Family. Scarabæidæ Sur.

(Petalocera Saprophaga

MacL.)

7. Sub-family. Scarabæ:næ Swo. (Scarabæidæ MacL.)

8. Genus. Scarabæus

$M a c L$.

9. Sub-genus. Helio. cantharus Auct. (Scarabæus proper.)

The demonstration of all these groups cannot, of course, now be entered upon, although full details will be given in their proper place. These, however, are the results ; and illustrate, in the most intelligible manner, the determinate number of graduated ranks of circles in the animal kingdom.

(334.) Althongh we have not yet detected in the scheme of nature more than nine gradations of circles, it by no means follows that all these are constantly to be met with in every circle of superior magnitude; as, for instance, in classes or orders. This inequality in the contents of two groups of the same analogical rank has already been fully accounted for.* Sometimes, as in the order Raptores, the primary groups do not appear of a higher rank than the families of the Insessores; and even of these, one, if not two, entire families are extinct. Aberrant groups are almost always fewer, both in point of numbers and of divisions, than such as are typical; and sometimes an aberrant genus, instead of having many species, so as to contain its own types of form, will be only represented by a single individual. This,

- See Preliminary Discourse on Nat. Hist. p.:231. 
as we have before explained*, may be accounted for in two ways, either by our imperfect acquaintance with the productions of nature, or by the extinction of those animals which would render such groups perfect.

(335.) Having now laid before the reader a few of those facts which serve to verify the general truth of the five propositions with which this division of our volume commenced, we must revert to a subject intimately connected with the definite character of natural groups, and of which they are, in fact, composed; we mean species and varieties - those individuals, in short, which constitute the assemblages in question, and whose variation leads to a knowledge of all higher combinations. We alluded to a theoretic belief, even now common among naturalists, that species are the only absolute divisions of nature. So far, however, from such being the fact, we believe that the truth consists in this position being reversed; in other words, that if there are any absolute natural divisions, they are to be found in the different gradations of groups and types here pointed out, but that in numberless cases it is utterly impossible to discriminate species from varieties ; species, in short, being, to human apprehension, the most indeterminate of all the links in the chain of being. This opinion is borne out by the sentiments of one whose peculiar line of study renders him, on this subject, one of the highest authorities in this country. $\uparrow$ Setting aside, however, those exceptions which give rise to these opinions, and where the discrimination of species from varieties is impossible, we shall now proceed to describe those peculiarities which generally constitute a species; and we do this fully, because we think the subject has not received that attention, in introductory works, which it merits.

(336.) A species, in popular language, may be defined as " a natural object, whose differences from those most nearly related to it are, as far as observation has

* See Preliminary Discourse on Nat. Hist. p. 213.

+ J. F. Stephens's Catalogue of British Insects, preface, p. xvi. 
extended, permanent; and are therefore presumed to have had their origin when it came from the hands of its Creator." Domestication and other causes will often produce some variation of these characters; but, in a state of nature, such variations are seldom, if ever, perpetuated through many generations. Species are very generally considered the only distinct or definite divisions in nature. But, if this were correct, we should not have some naturalists calling that a species, which others contend is a variety. The theory of variation, again, by which natural assemblages are regulated, clearly proves that groups are more definite than species.

(337.) It is difficult, if not impossible, to lay down any general rules for the positive discrimination of species; but we may suggest to the student a few of those distinctions which are most absolute: these chiefly relate to form, sculpture, and colour. The form of an animal is as much distinctive of the group it belongs to, as of its specific character; but so infinitely may the same general form be modified, either in the shape or the proportion of the whole, or of its parts, that, perhaps, the form, rigorously speaking, of no two species is the same. Under the general term of form, we comprehend size or bulk, contour, or shape, and the proportion of the parts to each other. In regard to the first of these, the size of all animals will vary according to the scarcity or abundance, the richness or poorness, of their food: their size will also be affected by their locality; that is, by the temperature of the particular climate they have lived in. Animals which are found to be most abundant in cold or temperate regions, will, in proportion as they extend their range to others much warmer, become smaller than their brethren who had not quitted the central region assigned to the species. The convolvulus sphinx of Europe, judging from the perfect insect, seems to be precisely the same in India as in Australia, in form, colour, and markings; but the latter specimens are nearly one third less than the European examples; thus showing 
that a warm temperature, upon some animals, produces the same effect as cold does upon others, whose natural metropolis is in warm latitudes. This variation in size will often occur in individuals found in the same country, or even on the same spot; just as we observe, among a family of children, different degrees of height and of robustness. This variation, however, is more observable among insects than among quadrupeds, while in birds it is somewhat rare. We do not here include domesticated races as examples, because it is well known that the several breeds of horses, pigs, cattle, fowls, \&c. not only vary in size in a most remarkable manner, but assume, in a state of domestication, such different modifications of their usual characters, that, were we to discover them in a wild state, they would be viewed as distinct species. The most variable species of birds, in regard to their size, are the hangnests of America; but more especially those of the genus Cassicus - the largest of which, the elegant crested cassican*, varies almost in every district it inhabits : and yet it is still doubtful whether a better acquaintance with some of these supposed varieties, particularly those of the red-rumped species $\uparrow$, may not make known peculiarities of habits and of manners, which may justify us in considering them distinct species. Generally speaking, however, there must be something more than a mere difference in size, to authorise our making it the only ground of specific difference.

(338.) Shape, or contour, is the second property of form: there are scarcely any instances in which animals, possessing a peculiarity of shape, however slight it may be, are not distinct species from their congeners. A peculiarity in the shape of the wingfeathers, or of the bill in birds; in the direction of the horns of oxen, antelopes, and beetles; in the shape of the antennæ, or of its joints, in almost all insects ; and many other peculiarities which will readily suggest themselves; may all be taken as good and

- Cassicus cristatus, Ornithological Drawings, pl. 32.

+ Cass. hamorrhous and affinis, Ornithological Drawings, pl. 1, 2. 
sound distinctions for species, or at most-among insects - for permanent or sexual differences. We recollect no instances among wild animals, in which these marks are known to vary : no better or more tangible character, indeed, can be named, than the relative shape of the wings of birds, in cases where the size and colour of two or more species are perfectly the same. A striking instance of this may be seen in the greenlets (Vireo V.) of America; where the different shape of the wings constitutes the only specific distinction of three, if not of four, species.* The possession of horns, protuberances, enlargements, \&c. are mostly characters of types, but their particular shape is a sure indication of species. When, however, the shape and direction are the same, but there is merely a difference of size or developement, such circumstance cannot constitute a species. Let us look, for examples of this, to the hornbills (Bucerida) among birds; the Scarahaida and the Cerambycida among insects, and the Muricida among shells. The young hornbills have seldom any of those protuberances on their bill, which they acquire with maturity; and even then they increase in size, without altering much in form, unto advanced age : from ignorance of this fact, former writers were very apt to describe the young and the adult bird as two different species. An analogous case to this is met with among the saprophagous beetles (particularly in the group of bulky Dynastida MacL., and in the genus Phanius of the same author): the hornlike protuberances, which, in the last, distinguishes the male sex, vary, in their length, in almost every individual; so that in some they are very prominent, while in others they are merely like short tubercles. It would be curious to ascertain whether this difference results likewise from age. The spines upon the different rock shells (Murex), and on the coronated volutes (Cymbiola Sw.), vary in like manner; some specimens having acute and prominent spines, while others are nearly smooth. These are the most remarkable excep-

* See Northern Zoology. 
tions to the foregoing rule that at present occur to us ; they relate almost as much to the size as to the shape of an object; but peculiarities drawn from the latter circumstance are much more to be depended upon than those of the former.

(339.) A form is modified by difference in its proportions. Hence, the comparative shortness or longness of an animal, or of its parts, when compared to another which it closely resembles, is (with the exceptions last mentioned) usually a sign that it is a distinct species. The comparative length of the tail in quadrupeds and birds, and of the wings in birds and insects, are excellent speeific distinctions : the antennæ of insects do not supply, in all cases, so good a criterion; for they often vary considerably, both as to structure and length, in the sexes of the same species: the same uncertainty attends the employment of specific characters drawn from their legs. In birds and quadrupeds, however, the structure of these latter members afford distinctions for groups; and these latter modifications give us a certain index for the determination of species. The entomologist should pay particular attention to the proportions of two insects, which come so close to each other, that he may be in doubt as to their specific difference : the greater enlargement of the thorax, the wings, the feet, or even of the antennæ, may frequently indicate a real difference.

(340.) The most general distinction of species is manifested by their colours: among these, however, we must not include black; for not only are nearly all the species of entire families (as the Harpalida MacL.) and sub-families (Edolince Sw.) of this colour, but nearly the whole of the saprophagous beetles are of the same sombre hue. Colours, among quadrupeds, unless when domesticated, seldom vary in individuals of the same species ; and still more rarely among birds, when arrived at maturity. It should be remembered, however, that in the feathered creation, young birds are almost always clothed in the garb of their mother; and that among the 
species of vultures, hawks, gulls, and a few others, the adult plumage is not put on until after two, three, or even four years. Humming-birds, and nearly all their splendid coloured congeners, during the first year, are devoid of those richly coloured plumes which they acquire in the second. These instances are sufficient to set the young ornithologist upon his guard; and yet, in mature life, the colours of birds are their best and most obvious distinctions. Among insects, also, they afford considerable help, especially in the Lepidoptera; where the ground tint and the pattern are almost invariable in the individuals of one species, although there may be some trifling variation in the latter. The ocellated spots, for instance, in our well known meadow butterflies, forming the groups of Hipparchia and Polyommetus, will frequently vary as to their size and number, although the pattern of the wings will be, in other respects, precisely the same. In this order, the colours of the sexes are rarely different; although there are some remarkable exceptions to this rule among the exotic diurnal tribes. In the Hymenoptera, also, the same species of bee will appear very different upon first emerging from the pupa, and when his short career is drawing to a close: the delicately coloured hairs, with which his body was at first defended, will be partly worn off ; and the dark colour of the abdomen, appearing beneath, will give the whole insect a different aspect to that which it had in youth. Let the young entomologist; if he wish to ascertain this fact, capture some of those species he will find on the wing at the end of July, and then renew his captures, in the same locality, in the month of September; in all probability he will meet with the same species, but apparently clothed in different hues. Colours, in the neuropterous order, are very evanescent. Those which ornament the bodies of the dragon flies, not only fade after death, but vary in individuals of the same sex: the beautiful green, so prevalent among the locusts, generally changes, in the preserved specimen, to a light brown : the under wings, 
however, of the grasshoppers (Gryllina Sw.) retain their colours very well; and they never vary in the same species. The colour and patterns of shells, particularly those of the marine tribes, afford very good specific distinctions ; for, upon the whole, they seldom vary to any great extent. When we except two or three species of olives (Oliva Lam.), a few land shells, and the tellin bivalves (Tellina) we specify the chief, if not the only, exceptions to the universality of this observation. It must be understood, however, that no dependence can be placed upon the presence or the number of bands, which often cross the whorls both of the land and the marine genera: these, and the precise pattern of the markings, will often vary in the same species; of which the common garden snail is a noted example. The pattern, also, of the angular zigzag markings, seen on the bat volutes* and other coronated species forming the genus Cymbiola, are scarcely alike in two individuals out of twenty, although the general style of these markings will be precisely the same. Passing from these few exceptions, the cowries may be cited as a group of shells remarkable for the specific uniformity of their colours : indeed, but for this, so slight are their modifications of form, that there are many species which we should find it difficult to distinguish in any other way.

(341.) There are other remarkable ways in which colours vary among, insects, of which the student should be apprised. In numerous species of the Chrysomelida, golden green is the prevalent hue; yet varieties of each are often found of a rich green blue, or of a greenish gold colour. The brilliant American Eumolpi frequently exhibit these variations, among individuals obviously of the same species. Most of all, the saltatorial Galleruci of tropical America, when alive, have a large proportion of pure white about them; yet when they die, and as they are seen in cabinets, these parts appear of a light ochre or dull yellow colour. Some of the small light-coloured Cassida of the same region are still more

* See Cymbiola Vespertilio, Zool. IIL ser. ii. pl 83. 
deceptive : see them alive, and they look like drops of burnished gold ; look at them in cabinets, and they appear like different insects, entirely of a dull yellowish colour : yet let these very specimens be plunged in warm water, and, while the moisture continues, all their rich metallic hues will revive, as if by magic. The colours of many of the apterous insects, especially of the spiders, would enable us to discriminate the species with much precision; but unfortunately they are more evanescent than those of any other insects, nor has any method been yet discovered for preserving them. We are therefore obliged, reluctantly, to seek for other means to define the species. The same remark applies to a large proportion of the crabs ; although they will exhibit, if well preserved, some faint indication of their original hues. Changes of colour, in individuals of the same species of birds, will be effected by extreme age : the green plumage of parrots changes to yellow; and aged females of the gallinaceous order are known to assume the plumage and colours of the male bird. We know not whether this circumstance has been observed in wild birds ; but many instances of this change are upon record in the cases of pheasants, fowls, and other domesticated species.

(342.) Sculpture is the last distinction of species which we shall here enumerate. This term comprehends all those various modes by which nature has diversified the naked parts of birds, the elytræ or external wings and other parts of insects, the scales of reptiles and of fish, and the hard or testaceous covering of molluscous animals. The bodies of quadrupeds and birds, being covered either with hair or feathers, show very little of this peculiarity: the horns of the ruminating animals, however, present us with different kinds of surfaces, as shown in the rings and nodules upon them; these are greatly diversified, and almost invariably indicate a difference in species. Sculpture, in birds, is restricted to grooves upon the bill of certain species of hornbills and toucans; and to the form, and mode of division, of the scales on the feet. These latter 
characters, however, are found so uniformly prevalent through the species of a natural group, that they are mostly employed in defining genera and sub-genera: slight alterations from such standards nevertheless occur in species; and they consequently claim the especial attention of the ornithologist. That he may be convinced of this, let him compare the form, size, and manner of disposition of the scales upon the feet of a few different groups ; as, for example, a crow, shrike, chatterer, and flycatcher; and he will at once perceive how singularly they are diversified. So, likewise, are the scales of reptiles and of fish. On proceeding to insects, we find this character rising in importance, particularly in the coleopterous order. Sometimes the wing-cases are punctured, either irregularly or in lines; in others, they are either grooved, ribbed, wrinkled, spined, or tuberculated; and each of these are again diversified in an almost infinity of ways. Better distinctions for species than these, cannot possibly be obtained ; and they accordingly are used for this purpose by the best writers. The same diversity may be observed both among the univalve and the bivalve shells ; the surface of which are diversified - according to the species - either with spines, nodules, tubercles, wrinkles, grooves, ridges, simple lines, or punctured lines; and sometimes these lines cross each other like the fabric of a basket, and they are then termed cancellated. The sculpture of corals, and of the spines upon the different sea eggs (Echini), afford excellent specific distinctions, and may always be so employed. Lastly, we may notice, under this head, that partial clothing on the surface of many animals, otherwise naked, which is termed pubescence. This is chiefly confined to insects ; and consists of downy hairs, of different degrees of density and length, spread either wholly or partially over their body. The highest developement of this is seen in the field bees (Bombus); but it is very prevalent among beetles, particularly such as represent, in their different circles, the order of Hymenoptera. This pubescence is either partial or 
general ; sometimes covering the body and limbs, while in other species it is restricted to only one of these parts. Many of the capricorn tribe (Capricornes Sw.) have their antennæ ornamented by elegant circular tufts of hairs, radiating in all directions, like the bristles of a bottle-brush : these tufts, again, in other species, are scattered at regular intervals over the elytræ and thorax, from whence they seem to spring. Many of the African Buprestidee and the Sicilian Cetoniada are so ornamented. Sometimes, although much more rarely, the hinder legs are tufted, as in some capricorn beetles; while we have a pretty vernal bee having these ornainents upon its middle legs. Few of the true Cicades, or singing Hemiptera, possess more than a slight pubescence; but several of those of tropical America and India have long tufts, resembling the finest cotton, projecting from the end of their bodies. Lastly, pubescence shows itself under the form of a very fine powder, either white or coloured, as in many of the Cocci, or plant lice. All these, and many other modifications, should be noted in the comparison of species; and they may be used, with confidence, as distinguishing characters.

(343.) It is unnecessary to expatiate further upon the diversified appearances in the external covering of animals ; for, whether that covering be hard or soft, its surface always possesses some characteristic. A species, therefore, is distinguished from others with which it is immediately connected, either by a very slight difference in its form, the relative proportions of its parts, its colour, its surface, or its sculpture: these characters, moreover, however refined they may be, are quite sufficient to point out a specific difference, provided they are permanent; that is to say, that they are discernable in all the individuals that have been seen or collected.

(344.) Difference of country, or of geographic distribution, when coupled with other considerations, may frequently excite a well-grounded suspicion that two individuals very closely resembling each other, are of 
distinct species. Before naturalists had discovered the necessity of that nice examination which is now so essential, it was customary to depend more upon the general aspect of an animal, than upon its minute details of structure; and in this way it not unfrequently happened that a host of true species were classed as varieties. Experience, however, has now taught us that the productions of every quarter of the globe have a marked and peculiar character; and that, although there are, for instance, some species of birds or insects common alike to the Old and the New World, yet that this wide geographic range is enjoyed by so very few, that they became rare exceptions to one of the most prevalent laws of nature. As a striking instance of this, we may cite the lions; which naturalists, up to this day, have viewed as constituting but one species. The fact, however, will turn out to be, that there are no less than five, if not six. One inhabits the north of Africa, and is that species best known to the ancients (Leo Africanus Sw.): another, now in the Surry Zoological Gardens, is peculiar to Asia; and which, upon its arrival, was examined and designated by me as the Leo Asiaticus* : the third is the black-maned lion, mentioned by Mr. Burchell (Leo melaceps Sw.); and the fourth is the lion of Southern Africa (Leo Australis Sw.). In like manner, we have ascertained that the giraffe of Northern Africa (Canelopardalis Antiquorum Sw.) is quite distinct from that of the southern part of the same continent (Cam. Australis Sw.). The hare of Europe, again, according to Mr. Gray, seems to be a different species from the hare of Nepaul : while very many of the lepidopterous insects of North America, until their larvæ were made known by Abbot and Smitht, were considered identical with those of Europe. On the other hand, too much stress must not be laid even

\footnotetext{
- The description and name of this species were communicated from these gardens to the editor of the "Naturalist's Library," but no allusion is made to the previous examination and name 1 had given it.

$t$ The Lepidopterous Insects of Georgia. See Introductory Discourse, on Nat. Hist. p. 66.
} 
upon the most remote differences of locality. The Sphinx convolvuli and the Cynthia cardui-both wellknown British insects - are likewise found in different parts of Asia, and even occur in New Holland. That pretty yellow butterfly, the Eurymus Electra of the south of Europe, and of Southern Africa, cannot be discriminated from those found in this country.

(345.) Individuals of a species which show any deviation from the usual characters by which that species is discriminated, are called varieties. These deviations from the ordinary characteristics of their race originate from a variety of causes; among which, climate, food, and domestication are the most influential. In nearly all cases, however, a variety is not permament ; for, the local or influential causes being removed, the generation which succeeds assumes all the genuine lineaments of the race from whence it originally sprang. Animals, whose chief metropolis is in a temperate climate, become smaller when they extend their limits into a warmer region, and vice versâ. The size of an animal is greatly influenced both by the quantity and quality of its food, no less than by its location; and both these, again, affect its colour. Variation in the colour of quadrupeds, in a state of nature, is more rarely observed than in birds; although, in a domesticated state, the former seem most disposed to deviation from the natural standard. The ox, dog, and cat are familiar instances of this fact; where the diversities of colour are much more remarkable than in the fowl, duck, goose, and turkey. Insects of the lepidopterous and the neuropterous orders are more prone to these variations from their original type, than any other. This is observable in the spots upon the wings of the Satyrida, or Argus butterflies, and in the colours of the genus Agrion. The testaceous shellfish, however, are sometimes very inconstant in their colours : strong instances of this are seen in many species of Helix, of Oliva, and of Tellina, as already intimated.

(346.) The radiated animals are much more con- 
stant; but the corallines assume an endless diversity of form, although the general structure of the species is essentially the same. Much experience, therefore, is sometimes necessary to discriminate a species from a variety : in general, however, a variety may be defined as local or accidental, whose peculiarities are not perpetuated in the next generation, and which cannot be traced in more than a few individuals. It must be again mentioned, nevertheless, that these observations are applied only to animals in a state of nature; since it is well known that the greatest variation of form, colour, and even of structure, have been produced by long domestication.

(347.) Having now sufficiently developed all those principles of the system of nature with which we are as yet acquainted, it follows that no arrangement of her groups yet discovered can be natural, unless they exhibit these principles in their details. It has frequently been observed, and with great truth, that " a natural arrangement will stand any test." But the test itself must first of all be proved genuine. It is not a sufficient test of our groups, that the individuals composing them are placed in a circular series; because hundreds of such circles can be made out, the fallacy of which, did no other test exist, can never be discovered. Neither is a group sufficiently verified by making out its parallel relations of analogy with another group; because, as all contain the same denomination of types, we may happen to compare a family with a genus, and, finding that both have parallel analogies, may be led to fancy that both are of equal value : both groups, indeed, may possibly be natural; but if we merely confine our analysis to these, without investigating others which are conterminous, we may combine them falsely, and thus throw a whole order into confusion. Parallel relations must also be of a definite character, or the imagination may be led astray: hence the necessity of verifying every group, not only by the system of representation; but also by the law of variation and succession of the pri- 
mary types explained in the preceding pages. If, in short, a zoological group be natural, it will not only bear a comparison with every other in the same class, but will give and receive a flood of light to and from all with which it is compared.

(348.) It follows, from the preceding remarks, that the verifications of a natural group are three: 1 . The circular series of its contents; 2. The parallel relations of its parts to other groups ; and, 3. The symbolical representation of the primary types of nature. On some of these points we have expatiated *; but this is the proper place for treating the subject in a more definite, clear, and connected manner.

(349.) There are no absolute rules, of universal application, independent of analysis, which can be laid down for the discovery of a zoological circle. We must begin, in fact, by arranging the objects with the nicest attention to their apparent affinities, and then testing the result. If these affinities are real, and the group is natural, there will be an evident tendency to a circle; and this tendency will be more or less strong, in proportion to the number of objects which enter into the series. When we consider, however, that the relations of objects are complicated, and by no means confined to those which precede, or those which follow them, in the series of affinity, it is obvious that false circles may be made; and that their fallacy can only be discovered by further tests. Before the naturalist proceeds to these, it is absolutely necessary that he endeavours to make out the two immediate circles which pass into that with which he has first begun. If, for instance, he was investigating the genus Picus Sw., as now constituted, after simply tracing the circular affinities of this group, he should proceed to investigate the two others which more immediately join it; namely, Chrysoptilus Sw. and Melanerpes. Unless this were done, he will have no definite ideas on the probable demarcation of his first circle, at those points where it touches, and passes

\footnotetext{
* Preliminary Discourse on Nat. Hist.
} 
into, the two adjoining ones. It may, indeed, be possible to discover a circular group without such collateral helps; but the discovery is highly improbable, and it may be laid down as a rule that his first arrangement will be more or less natural in proportion as he is acquainted with the objects immediately surrounding, or connected to, those which he is investigating. This plan, moreover, of making out the circular series of contiguous groups, is absolutely necessary for testing the contents of that circle more immediately under investigation.

(350.) II. The second test to which our supposed circle must be brought, is that of analogy; in other words, those relations which its contents bear to the neighbouring circles, and to all others in its own class or order. It is an easy matter to place a series of animals in a circle, and call it a natural group, and to repeat the same operation with such others as come near to the first; but to make the contents, or divisions, of these circles tally with each other is a very different matter, and imposes a check upon the fancy which will dissipate many illusions. No circle whose contents will not bear such a comparison can be natural. It may, indeed, happen, that one or even two of its subdivisions are wanting, while in the group with which it is compared they are present; yet even under these circumstances there will be so strong a resemblance between the two, in all other parts, that we may begin to hope our arrangement of both is correct. We should not, however, rest content with one or two tests of this sort, but bring our group, thus far safe, to encounter all the comparisons which we can institute. Should it be, for instance, the genus Picus; after tracing its subgenera, or divisions, in the two neighbouring genera, we should compare it with the sub-families of its own circle, and then with the families of the Scansores. If our arrangement is natural, we shall find parallel relations of analogy will result from these and all other comparisons we make, and thus proceeding to the 
tribes and orders of the whole class, we bring forth new and unexpected proofs of the harmonious simplicity of nature, and demonstrate our group by a mass of evidence perfectly unanswerable; but, to establish analogies, we must not be left to vague suppositions or fanciful conceits, and this obliges us to test our group by determining its types.

(351.) III. The system of representation, by which the types or divisions of a natural group are determined, is the third and last test. It is by this that we can judge, whether our group is perfect or imperfect; and by this we can calculate, from analogy, the probable extent of the gaps that may occur in a natural series. It is easy to divide the smallest circular groups, into three, four, five, or seven divisions, for the propriety of these divisions (they not being circular) cannot be controverted by the answer that has been given, of "putting them to the test of returning into themselves." The naturalist, therefore, requires something more to guide him in correctly dividing his group, not only as to the number of its divisions, but as to the structure or peculiarities which each should possess. Without this guide, he will be unable, in many cases, to establish the parallel analogies, and he must wander in all the uncertainties of conjecture. Hence it becomes necessary to compare his divisions with the characters of the types in the animal kingdom. If these exhibit a conformity, however remote, whether in their structure, nature, or habits, and if they follow each other in the same progression, he has no need of looking farther. His group is one of Nature's ; discovered, it may be, by himself, but existing "from the beginning."

(352.) But theory without analysis is like precept without example: we shall choose, therefore, an illustration to show the full force of these remarks. For this purpose we select one of the best known of our native birds, the hedge-sparrow (Accentor modularis Cuv.); chiefly because we have felt much interested in the delightful history which has been given of it by the amiable and 
intellectual author of that charming volume "The Journal of a Naturalist;" a book which should be in the hands of every lover of nature, no less than on the shelf of every philosophic zoologist. As it is important that the reader should have this history before him, and that, before proceeding to what follows, he should duly consider every part, we shall transcribe the whole passage.

(353.) "The hedge-sparrow, or shuffle-wing (Motacilla modularis Lin.), is a prime favourite. Not influenced by season or caprice to desert us, it lives in our homesteads and our orchards through all the year, our most domestic bird. In the earliest spring it intimates to us by a low and plaintive chirp, and that peculiar shake of the wing which at all times marks this bird, but then is particularly observable, the approach of the breeding season; for it appears always to live in pairs, feeding and moving in company with each other. It is nearly the first bird that forms a nest ; and this being placed in an almost leafless hedge, with little art displayed in its concealment, generally becomes the booty of every prying boy; and the blue eggs of the hedge-sparrow are always found in such. numbers on his string, that it is surprising how any of the race are remanning, especially when we consider the many casualties to which the old birds are obnoxious from their tameness, and the young that are hatched from their situation. The plumage of this Motacilla is remarkably sober and grave; and all its actions are quiet and conformable to its appearance. Its song is short, sweet, and gentle. Sometimes it is prolonged; but generally the bird perches on the summit of some bush, utters its brief modulation, and seeks retirement again. Its chief habitation is some hedge in the rickyard, some cottage garden, or near society with man. Unobtrusive, it does not enter our dwellings like the redbreast, but picks minute insects from the edges of drains and ditches, or morsels from the door of the poorest dwelling in the village. As an example of a household or domestic bird, none can be found with 
better pretensions to such a character than the hedgesparrow. I have often thought that this bird, the chaffinch, and some others, obtain much of their support in the winter and spring seasons, especially when the ground is covered with snow, by feeding upon the capsules or fertile heads of various mosses, having frequently noticed them pecking and masticating something upon the walls and in such places where these plants abound, and nothing besides, that could afford subsistence to any animated creature, particularly Bryum subulatum (Dillenius); and these races perfect their capsules principally during those periods in which other matter, which could afford them sustenance, is sparingly found. The object of the existence of many of these lowly plants has been considered as obscure, and their profusion a general subject of admiration. If this conjecture is correct, that they afford nutriment to these poor little creatures in a season of destitution, it affords us another instance of the benevolence of their Creator, extending, as far as we can perceive, through every department of creation: we cannot trace this chain, because we are ignorant of consequences, nor perceive the termination, because it is of infinite duration; but to attest any perception of wisdom and of goodness is a laudable and a just homage of the creature who observes it." * From this account we gather the following facts: -1 . That the hedge-sparrow " is a most domestic bird ;" evincing an innate and peculiar attachment to the haunts of man, feeding and building near his habitation, and by its familiarity courting his protection. 2. That its disposition is social towards its own species. 3. That its nest is built with little art. 4. That its plumage is plain, and that it seeks its food upon the ground; living as much upon seeds as upon insects.

(354.) Let us now enquire how far these peculiarities can be explained, and in what manner they are in unison with the station occupied by this bird, in the

* Journal of a Naturalist, p. 148-150.

U 2 
system of nature. Having already gone into all necessary proofs and details respecting the family to which it belongs, in another work *, we shall at present merely recapitulate the results thereby obtained, The Sylviada, or warblers, are a circular group, holding the rank of a family in the tribe of Dentirostres, or tooth-billed birds. This family is again divided into sub-families corresponding to, and representing, the primary types of nature. Now, one of those types is the Rasorial, which is the same as the Scansorial among the Perchers, and in it we consequently find all those warblers which, like the titmice, climb among trees more than any other warblers, and thus aptly represent the Scansorial parrots and woodpeckers. Still proceeding to analyse the contents of every minor division, we have shown that the Pariana, or titmice, form a circle of their own, and are again divided into genera, the characters and analogies of which have been thus stated $t$ : -

\section{Sub-Family PARIANæ. Titmice.}

Analogical Characters.

1. Typical group.

Bill short, strong, conic, entire. Parus.

2. Sub-typical group.

Bill more lengthened and slen-? what remotely from the tip. $\}$ Sylvicola. DENTIRosTres. Raptores.

3. Aberrant group.

Feet more especially adapted Setophaga. Fissirostres Natatores. either for perching, walking, Trichas. or climbing: bill various. S Accentor. S Scansores. RASORES.

(355.) Thus it is shown that although the Pariana, as a whole, represent the scansorial and rasorial division of the warblers, still that this division contains within itself representations of all the other types, and is therefore a perfect and circular group. If we spoke of the titmice generally, we should consequently term them the scansorial division or type of the warblers; but, if we wished to be more particular, and to name the precise rank of the genus Parus, in its own circle, we say that it is the typical genus. M. Cuvier has long

* North. Zool. vol, ii. p. 203. + Id. ibid. 
ago placed the hedge-sparrow in the genus Accentor, in which he has been followed by all succeeding ornithologists : this genus, preceded by Trichas, and followed by Parus, is found to occupy a station in its own circle precisely corresponding to that of the rasorial type of birds, which it therefore represents.

(356.) But as a diagram will bring these comparisons more immediately before the eye of the reader, we subjoin the following: the dotted lines showing the mutual analogy of the respective groups.

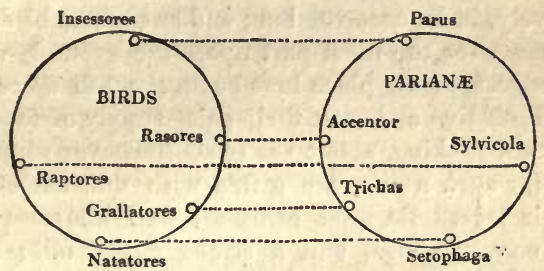

All these relations of analogy will be found substantiated, not merely by external structure, but by natural habits and economy. Our present enquiry, however, is entirely confined to the demonstration of the latter, and simply as regards the fact of the analogy between the hedge-sparrow and the rasorial type of the class of birds. Bearing in mind, therefore, the characters already given to this type (317.), let us now trace in what way nature has exhibited them in this instance; so that the hedge-sparrow should represent, symbolically, the $R a$ sores, or the gallinaceous order of birds.

(357.) The rasorial races, of all birds, are the most familiar, the most domestic, and the most fearless of man: this is their chief characteristic; and this is equally true of the hedge-sparrow; of all our warblers (with the exception of the robin, also a rasorial type), it is the most familiar; it pecks about our window with a certain degree of humble confidence and trusting security which is seen in no other of its family; it is, in short, 
as our observing naturalist truly remarks, "c a most domestic little bird." The Rasores are conspicuous for a permanent attachment between the sexes, long after the season of incubation, and when most other birds separate and disperse ; but our little hedge-sparrow possessess the constancy of its type, for "it appears always to live in pairs, feeding and moving in each other's company." Next, as to its nest : the loose slovenly way in which their habitation is fabricated by the Rasores is well known; so also is that of the hedge-sparrow, for " it has little art displayed in its concealment," or, comparatively, in its construction; and as rasorial birds build their nests for the most part upon the ground, so does the hedge-sparrow place hers but a short distance above it.* Both live and seek their chief supply of food upon the earth, pecking about for seeds, however small; and both, for such a life, are gifted with unusual strength in their legs. Rasorial birds are well known to have short convex wings, and a strong entire bill; so also has the hedge-sparrow, while the bill of the type of its genus, the Accentor alpinus, is so thick, that it might be compared to that of a finch. One of the great typical divisions of the gallinaceous order is remarkable for the variegated yet plain and homely colours of their plumage ; witness the whole of the grouse, partridges, and bustards ; so also is that of the hedge-sparrow; its colours, on close inspection, are prettily varied, yet the general effect is " remarkably sober and grave." Finally, it is among the Rasores we see that peculiar intelligence of parent birds in the preservation of their young, which is so well known in the partridge; either one or both the parents will entice those whom they fear away from their nest or infant brood, by feigning lameness, in a variety of ways. Now, the only native bird, in the whole of this division of warblers, that will do this, is the hedge-sparrow. Bewick, who was aware of this fact, observes, that, "during the time of sitting, if a cat or other voracious animal should come near the nest, 
the mother endeavours to divert it by a stratagem, similar to that by which the partridge misleads the dog; she springs up, flutters from spot to spot, and by such means allures her enemy to a safe distance." * Finally, it may be incontestably proved, that although this bird is no sparrow, yet that this name has been, in one sense, rightly bestowed upon it. The true-sparrow (Pyrgita, C.) and the genus Accentor, mutually represent each other; for, by comparing the circles to which they respectively belong (as we have just done with the hedgesparrow), these two groups stand in opposite or parallel relations: hence the general similarity of their colours, their familiarity, their mode of feeding, and the common nature of their food; and hence the name of hedgesparrow. Both, in short, are rasorial types, and much which we have said of one belongs likewise to the other.

(358.) When, therefore, it can be shown, as in the present instance, that every fact, however trivial or apparently unimportant, that has yet transpired on the structure or habits of an animal can be accounted for by the application of a few general laws, we may feel all the assurance that demonstration can give, that our arrangement is that of Nature. It seems impossible to conceive that the ingenuity of man can invent those innumerable proofs, and complicated verifications, thus applied to a natural group. The first test is that of affinity, the next of analogy, and the third of representation: and these having been now illustrated down to the lowest stage of analysis, we cannot conceive under what form further demonstrative evidence can be produced. We have selected for our purpose a faithful narrative of a familiar bird, and which has been drawn up by one who could have had no idea of the use that would subsequently be made of his remarks. But numerous others could have been cited, in addition to those whose affinities have been already explained upon the same principlest in a

* Bewick's Birds, vol. i. p. 222.

+ See various other examples in Northern Zoology, vol. ii. 
similar way ; particularly the American redstart (Setophaga ruticilla) and the common domestic duck.

(359.) Our exposition of the natural system must here terminate. We have endeavoured to treat the subject with that simplicity and clearness suited to an elementary work of this nature, but we foresee that many will consider it too abstruse for general application: this, indeed, must be granted; for although the arrangement of nature, as we have seen, can be reduced to the most simple and universal principles, the right application of these principles, amid the infinite diversity of her productions, can only result from study and experience. A knowledge of particulars as well as of generals, is equally essential to the discovery of a natural assemblage of beings, or, to speak technically, analysis and synthesis must walk hand in hand. Let not the student, however, be discouraged; for although there is no royal road to this or to any other science, his path, we trust, has been smoothed, he is in possession of that knowledge which has been the progressive growth of ages, and many of the stumbling-blocks, which heretofore impeded his way, are removed. Much has been done, but incalculably more remains for future discovery; new and untrodden regions lie before him: let him become qualified for their investigation : remembering that the boundaries of science are nowhere fixed, like the pillars of Hercules, nor inscribed with a ne plus ultra.

(360.) To those who are already distinguished as profound observers of nature, we shall now, in conclusion, address a few remarks on questions of a somewhat intricate nature. We have elsewhere expressed an opinion $\uparrow$, that the doctrine of analogical representation, at that period, was most imperfectly developed ; subsequent attention, nevertheless, has thrown much light upon this subject. We now believe that the true analogies of a group, when compared with the higher assemblages of which it forms a part, can only be detected when the typical division of one is placed opposite to the typical

* Journal of the Royal Institution, new series, No. iv. p.11.

+ North. Zool. vol, ii. p. 199. 
division of another. If the group under comparison be natural, all the other analogies of the types will be apparent. Thus, if we wished to test the tribe of $T e$ nuirostres with the order of the Insessores, and the orders of the class Aves, the three series would stand thus :-

Tenuirostres. Insessores.

1. Typical.

2. Sub-typical.

3. Aberrant.
Trochiliāæa.

Cinnyridæ.

Meliphagidæ.

$\left\{\begin{array}{l}\text { Paradisidæ. } \\ \text { Promeropidæ. }\end{array}\right.$
Conirostres.

Dentirostres.

Scansores.

Tenuirostres.

Fissirostres.
Aves.

INSESSORES.

RAPTORES.

RASORES.

Grallatores.

NATATORES.

For although the Trochilida are pre-eminently the tenuirostral type of the Insessores, they are not to be so denominated in their own circle. This, indeed, will be abundantly evident, when we consider that this very pre-eminence places them at the head of their own tribe, precisely on the same principle that the Insessores stand in the same relative situation among the orders of the whole class. In further proof of this mode of judging, we find that the climbing Meliphagide come opposite to the Scansores, and the syndactyle-footed Promeropida represent the Fissirostres and the web_ footed Natatores. None of these beautiful relations would be apparent, if the series of the Tenuirostres had been so placed that the Trochilidice stood parallel to the tenuirostral division, in the column of the Insessores: it seems, in fact, absolutely essential to reduce every group to its primary divisions, before the analogies of the group itself can be properly verified.

(361.) Against the above opinion, however, there seems to be a serious objection; inasmuch as that, upon looking to the last table, it will be perceived that the tribes of the Insessores follow each other, in the column, precisely in the same order as they do in nature, but in that of the orders of birds (Aves), the series is irregular, because, naturally, the Natatores, and not the Rasores, come after the Raptores; the question therefore is, . In what manner can this be accounted for? does it result from placing the Trochilida as representatives of the Conirostres, rather than of the Tenuirostres? or is 
this transportation occasioned by our ignorance of some unknown law of variation in analogies, resulting from the peculiar situation of the groups compared, in the higher circles to which they belong? Let us first try to verify the former supposition, and see what results would attend such a disposition of the analogies.

Circle of the Tenuirostres. Circle of the Insessores. Circle of the Class Aves.

Trochilidæ.

Cinnyridæ.

Meliphagidæ.

Paradisidæ.

Promeropidæ.
Tenuirostres.

Fissirostres.

Scansores.

Conirostres.

Dentirostres.
Grallatores.

NATATORES.

RASORES.

INSESSORES.

RAPTORES.

(362.) It might be perfectly easy to show analogies (whether true or false is not now the question) between the Trochilida and the Tenuirostres,-the Meliphagidae and the Scansores, - the Paradisida and the Conirostres; but when we proceeded to the others, and endeavoured to make out what possible resemblance, even the most remote, can be found between the Cinnyrida and the Fissirostres, the Promeropida and the Dentirostres, we must give up the whole theory of stating analogies on these principles; for only three out of five wear the least appearance of truth, and even these violate many other conclusions of a more certain nature. The Melliphagida, for instance, are related to the Scansores by affinity and not by analogy, because they form the immediate passage, or point of connection, between the Tenuirostres and the climbing birds.

(363.) Nor shall we get over this difficulty by stating the question under another form, viz., by preserving the natural series of the insessorial and the primary circles, but transposing that of the Trochilida, thus :-

Primary Circles. Transposed Circle of True Circle of True Circle of the

1. Typical. Trochilidæ. Conirostres. Insessores.

2. Sub-typical. Cinnyridæ. Dentirostres. RAPTOREs.

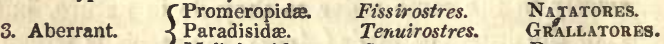
Meliphagida. Scansores. RAsores.

But here our difficulties, so far from being diminished, are increased: in the first place, we make absolute affinity subordinate to the purpose of preserving an appearance of regularity in our analogical series; for it can 
be indisputably proved by analysis, that the Meliphagida follow the Cinnyrida, and not the Promeropida. This disposition, again, would destroy the union of the three aberrant groups into one, a fact which is all but established by the Ptiloris paradiseus Sw. *, independent of the many other mutual resemblances, of a general nature, between the Promeropida and the Meliphagida; it seems, therefore, that we must account for this perplexing disturbance of such series on some other principle.

(364.) This brings us to the second question, whether this partial transportation of the series does not depend upon mathematical principles of variation, resulting from the different position which the groups on one side of a circle occupy to those upon the other. After much consideration on this abstruse question, I regret not being able to answer it more fully : does it not, in fact, belong more to the mathematician? Be this, however, as it may, I have uniformly observed that similar transportations occur when typical are compared with aberrant groups; but when all the groups compared are typical, then these different types fall into their natural series. As an instance of this, it must be remembered, that, of the two groups we have been comparing, one is an aberrant tribe, the other is a $t y$ pical order: the subject, however, deserves much more attention than I have yet been able to give to it. The naturalist will readily perceive, however, that these questions are totally unconnected with that which regards the definite denomination of groups, already noticed (268.), whether they are typical or aberrant.

(365.) This principle of definite denomination is most important, as, from not having been then discovered, all the diagrams of the "Horæ Entomologicæ," where these transportations occur in the situation of the groups, are rendered completely erroneous. It is one of the primary laws of nature that a typical group can never become an aberrant one, and vice versâ.

* See Zool. Journal, vol. i. p. 479. ; also North. Zool. vol, ii. p. 167. 


\section{PART IV.}

A FAMILIAR EXPLANATION OF THE FIRST PRINCIPLES OF PRACTICAL AND SCIENTIFIC ZOOLOGY, WITH SUGGESTIONS FOR A PLAN OF STUDYING THE DETAILS OF EACH DEPARTMENT.

\section{CHAPTER I.}

PRELIMINARY REMARKS. - DISTINCTION BETWEEN PRACTICAL AND SCIENTIFIC NATURALISTS. - QUALIFICATIONS FOR BOTH - AS ACCURACY OF OBSERVATION - PERSEVERANCE - CONCENTRATION OF STUDY - MEMORY. - EVILS OF INDISCRIMINATE COLLECTING. - PLANS FOR COLLECTING RECOMMENDED.

(366.) To those naturalists who have already acquired a knowledge of the actual state of our science, and to those few who are competent to extend its limits, we have devoted a large proportion of this volume. But as a much greater number of our readers will be students, anxious to see the first principles of zoology explained in familiar language, we feel that our labours may be usefully directed to this object ; for it is desirable that the rudiments of all sciences should be condensed and simplified. There is, indeed, no "royal road" to zoo- . logy, any more than to other branches of sound knowledge; but its first principles may be explained in simple language, and illustrated by familiar examples; its difficulties may be smoothed by avoiding unnecessary technicalities; and words and expressions, which may perplex the beginner, may be rendered intelligible as they occur, and thus become fixed upon the memory. We shall, therefore, in the following pages, occasionally adopt a style more colloquial than didactic; we shall converse rather than compose, and endeavour to smooth that path of instruction which every student must tread 
if he is desirous of acquiring solid information or correct ideas of the works of nature. In prosecuting this object we shall assume it as granted, that the student is more willing to be taught than to cavil; that he will be content to receive, as presumed truths, the results of the experience gained by his instructor; and that he will not consider it necessary that those difficulties and objections, elsewhere alluded to, are to be submitted to his fiat, before he is at all qualified to venture an opinion even upon the least of them. He must not, in short, ascend the stall of the critic before he has quitted the form of the scholar. Let him receive what instruction we can give him in the belief that it is sound. And when he has thoroughly imbibed and completely understands all that we can teach him, he may then fairly investigate for himself whether such things are really true.

(367.) Naturalists, in the general acceptation of the word, may all be classed under two distinct divisionsthe practical and the scientific. Their more immediate pursuits, no less than their necessary qualifications, are very dissimilar, but he only who unites them all is the true naturalist. The practical naturalist wanders abroad, and observes individuals. The fields and the woods are his museum and library. He contemplates living objects, but cares little for dead ones; he busies himself with watching the times and seasons when certain animals make their appearance; he strives to know their food, instincts, habits; he is dissatisfied until he is acquainted with the note of every bird familiar to his neighbourhood; he studies the construction of their nests, their periodical arrivals and departures, their loves, their lives, and their deaths. He watches their several changes of form, of colour, or of plumage ; he traces how these circumstances are modified and influenced by the seasons ; and he makes special notes of these things in his commonplace book. If he discovers that his crops or his fruit are injured by insects, he rests not until he traces the aggressor through all its series of depredations; and, 
being armed with a knowledge of its secret modes of doing injury, he is the best man for applying a successful remedy. As for its scientific name, that gives him no thought; he cares not whether the name be old or new; it is sufficient for him that it gives to the insect an appellation. He will walk through a magnificent museum with no more curiosity than is felt by an ordinary person; and as for systems, and technical terms, "he cannot away with them." He wonders how people can count the joints of an antenna of an insect, measure the quill-feathers of a bird, reckon the grinders of a quadruped, or number the rays of a fish's fin. His chief, if not his only interest is in the life of an animal. While others are poring over ponderous tomes of cramp technicalities, he is out in the woods, capturing an insect, or looking after a bird. He has, in fine, either a general disregard or a thorough contempt-according to the construction of his mind - for systems and their authors, and leaves to them to give what names they please to his discoveries.

(368.) Such are the general characteristics of a practical, or, as he is now usually termed, a field naturalist, of the present day, as gathered from the sentiments conveyed by this class of observers in our natural-history periodicals. There is not only much to commend in such pursuits, as regards their effect upon the individual, but the facts which they bring to light form a very material part of the history of nature. This is apparent from the writings of White of Selborne, Le Vaillant, D'Azara, and Wilson; all of whom, with little deviation, studied nature upon this plan. They were essentially field naturalists. They took to themselves that department of research which called them into the open air : and they are, of all others, the best qualified to write the natural history of species. Every thing, however, past this line of enquiry, is beyond their province. Those who have been really eminent as original observers, candidly confess this, and presume not to entertain the preposterous idea that theirs is the only department of 
natural history which deserves cultivation. They are satisfied with having gathered a stock of entertaining and instructive materials, to be subsequently worked up into general results and large generalisations by another set of naturalists, who take a different department in the extension of knowledge. It unfortunately happens, however, that men of all ranks are too apt to undervalue, or to treat with affected contempt, those acquirements of which they are ignorant. And as the business of the field naturalist requires little or no exercise of the higher powers of the mind, but may be pursued by any one possessing a tact for observation, so we find that the generality of these observers are too prone to fancy that their pursuits alone lead to the only information on natural history that is really worth acquiring. They will tell you to throw aside books and systems, and assure you that "a few walks in the fields" are sufficient to make "a very good naturalist." This royal road to science is no doubt very enticing to the young student, particularly if it is promulgated from the chair of a professor; but absurdities like this are unworthy of refutation. We must inform such sanguine beginners, that not only. many walks must be taken, but many years consumed, before he will earn the reputation of being " a very good naturalist ;" and that, when this title has been acquired, he will then, if he has good sense and real talent, be conscious himself that the praise is undeserved. We might be tempted merely to smile at such folly, and only to pity the contracted minds of those who gave it currency, were it not for the mischievous effect that such notions may have upon the young student, from their tendency to repress all mental exertion, and all aspirations after any higher knowledge than the composition of a dabchick's nest, or the colour of a sparrow's egg. Inflated ideas of our own pursuits, and unmeasured abuse of others, are the natural results of ignorance and conceit.

(369.) The business of the systematic or closet na. turalist commences where that of the practical observer 
ceases. If he is not a mere catalogue-maker, or a devotee to systematic names - a race of worthies which in these days is almost extinct, - he treasures all the facts communicated by his brethren of the field, and applies them, as occasion serves, to their ultimate use. While the one collects, the other combines. By means of his library, he ascertains which of the facts are really new, and which have been previously observed and recorded: he combines the scientific with the natural history of an animal. He examines its structure in every minute particular, and is thus enabled to trace the particular adaptation of this structure for performing all those functions which the field naturalist has witnessed during its life ; an intellectual gratification, by the way, which the latter, if he disregards such minutiæ, cannot enjoy. He observes all those external peculiarities of shape, of colour, or of markings, which distinguish the object before him as a species; he refers to his collections, compares it with others, and thus ascertains its true characters. But all this is but preliminary to other investigations; his business is not only with species, but with groups, which are congregations of species; he has to condense particulars into generals ; in other words, to search after and obtain general results from a multiplicity of isolated facts. He detects natural groups, and distinguishes them by characters applicable to the individuals which respectively compose them ; he next compares these assemblages with others, and studies their several degrees of relationship. Proceeding in this manner, and ascending higher and higher in his generalisations, he concentrates the facts, spread into an octavo volume of zoological anecdotes and "field" remarks, within the compass of a few pages. And while he thus makes use of the diffuse and disconnected observations of the field naturalist, he gives to them a stamp of importance which even their authors never imagined they possessed. Conversant with the different relations which one group of beings bears to another, he is enabled to trace the most beautiful and unexpected 
analogies throughout the animal kingdom, until he at length gains a full conviction of the paucity and simplicity of nature's laws, amidst the countless variety of her forms and modifications.

(370.) The two departments of study here sketched, as pursued by the practical and the scientific naturalist, are brought before the reader, not for the purpose of vaunting the superiority of one over the other, but that he should clearly understand their nature, and make up his mind, at the outset, which path of enquiry he will pursue. But, indeed, if he be not frightened by the difficulties attending an enlarged knowledge of the science, he may combine both these trains of enquiry, in moderation, without the smallest detriment either to one or the other. He may observe in the fields, and study in his closet; and this is usually done by all the rising naturalists of the present day. Those who are satisfied with being mere amateurs, may confine their researches to what they can learn in the open air; yet even these would find a far superior delight in their favourite pursuit, by viewing it in a more intellectual and philosophic spirit : just as a person who understands the mechanism of a watch derives much more pleasure from knowing the relations of its parts, than he did when he merely viewed it as an ingenious assemblage of wheels and springs.

(371.) There are certain qualifications, however, which, if not already possessed, must nevertheless be acquired by both these classes of observers. These we shall now briefly touch upon, and then proceed to speak of others more particularly applicable to these separate paths of enquiry.

(372.) Accuracy of observation is one of the first qualifications which the student should acquire. A quick and discerning eye, accustomed, by practice, to distinguish differences which an ordinary observer would overlook, is absolutely essential. The most perfect acquaintance with all the systems that were ever invented, and with all the theories that have ever been pro- 
mulgated, will never compensate for the want of this primary requisite. In ordinary life, we see some people who have an instinctive perception of differences to a much greater degree than others: as if, in short, the faculty was natural to them. Such persons will always make the best naturalists. This keenness of perception can, doubtless, be acquired; and, as no science requires more observation, or greater nicety of discrimination, than natural history, so, upon this account only, it is the very best pursuit that can engage the youthful mind; since it will be thus qualified to apply that acuteness and judgment upon greater things, in afterlife, which may call for the exercise of sound reason and just discrimination. Many people, for instance, would be utterly at a loss to discover the difference of structure between a swift and a swallow, even if the two birds were before their eyes. Their colours, it is true, are not the same; but both have little, triangular, short bills, long pointed wings, and fly and feed in the same manner. A glance, however, at their feet shows a material difference. This difference is so great, that a young naturalist would immediately be convinced they could not belong to the same genus; because these opposite structures of the feet indicated a corresponding dissimilarity of manners. Again, we hear the names of butterfly or moth used indiscriminately, even by wellinformed people; who, were they asked why, could give no satisfactory answer. A boy, who merely knew the first elements of entomology, might immediately answer by pointing to the antennæ, or horns (as they are vulgarly called), of the insect, and stating, that in a butterfly these members end in a thickened knob; while in the generality of moths they terminate in a fine point. This tact for observation, like every other habit, is to be acquired by practice; and the more it is exercised, the more acute it becomes. The student would derive much advantage, in this respect, from placing before him ten or a dozen species of insects rery closely resembling each other: such, for instance, as those com- 
posing the genus Harpalus (beetles of easy acquisition, and which any entomological friend will point out to him), and then endeavouring to find out, and to define in writing, in what manner each species may be characterised. Occasional exercises of this sort will soon give him a keenness of perception, and a tact in discriminating, which he will be long in acquiring by other means.

(373.) Perseverance is another quality, not only requisite for acquiring, as far as possible, a knowledge of every thing already known upon any given object, but also in discovering new or unrecorded facts in its history. Amateur naturalists are too apt to believe that the histories of our native animals are complete, seeing that they have been so repeatedly described; yet so contrary is this from the real fact, that almost every monthly number of our natural-history periodicals brings to light some new feature, or some hitherto unobserved circumstance, in the economy of animals which have been described by fifty authors. Strange as it may appear, we may cite even the robin as a bird whose habits have been treated of most partially and imperfectly. In regard to insects, we are, in general, most deplorably ignorant, even on the history of such as annually inflict no small injury on the crops of the agriculturist. This deficiency of information originates, in a great measure, from want of perseverance in establishing facts by repeated observation, and thus distinguishing such as are casual and incidental, from those that truly belong to the habitual economy of the animal. Perseverance is a very different quality from zeal : for the one implies patient investigation, - the other, ardour, or enthusiasm. Perseverance, to a naturalist, is a quality not easily attained; for, amid the boundless variety of nature, there are so many objects which court his attention, - so many new investigations suggest themselves to his mind, even when employed upon the elucidation of one,- that he is generally led away from that which he should finish, before he has given to it half the attention it requires. In this way, he finds himself, not unfrequently; involved in several 
distinct trains of enquiry, which have probably grown out of the one he originally commenced, but which he has not yet completed. Against this fascination of being drawn away to new investigations, before he has completed that upon which he first began, the naturalist should particularly guard himself. It is here that, if he really wishes to make his labours honourable to himself, or beneficial to others, it is here that he should call up a spirit of determined perseverance, and steadfastly resolve to finish what he has begun, before he commences a new subject. Let not the syren Procrastination lure him into the belief that he will return again to that which he postpones, with renewed ardour or increased knowledge. Setting aside those minor evils, arising from a want of perseverance, which affect the individuals themselves, how much have the interests both of science and the public suffered from its peculiar prevalence among zoological writers! We may venture to affirm, that, of all the works upon natural history which have been either announced or commenced in this country, within the last few years, not one half have been fairly completed. Not only does the cause of science suffer from this infirmity of purpose in men who have the ability to do her good service, but the evil effects fall both upon the innocent and the guilty. From the great expense attending zoological illustrative works, they are usually published in periodical numbers; but it now so frequently happens that the major part of these works are discontinued after a few numbers have appeared, that the public, seldom discriminating, set their faces against all such publications; and those who, on former occasions, have faithfully performed their engagements, are yet looked upon with the same suspicion as those who have acted precisely the reverse.

(374.) Perseverance in discovering new objects, or new facts, is likewise to be recommended. No branch of shuman knowledge is more open to such discoveries than zoology: whether we look to the chance of finding new species, or of bringing to light something in the 
structure, manners, or history of such as are already described. If we merely desire the acquisition of new objects, there is a wide field in every quarter of the globe, particularly in the warmer regions of both hemispheres. Mr. Stephens, one of the most persevering of our entomologists, has published the names of more than tell thousand species of insects inhabiting Britain; yet, as every year brings with it fresh discoveries, who can say when these are to cease? The conchology of our native seas is still furnishing new species to our collectors ; while hundreds of the " soft creeping things" of the ocean, of strange forms or minute dimensions, may be unknown and unrecorded, even within the range of our own coasts. Let not the young naturalist, therefore, imagine that he can discover nothing new even at home: while, if he pursues his researches in foreign climes, he may discover much more than he will ever be able to investigate. An equally boundless field for observation lies open, as already intimated, in the manners and habits of well-known species, almost daily before our eyes. It is a misfortune resulting from the passion for collecting, that nearly all naturalists are more bent upon increasing the contents of their cabinets, than on studying the economy of those living objects which are perpetually crossing their path.

(375.) The observation of facts, connected with the habits and economy of living animals, should therefore be a primary object with all naturalists, nor can its im portance be too strongly impressed on the mind of the young student. It is not only the most pleasing, but one of the most essential departments of zoology ; since the knowledge of the system of nature must be mainly supported by such facts, brought together, and applied to illustrate general truths. It is also the most popular, because it may he prosecuted without the aid of scientific acquirements. Almost every one, having the least taste for natural history, will peruse with pleasure a well-written account of an animal, whose habits, manners, and modes of living are not generally known, 
although they may have no idea of studying natural history as a science. In like manner we may bring to light innumerable interesting traits, regarding some of the most familiarly known animals, which are not to be found recorded by any writer. In proof of this, let any experienced observer read the best accounts we have of some of the commonest animals, and then ask himself if he could not add much more from his own observation? What do we know, for instance, of the different modes by which the various species of the British warblers capture their insect prey? or what is the vegetable food they are respectively fond of ? We should recommend every lover of nature, or of a country life, to possess White's " Natural History of Selborne" (a book which we were the first to bring under the notice of the present generation), and he will there find incitements held out to a constant watchfulness of the animals living in his own neighbourhood; he will see what interest may be given to his walks, and he will learn with astonishment that some of the most important truths of ornithological science are mainly supported by the simple, and apparently trivial facts detailed in this interesting book. The "Journal of a Naturalist," more recently published, is by no means inferior; and both are fit companions to the charming volume of Izaak Walton.

(376.) A fixed plan, or a concentration of study, is greatly to be recommended. When first a person is seized with a passion for natural history, he begins collecting every thing; plants, mosses, insects, shells, fossils, pebbles - nothing comes amiss - all are hoarded, and equally prized. By degrees, however, if he has good sense, he begins to find he cannot go on in this way. He wants more room, and he requires more boxes or cabinets than the house can hold. If his new pursuit is intended merely as an amusement to fill up small intervals of leisure, or to give some interest to a country life, he may possibly resolve to circumscribe his collec. tions, and content himself with possessing the natural 
productions found in his immediate neighbourhood, or in his own parish, or peculiar to the county; but these, if he wishes to understand them, will dissipate his mind over every branch of zoology, and he will then find it expedient still farther to restrict his acquisitions; and thus he must ultimately be brought to that plan with which, as a collector, he should have begun. He must confine himself to one department of his favourite pursuit. It is better, therefore, to do that first, which generally will be done last; supposing, of course, that his love for natural history continues. Let the country naturalist, therefore, make an early choice: the ornithology, the entomology, or the conchology of his native country have each their charms, and they lie before him. If he confines his attention to any one of these branches, he will not only feel more interest in its undivided pursuit, but he will understand it better, and he may ultimately make useful, and even important discoveries. But let him not aim at more than one department. British entomology alone, to be. well understood, is the study of a life. Hence it has become much more common, than formerly, among our young naturalists, to confine the attention even to one particular order of insects. The learned and venerable father of entomology in this country, Mr. Kirby, must have devoted several years to the study of the Hymenoptera, before he could have written his valuable descriptions of the British bees. If the student resolved to restrict himself to either of the orders of Coleoptera Lepidoptera or Diptera, he would find that any one of these would give him full occupation for several years. The more, in short, that our study of nature is concentrated upon a given object, the more are we likely to make discoveries, and the more interested shall we ourselves feel in the pursuit. The mere collector heaps together materials which he neither understands nor knows how to use: the very extent of his possessions; unnamed and unarranged, ultimately engenders discontent, and not unfrequently terminates in disgust.

(377.) A retentive memory is a desirable, although $\times 4$ 
not a very essential acquirement; and less so to the practical than to the scientific naturalist. The former relies upon his common-place book for facts, and troubles himself very little about names. But the scientific student has great need of a good memory, and should not only be well versed in the terminology of his science, but also in its nomenclature, that is, in remembering scientific names. He must not, however, be frightened by the formidable lists of those now in use, as they appear marslialled in an index, nor must he suppose that it is a necessary part of his studies to remember them by rote: such an exertion of memory, even were it possible, is not called for. An ornithologist or an entomologist of the old school, commenced, indeed, with learning the names and characters of every genus of birds or of insects then established; and if, in process of time, he could get those which designated the principal species also by heart, every thing was thought to have been accomplished. At present, however, no naturalist attempts to learn more than the names and essential characters of those minor divisions, or genera, which belong to the particular group he may be actually studying. It is expedient, nevertheless, that a general knowledge should also be gained of the greater divisions - as the crders, tribes, families, and sub-families - lof the class of animals to which the former belongs. The systematic student will be materially assisted in this task by the plan of affixing labels to his specimens, immediately upon ascertaining their names; while, to impress upon his memory the essential characters of the larger groups, short synoptical tables may be copied into his common-place book, similar to those which will be occasionally inserted in our subsequent volumes.

(378.) Collecting specimens, in any department of zoology, for mere private collections, should be conducted upon some fixed plan; not only on the score of expense, and the space they require, but from their tendency to distract the attention of the student from those subjects he is more particularly desirous of under- - 
standing. In our volume which will include Taxidermy, the reader will find many hints upon this subject, and many plans for forming collections, which may materially assist him. We strongly recommend his attention to this subject, and we proffer him the fruits of our own experience in this matter. Looking back to the early years of my own life, when I collected every thing, and understood nothing, I feel how much more profitably time might have been employed, had some judicious friend directed my enthusiasm to the accomplishment of a definite object, and had guided my exertions into a regular channel. The remarks (374.) that have been already made on the concentration of study, are equally applicable to the concentration of materials for that study. The collector of a museum, even under every advantage, will find the whole of his time barely sufficient for the arrangement and the preservation of his specimens; to make them the objects of his study, under such circumstances, is impossible. It is well for science that such collections are often accumulated by wealthy amateurs, who liberally permit others to turn them to effectual use. But the student, who really desires to understand what he possesses, should resist all temptations to collect indiscriminately. His mind will be distracted from the steady prosecution of any one course of investigation, and he will be bewildered in the variety of his materials. The passion for collecting increases with its indulgence; and he will finally not be unlike one of our modern bibliologists, who went on purchasing entire libraries, until obliged, for want of room, to deposit them in cases and dark garrets, only to see the light and be put again into circulation at the death of their owner.

(379.) It is obviously impossible to lay down any specific rules for the systematic naturalist, in the formation of his collection; seeing that so much depends upon the opportunities or advantages he may possess of acquiring specimens, and upon the nature of that line of study he intends to pursue. Should he confine himself either to the birds, the insects, or the shells of his 
own country, the acquisition of which will mainly depend upon his own exertions, it is obviously the best way to collect them as they occur; without commencing on a regular plan of selection. But if he extends his studies, in either of these departments, to foreign productions, most of which are only to be acquired by purchase, he will find the beneficial consequences of proceeding upon a systematic plan. Should he limit his attention, for instance, to ornithology, let him first procure types of the great orders of birds, which are represented by such common species as a hawk, crow, fowl, snipe, and duck. These, for the sake of easy examination, should be in skins, that is, stuffed, but not set up in position with wires. Let him well study the different structures displayed by these specimens, and compare their corresponding members, until he is well informed on the mode in which these members vary. Having thus informed himself on the essential or primary characteristics of the first great divisions in ornithology, he may proceed a step farther, and procure examples of the tribes. The crow is the type of the perching order (Insessores), the additional tribes of which will be represented by a shrike, woodpecker, humming-bird, and swallow. These, in like manner, should be well examined, and then compared with the characters assigned to them in books. A student, in this manner, should progressively procure specimens, husband his resources, and concentrate his attention; while, as his knowledge increases, or as opportunities occur, he may successively increase his materials by examples of the families, sub-families, and genera ; always remembering, that, in point of real utility, although frequently not of beauty, the acquisition of a generic type is infinitely more desirable than that of a species; unless, indeed, the investigation of the contents of a genus is decided upon. What has been said upon ornithology is of equal force when applied either to entomology or conchology. It will sometimes happen, however, that the excessive rarity or the great bulk of 
a generic type renders its acquisition either inconvenient or unattainable. Few private collections, for instance, have space sufficient for an ostrich, a cassowary, or a peacock: while the plantain-eater (Musophaga), the Argus pheasant (Polyplectron), and a number of smaller birds, which at present stand as almost solitary examples of their respective genera, are so rare, and bear so high a price, that they are placed beyond the reach of ordinary collectors. In such cases, our plan is, to make slight but accurate pencil-drawings of the head and feet, of their natural size, whenever an opportunity occurs. This advantage, in most cases, may be enjoyed by consulting the specimens in the British Museum, where many of these rare birds are to be seen, and where they are at all times gratuitously opened, with alacrity and liberality, for the inspection of the scientific student.

(380.) The practical naturalist, whatever he may think on the inutility of a collection to illustrate his department, will derive no small advantage from the power of referring to specimens at his pleasure; and of enabling others, by examining them, to complete the history of an animal, the active properties of which he has alone investigated. It is almost impossible, in fact, for a field-naturalist, when speaking of the habits or economy of a species, to make himself well understood unless he has sufficient knowledge of his pursuit, as a science, to describe the subject itself in such language that it may be understood by those who have never seen it; or unless he preserves specimens for future inspection. A remarkable instance, illustrating this necessity, has already been mentioned; where, from inattention to these requisites, the naturalists of Europe could not make out even the order, much less either the genus or the species, to which the Hessian fly of the Americans belonged. This was the more extraordinary, since a pile of reports, pamphlets, and other publications, had been expressly devoted to describe the injuries it produced. Travellers, who collect the ani- 
mals of the country they go through, and come under the denomination of practical naturalists, find that the preservation of specimens is absolutely necessary, and for the same reasons. It is obvious, however, that the principle upon which, in these cases, they should proceed, is very different from that already suggested for the adoption of the scientific naturalist. There is no occasion to preserve objects to which they can attach no anecdote or history, unless they collect for the ulterior purposes of general science. In either case, however, every naturalist and traveller would do well to make himself acquainted with the ordinary process of preserving skins, and of collecting and preserving insects and shells. As for the soft mollusca, very little information can be obtained from them, after they have been contracted by being put into spirits.

(381.) Technical words will prove, at first, a great hinderance to the student; but they are inevitable. They constitute, in fact, the language of zoology, since they are employed to express ideas which cannot be conveyed by words in ordinary use. To lessen this difficulty, we shall arrange all the words of this description, as they occur, at the end of each succeeding volume, where they may be immediately referred to. Such as are of frequent occurrence had better be copied out in a memorandum book for more perfect recollection; a plan which would tend more to fix them upon the memory than any other we could recommend.

(382.) The assistance of books is as important as the assistance derived from specimens: by the latter we study nature, while by the former we learn the opinions of her expounders, and the progress they have made in recording her manifold works. Let us remember that the latter are Divine, while the former partake more or less of that imperfection which belongs to every thing human. 


\section{CHAP. II.}

IMPORTANCE OF ACQUIRING FIRST PRINCIPLES. - REASONS FOR SUPPOSING A PLAN IN CREATION. - OPINIONS THEREON. THE CIRCULAR THEORY, AND THE DIFFERENT TESTS WHICH IVERY CIRCLE MUST UNDERGO, EXPLAINED AND ILLUSTRATED.

(383.) IN the foregoing chapter we have laid before the student the qualifications which should be possessed both by the practical and the scientific naturalist; and, having stated the objects of the former, we must now turn to the latter; with the hope that the reader has both the time and disposition to acquire more than a superficial knowledge of zoology; and that he is more desirous of pursuing it as a science, than to rest contented with being a mere collector of objects and facts. It has hitherto been but little the custom, with the inventors of systems, to lay before their disciples the reasons which have guided them; it being generally taken for granted that the reputation of the writer rendered such a step unnecessary. It seldom happens, indeed, that students desire such information; for if, from whatever cause, they resolve to adopt any paricular system not connected with general principles, they trouble not themselves with seeking to know and to criticise the reasons upon which a system is founded. It is received by them as a law, propagated by a ruler of science, which they have neither the disposition nor the knowledge to call in question. This feeling continues, until they acquire sufficient knowledge to discover the defects (real or imaginary) of their favourite oracle. It is then that the desire arises to know the reasons which have influenced the author, and the principles, if any, upon which he has proceeded. The student, in the mean time, has probably become an adept, and feels himself qualified to criticise that which, at the commencement of his studies, he 
looked upon as oracular. It may, nevertheless, happen, even in systems grounded upon universal prin. ciples, that what appeared in the first instance an example of defective, unnecessary, or unnatural combination or arrangement, may be truly unexceptionable when viewed with reference to those general principles upon which the system itself is founded.

(384.) Hence it becomes necessary that a general knowledge of the principles of natural arrangement should be first acquired; for, as these principles are as conspicuous in the smallest groups of nature as they are in the largest, they form the basis of every true combination above that of a collection of individuals of the same species. If the student resolved, for instance, to confine his attention to the parrot family, of which there are probably 200 species, he will discover that the natural arrangement of these species, among themselves, is regulated precisely by the same laws as those which divide the classes of vertebrated animals. In like manner, if he studies the lepidopterous order of insects, he will find their natural series to tally not only with those of the parrots and the vertebrated classes, but also (and, of course, more intimately) with those of the apterous and the winged insects. A general idea, therefore, of those fundamental principles of classification by which all these dissimilar groups are naturally arranged, is indispensable. When this is acquired, the student is qualified to enter upon the details of that particular portion he has selected for study; he will receive an elevated pleasure in tracing these principles in the arrangement of the objects before him ; and he becomes, in some degree, qualified to judge of their correctness. Having, in the last chapter, intimated those requisites which should prepare him for this enquiry, we now proceed to a familiar explanation of these principles. The student, thus prepared, will be qualified not only to understand the former disquisitions in this volume, but will peruse those which succeed with feelings of interest he could not otherwise entertain. 
(385.) No one who believes in the existence of an Omnipotent Creator, can suppose, for a moment, that the innumerable beings which $\mathrm{He}_{\mathrm{e}}$ has created were formed without a plan. If an architect sat down and made innumerable models of cornices, entablatures, columns, friezes, and all those ornaments used in a stately building, yet without any design of subsequently combining them, we should naturally say, however much we might admire the parts, that his work was imperfect. Let us apply this reasoning to the creation: however perfect an animal may be in its structure, it would still only resemble one of the ornaments we have just alluded to. It is beautiful in itself; but it is only when we attain some glimpse of the station it occupies with its fellows, and of the manner in which it is combined with others into one great whole, that we see this beauty in its true light. No rational being can therefore suppose that the great Architect of the world has created its inhabitants without a plan.

(386.) The plan of creation, therefore, implies universality, order, and harmony; and, in the view we now take of it, is only another name for the natural system : what, then, is the basis of this system? Has any part of it been discovered, or are we still wandering in the mazes of error? Let us briefly consider these questions. Had this plan or system been simple, and of easy apprehension, it had long ago been discovered, or each succeeding age would not have produced systems, totally at variance with each other. It was long supposed, indeed, that this plan, aptly termed the chain of being, was in a simple series, beginning with a worm or an animalcule, and proceeding step by step, until the series terminated in man. This, at first sight, strikes ordinary minds as the most rational theory; but when we begin to trace this scale, to search after the innumerable steps which are supposed to lead, in a straight line, from the despised worm, to man, the lord of the creation, we are very soon perplexed; we discover that every animal has more relations than one, and that many 
appear, as it were, to wander out of the series, as if they were joined to others which neither preceded nor followed them directly. As we advance, these deviations out of the simple and direct line, which we are vainly endeavouring to trace, become more frequent and more perplexing; we relinquish the investigation as hopeless, and become convinced that, however rational or probable such a supposition may appear in theory, it is utterly impossible to exemplify it in its details. This has been the conclusion, avowed or implied, at which every philosopher, who has investigated the subject, has ultimately arrived.

(387.) By another theory, the system of nature has been compared to an extensive piece of network, where the different knots and meshes represent the mode in which different animals are connected together in every direction. The advocates of this theory, however, consider it hopeless to discover by what general principle these innumerable ties of affinity are affected, and content themselves with asserting the probability of the theory, without venturing to its demonstration. It was not until the beginning of the present century that a new light was thrown upon this interesting question. $\mathrm{A}$ belief that there existed a branched or double progression of affinities, which ultimately met together, and united, originated with Lamarck; but this was only the "shadowing forth" of the discovery that affinities are really circular, demonstrated by Messrs. MacLeay and Fries. This is called the Circular Theory; and has now been so extensively verified, that it may be pronounced the first law of natural arrangement. As the details of this theory have been already enlarged upon, our present object is merely to explain its leading peculiarities by the most simple and familiar illustrations.

(388.) The circular series, by which the gradations of natural beings are regulated, may be thus explained. We will suppose it proved that, in the scale of nature, birds are followed by quadrupeds, quadrupeds by fishes, fishes by frogs, and these latter by reptiles and tortoises. 
This, the student may probably say, is a simple series, beginning with birds, and proceeding in a direct line to tortoises; but if so, the question arises, which is the next class? what animal is there which belongs to a class different from that of the reptiles, but which makes the nearest approach to a tortoise? The ornithologist will immediately point to the penguins. These are indeed birds, but they cannot fly; they have feathers, but they are so formed as to resemble scales; they have wings, but they are transformed into the shape, and perform the same office, as the fore-feet of the turtle; both lay their eggs, without a nest, upon the sand, and both seem out of their natural element when they are upon the dry ground. There still is, it is true, a great difference between them; but that is not the immediate question: the point we must keep in view is this, what animals are we to place after the tortoises? They are preceded by the reptiles, but by what class are they followed? if the penguins possess a greater similarity to them than any other existing race, then these birds must be placed next in succession, and we consequently come back again to the first class of animals we commenced with, namely, birds; the series thus forms a circle, and this union is expressed when it is said, "that the circle returns into itself."

(389.) If any one of our readers find a difficulty in fully comprehending the mode by which a series of animals forms a circle, let him take a straight piece of cane, and affix to it, at equal intervals, the following labels : penguins, birds, quadrupeds, fish, frogs, reptiles, tortoises. That with "penguins" will, of course, be the first, and that with "tortoises" the last. Let him then bend the cane into a hoop, the first label and the last will thus be brought together without deranging the rest of the series; by this contrivance he will immediately comprehend what is meant by a "circle of affinity," " a circular succession," "the closing of a circle," or " a circle returning into itself;" all which phrases are only different modes of expressing that circu- 
lar succession of affinities which is the first great principle of the natural system. Between the first group or genus of a natural series, and the last, there is no line of absolute distinction; the one blends into the other; and the series, to use the expressive phrase, "returns into itself."

(390.) Let us now look to what are the natural divisions of a circle. Mr. MacLeay considers that every circle first divides itself into five minor circles: hence the system which he has developed is called quinary; five being the primary number employed. As it is better that the student should understand this principle of division before he proceeds farther, we shall illustrate it by calling his attention to the vertebrated animals, or such as have an internal bony skeleton; the five classes of which follow each other in the series mentioned in the last paragraph. We begin with birds and quadrupeds, proceed to fishes and amphibious animals, and end with reptiles. Here, then, are five divisions of vertebrated animals, each of which, upon investigation, are found to constitute a separate circle of their own; these, again, contain five minor circles. Let any one of these minor circles be selected for more close examination, and the same principle is discovered: every circle, in short, whether large or small, comprehensive or limited, contains five minor circles, and thus we go on, gradually descending from the highest to the lowest divisions, until we come to the smallest groups in nature, formed by the first assemblage of individual species.

(391.) According to this theory, we have five principal divisions in every circle, the nature of which must now be explained. Two of these divisions are called typical; because they contain those animals which exhibit the greatest perfection of those particular qualities which more or less belong to all the five. Thus, the vertebrated and the annulose animals are the typical groups of the animal kingdom. The birds of prey and the perching birds are the typical orders of the feathered tribes. The apterous and the winged insects are typical 
of the Annulosa, or insects. The other three divisions are termed aberrant, because they lead off from their own circle into others, and exhibit the characters of the typical groups under a more diminished or less perfect form. Thus, reptiles, amphibia, and fishes, are the aberrant, or the most imperfect divisions of the vertebrated animals. The barnacles (Cirripedes), the worms (Vermes), and the sea-worms (Annelides), are the aberrant divisions of the annular circle, or of insects ; and the swimming, wading, and gallinaceous orders hold the same station among birds. The aberrant groups of a circle, in short, are always the most imperfect of their kind, and are the points of connection by which the circle to which they belong is united to that circle which precedes, and to that which follows.

(392.) The nature of the typical and aberrant divisions may be further illustrated by a more direct example. We will, therefore, look again to the circle of vertebrated animals. Quadrupeds and birds are clearly higher in the scale of creation than reptiles, frogs, or fishes: they are furnished with limbs capable of many uses ; their structure is more complicated, and their anatomy, although peculiar, is still more like that of man than what we observe in fishes and reptiles. They are, consequently, the two typical divisions of the vertebrate circle. Let us now turn to the three others. Reptiles, frogs, and fishes are obviously less perfect animals than quadrupeds or birds. They seem only to have that slight developement of instinct necessary to preserve and support existence: many of them have no feet; and their blood is always cold. They are nearly incapable of affection towards man, and have never been improved by domestication. All these circumstances tend to show their inferiority to birds and quadrupeds ; they are, consequently, the aberrant (or the least developed) groups of the five classes of vertebrated animals. The student cannot longer be at a loss to comprehend the meaning of typical and aberrant forms, groups, or genera, so frequently alluded to. Mr. MacLeay has gene- 
rally used the term normal in the same sense as we apply the word typical; but we have preferred the latter, throughout the whole of this work, as being more expressive.

(393.) We shall now attempt another mode of explaining the difference between typical and aberrant groups, which will bring the matter home to the most ordinary capacity. Let the reader suppose that each of his five fingers represents one of the five divisions of every circle. Let him further suppose the thumb and forefinger to represent the two typical groups, and the three others, the aberrant. The first, or typical groups, as before stated, are always the most perfect; that is, they are distinguished by possessing more strength, and are endowed with greater qualifications or perfections, than any others. Now, the thumb and the forefinger are the most important to the human hand: consider for a moment the strength and security which is given by the thumb to every office which the hand performs : how weak would be our grasp, how unsteady our writing, how insecure our handling, if we were unfortunately deprived of this member! The loss of any one, or even of any two, of our three last fingers would not subject us to half the inconvenience of the loss of the thumb. The forefinger is nearly as important: it acts more immediately in unison with the thumb, and is only inferior to it in strength and utility. It matters not whether this prevalent use of the forefinger is the result of habit; nor is it any argument against the assertion to urge, that a man who loses his forefinger, or even his thumb, may, nevertheless, acquire the power of doing almost every thing necessary with his remaining fingers. The first two were manifestly intended to be more used than the others; and a greater power, or, what is the same thing, a greater perfection, has consequently been given to them. So far, then, for an illustration of the two typical groups. The aberrant groups are three: they always preserve a sufficient similarity to the two others to show their absolute connection 
with them; but they are lower in the scale of perfection. They seem, as it were, supplementary ; and, taken abstractedly, convey a very inadequate idea of the typical excellency of the other two groups, to which they are, nevertheless, connected : just as children, although belonging to their parents, exhibit only the immature excellencies and perfections of those who are their closest kindred. Now, there is a very singular analogy in all this to the last three fingers of the hand. They seem, indeed, to be necessary, but inferior auxiliaries to those offices chiefly performed by our typical fingers. They are material aids, but not so vitally essential; since the loss of any one would not prevent an author, a painter, or a sculptor, from going on with his pursuits, nearly as well as if his hand was perfect. Could this be said, if either the thumb or the forefinger was lost? Certainly not.

(394.) Let the student now apply these analogical facts to the five great divisions of vertebrated animals. Quadrupeds may be compared to the thumb; they are the strongest, the most bulky, the most developed, and the most perfect of all animals. Birds, in all these qualities, rank next to quadrupeds; and they may, therefore, be compared to the forefinger. The longest of all vertebrated animals, in proportion to their circumference, are the serpents and reptiles; and the middle finger will remind the student of this very peculiar characteristic. The two next fingers may be compared to the frogs and other Amphibia, and to the fishes : these last seem to be the farthest removed from quadrupeds, because they have no feet : they comprehend, also, the smallest of all the Vertebrata; but yet they are joined to quadrupeds by dolphins and whales. The little finger will remind us of many of these facts. As regards size and thickness, it is the weakest and the least of all, and is, therefore, the most different from the thumb; but they are the only two which are of the same length, and they thus preserve the graduated scale which runs through the whole. It may be said that such familiar illustrations 
are trifling; but it must be remembered that no facts supplied by one part of creation to illustrate another part, can deserve that epithet. On the contrary, the more simple the illustration, and the more familiar the example, the greater force does analogical reasoning acquire.

(395.) The nature of a circle of affinity, and the number of natural divisions which compose all such circles, have now been sufficiently explained. As these constitute the first principles of natural arrangement, the student would do well, by frequent perusal, to retain them in his memory, or he may consider these familiar illustrations as introductory to the fuller exposition, already given on these subjects, in the second portion of this volume.

(396.) We shall now lead the student a step farther, by calling his attention, first, to the properties of natural groups; and, secondly, to the means by which such groups are to be detected and proved. An attentive consideration of the relations subsisting between different groups of animals has led to the discovery of certain properties peculiar to each of those which we have, in the last section, denominated typical and aberrant. A few of the most remarkable circumstances so elicited we shall now briefly explain.

(397.) By the word group, the reader is to understand an assemblage, large or small, of individual species or higher assortments, possessing among themselves certain characters definite and peculiar. The term is used, in a general way, to express either a class, an order, a family, a genus, or any other division which is employed in system, the class of birds being as much a group as is the family of crows. When such an assemblage is formed upon characters or circumstances which have no general reference to primary laws, the group is termed artificial. The genera Sylvia and Muscicapa of the Linnæan school, for instance, are good examples of artificial groups : every small bird, with a slender bill, was placed in the first; and all 
those with broad bills were referred to the second; and in neither were habits, analogies, or general structure, taken into the account. On the other hand, we deem a natural group to be an assemblage which is represented by other groups in different classes of animals; and which is characterised not by one or two peculiarities, but by distinctions drawn both from economy and structure. The toucans, the humming-birds, the lamellicorn floral beetles, and numerous others, are natural groups, not so much because they are obvious to the inexperienced eye, as because they represent analogically other groups in totally different departments of nature. Strictly speaking, and using the term in its true sense, no group can be termed natural, until its circular tendency is detected, and its analogical relations pointed out.

(398.) We are thus led to seek farther information upon the question - How are we to prove that a group is natural? One naturalist selects one set of characters, which by another are slighted ; some look only to the internal structure, others confine their characters to the external; and all are prepared with reasons in support of their different theories. How are we then to discover which are the essential requisites or properties of a natural group? Now, as the series in which natural objects follow each other is circular, it follows that the circularity of a group is its primary requisite. Every group, therefore, which, upon close investigation, does not form its own particular circle, or which does not exhibit a tendency thereto, may be considered artificial ; while, on the contrary, every one which has its affinities returning into itself, exemplifies the first general law of nature, and wears the aspect of being natural.

(399.) The first property, therefore, which we must look for in a natural group, is, that the affinities of the objects it contains proceed more or less in a circle. It is rarely that a group, which from other circumstances we know to be natural, contains so few subjects, and these so wide apart from each other, as to prevent us from detecting their tendency to a circle; while, on the 
other hand, so numberless are the forms of nature, that false circles can be made, and are frequently made, by putting in, to fill up our gaps, animals which have no real connection with that circle which we wish to render perfect. Hence, although we must first look to the circularity of a group as a primary requisite, still the accuracy of this circle must be proved by other tests, which will be shortly explained.

(400.) The second property possessed by natural groups regards those only which we call aberrant, and consists in the three aberrant groups or divisions of a circle being united among themselves into one circle, independent of their union also with the two typical groups. This theory, although it virtually makes the primary division of every circle to be three, does not, in fact, affect the accuracy of a group which is first divided into five, any more than this, that it shows these aberrant divisions to have other properties than were formally suspected; so that, besides being united to the typical groups, they also blend in a circle of their own, as if they were independent of the two others.

(401.) As we have hitherto looked to the vertebrated animals as furnishing one of the most familiar illustrations of natural arrangement, we will again use them to exemplify the union of which we are now speaking. Quadrupeds and birds, then, are the two typical groups of vertebrated animals; while reptiles, amphibia, and fishes are the three aberrant. Now, if these latter are found, upon investigation, to form a circle by themselves, it naturally follows that the primary circles in every group are three, and not five; the three aberrant divisions being merged into one. This union, however, cannot always be traced, from the causes elsewhere assigned ; and therefore, in dubious cases, it is more advisable to adhere to the usual method of distinguishing each of the aberrant groups separately by themselves. It follows, nevertheless, that, wherever it can be demonstrated, we must consider that the circle is first divided into three others, each of which is again resolved into 
three lesser ones, and so on, until we arrive at the lowest groups in nature, which are called sub-genera.

(402.) Some other properties of natural groups need not here be alluded to, since they belong to a more intimate acquaintance with the science than is usually aimed at by beginners, and they have already been discussed in the body of this work. So soon as the student understands so much of the nature of groups as we have now endeavoured familiarly to explain, he will be fully competent to pursue the subject as discussed in the former chapters. There are, nevertheless, certain other properties in natural groups, which the young. naturalist should be acquainted with; because they serve as tests by which all groups should be tried; as these enter into the laws of verification, they will not now be considered.

(403.) After perusing thus far, the student may probably say, "I understand that all natural groups form their own circle; and that each circle contains three smaller ones, two of which are typical, and one aberrant: but in what manner am I to prove my circle, whether it be natural, since $I$ have been told that false circles can be made? If, for instance, I am desirous of discovering, without the aid of books, the manner in which the family of thrushes (Merulida Sw, ${ }^{*}$ ) describe their circle of affinity, what check have I upon my own arrangement, after $I$ have placed these birds in such a way as to exhibit a circle? Must I be guided only by what appears to be the circle of affinity? or are there other circumstances by which my circle is to be verified, and my fancy kept in check?"

(404.) These are questions which may naturally be asked, and which we shall now proceed to answer. There are three modes, or processes, then, by which natural groups are to be verified. 1. By their circularity. 2. By the parallel analogy of their contents to other groups; and, 3. By the order in which their types or subordinate divisions occur. This latter may be termed the theory

* See their natural arrangement in Northern Zoology, vol. ii. p. 149. 
of variation. Having already explained the nature of the first of these proofs, we shall now give to the two latter a separate consideration.

(405.) The difference between analogy and affinity being well understood, the naturalist is to compare his supposed circle with some others, which, from having been verified and tested in every possible manner, are looked upon as established. To these circular groups, so substantiated, he may refer as standards of authority, with which he must compare his own circle in all its component parts. This brings us to the application of the theory of analogy, by which we shall discover that the contents of one group will represent, in some remarkable manner, the contents of another group. This representation, moreover, is not confined to a general similitude, nor does it rest upon one or two particular instances, which may be selected, according to mere fancy, from a number of others presenting no common similitudes; neither is it irregular, that is, the points of resemblance are not to be selected in an indefinite manner, in order to make one group tally with the other. No. The analogies of two groups, if they are natural, will occur in precisely the same order, and in the same succession; and all the parts of one circle will represent those of another. When the student finds that his group will bear this test in one instance, he must proceed to verify it, in the same manner, by another. While, in proportion to the extent to which he can carry this comparison, and establish such similitudes or analogies between different parts of the animal kingdom, the greater confidence may he entertain that his circle is truly natural.

(406.) Let us now illustrate this precept by an example. We will suppose the student to have investigated the family of birds just mentioned, viz. the Merulida, or thrushes; that he has arranged them in a circle, and discovered the typical and aberrant divisions. His exposition of the whole group will accordingly stand thus :- 


\section{MERULID瓜.}

Typical group. $\left\{\begin{array}{l}\text { Bill gradually arched, slightly notched; } \\ \text { wings adapted for perfect flight; Iegs } \\ \text { moderately long; toes disunited. True } \\ \text { Thrushes. }\end{array}\right\}$ Merulinæ

2.
$\begin{gathered}\text { Sub-typical } \\ \text { group. }\end{gathered}$$\left\{\begin{array}{l}\text { Bill abruptly bent, strongly notched; } \\ \text { wings short, feeble; tarsi moderate; } \\ \text { toes frequently united at the base. Ant } \\ \text { Thrushes. }\end{array}\right\}$ Myotherinæ.

$\left.\begin{array}{c}\begin{array}{l}\text { A. } \\ \text { grount } \\ \text { group. }\end{array} \\ \text { wings rourded; legs short, not adapted } \\ \text { for walking. }\end{array}\right\} \begin{aligned} & \text { Brachypodinæ. } \\ & \text { Oriolinæ. } \\ & \text { Crateropodinæ. }\end{aligned}$

Now this circle is founded simply upon the affinity he discovers between the divisions : he finds that the $M e$ rulina insensibly pass into the Myotherina, that these conduct him to the short-legged division, Brachypodina, which blend into the Orioles; that from the Orioles the affinity is traced to the long-legged thrushes ( $\mathrm{Cra}$ teropodina), and that these again lead back to the $M e$ rulince. The above is a tabular exposition of this series; but if we throw it into a circle, it will stand as follows : -

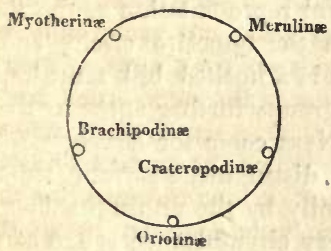

(407.) Now the verification of this circle is to be accomplished by showing that all its divisions are represented, in the same order, in some other well-known and established series. No circular group, for instance, is better known than that which exhibits the first great orders of the whole feathered creation., These divisions are composed of the rapacious (Raptores), the perchers (Insessores), the gallinaceous (Rasores), the waders (Grallatores), and the swimmers (Natatores). Let us now throw this series, like the last, into a circle, bring them together, and then see in what manner they represent each other: - 


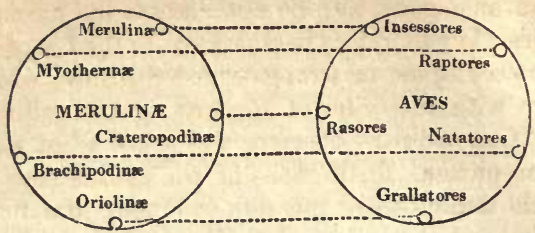

(408.) By. this diagram the two circles are brought into immediate comparison, and we are now to consider their component divisions. The most perfect or typical of the minor groups, among the thrushes, are the blackbirds and throstles; and the most perfect of all birds are the Insessores, or perchers. The typical groups of each circle, therefore, agree in analogy, and are therefore placed opposite each other. The ant thrushes (Myotherina) are more especially distinguished by the tip of their bill being abruptly hooked, and the notch very deep, so as to assume the appearance of a tooth; this character gives us a beautiful representation of the Rap tores, or birds of prey, in the opposite circle, one of whose chief characteristics is a hooked bill armed with a strong tooth. The two groups further agree in living only upon other animals. Next come the Brachypodina, or short-legged thrushes, distinguished from all the other divisions of their family by the unusual shortness of their feet. Now this very circumstance is one of the most prominent distinctions of the Natatores, or swimmers ; for it is notorious that the ducks, pelicans, grebes, penguins, \&c. are the shortest-footed birds in creation; just, in fact, as the Brachypodina are the shortest-footed thrushes. To these succeed the orioles, Oriolina, remarkable for living only upon the softest nourishment, as caterpillars and tender berries. Now this is precisely the description of food - in substance, although not in kind - of the great majority of the waders; with this difference only, that, instead of soft caterpillars and pulpy fruits, they eat soft worms, and pulpy marine animals - the caterpillars of the sand, and the fruits of 
the ocean, instead of the forest. These groups, therefore, are analogous, and do not disturb the harmony of the series. We therefore pass onward to the last, namely, the Crateropodina, or strong-legged thrushes, which we compare with the order of Rasores, or the gallinaceous birds. If an ordinary observer was asked what were the most conspicuous distinctions of the gallinaceous order, he would undoubtedly mention as among the first, the great size and strength of their feet, and their short and comparatively feeble wings. The first of these peculiarities, in fact, is absolutely essential to them, because they habitually live upon the ground; while the last, which in a tribe of flying birds would be an imperfecfection, among these is in perfect harmony with their general habits. It would, moreover, be remarked, as a third distinction of the rasorial group, that it contains the largest birds in creation; witness the ostrich, cassowary, bustard, \&c. Now what the rasorial order is to the whole feathered creation, the Crateropodince are to the family of thrushes; they have, as their name implies, the strongest feet, they have the shortest wings, and they are the largest birds in their particular group. With three such strong and remarkable points of analogical resemblance, there can be no doubt that the Crateropodina are the representatives of the Rasores; or, in other words, that these two groups are parallel and analogous.

(409.) When results like these attend the comparison of a doubtful circle with one that is universally deemed to be natural, there is good reason to believe that we have discovered the true series ; for, however fancy might deceive us in the first formation of a circle, it is impossible to believe that so much harmony would result from an erroneous application of a theoretical truth. Nevertheless, it must be remembered that our group has yet only been proved by one test. It has been compared with the circle of the leading orders of birds ; but this is not sufficient for complete demonstration. The analogies, although strong, are nevertheless remote; and it therefore is expedient, if not essential, that our 
group should receivestronger verification; that it should be compared with others of its own order, and finally with one of its own rank ; as, for instance, with the family of shrikes (Laniadae Sw.), and these comparisons are to be instituted on precisely the same principles as those we have just exemplified. If, therefore, our group will bear all these comparisons, and if the same analogical results follow, and in the same order, we may then be assured that our circle is a true one. And if, to "make assurance doubly sure," we can extend our comparisons, and detect the same analogical resemblances in other groups belonging to different classes of animals, we not only demonstrate our arrangement of the Merulida with almost mathematical certainty, but we pile accumulated proofs upon the thoretical assertion that there is but one uniform plan of variation throughout nature.

(410.) The student will now see the worthlessness of all assumed circles of affinity which have not been put to these necessary tests, and which merely repose on the assertion of their inventors. This, in short, has been the rock upon which some of the warmest advocates of this theory have split. While, from the fallacy of their circles having been detected, occasion has been given to shallow reasoners to throw doubts upon one of the greatest truths in natural science; truths, in fact, of which. such persons have only a partial knowledge, by judging of their value from their mistaken application by zealous but ill-informed advocates. The fanily of Merulida, no doubt, might be arranged in two or three circular ways, each of which, if their analogical resemblances to other groups are dispensed with, would appear to be just as natural as the one here given ; for we have tried the experiment. Yet the moment these assumed circles are brought up for verification, their falsity is at once demonstrated, by their discordance with authenticated circles. Hence the student will see the reason of our former remark, that false circles of affinity can be made with every appearance of being natural; and that these will "pass muster" with all those 
naturalists who think that other proofs are unnecessary. But the verification of such an extensive group as that we have now instanced, namely, the Merulida, is by no means yet complete.

(411.) The third test by which a circular group is to be verified, consists in its being in unison with the theory of variation: that is to say, each of its principal modifications of form are to follow each other according to a definite rule. This rule has been so fully and so clearly explained in the body of the work, that it seems hardly necessary to repeat it here : familiar examples, however, will render it more apparent to the student; and these examples, - to prevent the recital of those exceptions which must be noted if we attempted to speak generally of the whole animal kingdom - will be drawn from some of the groups of ornithology. We have shown that groups can be made to appear natural and circular, when in reality they are not so; and we have now to show that their erroneous composition cannot always be detected, even by comparing their contents with those of another established group, and thus testing them by the theory of parallel analogies. An ornithologist of this country, now retired from science, who has done much towards the determination of the leading families of birds, and who in many instances has shown great judgment in the location of the groups, has nevertheless been led into an arrangement of the shrike family (Laniada $\mathrm{Sw}$.) which exemplifies the error we are now speaking of : he disposes the groups of these birds in the following manner:-

\begin{tabular}{|c|c|c|}
\hline $\begin{array}{l}\text { Typical. } \\
\text { Sub-typical. }\end{array}$ & $\begin{array}{l}\text { Lanius. } \\
\text { Edolius. }\end{array}$ & $\begin{array}{l}\text { True Shrikes. } \\
\text { Drongo Shrikes. } \\
\text { Tyrant Shrikes. }\end{array}$ \\
\hline Aberrant. & $\left\{\begin{array}{l}\text { Ceblepyris. } \\
\text { Thamnophilus. }\end{array}\right.$ & $\begin{array}{l}\text { Caterpillar-Catchers } \\
\text { Bush Shrikes. }\end{array}$ \\
\hline
\end{tabular}

(412.) These divisions, it has been said, form a circular group, and each division follows in the order of succession here stated : and as the bush shrikes, as every one knows, blend into the true shrikes, the circle is closed, and the whole has a verisimilitude of being truly natural. 
True it is that the author in question did not think it necessary to verify this group by tracing its parallel analogies in the next (the Merulida, or thrushes) which succeeds to it. Had he done so, he might probably have discovered that this, so far as concerns the order of the divisions just specified, were in reality an artificial circle. And yet this conviction might not have been arrived at; for, if implicit reliance were placed upon the accuracy of this series, and we merely proceeded to fix upon the groups analogical to these in the next family circle, we should be at no loss to make them out in the following manner :-

SHRIKES. Characters common to both:
Lanius.
Edolius.
Tyrannus.
- $\left\{\begin{array}{l}\text { The most complet } \\ \text { spective circles. }\end{array}\right.$
Feet very short.
Ceblepyris.
Live in the vicinity of water.
$\left\{\begin{array}{l}\text { Wings rather long; rump feathers more or } \\ \text { less rigid. }\end{array}\right.$
Thamnophilus. Bill hooked at the tip.
\} Merula.
Brachypus. Crateropus.
\}oriolus.
Myothera.

Tarushes.

(413.) Nothing can be more perfect than the parallel analogies resulting from comparing these two groups; and yet, as we have elsewhere demonstrated*, although the divisions and analogies in both these columns, taken separately, are correct, yet both are nevertheless disposed falsely. Here then is a group which has undergone two tests, - in the first instance, it has a verisimilitude of being truly circular, and then, being compared with an adjoining group, it is found to possess parallel analogies thereto, - and yet the great error of its composition remains to be detected. How then are we to proceed in our process of verification? or how can a false circle be distinguished from a true one? It is here that the third test we have intimated, namely, the definite system of variation, must be resorted to, as a last and final criterion of the true value of all groups, supposed to be natural.

(414.) Now, the principles by which all the variations of form throughout the class of birds are regulated may be thus concisely stated:-First, we have, in the typical form, a union of the greatest number of

* Northern Zoology, vol. ii. p. 164. 
different perfections, or qualities; or, in other words, the highest degree of organisation. This is the first, or typical group. Next in succession comes one closely resembling it, but deficient in some few points; which deficiency, however, is made up by a superior degree of courage or ferocity, and which, with an organisation conformable thereto, leads them to feed upon other animals : this is the second in rank, or the sub-typical variation. Following this, nature proceeds to another, characterised by a large head, great breadth of bill, and very short feet; whose instincts lead them to frequent water, or to live in its vicinity. This modification always succeeds the sub-typical group, and is followed by another, whose chief character is the soft nature of its food; but it is also known by the superior length of the bill, and, generally, by the length of its legs. The last variation to be found in a true ornithological circle is manifested by superiority of bulk, very strong legs, glossy plumage, crested head, large tail, short wings, gregarious habits, and often a marked predilection for the society of man. The voice, also, is peculiarly loud, and always discordant. This type of form invariably conducts to that which is pre-eminently typical, and, consequently, closes the circle. As this series of variations can be traced, more or less, throughout the whole animal kingdom, it may, perhaps, be expedient hereafter to designate each of them by a general name; at present, however, they may be called after the primary divisions of birds : viz. 1. Insessorial ; 2. Raptorial ; 3. Natatorial ; 4. Grallatorial or Suctorial ; 5. Rasorial.

(415.) This definite mode of variation explains the nature of the third and last test for the verification of the group of shrikes, which we are now considering. The question, therefore, is this, will the series, as before detailed, correspond with this series of the variation in all other birds? if it will, the group is a natural one; if not, there must be some error in the disposition of the sei ies. Let us now make the comparison :- 
Shrikes. Distinguishing Characters. TyPEs of BIRDs.
1. $\quad\}$ Lanius.
$\left\{\begin{array}{c}\text { The most rapacious of all } \\ \text { the perching birds; conse- } \\ \text { quently the }\end{array}\right\}$ Raptorial.
$\underset{\text { Sub-typical. }}{2 .}\}$ Edolius.

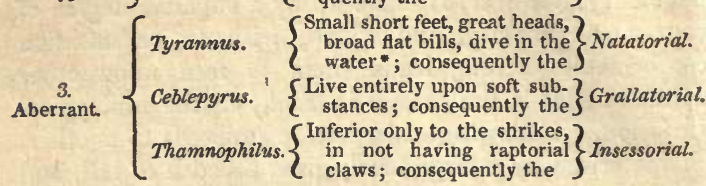
$\left\{\begin{array}{l}\text { Glossy plumage, great tails, } \\ \text { crested heads; conse- } \\ \text { quently the }\end{array}\right\}$ Rasorial.

Here, then, it is seen, that in this supposed circle the Rasorial type of form is followed by the Natatorial, and not, as in all other birds, by the Grallatorial; while the genus Thamnophilus, whose structure, being only inferior to that of Lanius, shows it to be one of the typical groups, is placed in the aberrant division. The series of variation, in short, in the circle we are now testing, turns out to be different from that in all other groups of birds, and it therefore cannot be the true one.

(416.) Our imaginary circle, therefore, not being able to stand the test supplied by the theory of definite variation, we have to retrace our steps, and ascertain whether an equally good circle cannot be formed by_placing these divisions in a different series. This we find can be done, - the new circle is just as complete as the old, - and we then compare it with the types of variation (as above specified), as follows :-

'Typical. $\quad\left\{\right.$ Lanius. $\quad\left\{\begin{array}{c}\text { The most rapacious of all the } \\ \text { perching birds; therefore } \\ \text { the }\end{array}\right\}$ Raptorial.

$\left.\begin{array}{c}2 . \\ \text { Sub-typical. }\end{array}\right\}$ Thamnophilus. $\left\{\begin{array}{l}\text { Inferior only to the last, bill } \\ \text { conic-shaped, claws not } \\ \text { raptorial ; therefore the }\end{array}\right\}$ Insessorial.

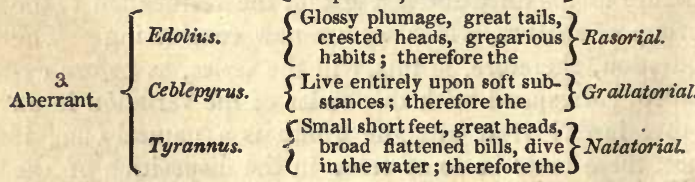

- See Wilson's American Ornithology ; also Northern Zoology, vol, ii. p. 136 . 
(417.) Thus we see that our new circle has this advantage over the old, that the variation of the series composing it turns out to be in accordance with the variation of all other ornithological groups. It can consequently stand three tests, - its circularity, its parallelism of analogy with other groups, and its coincidence with the established mode, or progression, in which nature varies her groups. The old group would not bear this latter verification, notwithstanding it appeared to be circular, and notwithstanding its analogies could be traced in the family of Merulida, although the series in the latter family, being made to correspond with the erroneous disposition of that of the Laniada, necessarily shared in the error, the analogies being correct, but the series in which they are made to follow incorrect ; the exposition of the two groups, as now re-formed, being as follows :-

True Circle of the Shrikes.

Lanius.

Thamnophilus.

Edolius.

Ceblepyrus.

Tyrannus.
The most typical of their respective families.

Bill hooked at the tip.

Feet very short.

Rump feathers more or less rigid.

Frequent the vicinity of water.
True Circle of the Thrushes.

\section{Merula.}

Myothera.

Brachypus.

Oriolus.

Crateropus.

(418.) But it is not sufficient that each of the divisions in these two families, as divisions, are correct ; for some of them are either very numerous in species, or contain many striking deviations in their form. Before, therefore, we can pronounce that either of these families are strictly proved, in all their parts, it becomes necessary to institute a further analysis, to select any one of the subordinate divisions, and to submit its contents to the very same tests as we have just applied to its family, as a whole. For instance, the Myotherine, or ant thrushes, represented by the genus Myothera, is one of the divisions, or lesser groups, in the circle of the thrushes. Now, is this a truly natural group? that is, is it circular? We may fairly conjecture it is natural, because its most obvious distinctions are in accordance with analogies to be traced in other circles, and with the principle of variation. But this, strictly speaking, is 
not enough for demonstration : its circularity must be made out, and its contents submitted to the very same tests that have been applied to the entire family. If the Myotherine, then, form a truly natural, and, therefore, a circular group, its component parts will represent all the divisions of its own family; and we shall find the subordinate variations analogically representing Merula, Crateropus, Oriolus, and Brachypus. So far is this beautiful uniformity of consistent and definite variation from being chimerical, that we have, in another work *, selected the Myotherine for this especial purpose, and have demonstrated that they form a natural group, capable of the same degree of verification as we have been here insisting upon. To that work we must refer the reader, who desires to see in what manner relations of analogy, in so small a circle, can be made out. To pursue the subject farther, on the present occasion, will be needless. We have confined our illustrations to ornithology; but it must be remembered that the same laws are applicable to every group in the animal kingdom.

(419.) Natural groups are thus to be detected by three different tests : 1 . By their simple series of circular affinity; 2. By the theory of analogy; and, 3. By the theory of variation. We draw the first of these proofs from affinity; but the two latter entirely depend upon analogy. No group which will not bear these tests can be natural ; whereas, if it will stand such an ordeal, it has passed all the trials necessary to establish its correctness.

(420.) We trust that the young naturalist will now see the truth of the observation long ago made by a well-known naturalist, that nothing can be easier than to make circles, provided it is not thought necessary to prove them: in other words, to give them more value than they possess, either from mere assertion, or from wearing an appearance, at first sight, of being really what they are affirmed. We trust, moreover, that he

* Northern Zoology, vol, ii. p. 168. 
will pause before he commits his own fame, and inflicts an injury upon science, by publishing to the world crude and superficial theories of primary divisions and circular groups, which have no foundation but in his own heated imagination - the result, not of extensive experience and matured investigation, but of limited materials, and an ignorance of all but one department of nature. Let him first become master of all the existing knowledge on these subjects, and let him prove the accuracy of his theories by facts, drawn from all the groups of the animal kingdom. He will then be justly entitled to have his opinions regarded, and his theories investigated.

\section{CHAP. III.}

ON THE RANK AND NAMES OF THE NATURAL DIVISIONS, OR GROUPS, IN THE ANIMAL KINGDOM. - OF SFECIES AND VARIETIES.

(421.) Ir is not only convenient, but absolutely essential, that the different groups of animals should be distinguished by names, indicative, in some measure, of their size and relative rank; just as we should distinguish the component parts of an army, or the different ranks of those by whom it is commanded. These groups, in fact, are divisions, some large, some small, to which various systematic writers have given different names. As these names, however, have been bestowed, for the most part, without any ulterior reference to a uniform plan, and the divisions themselves made altogether arbitrarily, we have endeavoured, in another part of this volume, to place these designations upon a more secure footing, and to show that all the divisions, hereafter enumerated, do actually exist in nature; not, indeed, in a strictly arbitrary and rigorous sense, but 
sufficiently marked to render them recognisable. Whether we term these parts of the great system of nature, circles, divisions, or groups, is immaterial, the three words, in fact, to prevent tautology, will be here considered synonymous : the,reader, however, must understand that they designate, each and all, an assemblage of objects, whose affinities, more or less, are circular.

(422.) It is obvious that, in proportion to the precision which we can attain in the determination of a group, so do we also give stability to all that belongs to it. So soon as a group, therefore, has been verified by the tests enumerated in the last chapter, it becomes, in the truest sense of the word, definite: it therefore follows, if we can ascertain what is the relative rank or value of such a group, in reference to other definite groups, we can then give a definite meaning to the name we bestow upon it. If, in short, groups are definite, the names indicative of their rank must be definite also, provided a uniformity in their nomenclature is preserved. Authors, indeed, are accustomed to distinguish their artificial groups by many of the same terms (as order, tribe, family, \&c.) which we are about to explain; but the student must remember that, unless otherwise stated these terms, which he will meet with in other systems, are merely conventional ; being founded, not upon any fixed plan of proceeding, but upon the mere opinion of the author. It is to Mr. Macleay and to his disciples that our science is indebted for the introduction of this definite system of naming groups, the least advantage of which is, that, when we now talk of a natural family, or a natural order*, we immediately know the determinate value of the group spoken of. We shall devote this chapter to the explanation and illustration of those groups whose rank or value have been ascertained; and conclude with a few remarks upon species and their varieties. The different ranks of divisions or

* I regret to observe, however, that very recently some of our entomolo. gists call their divisions by these names, without bringing forward any evi. dence or proof whatever that they are "natural," 
groups that have been detected in the animal kingdom, whose affinities proceed in a circle, are NINE, and they are thus designated, commencing from the highest and descending to the lowest: -1 . Kingdom, 2. Sub-kingdom, 3. Class, 4. Order, 5. Tribe, 6. Family, 7. Subfamily, 8. Genus, 9. Sub-genus.

(423.) It has been long customary, not only in science, but in ordinary parlance, to designate the three great divisions of ponderable matter as the animal, the vegetable, and the mineral kingdoms of nature; and, although it is not yet ascertained in what precise manner the vegetable, or, perhaps, also, the mineral kingdom *, describe their own circles, yet it is sufficient for our present purpose that the animal kingdom forms a circular group, comprehending all beings which usually pass under that name, and all the ranks of 'groups we are about to describe. A kingdom, therefore, is the first and greatest circle ; and a sub-kingdom, as its name implies, is one of the primary divisions of the animal kingdom: of these, according to Mr. MacLeay, there are five, namely, 1. the Vertebrata, or vertebrated animals, having an internal bony skeleton; 2. THE ANNULOSA, or annulose animals, as insects, where the body and legs are jointed, and the hardest parts are outside ; 3. the Radiata, or radiated animals, which, like the star-fish, have the mouth in the middle; 4. тHe Acrita, or the animalcules; 5. THE Moluusca, or shell-fish, whose nervous system is composed of several scattered masses or ganglions, united by nervous threads, and whose soft bodies are generally protected by a shell. The three last groups, the Mollusca, the Acrita, and the Radiata, are the aberrant divisions or sub-kingdoms of the animal kingdom; which, if our conclusions be correct, form a circle more or less complete among themselves. We shall not, however, in this part of our work, proceed to alter the definite divisions from five to three, it being much better that the first of these numbers

* See Northern Zoology, ii. Preface, p. liv. 
should be here used, to avoid all confusion in the mind of the student.

(424.) By Class is implied the first divisions of a subkingdom. The vertebrated animals are first divided into classes, which Mr. MacLeay was the first to designate and define by their true characters: this name, therefore, is appropriated to those divisions which respectively contain quadrupeds, birds, reptiles, amphibia, and fishes: these are the classes of the sub-kingdom Vertebrata. Those of the annulose animals, on the other hand, have never yet been correctly made out; it will, nevertheless, be our object, hereafter, to prove that the Ptilota, or winged insects, the Aptera, or wingless insects, the Cirripeda, or barnacles, the Vermes, or worms, and the Annelides, or red-blooded sea-worms, are so many classes, or first divisions of the sub-kingdom Annulosa; representing, of course, those of the vertebrated circle. The classes of the other sub-kingdoms have never yet been defined with precision, nor will it be necessary, in this place, to cite further instances of this description of groups.

(425.) Orders come next in rank to classes. Looking to the class of quadrupeds, we find there are five natural orders, following each other, however, in a somewhat different series to what has been stated elsewhere.* In birds, again, the same groups occur, and they have been correctly designated in the following natural series $\uparrow:-$ 1. RAPTORES, or birds of prey; 2. Insessones, or perchers; 3. Rasores, or fowls; 4. Grallatores, or waders ; 5. Natatores, or swimmers. The first divisions, also, into which both the apterous and winged insects are naturally grouped, are strictly classes ; of which Linnæus, indeed, seems to have had an intuitive perception; his Coleoptera, Hemiptera, Neuroptera, \&c., being truly groups of this value, notwithstanding the dismemberment they have received from some of the best modern entomologists. In like manner the Acephala, or bivalves, and the Gasteropoda, or univalves, among the molluscous

* Linnæan Transactions. + Ibid. 
shell-fish, when properly restricted, will be found groups of the same value, that is, if we consider the Mollusca as a class ; but if we view it, with Mr. MacLeay, as a sub-kingdom, then they must be considered as classes.

(426.) We shall illustrate the rank of Tribes from one of the most perfect, and, now, the best-established groups in zoology, namely, the order of Insessores, or perching birds. This most extensive order has been correctly stated* as the only one in the ornithological circle which contains tribes, designated and characterised as follows : -1. Conirostres, with a conic bill, and pre-eminently perchers. 2. Dentirostres, or perchers of prey, with sharp claws, and living chiefly upon insects. 3. Fissirostres, with large heads, flat bills, and weak feet, as the swifts and swallows. 4. Tenuirostres, with small eyes and mouth, and long bills, like the humming-birds. And, lastly, 5. The Scansores, or climbers, which brings on the woodpeckers, parrots, and cuckoos. These are the only tribes, or groups between families and orders, to be found in the class of birds. But in most of the orders of the Ptilota, or winged insects, tribes are very prevalent. The lepidopterous order, for instance, has the five tribes of Diurnes, or diurnal butterflies ; Sphingides, or hawk-moths; Bombycides, or silk moths ; Phalcenides, or geometric moths; and Noctuides, or night moths : although, as Mr. Kirby truly remarks, the primary division of this order is into three; the three aberrant tribes forming one circle. In the coleopterous order the tribes are very large, of which we shall cite the Lamellicornes (Scarabcaus Lin.), or herbiverous beetles, and the Pradatores, or rapacious beetles (Chilopodomorpha MacL.) as examples, to be hereafter verified. It is questionable whether tribes occur in the aberrant orders of either the Annulosa, Mollusca, Radiata, or Acrita, any more than they do in the aberrant orders of birds. At all events we have not yet detected them.

(427.) Families are comprehended under tribes, when the latter exist; otherwise, as in the case of the Rasores,

* Linnæan Transactions. 
\&c. among birds, they come immediately after orders. This, next to genera and sub-genera, is perhaps, the most prevalent description of group in the animal kingdom; it is used, in artificial systems, to designate an indefinite number of genera, having a few characters in common; but in natural classification its meaning is as determinate as any other of the circular groups here named. The crows, shrikes, parrots, woodpeckers, \&c. are so many families, both in a natural and philosophic sense of the word, and speak at once to the apprehension of the reader. The genera of the old authors are more similar to the families of the moderns, in the nature of their contents, than to any of the groups here enumerated. According to our views, the groups called stirpes, or races, by Mr. MacLeay*, are no other than families of the Predatorial tribe of beetles. Among birds, the shrike, thrush, warbler, chatterer, and flycatcher represent the five families of the tribe Dentirostres; while Papilio, Nymphalis, Satyrus, Ericina, and Hesperia of Latreille give us the types of the families in the tribe of Diurnal butterflies (Diurnes). It is essential here to remark, that the names of all families are terminated in -ida, as Papilionida, Nymphalida, \&c.: a plan of nomenclature which at once points out the rank of the group bearing a name so constructed.

(428.) Sub-families constitute the primary divisions of the last group; and, although the term is but seldom met with in artificial systems, yet groups of this rank are every where to be found in nature. To account for this omission, it may be observed, that it is comparatively easy, in most cases, to know the family to which a bird or an insect belongs, even at first sight, but to ascertain into which of the primary divisions of that family it naturally enters, imposes the necessity of a severe and frequently a laborious analysis, which few have the leisure or the opportunity of undertaking. Hence, in describing a new object, it is usual to designate the family, and then at once proceed to the genus (or rather the

$$
\text { * Annulosa Javanica, p. } 6 .
$$


sub-genus) and the species. That there is an intervening description of circles, however, between families and genera, has been so extensively demonstrated in ornithology that the matter has been set at rest, for it cannot be supposed for a moment that such groups should exist in, comparatively, so small a class as that of Aves, and yet not among true insects, whose numbers exceed those of birds, as much, probably, as in the proportion of twelve to one. Following our plan of giving examples, we may cite the divisions of the two families of shrikes and thrushes (418.) as so many sub-families, the genera there named being only typical examples. If the student wishes to see the demonstration of one of these sub-families, the Myotherina, or ant thrushes, he will find their analysis detailed at some length in " Northern Zoology," p. 168., and also that of the subfamily Piciana, or the pre-eminently typical woodpeckers, at p.300. of the same volume. Names designating this description of group are made to terminate in -inæ, as a ready mark of distinction from such as, ending in -i $d æ$, indicate the names of families.

(429.) We now come to Genera, of which more definitions have been given than of any other group in nature. It is quite unnecessary to repeat, in this place, the various and conflicting opinions of those who-by supposing there are no really definite groups in the creation - affix to the term a meaning either so vague or so circumscribed as to leave every one at liberty to put their own interpretation upon the alleged definition. A genus, by the old writers, was the first assembling together of species; but no fixed rules were laid down for determining what degree of variation, among these species, would exclude them from being ranked under one generic name, or, if laid down, they were so frequently violated; that, in process of time, the original type seems to have been lost sight of, and a host of other species became associated with it, which frequently bore but a mere outward or remote resemblance thereto. Do what we will to define a genus, - or, in fact, any other 
group, - we shall never succeed, unless that definition is so constructed that it becomes definite, - that it must have certain assigned characters, and that these characters, under different modifications, will be found in all other genera. Mr. MacLeay, no doubt, was impressed with this conviction, for he was the first who restricted a genus to an assemblage of species, in which five distinct modifications of form were discoverable, and which he further illustrated by showing their actual existence in the genera Phenius and Scarabcus. Now, as this was the first definite explanation of a genus, we are surely bound to adopt it, not only as emanating from our learned countryman, but because, by rejecting this definition, and applying the term to another description of groups, we perpetuate a confusion of terms, without gaining a single advantage. Let every one be at liberty to call an insect or a bird by its generic or its sub-generic name; but let not these two sorts of groups be misnamed and lost sight of, even in our artificial systems, for they cannot be so overlooked in any natural arrangement, without a direct violation of that uniformity and consistency which are absolutely essential to such arrangements. A genus, like every other natural group, must, of course, be circular in its affinities, and it must likewise contain within itself certain types or divisions which shall correspond with or represent those of all other natural genera. We have just cited the examples that have been given of natural genera among the coleopterous insects; and in the " $\mathrm{ZoO}$ logical Illustrations *" the reader will find another, taken from the lepidopterous order. The genus in question is that of Polyommatus, one of the most interesting to British entomologists, as containing all the beautiful little blue butterflies of our meadows. Up to this time these are the only genera in entomology which have been so verified.

(430.) Sub-genera are the leading types or divisions just spoken of, as belonging to a genus. It is very seldom they are so 'numerous in species that their cir-

* Second series, Plate 182. 
cularity can be traced; but in some few instances this can be done: we are, therefore, justified in believing they would invariably possess this property, were they, in all instances, equally abundant in species. Subgenera thus become the lowest circular groups in nature, or, in other words, they are the first assembling together of species : all of which belong to the same type of formation. Nearly all the modern genera are, therefore, in fact, sub-genera, because every deviation from a type of formation is made into " a genus ;" but no effort is made to assemble these types under those intervening groups, which come between genera and families. It has nevertheless been repeatedly proved to demonstration that two intervening circular groups do actually exist in nature ; and which, as already stated, are bon $\hat{a}$ fide genera and sub-families. The modern practice of defining and naming these sub-genera is very useful, provided their true distinctions are conspicuously noted; but, as the theory of definite variation (415.) has hitherto received no attention, at least in entomology, it frequently happens that the essential characters are overlooked, and the unimport ant ones brought forward. As an example of sub-genera really natural, we must refer to the "Zoological Illustrations," where the reader will find all those of the genus Polyommatus described and figured. It will be further remarked, that these sub-genera are to be regulated in their selection by the same laws as are applicable to higher groups. Their individual circularity, indeed, cannot be always traced, unless they are united in their proper genus, as in Polyommatus; they will then represent all the higher divisions of their own order. The sub-genus Polyommatus, for instance, stands at the head, as representing Papilio Lath. Next follows Lycana, or the copper butterflies, united most completely to the last, and representing Nymphalis Lath. Naïs comes next, as typical of the Hesperida. Lucia represents the Erycinida; and Erina brings us again to Polyommatus, with which it not only unites, but represents in itself the Satyrida. Now, each of these, according to the 
nomenclature of the "Horæ Entomologicæ" and the "Northern Zoology," are strictly sub-genera. T'hey are not - each taken by itself - circular, because they have really but a few species; or, what is the same thing to the present question, we are only acquainted with a few species; but, taken collectively, they form a circular group, or, in other words, a genus, such as we have here defined. These are examples of sub-genera which are not in themselves circular; but, from recent researches into the large and diversified assemblage of forms constituting the genus Papilio of Latreille, we feel thoroughly persuaded that, where there is a great numerical preponderance, sub-genera are not only circular, but that they contain their own internal types, as definitely and perfectly as do genera and all higher groups. This latter question we shall probably investigate in its proper place. In the mean time, having now enumerated all the ranks and degrees of circular groups yet detected, we shall proceed to make a few concluding observations upon species and their varieties.

(431.) A Species, in the usual acceptation of the term, is an animal which, in a state of nature, is distinguished by certain peculiarities of form, size, colour, or other circumstances, from another animal. It propagates, "after its kind," individuals perfectly resembling the parent: its peculiarities, therefore, are permanent. When animals are domesticated, the changes of life, of food, and frequently of country, which they undergo, are known to have the effect of altering and destroying those marks by which, in a state of nature, they were always distinguished. We see this in all the domestic quadrupeds and birds, which, when under the dominion of man, diverge, as it were, into endless variety. The discrimination of species, in many instances, requires a very practised eye ; but where, on the other hand, there is an obvious difference in colour, size, markings, \&c., the task becomes easy. Sometimes all the species of a whole genus will be entirely black, as in the Drongo shrikes (Edolius), and in many of those composing the family 
of Carabida: these, therefore, must be examined with more attention. The size of the bill, and the relative length of the quill-feathers, among birds, will often, in the absence of other information, decide the question. The pattern, form, \&c. of the rows of punctures in the wing-covers of beetles is also a good criterion. A smooth and a hairy beetle can never be of the same species. The young entomologist will do well to collect together all the specimens he meets with, in his walks, of the Linnæan genus Carabus, and then sit down, and endea vour to make out how the different sorts of all those which may be of a black colour can be distinguished. This plan will greatly awaken his powers of observation; and he will then be surprised to find how many of those he first thought were the same, are really different. The species, in some genera, much more closely resemble each other than in others. Thus, among shells, the different tellens (Telline) are only to be known by nice distinctions in their form and sculpture, that is, the indented or elevated marks or strice upon their valves. These shells are further remarkable for the great variety they exhibit in their colours: for, of the same species, it will sometimes happen that scarcely two individuals will be of the same tint. Colour, moreover, is a most uncertain guide for distinguishing the pectens. Our common English species varies between every shade of dark brown, rich orange, pink, and pure white. The form and sculpture, however, in all these varieties, are the same; but the most difficult of all shells to characterise are those of the oyster family, where even the shape varies in different individuals. Lepidopterous insects are best distinguished by their markings, as the form, number, and relative disposition of their bands and spots, both on the upper and under surface of their wings. Sometimes the upper surface of the greater number (as in the Satyrida) will be uniform brown; while in other groups, as the genera Thecla and Polyommatus, the prevalent colour will be blue. In all these, however, the under sides are variegated in a beautiful 
manner, either with eyelike spots, or delicate stripes, so that the species can be easily detected. As what we have already said, on this subject is intelligible even to the student, there seems no occasion to dwell further upon the distinctions of Species.

(432.) Varieties, in a state of nature, have their origin from some unusual, local, or accidental cause, either in their birth, their situation, or their food : they do not perpetuate the peculiarities they possess; but, the causes being removed, nature returns again, as it were, to her original type. Scanty food produces dwarfs, so also does unusual heat or cold with insects removed from that temperature most congenial to their constitution. 'Varieties, generally speaking, are rare, even where the species from which they vary are common. As they are evanescent, so they need hardly be described, except to illustrate something more than the bare fact.

(433.) We have now laid before the young naturalist the essence of those general principles which have been more fully and more scientifically discussed in a former part of this volume. He may possibly be disposed to question the necessity of grounding himself in this sort of information, but he may rest assured that it will give to his more immediate pursuits, and to his future progress, a degree of interest and of facility which no other plan of study can produce. The more thoroughly we understand the groundwork of any department of knowledge, the more rapid will be our subsequent advancement in its details. These preliminary chapters, on the principles of his science, should therefore be perused until their substance is impressed upon the memory; he will then be better qualified to understand, and to be interested in, the more enlarged views already taken of the subject : while the amateur, not desiring to be profoundly versed in the philosophy of that which is to him a mere recreation or amusement, may at once proceed to the following chapter. 
CHAP. IV.

A CONVERSATYONAL CHA PTER, CONVEYING HINTS FOR A PLAN OF STUDYING, IN DETAIL, THE DIFFERENT DEPARTMENTS OF ZOOLOGY, WITH EXAMPLES DRAWN FROM THAT OF ORNITHOLOGY.

(434.) Honest scholar, as Izaak Walton says, I shall now throw aside the professor's gown, with which the critics have bedecked me, and appear in my every-day suit. Let us talk of science as of ordinary matters ; and, although I cannot conduct you by a short cut to what I have been some thirty years in learning, I may still make the way smoother and easier than if you were left to pore over strange phrases and unknown circles. Think yourself fortunate, by the way, in having a master of any sort. When I first began to collect shells and catch insects, the only guides we then had were " $\mathrm{Da}$ Costa's Conchology," and "Yeates's Entomology;" neither of these worthies having any more idea about analogy and affinity than I had myself. Times, you see, are strangely changed. Now you may choose out of twenty systems ; and, if you believe a modern professor, may become a " very good naturalist," after taking "two or three walks in the country." This, to be sure, is a most royal, or rather a rail-road, way to knowledge; but who will believe it is the right one? Not you, at least, if you think me worthy of being your master. Remember that knowledge implies study ; and that both are requisite to make a good pin, as well as a good naturalist. "Alphabets" are very useful; but of what service are letters if they do not teach us words? and what are words without sentences? So with natural history. To get a few Latin names by heart is like learning a few letters ; any body can do this. Get some knowledge, therefore, of first principles; and, after read- 
ing the last chapter two or three times over, look upon this as a conversation between us.

(4.35.) Whatever may be the department of nature you feel a predilection for studying, you will find that some acquaintance with the general arrangement of that class or division of which it forms a part will not only be interesting, but highly useful. If, for instance, attracted by the beauty of their plumage, and by the interest which an observance of their manners gives to a country walk, you fix your choice upon birds, you should begin with understanding what relation they bear to other vertebrated animals ; then, upon looking to the first great divisions of ornithology, you will perceive that the order of Natatores, or swimmers, by constantly living in the water, represent fishes; the Grallatores, or waders, whose habits lead them as much to the land as to the water, typify the frogs and other amphibia; while the gallinaceous birds, forming the order Rasores, and comprising the peacocks, fowls, pheasants, \&c., all distinguished by an uncommon length of tail, find their prototypes among the lizards, crocodiles, and other groups of the order of reptiles. Eagles and vultures, by masticating or tearing their food, resemble quadrupeds ; while the great order of Insessores, or perchers, comprehending the most perfectly formed of the feathered creation, comprise, of course, the most perfectly organised birds. You thus gain, with very little trouble, a general acquaintance with the rank or relations of your favourites, without entering into the further details of those groups with which you compare it. There are, indeed, few of the large divisions of zoology wherein, at present, this can be done; but a general acquaintance with the more obvious analogies is all that we can be supposed to recommend.

(436.) You may next proceed to acquire an insight into the primary groups, and to understand upon what leading characters they are chiefly founded. Should you be desirous of studying Entomology, a general acquaintance with the manner in which the class 
Annulosa is divided, will point out the distinction of true insects from such as are destitute of wings; and you will be in no danger of referring an apterous moth or a female glowworm to a wrong order. Proceed in this manner, gradually entering into further details as you approach that particular portion which you intend to investigate. The study of any one of the great divisions of annulose animals is ample occupation for a life; and the more you restrict your attention to one department, the more will you ultimately rejoice at your forbearance, in not wandering over the tempting but boundless fields of nature.

(437.) To discover the name of a species is the ultimate object which all amateurs, and many professed naturalists, have in view. To do this, by merely turning over the plates of a zoolngical work, is manifestly a short and easy road to knowledge ; but the superficial acquaintance thus obtained, however convenient and useful upon many occasions, will not satisfy the true naturalist. Hence, he will begin by studying the composition of groups, before he descends into further details; and this, indeed, is inevitable, whether the student willingly consents or not. He finds, for instance, a beetle, and he wishes to know its name. He must therefore first ascertain to which of the great divisions of insects it belongs ; the winged (Ptilota) or the wingless (Aptera): but this is not enough, he finds there are several orders in each of these great divisions, and he is detained in his search, until he discovers to which of these orders his insect belongs. He finds' that all such as have hard wing-covers come under the order Coleop. tera. He may possibly think his search is now drawing to a conclusion, but he will be very much deceived. He has to compare his insect with the characters of all the different tribes, families, and genera of this order. If, in the present paucity of good elementary books, he succeeds so far as to ascertain the genus of his insect, he may consider himself very fortunate. One more trial, and he comes to the species. Now it is quite evident

$$
\text { A A } 2
$$


that, if he first makes himself acquainted with the leading characters of the great or primary divisions of entomology, he will be at once prepared to commence this search among the families or the sub-families, and thus abridge a great part of his labour. The adage says, the longest way at first is the nearest at last ; and so the beginner will find in the case we have just instanced. To learn names by rote is parrot-like; it farther partakes of the scansorial nature, by teaching him to be climbing over the wall, instead of pursuing the regular road to knowledge.

(438.) Distinguishing names have been assigned to the study of distinct portions of the animal kingdom, and are employed to designate its different branches. The study of the Mammalia, or quadrupeds has been termed Mammalogy, that of birds Ornithology, that of reptiles Erpetology, and that of fishes Ichthyology. Entomology has been usually applied to the study of all the annulose class, although it might be as well, perhaps, were it limited to true insects. Conchology, in like manner, designates the study of shell-fish. The studies of the radiated and of the polypous animals have not yet received distinguishing names. The use of these terms is of much convenience, and will be employed in the following hints.

(439.) The study of quadrupeds, although they form the most important division of all animals, is not particularly inviting. Those of our own country are very few, and come not daily before us ; while those of other countries are but thinly scattered in public museums, or are merely seen, in a state of confinement, in travelling menageries or zoological gardens. The species, moreover, from their comparative fewness, have been better investigated and are more thoroughly known, than those of any other class. Travellers, or those who reside out of Europe, may yet make important discoveries, both as to new species, or by supplying information on the natural habits of such as are already known. The latter, indeed, even as regards 
our native quadrupeds, is a wide and much-neglected field for interesting observation, carrying with it a degree of popular information, which interests both the man of science and the general reader.

(440.) There is no work in our language on the natural arrangement of quadrupeds; and all those which are intencled to describe the species, are expensive. The best arrangement you can at present follow is that of Cuvier's "Animal Kingdom." Keep it as a book of reference; as such it is invaluable : but, if you wish to follow up the views exhibited in this volume, the less you burthen your memory with the details of the arrangement in the "Règne Animal," the better. Quadrupeds may probably form the next volume of this series: but, if you are in a hurry, procure Cuvier; for to him I shall very frequently refer. As for species, I am really unprepared to say which of the many cheap compilations now publishing is the best. Bewick's quadrupeds, however, is a standard book, notwithstanding its obsolete names and occasional errors. Lesson's "Manuel," in French, is useful; but Desmarest much better. Of works with coloured figures, several have been published on the Continent, particularly in France; but they are, of course, partial in their range, and very expensive. One of these, by Professor Temminck *, however, is within a moderate sum, and is absolutely essential to every one who studies mammalogy. You will perceive that upon the teeth of quadrupeds most of the modern arrangements are founded; and as the different forms of these organs are often very difficult to be expressed by words, yet may be rendered immediately intelligible by figures, I should recommend your procuring the valuable octavo volume of Frederick Cuvier, brother to the great anatomist, where you will find nearly all the modern genera illustrated by admirable plates of their teeth, exhibited in different posi-

* Temminck, Monographes de Mammalogie, ou Descriptions de quelques Genres de Mammifères dont les Spécies ont ét $\epsilon$ observés dans les différens Musées de l'Europe. 1 vol. 4to. in seven numbers.

$\wedge$ A 3 
tions. Mr. Wood has announced the commencement of a general work upon quadrupeds, but I have not yet had the opportunity of seeing the first number.

(441.) No private individual ever thinks of making a collection of these animals, for a moderate number would fill a house: but a collection of their skulls is within compass, and is both instructive and interesting. The skulls, for instance, of a monkey, a cat, a dolphin or porpoise, a rabbit or hare, and a horse or sheep, will give you the types of the leading divisions of this class, and these are such common animals, that they can be easily procured. Study the differences they exhibit, with a good elementary book before you; and you will learn more about them, in half an hour, than if you read their details in a book for half a day. This is the case in every department, and shows the real use of collections; you read specimens as you would a book,-with this incalculable advantage, that the eye at once embraces all the information which it will take a page to describe.

(442.) Ornithology is a very delightful branch, for it concerns the most elegant of those animals which move about us ; and which attract our attention, whether we will or no, either by flitting before our path, singing their pretty song, or coming about our dwellings. Thus the study of our native birds may be prosecuted by all who live in the country: their acquisition, which leads to healthy exercise, is comparatively easy, and their preservation neither difficult nor expensive. If you reside in foreign countries, the study of these lovely and elegant creatures opens a field for much discovery; while, if you choose to increase your collection of native birds by purchasing foreign ones, their price on the average is very moderate. In a few years, with the requisite knowledge, you may form a very valuable cabinet.

(443.) The necessity of acquiring a general knowledge of large groups is especially requisite if you study birds. You will very soon understand the difference between a foot formed for swimming, another constructed for 
wading, a third for scratching and walking; and so on. You will thus be able to decide, at a glance, whether a bird belongs to the typical, the sub-typical, or the aberrant orders; and these are the first divisions. If its claws or talons are hooked and retractile, like those of a cat, you may be sure it belongs to the order Raptores, (fig. 56.) a, or birds of prey; if its hind toe is on a

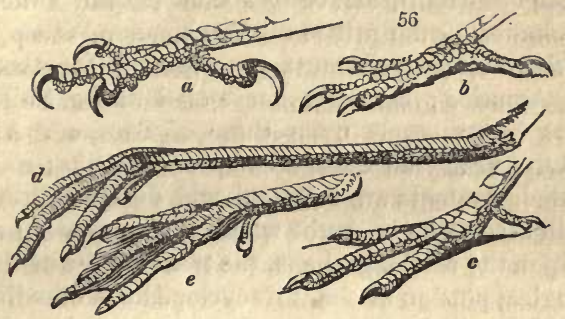

level with the others, so as to rest upon the ground with them, and its claws are merely curved, and are not retractile, you may conclude it is of the order of perchers (Insessores) $b$; while, if the hind toe is wanting, or is placed high up on the heel, you may feel assured that the species belongs to one of the three aberrant groups, composed of the gallinaceous (Rasores) $c$, the wading (Grallatores) $d$, and the swimming tribes (Natatores) $e$. I shall now give you a short explanation of these primary divisions.

(444.) In the investigation of the rapacious order you will have no difficulty. A vulture, a hawk, and an owl, gives you a perfect idea of the Vulturida, the Falconida, and the Strigida: these are the only great divisions yet known, and they follow each other in beautiful succession. The family of vultures is so small, that you will have no great trouble in ascertaining the name of a species, by the help of some of the general works upon birds I shall presently name. You will also find a valuable paper upon them by Mr. Vigors, in the Zoological Journal." 
But if you wish to investigate the species of the next family (Falconida), you will be sadly perplexed. It will be a great point gained, however, if you know the habitat or country of your specimens, since this knowledge will very much abridge your labour. For the European species, Temminck's "Manuel" is an authority which may be looked upon as almost oracular; while for those of Britain, Mr. Selby's work is quite sufficient. The volumes of the prince of Musignano, Wilson, and " Northern Zoology," must be consulted for those of North America; Spix for those of Brazil; while Le Vaillant is an oracle upon those of Southern Africa. Unluckily, nearly all these are expensive books; so that, until their contents are collected and digested into one, you will always be in doubt whether a species is new or old. Upon the whole, perhaps, the two volumes of the ornithological portion of the "Encyclopédie Méthodique," by Vieillot, will be the best manual you can have; and they may be purchased in Paris, or of any of the foreign booksellers in London, without the third volume of plates, which are not only expensive, but absolute caricatures. Birds of prey, when young, have a plumage very different from that which they acquire in adult age ; and that of the females, as in other birds, is sometimes different from the males. It will require a certain degree of tact (only to be got by experience) to distinguish a young from an adult falcon; but, by examining the specimens of these birds in the British or any other museum, you will soon get some ideas on this point. M. Temminck, who excels all other ornithologists of the day in a practical knowledge of this intricate family, has figured many of the foreign species in his "Planches Colorées ;" all which are incorporated in the "Traité d'Ornithologie" of Lesson. The species of owls are as difficult to determine as the falcons, and you must consult for them the same authors.

(445.) Next come the order of Insessores, or perching birds, and this order is larger than all the others put together; hence the groups belonging to it are much 
varied. You may perhaps be at a loss to comprehend how a swallow, a humming-bird, and a crow, can belong to the same order. But look to the characters of the order. All birds having their hind toe or toes placed upon a level with the ground, are perchers, provided, of course, that the claws are not retractile; for this latter circumstance distinguishes the birds of prey. You have, therefore, only to see if the foot of a swallow, hummingbird, and crow, are so formed : this is your first point to ascertain. Other distinctions follow in their proper order. Having, therefore, ascertained this primary character, you next look to the bill, the foot, and the claws. If the bird before you has the upper mandible distinctly notched, the legs of moderate length, and the toes three before and one behind, you may conclude at once that it belongs to the tribe of Dentirostres. If, on the contrary, you see that the bill is very slightly, if at all, notched near the end, but that the feet are still moderately long, as in the crow or sparrow, you have the general characters of the Conirostres. All other birds (and they amount to many hundreds) which do not possess these characters, whatever their general appearance may be, you may safely throw out of these two principal and typical tribes. You will find that their legs are much shorter; that their toes are either united at their base, or placed two and two ; and that their bill is without a notch : they, consequently, belong to the large aberrant circle of the Curtipedes, or short-footed birds.

(446.) Here, however, you will begin to see that mature's groups cannot be rigorously defined: and this fact will become more and more apparent, in proportio, as you proceed into details. It is one of the chief, or typical, distinctions of the Dentirostres to have the bill (istinctly notched; but this character disappears in some of the titmice (Parus), and is not perceptible in all the mock-birds (Orpheus). The long-legged thrushes (Crateropodina) have the bill entire. All these groups, hevertheless, have the feet so long, and so per- 
fectly formed, that you can have no hesitation in excluding them from the Curtipedes; while their compressed bill, destitute of that thickened, conic form which belongs to the Conirostres, indicates, on the other hand, that they still form a part of the Dentirostres. Again, if we were merely to judge of the natural station of the short-legged thrushes (Brachypodina), the orioles (Oriolina), or the flycatchers (Todida), by the length of their feet, we should class them in the order Curtipedes: but then, the very distinct manner in which their bills are notched must be taken into consideration; and, as this character is so very conspicuous, it is sufficient to point out that they are of the tooth-billed families, notwithstanding their short feet: they are, in fact, aberrant groups; and all the aberrant groups have only some, not all, of the typical characters - just as a hornless cow is still a cow, although it has no horns.

(447.) Having now acquired a general idea of the Dentirostral division as a whole, read over the characters of the families, and learn their chief distinctions. If you could get the skins of a shrike, thrush, warbler, chatterer, and flycatcher, you would then have examples before you of each family, and might compare them with what you read of each. For the present, I must refer you, for this information, to "Northern Zoology," where a good deal is said about each of these families: but, when I finish the ornithological volume of this series, you will want no other introduction to $m y$ views of arrangement. From the families you proceed, of course, to the genera and the sub-genera; thus gradually descending from one circle to another, and getting general ideas on the nature of each; without, however, endeavouring to commit to memory, as you would do a lesson, all that you read.

(448.) But nothing will make this plan of proceeding more intelligible to you than taking an example. Suppose, therefore, we select the common blue titmouse (Parus caruleus L.), as a bird whose family, genus, and species you wish to make out. First, you look to the primary 
divisions of birds, to see under which it will come. In this there is no difficulty. The structure of its toes, three before and one behind; and this latter resting on the same level with the others, shows at once that it belongs to the order of Insessores, or perchers. Now, as this order is again divided, you carefully look over the next set of divisions, namely, the Dentirostres, or toothed-billed; the Conirostres, or conic-billed; the Scansores, or climbers; the Tenuirostres, or honeysuckers; and the Fissirostres, or swallows. Now, here perhaps, you will have some difficulty in deciding whether your bird belongs to the Conirostres or the Dentirostres; because, in some measure, it unites the characters of the two. Its somewhat conic bill, without a notch, seems at variance with one of the chief characters of the Dentirostres; but then its small size, animal food, sharp curved claws, and climbing toes, are in its favour; and, therefore, the preponderance of its characters decides the question. At the same time, you perceive that, as it has not all the dentirostral characters, it must belong to one of the aberrant divisions ; in other words, to the warblers. To the family of Sylviada you accordingly turn : and here you find a division (or subfamily) called Pariance, characterised by their facility of climbing, a habit which exactly tallies with your bird. To this division, therefore, you refer ; and there the very first genus you meet with is Parus, defined as having a compressed conic entire bill, strong feet, inner toe shorter than the outer, long, curved, and sharp hind claw, and wings with the third, fourth, and fifth quills of equal length; all this answering precisely to the bird before you. All that now remains is to ascertain the species, which depends upon the colour of the plumage. Thus, you have traced your bird through the order, tribe, family, sub-family, and genus to which it belongs; and, having found its specific and common name, you may read its particular history in any of the authors who have written upon the species.

(449.) Such is the plan of study and mode of investi- 
gation I should recommend you to pursue. It is true that, knowing the bird we have been speaking about was a titmouse, you might have saved yourself all this trouble, and have turned at once to the page of the book wherein you thought it might be described. This mode of proceeding will be all very well, when you are so far advanced as to know by heart the chief divisions; but if you begin in this way, your reason and observation will not be called into exercise; you will overlook things apparently trivial, but upon which a great deal depends. You will, in fact, learn your lesson like a parrot, without being able to assign reasons when your book is taken from you.

(450.) Here, then, is an example of the mode in which you should proceed, not only in ornithology, but in every other branch. It is quite useless to multiply instances in entomology, conchology, or any of the other departments. The names only would differ, the principles would be precisely the same. Besides, if you wish to follow my plan of study, you must wait until the volumes, to which I must inevitably refer you, are published. If you are impatient, you may, however, in the mean time, pursue this plan with Linnæus, Temminck, or on any other of the artificial systems ; although there is great fear that, as my scholar, having to unlearn a good deal of what you will there learn, your ideas at first will become confused, and you will be less prepared to receive instruction in the system you ultimately intend to follow, than if you kept your mind free from different impressions. Be this, however, as it may, the plan of study I have chalked out is equally applicable to any system, no matter who is the expositor; and I shall end with this advice, - Follow that arrangement which is most agreeable to what you see in nature, and most conducive to exhibit the infinite beauty of that system, whatever it be, which must belong to the harmonious plan of an Omipotent Creator. 


\section{IN DEX.}

\section{A.}

A berrant circles explained, 323. 328. Groups, characters of, 249. Various, compared, 253.

Accentor modularis, 289.

Acrita, their diversity explained, 209.

Affinity, three relations of, 233.

African animals in general, 91.

America, tcmperate, 62.

American animals generally, 56 .

Amphrisius Priamus, 54.

Analogical tables : - Insessores and Aves, 231. Raptores and Insessores, 239. Tenuirostres and Conirostres, 297, 298. Merulidæ and Aves, 332.

Analogical tests of circles, 333.

Analogies, different modes of stating, 296. True and false, 241. Of the Merulidæ, 3:22.

Analogy, theory of, 288. 296.

Analogy and affinity illustrated, 231.

Animal geography, different opinions upon, 4. First divisions

of, 16. . Asimals of Europe, 43. Africa, 91. America, 56. Australia, 114.

Ants of Africa, 98. 100. America, 87.

A quatic or natatorial forms, 249.

Arctic America, 58.

Arctic Europe, 30.

Arctic regions, animals of, 17. 20.

Aristotle, system of, 134.

Artificial systems, 125.

Australian animals generally, 114.

B.

Binary systems, 193.

Birds, class of, illustrated, 237.

Birds of Europe, 19. Feet of the orders of, 359.

Brazll, general view of, 73. Quadru- peds of, 77. Birds of, 80. Rep. tiles of, 83. Insects of, 84 . Shells of, 88 .

C.

Camelopardalis, two species of, 95 .

Central Asia, 46.

Central Europe, animals of, 33.

Central group of Fries, 216.

Characters of species, 274.

Chilopoda and Thysanura, 217.

Circular arrangement of the animal kingdom, 203. Theory explained, 202. 320 .

Circular arrangement of the class Aves and genus Parus, 293. Laniadæ and Merulidæ, 234. Merulidæ, 331.

Classification, first laws of natural, 224.

Collecting, plans for, recommended, 910. Hints for, 915 .

Colour of species, 279.

Comparison of groups, 330.

Creation must have a plan, 319 .

Crow, qualities of, 243.

Cuvier, system of, 170 .

\section{D.}

De Geer, system of, 187.

Denomination of groups, 325.

Dentirostral birds, remarks upon, 361 .

Diagrams of the first divisions of a circle, 227. Of the animal kingdom, 203. Of the class Aves and genus Parus, 293. Laniadæ and the Merulidæ, 234. Merulidæ, 331.

Dichotomous systems, 193.

Divisions of a circle, 227. 322.

Dodo of Madagascar, 112.

E.

Entomology of tronical Africa, 98. Equinoctial Atrica, y5. 
European animals. 1.

External affinities, 235.

\section{F.}

Fabricius, system of, 189.

Facts, the observation of, 809.

False circles, $€ 3$.

Familiar conversation with beginners, 353.

Field naturalist's occupations, 301.

First principles to be learned, 318 .

Fries, system of, 213.

\section{G.}

Genera of African animals, 112. Asiatic animals, 55. American animals, 89. Australian animals, 120. European animals, 42.

Genus, a natural, illustrated, 210. Meaning of the term, 347.

Group, meaning of the term, 326.

Groups, primary divisions of circular, 225.

H.

Harpula vexillum, rank of, 273 .

Hedge-sparrow, its uat ural and analogical characters, 290.

Hermann, 198.

\section{I.}

Illiger, system of, 183.

\section{K.}

Kingdoms, the three, of nature, 269.

\section{L.}

Lamarck, system of, 199.

Laniadæ, false circles of, 335. 338. True circle of, 338.

Latreille, system of, 191.

Laws, primary, of the natural system, 224.

Leach, system of, 192 .

Linnæus, system of, 140.

Lions, different species of, 284. Of Africa, 49.

\section{M.}

MacLeay, system of, 201.214.

Madagascar, animals of, 110.

Man, variations of, 15.

Memory to be exercised, 311.
Merulida, the circle of the, 331.339.

Mexican birds, 70.

Mexico, animals of, 68 .

Myotherinæ, circle of, 310 .

N.

Names of divisions in the animal kingdom, 343.

Natatorial type described, 249.

Natural system, the primary laws, 224.

Natural systems, requisites of, 128. 196.

Naturalists, two classes of, 301.

New Guinea, 117.

New Holland, 118.

Newman, Mr., theory, 220.

Northern Africa, 92.

Northern Asia, 45.

Nycthemerus pictus and argentatus, 47.

\section{o.}

Observation, accurate, recommended, 305

Orders of birds, 344.

Ornithology, plan for studying, 358 . Books upon, 359. Of Europe, 19.

$\mathrm{Ox}$ and the bison, 247.

\section{P.}

Pacific Islands, 119.

Parianæ, exposition of the, 292.

Parus biarmicus, rank of, 271.

Parus cæruleus, 362.

Perseverance recommended, 307.

Petalocerous beetles, the two first groups, 248.

Podalirius Machaon, rank of, $2 \% 1$.

Polyommatus, the division of, 349 .

Prichard's, Dr., theory, 5. 14.

Primary types of nature, 241.

Properties of natural groups, 324.

\section{Q.}

Quadrupeds, works upon, 357.

Quadrupeds of Europe, 32 .

Qualifications of a naturalist, 305.

Quinary system explained, 205.

R.

Rank of groups, 343.

Ranks of natural groups, 367. 
Rasorial type described, 257.

Representation, law of, 237. 241. 289. Theory of, 298.

\section{S.}

Scarabæus sacer, rank of, 279.

Septenary and other systems, 221.

Shells of Europe, 40.

Smeathman on African insects, 99.

Southern Africa, 100. Asia, 47. Europe, animals of, 35 .

Species, a, defined, 350 . Characters of, 275 ,

Study, a plan of, desirable, 310. General plan of, 355 .

Subgenus, meaning of, 348 .

Sub-typical form described, 245.

Suctorial type described, 254.

System of nature, first laws of, 224.

Systematic naturalist, objects of, 303.

Systems, artificial, the principal, 134.

Systems and methods, 122. Mixed, 127. Natural and artificia', 124.

T.

Tables of the rank of groups, 271. 273. Insessores and the class Aves, 231. Merulidæ, or thrushes, 331. Parianæ, 292. Raptores and
Irısessores, 239. Rasorial birds, 264.

Temminck, system of, 184 .

Tests of a natural group, 287. The circle of Merulidæ, 332 .

Theory of representation, 237.

Thysanura and Chilopoda, 217.

Titmouse, blue, 962.

Transportation of groups, 217. 296. 299.

Tropical America, 67. 72 .

Types of a typical circle, 243. Of an aberrant circle, 243 .

Typical and aberrant circles explained, 323.

Typical form defined, 242.

V.

Variation, principle of, 296. Theory of, 335. 337.

Variety, a, defined, 352.

Vertebrated animals, circle of, $\$ 20$.

Verification of a natural group, 287.

Vieillot, system of, 183.

W.

Willughby and Ray, system of, 138.

Woodpecker, qualities of, 243. 
LoNDON:

Printed by A. SPOTriswoode, New-Street-Square. 
THE

\title{
C A B I N E T
}

OF

\section{NATURAL HISTORY.}

\author{
CONDUCTED BY THE
}

REV. DIONYSIUS LARDNER, LL.D. F.R.S. L. \& E.

M.R.I.A. F.R.A.S. F.L.S. F.Z.S. Hon. F.C.P.S. \&c. \&c.

ASSISTED BY

EMINENT SCIENTIFIC MEN.

A TREATISE

ON

THE GEDGRAPHY AND CLASSIFICATION

or

ANIMALS.

BX

WILLIAM SWAINSON, ESQ. A.C.G.

HONORARY MEMBER OF.THE CAMBRIDGE PHILOSOPHICAL SOCIETY, AND OF SEVERAL FOREIGN ACADEMIES.

\section{LONDON :}

PRINTED FOR

LONGMAN, REES, ORME, BROWN, GREEN, \& LONGMAN,

PATERNOSTER-ROW ;

AND JOHN TAYLOR,

UPPER GOWER STREET.

1835. 
IONDON :

Printed by A. Sportiswoode,

New-Street-Square. 




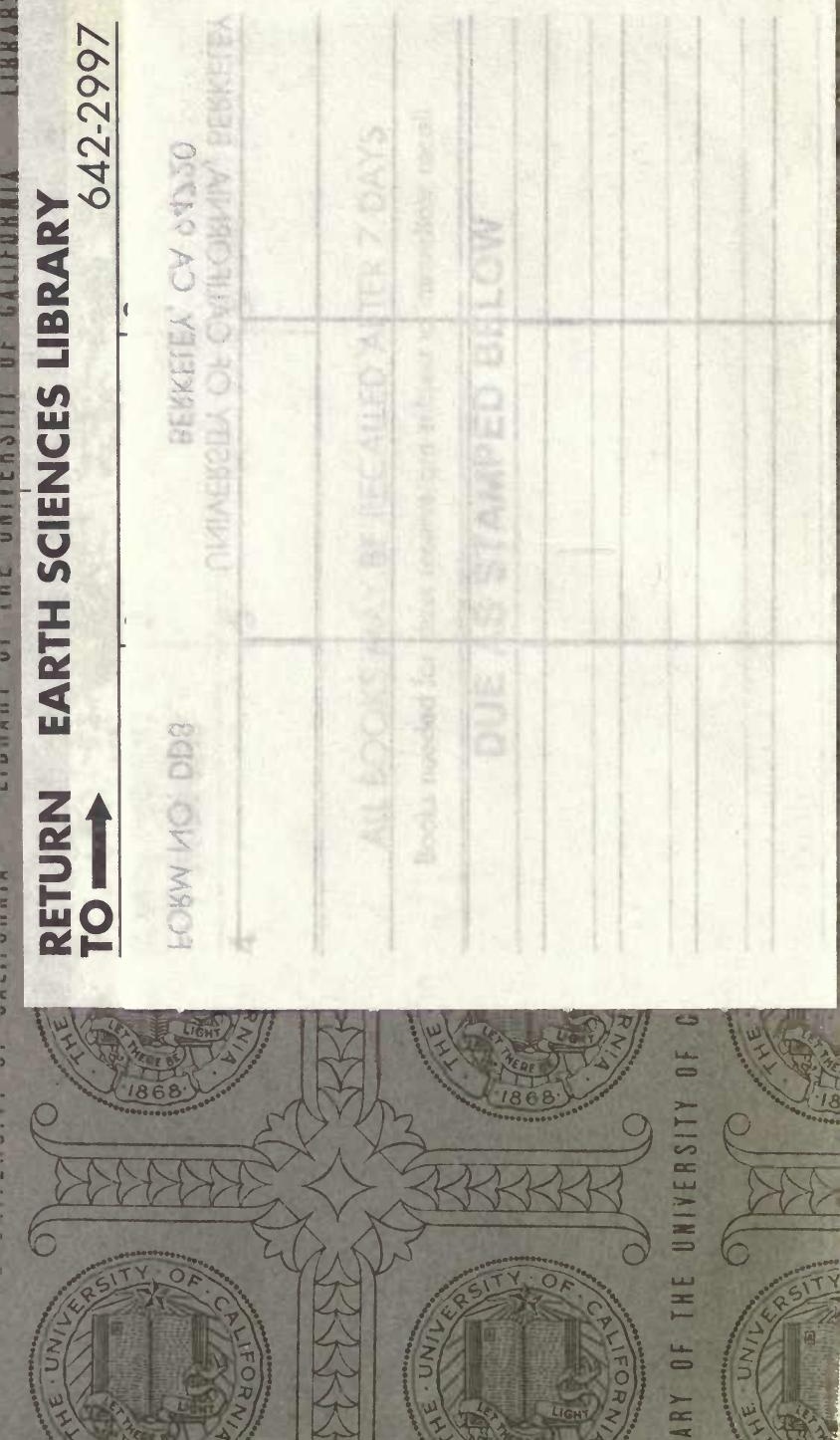


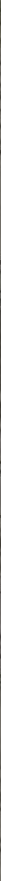

ERSITY OF CALIFORNIA LIBRARY OF THE UMIVERSITY OA

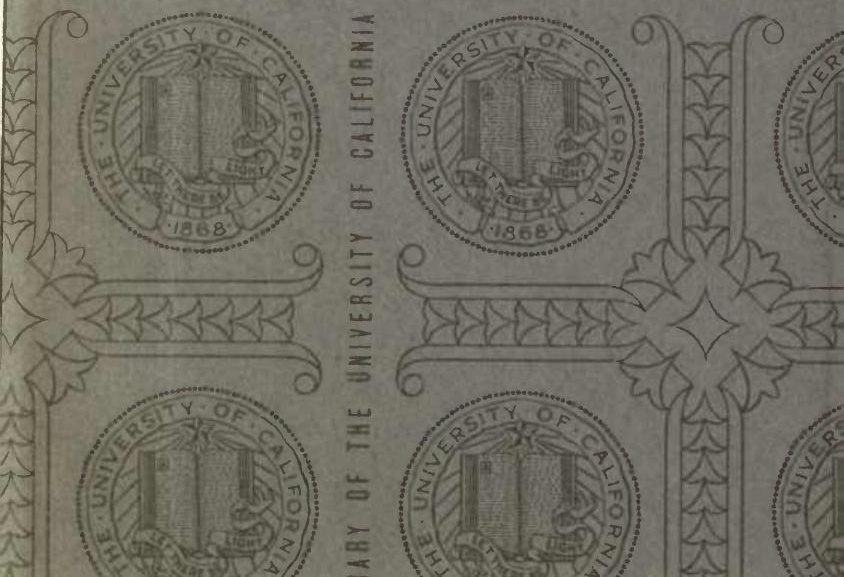


